\author{
UNIVERSIDADE DE SÃO PAULO \\ FACULDADE DE CIÊNCIAS FARMACÊUTICAS \\ Programa de Pós-Graduação em Fármaco e Medicamentos \\ Área de Produção e Controle Farmacêuticos
}

\title{
Desenvolvimento e caracterização de dispersões sólidas de efavirenz
}

Edilson Marcelo Nazareth Junior

Dissertação para obtenção do

Título de MESTRE

Orientadora: Profa. Dra. Cristina Helena dos Reis Serra Coorientador: Prof. Dr. Gabriel Lima Barros de Araujo 


\author{
UNIVERSIDADE DE SÃO PAULO \\ FACULDADE DE CIÊNCIAS FARMACÊUTICAS \\ Programa de Pós-Graduação em Fármaco e Medicamentos \\ Área de Produção e Controle Farmacêuticos
}

\title{
Desenvolvimento e caracterização de dispersões sólidas de efavirenz
}

\begin{abstract}
Edilson Marcelo Nazareth Junior
Versão corrigida da Dissertação conforme resolução CoPGr 6018

Dissertação para obtenção do Título de MESTRE
\end{abstract}

Orientadora: Profa. Dra. Cristina Helena dos Reis Serra Coorientador: Prof. Dr. Gabriel Lima Barros de Araujo 
Autorizo a reprodução e divulgação total ou parcial deste trabalho, por qualquer meio convencional ou eletrônico, para fins de estudo e pesquisa, desde que citada a fonte.

Ficha Catalográfica elaborada eletronicamente pelo autor, utilizando o programa desenvolvido pela Seção Técnica de Informática do ICMC/USP e adaptado para a Divisão de Biblioteca e Documentação do Conjunto das Químicas da USP

Bibliotecária responsável pela orientação de catalogação da publicação: Marlene Aparecida Vieira - CRB - 8/5562

Nazareth Junior, Edilson Marcelo Desenvolvimento e caracterização de dispersões sólidas de efavirenz / Edilson Marcelo Nazareth Junior. - São Paulo, 2020. $176 \mathrm{p}$.

Dissertação (mestrado) - Faculdade de Ciências Farmacêuticas da Universidade de São Paulo. Departamento de Farmácia.

Orientador: Serra, Cristina Helena dos Reis Coorientador: de Araujo, Gabriel Lima Barros

1. Efavirenz. 2. Dispersão sólida. 3. Poloxâmero. 4. Solubilidade. 5. Fármacos pouco solúveis em água. I. T. II. Serra, Cristina Helena dos Reis, orientador. III. de Araujo, Gabriel Lima Barros, coorientador. 
Edilson Marcelo Nazareth Junior

Desenvolvimento e caracterização de dispersões sólidas de efavirenz

Comissão Julgadora

da

Dissertação para obtenção do Título de MESTRE

Profa. Dra. Cristina Helena dos Reis Serra (orientadora/presidente)

FCF-USP

Profa. Dra. Marina de Freitas Silva (1 ${ }^{\mathrm{a}}$ examinadora)

UNIP

Dr. Hélio Salvio Neto ( $2^{\circ}$ examinador)

Biolab

Prof. Dr. Vinicius Danilo Nonato Bezzon ( $3^{\circ}$ examinador)

UFABC

São Paulo, 17 de junho de 2020 
Dedico esse trabalho às três mulheres fundamentais da minha vida minha mãe Vanderli Soares Nazareth, minha tia Viviane Soares e minha avó Lourdes Apparecida Lopes Soares (In memoriam), tudo que sou hoje, devo a vocês.

Muito obrigado por tudo! 
O racismo no Brasil se caracteriza pela covardia. Ele não se assume e, por isso, não tem culpa e nem autocrítica. Costumam descrevê-lo como sutil, mas isto é um equívoco. Ele não é nada sutil, pelo contrário, para quem não quer se iludir ele fica escancarado ao olhar mais casual e superficial.

Abdias do Nascimento 


\section{AGRADECIMENTOS}

Ao Criador, pelo dom da vida e por me dares exatamente o que preciso e sempre na hora certa.

À minha mãe Vanderli Soares Nazareth, por sempre acreditar em mim e nunca me deixar desistir. Te amo muito.

À minha tia Viviane Soares e minha avó Lourdes Apparecida Lopes Soares (In memoriam), por sempre apoiarem meus sonhos e serem o meu porto seguro.

Aos meus irmãos Douglas Soares Nazareth e Vitor Soares Nazareth, por sempre estarem ao meu lado nos bons e maus momentos.

A todos os meus familiares e amigos que me incentivaram na conclusão do trabalho. À Profa. Dra. Cristina Serra, pela oportunidade, orientação, amizade, ensinamentos e acreditar no meu sonho de me tornar um pesquisador.

Ao Prof. Dr. Gabriel Araujo, pela coorientação, ensinamentos, paciência e ser um exemplo de pesquisador.

Aos amigos que fiz durante essa jornada, que me ensinaram, auxiliaram e ampararam em todos os momentos da pós-graduação. Andressa Oliveira, Frank Gavilano, Rosmery Leon, Gabriela Carvalho, Ilia Repin, Felipe Nambu, Fernando Kaneko, Paulo Gonçalves, Thamires Batello, Denise Eulálio e Erika Mol.

Aos alunos de iniciação cientifica Tatiana, Mariana, Raul, Victor, Joseph, Yoel, Camila, Rodrigo, Cibeli, Felipe e Jesus, pelos ensinamentos e ajuda na realização dos experimentos.

A todos os docentes do programa de pós-graduação especialmente para Prof. Dr. Felipe Rebello, Profa. Dra. Maria Aurora, Prof. Dr. Paulo Moreno, Profa. Dra. Vlad Consiglieri e Profa. Dra. Juliana Ract, por contribuir cientificamente com o trabalho. À colaboração dos colegas de laboratório Bruna, Ruberlan, Michele, Marina, André e Thaísa na conclusão desse trabalho. 
Aos funcionários da FCF-USP Claudinéia, Doralice, Edgar, Lucineide, Roberto, Alexandre, Inês, David, Sueli e Shirley, pelo suporte prestado na conclusão do trabalho.

À Faculdade de Ciências Farmacêuticas da Universidade de São Paulo, pela oportunidade de realização do curso de mestrado.

À Dra. Luciana Galvão, do Laboratório de Análises Químicas do IPT por me ajudar com as análises das amostras.

Ao Dr. Hélio Salvio, pela contribuição no exame de qualificação.

Ao Dr. Flávio Carvalho, do Laboratório de Difração de raios X pelos ensinamentos da técnica e realização das análises.

Ao Rui Cruz, da empresa Disotax pelo treinamento e suporte no manuseio do equipamento aparato IV.

À empresa Cristália Produtos Químicos e Farmacêuticos Ltda, pela doação do fármaco.

À empresa BASF, pela doação dos polímeros.

À CAPES, pelo suporte financeiro, que possibilitou a realização desse trabalho.

A todos que contribuíram de maneira direta ou indireta para realização deste trabalho e concretização deste Mestrado.

Muito obrigado! 
SUMÁRIO

ב. SUMARIO 
SUMÁRIO 1

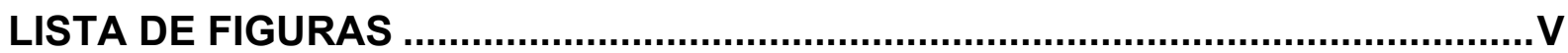

LISTA DE QUADROS

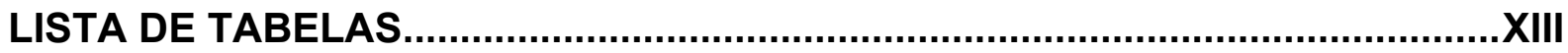

LISTA DE ABREVIATURAS E SIGLAS ........................................................ XVI

LISTA DE SÍMBOLOS E UNIDADES ............................................................... XIX

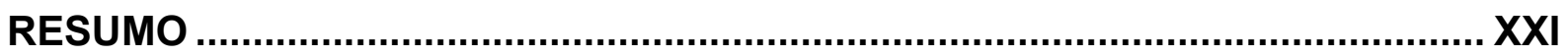

ABSTRACT

1. INTRODUÇÃO

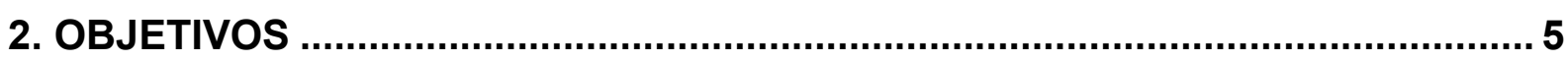

2.1 Objetivo geral ................................................................................................ 6

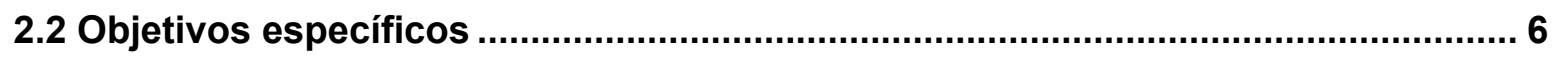

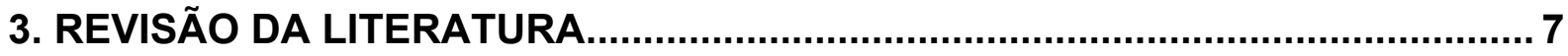

3.1 Solubilidade aquosa do fármaco e as implicações na eficácia do medicamento . 8

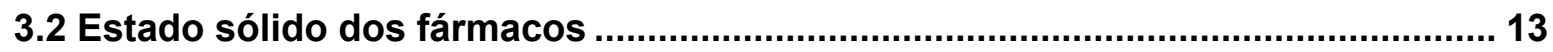

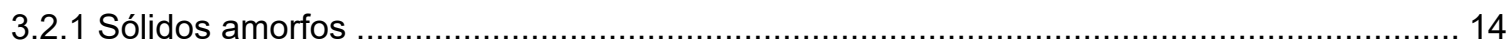

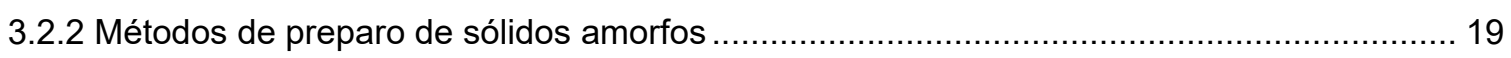

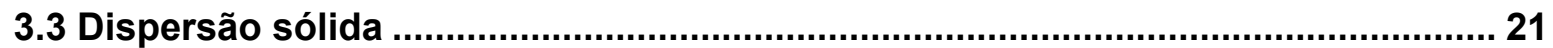

3.3.1 Classificação das dispersões sólidas e tecnologia de obtenção....................................... 25

3.3.2 Estabilidade física e inibição da cristalização das dispersões sólidas ................................ 29

3.3.3 Características dos carreadores selecionados ............................................................ 31

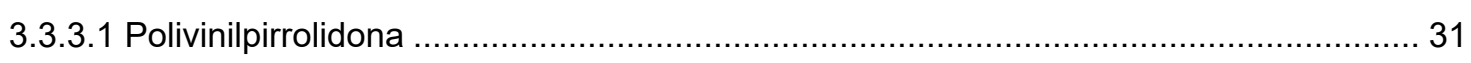

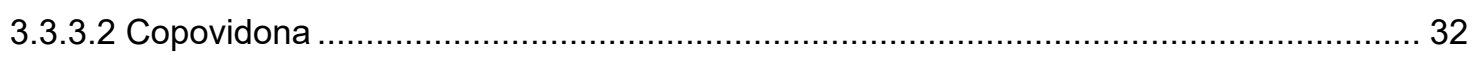

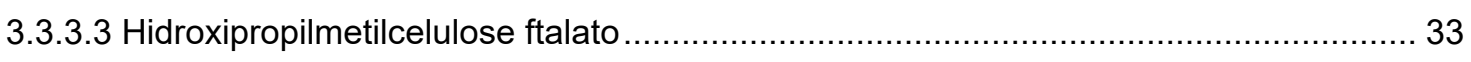

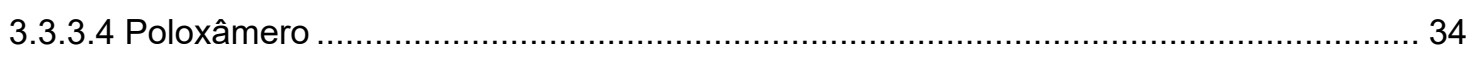

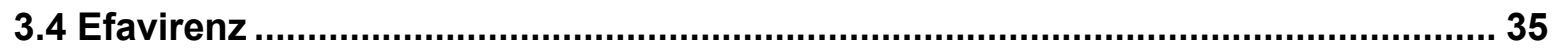

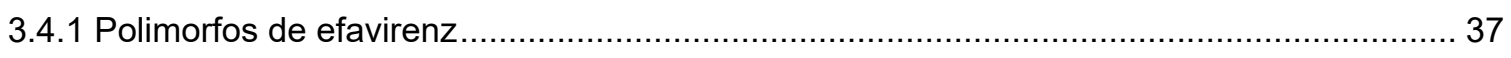

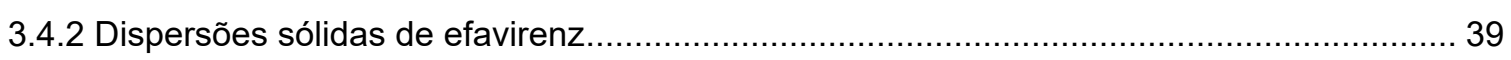

4. MATERIAIS E MÉTODOS......................................................................... 41 
4.1 Materiais 42

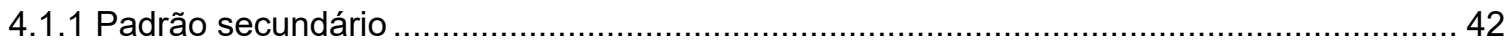

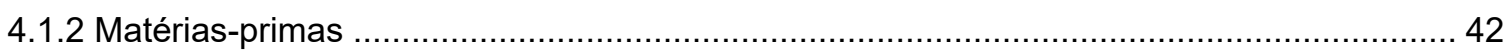

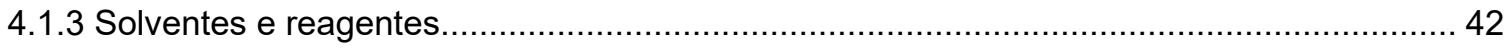

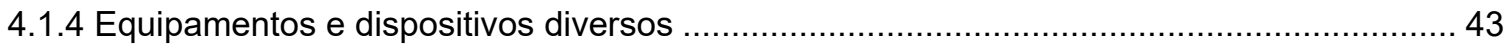

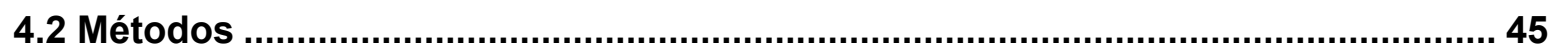

4.2.1 Desenvolvimento e validação do método de cromatografia líquida de alta eficiência (CLAE)

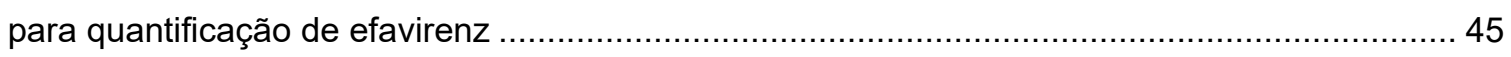

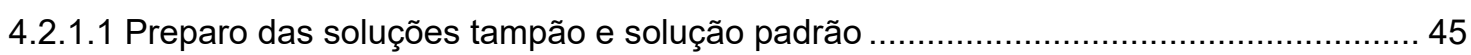

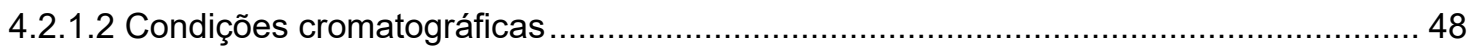

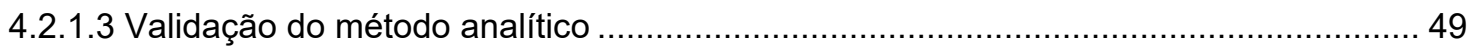

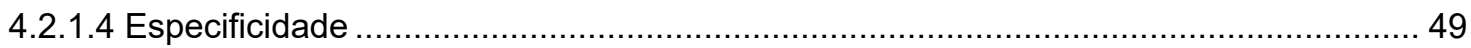

4.2.1.5 Linearidade

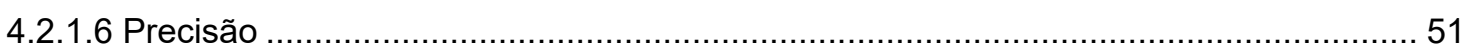

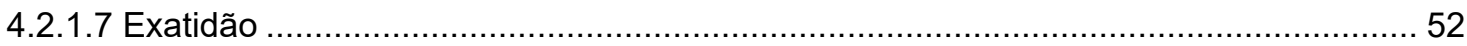

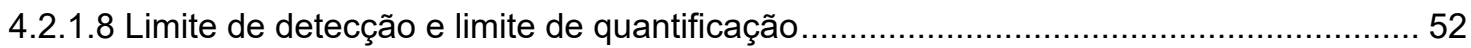

4.2.2 Desenvolvimento das formulações de dispersões sólidas de efavirenz por evaporação do

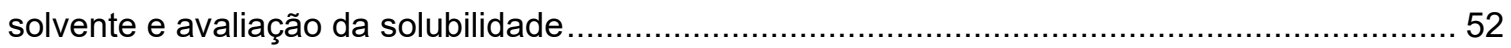

4.2.2.1 Seleção racional miniaturizada de solventes e carreadores ...................................... 53

4.2.2.2 Obtenção em maior escala das formulações de dispersões sólidas de efavirenz ........ 55

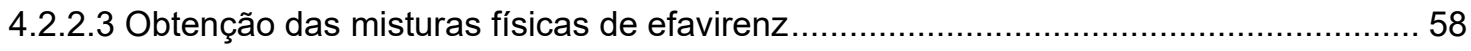

4.2.2.4 Determinação da solubilidade pelo método do equilíbrio (shake-flask) ...................... 59

4.2.3 Impactos nas alterações das proporções de polímeros nas formulações de dispersões

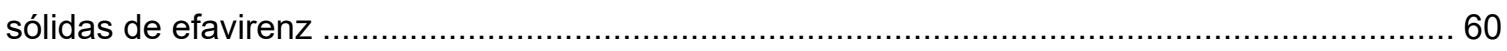

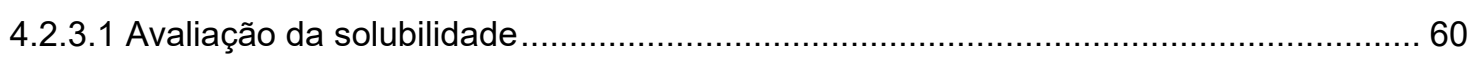

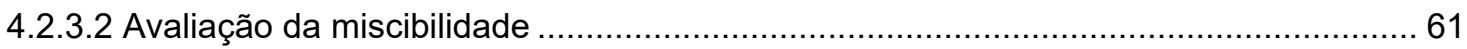

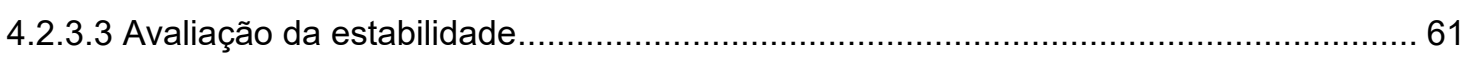

4.2.4 Caracterização físico-química das dispersões sólidas de efavirenz ................................... 62

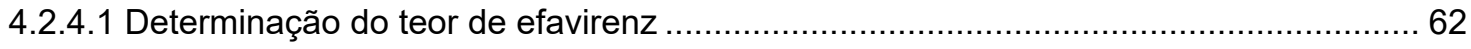

4.2.4.2 Estudo de dissolução em condição sink pelo aparato 4 (Flow-Cell) e avaliação da

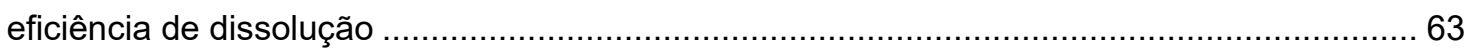

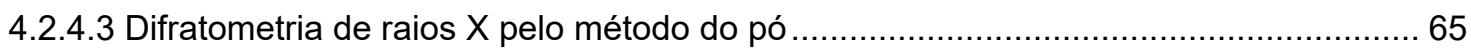

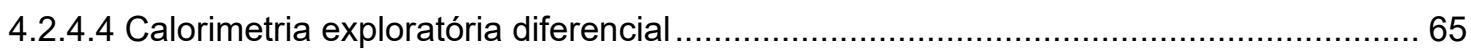

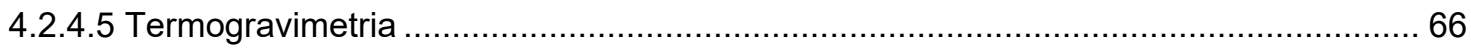

4.2.4.6 Espectroscopia na região do infravermelho com transformada de Fourier .................. 66

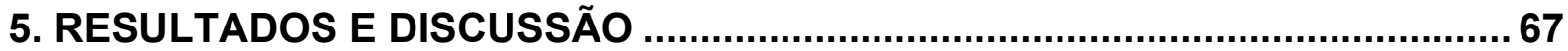


5.1. Validação do método por cromatografia líquida de alta eficiência (CLAE) para

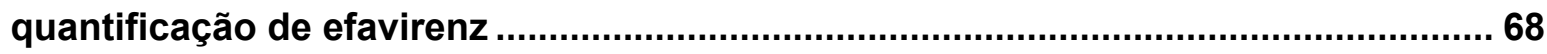

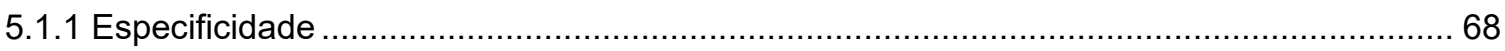

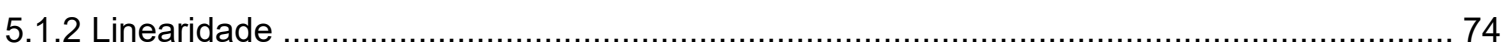

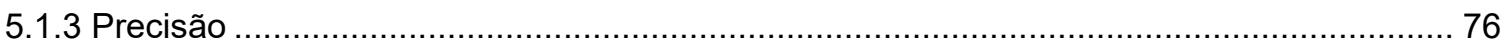

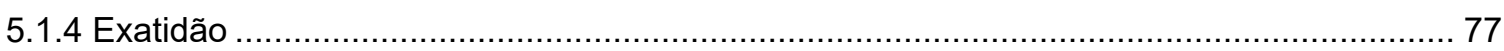

5.1.5 Limite de deteç̧ão e limite de quantificação.................................................................. 78

5.2 Desenvolvimento das formulações de dispersões sólidas de efavirenz por evaporação do solvente e avaliação da solubilidade .................................................. 78

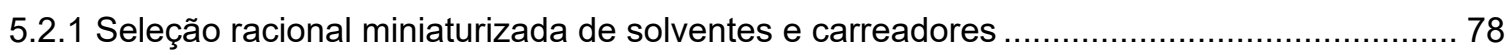

5.2.2 Obtenção em maior escala das formulações de dispersões sólidas de efavirenz ............... 85

5.2.3 Determinação da solubilidade pelo método do equilíbrio (shake-flask) ..............................90

5.3 Impactos nas alterações das proporções de polímeros nas formulações de

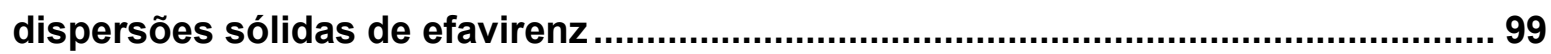

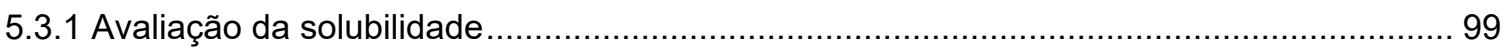

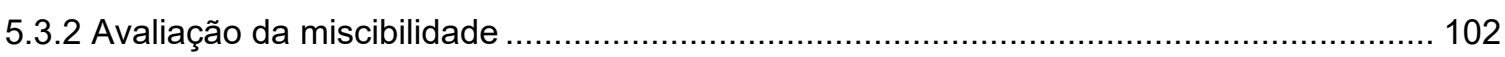

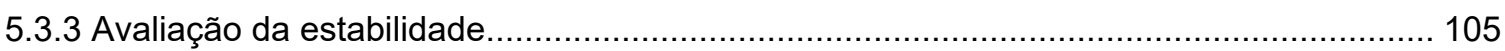

5.4 Caracterização físico-química das dispersões sólidas de efavirenz ................... 108

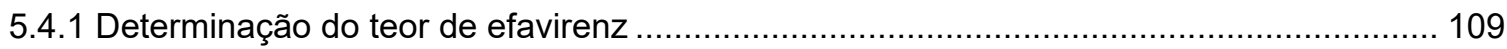

5.4.2 Estudo de dissolução em condição sink pelo aparato 4 (Flow-Cell) e avaliação da eficiência

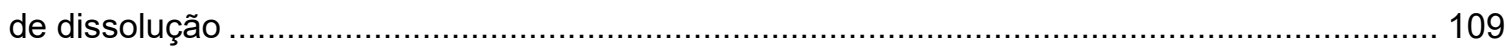

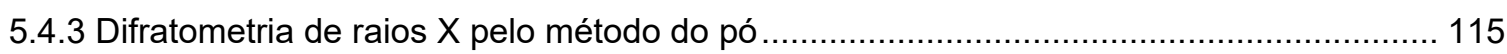

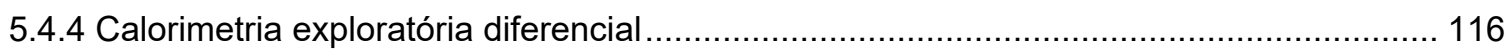

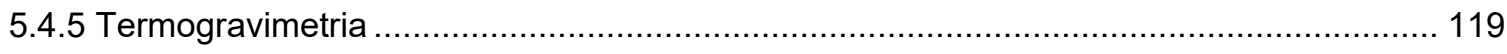

5.4.6 Espectroscopia na região do infravermelho com transformada de Fourier ....................... 121

6. CONCLUSÃO

7. REFERÊNCIAS BIBLIOGRÁFICAS .............................................................127

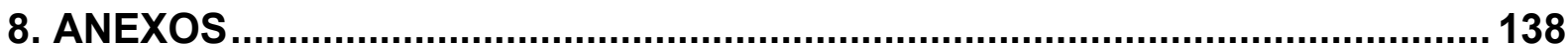




\section{LISTA DE FIGURAS}


Figura 1 - Diferentes formas de modificações físico-químicas e farmacotécnicas para fármacos de baixa solubilidade aquosa.

Figura 2 - Representação esquemática do estado cristalino (lado esquerdo) e estado amorfo (lado direito), as moléculas são vistas como círculos.

Figura 3 - Diagrama de temperatura e energia livre para um sistema de único componente. 15

Figura 4 - Mudança na capacidade calorífica durante a transição vítrea. No gráfico é

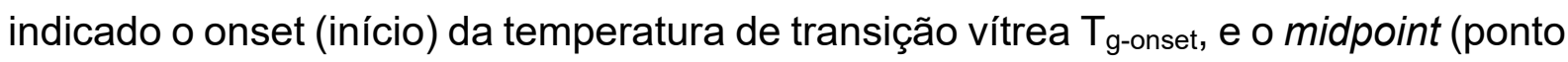
médio) da temperatura de transição vítrea $\mathrm{T}_{\mathrm{g} \text {-mid. }}$...

Figura 5 - Representação esquemática dos arranjos dos átomos e moléculas nos estados cristalino e amorfo.

Figura 6 - Comparação dos padrões de DRXP do fármaco efavirenz nos estados sólido cristalino e sólido amorfo.

Figura 7 - Representação esquemática da classificação de dispersão sólida cristalina, dispersão sólida amorfa e solução sólida de moléculas de fármacos na matriz polimérica carreadora.

Figura 8 - Gráfico representativo do perfil de solubilidade do fármaco evidenciando o efeito mola e paraquedas ao comparar as formas amorfa e cristalina. 23

Figura 9 - Número de publicações dos últimos 10 anos (2009-2019) do site Web of Science, sobre dispersões sólidas.

Figura 10 - Fluxograma empregado para a produção de dispersões sólidas. 29

Figura 11 - Gráfico representativo do processo de nucleação e crescimento cristalino.

Figura 12 - Estrutura molecular da polivinilpirrolidona.

Figura 13 - Estrutura molecular da copovidona. 33

Figura 14 - Estrutura molecular da Hidroxipropilmetilcelulose ftalato. 34

Figura 15 - Estrutura molecular do poloxâmero. 35

Figura 16 - Estrutura molecular do efavirenz. 36 
Figura 17 - Microscopia eletrônica de varredura dos polimorfos I (lado esquerdo) e polimorfo II (lado direito) do fármaco EFV.

Figura 18 - Comparação dos difratogramas de raios $X$ dos polimorfos descritos do $\operatorname{EFV~}(\mathrm{A}=$ polimorfo I, $\mathrm{B}=$ polimorfo $\mathrm{II}$ e $\mathrm{C}=$ polimorfo III $)$.

Figura 19 - Fluxograma do método utilizado no preparo das formulações contendo os carreadores PVP K-28/32 e CoPVP. 56

Figura 20 - Fluxograma do método utilizado no preparo das formulações contendo os carreadores P188 e P407. 57

Figura 21 - Fluxograma do método utilizado no preparo das formulações contendo os carreadores HPMCP-50, HPMCP-55 e HPMCP-55s. 58

Figura 22 - Célula de fluxo pós e grânulos 64

Figura 23 - Cromatograma obtido a partir da análise da solução padrão de EFV $(20,0$ $\mu \mathrm{g} / \mathrm{mL}$ ) utilizando como diluente a fase móvel.

Figura 24 - Cromatogramas obtidos a partir das análises das amostras obtidas para avaliação da especificidade, designados conforme descrito a seguir: A - branco

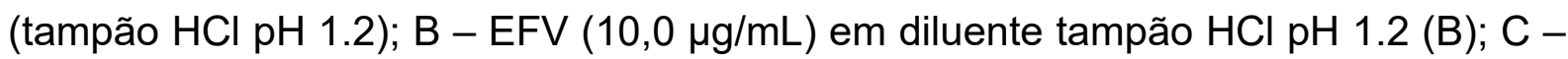
branco (tampão acetato pH 4.5) e D - EFV $(10,0 \mu \mathrm{g} / \mathrm{mL})$ em diluente tampão acetato $\mathrm{pH} 4.5$.

Figura 25 - Cromatogramas obtidos a partir das análises das amostras obtidas para avaliação da especificidade, designados conforme descrito a seguir: A - branco (tampão fosfato $\mathrm{pH} 6.8) ; \mathrm{B}$ - EFV $(10,0 \mu \mathrm{g} / \mathrm{mL})$ em diluente tampão fosfato $\mathrm{pH}$ 6.8; C - carreador PVP K-28/32 (20,0 $\mu \mathrm{g} / \mathrm{mL})$ em água ultrapurificada e D - mistura do EFV (20,0 $\mu \mathrm{g} / \mathrm{mL})$, diluído na fase móvel, e carreador PVP K-28/32 $(20,0 \mu \mathrm{g} / \mathrm{mL})$ utilizando como diluente água ultrapurificada. 70

Figura 26 - Cromatogramas obtidos a partir das análises das amostras obtidas para avaliação da especificidade, designados conforme descrito a seguir: A - carreador CoPVP $(20,0 \mu \mathrm{g} / \mathrm{mL})$ em água ultrapurificada; B - mistura do EFV (20,0 $\mu \mathrm{g} / \mathrm{mL})$, diluído na fase móvel, e carreador CoPVP $(20,0 \mu \mathrm{g} / \mathrm{mL})$ utilizando como diluente água ultrapurificada; C - carreador P188 ( (20,0 $\mu \mathrm{g} / \mathrm{mL})$ em água ultrapurificada; D - mistura 
do EFV $(20,0 \mu \mathrm{g} / \mathrm{mL})$, diluído na fase móvel, e carreador P188 $(20,0 \mu \mathrm{g} / \mathrm{mL})$ utilizando como diluente água ultrapurificada.

Figura 27 - Cromatogramas obtidos a partir das análises das amostras obtidas para avaliação da especificidade, designados conforme descrito a seguir: A - carreador

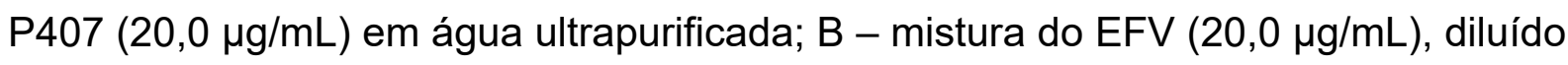
na fase móvel, e carreador P407 $(20,0 \mu \mathrm{g} / \mathrm{mL})$ utilizando como diluente água ultrapurificada; C - carreador HPMCP-50 ( (20,0 $\mu \mathrm{g} / \mathrm{mL})$ em metanol; D - mistura do EFV $(20,0 \mu \mathrm{g} / \mathrm{mL})$, diluído na fase móvel, e carreador HPMCP-50 (20,0 $\mu \mathrm{g} / \mathrm{mL})$ utilizando como diluente metanol.

Figura 28 - Cromatogramas obtidos a partir das análises das amostras obtidas para avaliação da especificidade, designados conforme descrito a seguir: A - carreador HPMCP-55 (20,0 $\mu \mathrm{g} / \mathrm{mL})$ em metanol; B - mistura do EFV $(20,0 \mu \mathrm{g} / \mathrm{mL})$, diluído na fase móvel, e carreador HPMCP-55 $(20,0 \mu \mathrm{g} / \mathrm{mL})$ utilizando como diluente metanol; C - carreador HPMCP-55s (20,0 $\mu \mathrm{g} / \mathrm{mL})$ em metanol; D - mistura do EFV $(20,0 \mu \mathrm{g} / \mathrm{mL})$, diluído na fase móvel, e carreador HPMCP-55s $(20,0 \mu \mathrm{g} / \mathrm{mL})$ utilizando como diluente metanol.

Figura 29 - Curva analítica do método cromatográfico para análise do EFV obtida no tampão $\mathrm{HCl}$ pH 1,2.

Figura 30 - Curva analítica do método cromatográfico para análise do EFV obtida no tampão acetato $\mathrm{pH} 4,5$. 75

Figura 31 - Curva analítica do método cromatográfico para análise do EFV obtida no tampão fosfato $\mathrm{pH} 6,8$. 75

Figura 32 - Difratogramas de raios $X$ obtidos pelo método do pó a partir das análises das matérias-primas (EFV e carreadores: PVP K-28/32, CoPVP, HPMCP-50, HPMCP55, HPMCP-55s, P188 e P407) e da lâmina de vidro virgem. 83

Figura 33 - Difratogramas de raios X pelo método do pó do EFV amorfo em T1 e T2 e das misturas binárias com os carreadores obtidos na proporção de 1:3 em T2: DS PVP K-28/32, DS CoPVP, DS HPMCP-50, DS HPMCP-55, DS HPMCP-55s, DS P188 e DS P407. 83 
Figura 34 - Fotografias das lâminas de vidro contendo o fármaco puro amorfizado e as misturas binárias após a finalização do estudo de estabilidade. A - EFV puro, EFV e carreadores (B - DS PVP K-28/32, C - DS CoPVP, D - DS HPMCP-55, E - DS HPMCP-55s, F - DS HPMCP-50, G - DS P188 e H - DS P407).

Figura 35 - Fotografias das dispersões sólidas nas proporções de fármaco e carreador 1:3 (A - DS PVP K-28/32, B - DS CoPVP, C - DS HPMCP-50, D - DS HPMCP-55, E - DS HPMCP-55s, F - DS P188 e G - DS P407). 87

Figura 36 - Gráfico do rendimento do processo de produção das DS amorfas de EFV em (\%), nas proporções de fármaco e carreador 1:3 (A - DS PVP K-28/32, B - DS CoPVP, C - DS HPMCP-50, D - DS HPMCP-55, E - DS HPMCP-55s, F - DS P188 e G - DS P407).

Figura 37 - Resultados das solubilidades obtidas através do método do equilíbrio do EFV puro, das MF e das DS na proporção 1:3. As barras de erros indicam o desvio padrão dos testes realizados em triplicatas. 98

Figura 38 - Resultados das solubilidades obtidas através do método do equilíbrio do EFV puro e das MF na proporção 1:1. As barras de erros indicam o desvio padrão dos testes realizados em triplicatas. 101

Figura 39 - Curvas DSC do EFV puro, P188 puro e MF nas proporções de 1:1, 1:2, 1:3, 1:4, 1:5 e $3: 1$ obtidas a $10^{\circ} \mathrm{C} / \mathrm{min}$ e atmosfera dinâmica de nitrogênio com vazão de $50 \mathrm{~mL} \mathrm{~min}^{-1}$. 104

Figura 40 - Curvas DSC do EFV puro, P407 puro e MF nas proporções de 1:1, 1:2, $1: 3,1: 4,1: 5$ e $3: 1$ obtidas a $10^{\circ} \mathrm{C} / \mathrm{min}$ e atmosfera dinâmica de nitrogênio com vazão de $50 \mathrm{~mL} \min ^{-1}$. 104

Figura 41- Difratogramas de raios $X$ pelo método do pó do EFV puro, do P188 puro, da MF P188 1:1 e das DS P188 1:1 nos tempos (T1 e T2). 107

Figura 42 - Difratogramas de raios X pelo método do pó do EFV puro, do P407 puro, da MF P407 1:1 e das DS P407 1:1 nos tempos (T1 e T2). 107

Figura 43 - Fotografias das lâminas de vidro contendo as misturas binárias, após a finalização do estudo de estabilidade. A - DS P188 e B - DS P407. 108 
Figura 44 - Perfis médios de dissolução do EFV em função do tempo obtidos a partir do EFV puro, das MF e das DS empregando os carreadores P188 e P407, preparadas na proporção de 1:3, em experimento utilizando o aparato IV Flow-Cell, fluxo de 8 $\mathrm{mL} /$ min e gradiente de $\mathrm{pH}$ como apresentado a seguir: solução tampão de $\mathrm{HCl} \mathrm{pH} 1,2$ nos primeiros 125 minutos, solução tampão de acetado pH 4,5 de 125-250 minutos e solução tampão fosfato $\mathrm{pH} \mathrm{6,8} \mathrm{de} \mathrm{250-375} \mathrm{minutos} \mathrm{finais} \mathrm{do} \mathrm{ensaio.}$

Figura 45 - Difratogramas de raios $X$ pelo método do pó do polimorfo I do EFV puro, do P188 puro, P 407 puro, das MF e das DS obtidas na proporção de 1:3. 116

Figura 46 - Curvas DSC do EFV puro, do P188 puro, da MF P188 e da DS P188 (1:3) obtidas a $10^{\circ} \mathrm{C} / \mathrm{min}$ e atmosfera dinâmica de nitrogênio com vazão de $50 \mathrm{~mL} \mathrm{~min}{ }^{-1}$. 118

Figura 47 - Curvas DSC do EFV puro, do P407 puro, da MF P407 e da DS P407 (1:3) obtidas a $10^{\circ} \mathrm{C} / \mathrm{min}$ e atmosfera dinâmica de nitrogênio com vazão de $50 \mathrm{~mL} \mathrm{~min}{ }^{-1}$.

Figura 48 - Curvas TG do EFV puro, do P188 puro, da MF P188 e da DS P188 (1:3) obtidas a $10^{\circ} \mathrm{C} / \mathrm{min}$ e atmosfera dinâmica de nitrogênio com vazão de $50 \mathrm{~mL} \mathrm{~min}{ }^{-1}$.

Figura 49 - Curvas TG do EFV puro, do P407 puro, da MF P407 e da DS P407 (1:3) obtidas a $10^{\circ} \mathrm{C} / \mathrm{min}$ e atmosfera dinâmica de nitrogênio com vazão de $50 \mathrm{~mL} \mathrm{~min}{ }^{-1}$. 120

Figura 50 - Espectros de infravermelho com transformada de Fourier do EFV puro, do P188 puro, da MF P188 e da DS P188 obtidas na proporção de 1:3.

Figura 51 - Espectros de infravermelho com transformada de Fourier do EFV puro, do P407 puro, da MF P407 e da DS P407 obtidas na proporção de 1:3. 123 
LISTA DE QUADROS 
Quadro 1 - Sistema de classificação biofarmacêutica. 9

Quadro 2 - Termo descritivo de solubilidade e seus significados.

Quadro 3 - Diversos métodos de produção do estado amorfo.

Quadro 4 - Classificação dos subtipos das dispersões sólidas de acordo com a forma física do fármaco e o do carreador.

Quadro 5 - Diferentes tipos de poloxâmeros s dependendo do número de segmentos de $a$ e b.

Quadro 6 - Descrição dos procedimentos para preparo das soluções empregadas para as análises por meio de CLAE do EFV (soluções tampão e solução padrão de EFV). 46

Quadro 7 - Condições cromatográficas empregadas para análise e quantificação de EFV. 48

Quadro 8 - Descrição dos dados para o preparo dos pontos da curva analítica a partir da solução mãe de EFV de $400 \mu \mathrm{g} / \mathrm{mL}$.

Quadro 9 - Descrição das amostras e das condições empregadas para obtenção do teste miniaturizado das misturas binárias (fármaco, carreador e solvente). 55

Quadro 10 - Descrição das condições empregadas para obtenção das formulações (em maior quantidades empregando a proporção 1:3).

Quadro 11 - Descrição das condições empregadas para diluição do EFV puro, das misturas físicas (MF) e dispersões sólidas (DS), preparadas na proporção de 1:3. . 60 Quadro 12 - Descrição das condições empregadas para diluição do EFV puro e das MF preparadas na proporção de 1:1.

Quadro 13 - Descrição das amostras e das condições empregadas para obtenção das misturas binárias (fármaco, carreador e solvente) para verificar a estabilidade das formulações.

Quadro 14 - Programação do aparato IV (Flow-Cell) considerando o tipo de meio de dissolução, período e intervalo de coleta e quantidade recolhida e descartada. 65 
LISTA DE TABELAS 
Tabela 1 - Precisão (repetibilidade e precisão intermediária) do método analítico para a determinação de EFV em tampão $\mathrm{HCl}$ pH 1,2 76

Tabela 2 - Precisão (repetibilidade e precisão intermediária) do método analítico para a determinação de EFV em tampão acetato $\mathrm{pH} 4,5$ 76

Tabela 3 - Precisão (repetibilidade e precisão intermediária) do método analítico para a determinação de EFV em tampão fosfato $\mathrm{pH} 6,8$. 76

Tabela 4 - Exatidão do método analítico para a determinação de EFV em tampão HCl $\mathrm{pH} \mathrm{1,2}$ .77

Tabela 5 - Exatidão do método analítico para a determinação de EFV em tampão acetato $\mathrm{pH} 4,5$.

Tabela 6 - Exatidão do método analítico para a determinação de EFV em tampão fosfato $\mathrm{pH} 6,8$.

Tabela 7 - Limites de detecção e de quantificação para as três soluções tampão utilizados no experimento .78

Tabela 8 - Resultados dos difratogramas de raios $X$ das matérias-primas (pura) e do EFV puro amorfizado e das misturas binárias, após o estudo de estabilidade acelerado onde foram classificadas como: totalmente amorfo (AAAA), semicristalino (AACC) e totalmente cristalino (CCCC) . 84

Tabela 9 - Valores de solubilidade de saturação $(\mu \mathrm{g} / \mathrm{mL})$ do EFV puro e das DS com os polímeros PVP K-28/32, CoPVP, HPMCP-50, HPMCP-55, HPMCP-55s, P188 e P407, na proporção 1:3. Os resultados representam a média e desvio padrão de três análises 97

Tabela 10 - Valores de solubilidade de saturação $(\mu \mathrm{g} / \mathrm{mL})$ do EFV puro e das MF com os polímeros PVP K-28/32, CoPVP, HPMCP-50, HPMCP-55, HPMCP-55s, P188 e $P 407$, na proporção 1:3. Os resultados representam a média e desvio padrão de três análises .97

Tabela 11 - Valores de solubilidade de saturação $(\mu \mathrm{g} / \mathrm{mL})$ do EFV puro e das MF com os polímeros P188 e P407, na proporção 1:1. Os resultados representam a média e desvio padrão de três análises 
Tabela 12 - Resultados dos difratogramas de raios $X$ das matérias-primas (pura) e das misturas binárias, após o estudo de estabilidade onde foram classificadas como: totalmente amorfo (AAAA), semicristalino (AACC) e totalmente cristalino (CCCC) 108 Tabela 13 - Valores de teor de EFV presente na matéria-prima e nas DS. Resultados representam os valores médios de três determinações e os respectivos desviospadrão (DP) 109

Tabela 14 - Porcentagem de EFV dissolvida em função do tempo a partir do EFV puro, das MF e das DS empregando os carreadores P188 e P407, em experimento utilizando o aparato IV, fluxo de $8 \mathrm{~mL} / \mathrm{min}$ e gradiente de $\mathrm{pH}$ como apresentado a seguir: solução tampão de $\mathrm{HCl}$ pH 1,2 nos primeiros 125 minutos, solução tampão de acetado pH 4,5 de 125-250 minutos e solução tampão fosfato pH 6,8 de 250-375 minutos finais do ensaio 112

Tabela 15 - Valores de eficiência de dissolução (ED\%) do EFV puro, das MF e das DS empregando os carreadores P188 e P407 obtidos na proporção de 1:3, avaliados em tempo de ensaio de 375 minutos em gradiente de $\mathrm{pH}$ 115 


\begin{tabular}{ll} 
AAAA & Totalmente amorfo \\
AACC & Semicristalino \\
AIDS & Síndrome da Imunodeficiência Adquirida \\
ANIVSA & Agência Nacional de Vigilância Sanitária \\
CCCC & Totalmente cristalino \\
CLAE & Cromatografia Líquida de Alta Eficiência \\
CoPVP & Copovidona \\
Cu & Cobre \\
DNA & Ácido desoxirribonucleico \\
DP & Desvio padrão \\
DRP & Desvio padrão relativo \\
DRXP & Difratometria de raios X pelo método do pó \\
DS & Dispersão sólida \\
DSA & Dispersão sólida amorfa \\
DSC & Calorimetria exploratória diferencial \\
ED\% & Eficiência de dissolução \\
EFV & Efavirenz \\
Endo & Reação endotérmica \\
FaSSIF & Fluido intestinal simulando o estado de jejum \\
FDA & Food and Drug Administration \\
FTIR & Espectroscopia na região do infravermelho com \\
HAART & transformada de Fourier \\
HCl & Terapia antirretroviral de alta atividade \\
HIV & Ácido clorídrico \\
HIV-1 & Vírus da Imunodeficiência Humana \\
HPMC & HIV tipo 1 \\
HPMCP & Hidroxipropilmetilcelulose \\
HPMCP-50 & Hidroxipropilmetilcelulose ftalato \\
HPMCP-55 & Hidroxipropilmetilcelulose ftalato 50 \\
HPMCP-55s & Hidroxipropilmetilcelulose ftalato 55 \\
ICH & Internacional Conference on Harmonisation \\
IFA & Insumos Farmacêuticos Ativos \\
In & Índio \\
KBr & Brometo de potássio \\
LD & Limite de detecção \\
LDH & Layered double hydroxides \\
Log P & Coeficiente de partição \\
LQ & Limite de quantificação \\
\hline
\end{tabular}




\begin{tabular}{|c|c|}
\hline LSS & Lauril sulfato de sódio \\
\hline MF & Mistura física \\
\hline $\mathrm{NaOH}$ & Hidróxido de sódio \\
\hline NN & Vizinho mais próximo \\
\hline NNN & Próximo vizinho mais próximo \\
\hline NNRTI & Inibidores Não Nucleosídeos da Transcriptase Reversa \\
\hline NRTI & Inibidores Nucleosídeos da Transcriptase Reversa \\
\hline P188 & Poloxâmero 188 \\
\hline P407 & Poloxâmero 407 \\
\hline PDF & Pair distribution funcion \\
\hline PEG & Polietilenoglicol \\
\hline pH & Potencial hidrogeniônico \\
\hline pKa & - log de Ka onde Ka é a constante de dissociação ácida \\
\hline POE & Polioxietileno \\
\hline POP & Polioxipropileno \\
\hline PVP & Polivinilpirrolidona \\
\hline PVP K-28/32 & Polivinilpirrolidona K-28/32 \\
\hline PVP-VA & Polivinilpirrolidona-co-acetato de vinila \\
\hline$Q_{\min }$ & Porcentagem de fármaco dissolvido \\
\hline $\mathbf{R}^{2}$ & Coeficiente de determinação \\
\hline RNA & Ácido ribonucleico \\
\hline rpm & Rotação por minuto \\
\hline SCB & Sistema de classificação biofarmacêutica \\
\hline SM & Solução mãe \\
\hline SP & Solução padrão \\
\hline T1 & Tempo um \\
\hline T2 & Tempo dois \\
\hline Tf & Temperatura de fusão \\
\hline$T_{g}$ & Temperatura de transição vítrea \\
\hline TG & Termogravimetria \\
\hline TGI & Trato gastrointestinal \\
\hline $\mathbf{T}_{\text {g-mid }}$ & Ponto médio da temperatura de transição vítrea \\
\hline $\mathbf{T}_{\text {g-onset }}$ & Início da temperatura de transição vítrea \\
\hline $\mathbf{T}_{\text {onset }}$ & Temperatura de início do evento térmico \\
\hline $\mathbf{T}_{\text {pico }}$ & Temperatura máxima do evento térmico \\
\hline UNAIDS & United Nations Programme on HIVIAIDS \\
\hline USP & United States Pharmacopeia \\
\hline UR & Umidade relativa \\
\hline UV & Ultravioleta \\
\hline
\end{tabular}




\begin{tabular}{|c|c|}
\hline$\%$ & Porcentagem \\
\hline${ }^{\circ} \mathrm{C}$ & Grau Celsius \\
\hline$\theta$ & Theta \\
\hline$\sim$ & Aproximadamente \\
\hline$\geq$ & Maior igual \\
\hline$\lambda$ & Lambda \\
\hline \pm & Mais ou menos \\
\hline$\leq$ & Menor igual \\
\hline Ka & K alfa \\
\hline kV & Quilovolts \\
\hline$<$ & Menor \\
\hline$\Delta \mathbf{H}$ & Variação de entalpia durante o evento térmico \\
\hline$\mu \mathrm{L}$ & Microlitro \\
\hline$\mu \mathrm{m}$ & Micrômetro \\
\hline$\mu \mathrm{g}$ & Micrograma \\
\hline$\AA$ & Ångström \\
\hline $\mathrm{cm}^{2}$ & Centímetro quadrado \\
\hline $\mathrm{cm}^{3}$ & Centímetro cúbico \\
\hline $\mathbf{c m}^{-1}$ & Centímetro menos um \\
\hline $\mathrm{cm}^{-2}$ & Centímetro menos dois \\
\hline g & Grama \\
\hline $\mathrm{J} / \mathrm{g}$ & Joule grama \\
\hline $\mathbf{L}$ & Litro \\
\hline mA & Miliampere \\
\hline mbar & Milésimos de bar \\
\hline mg & Miligrama \\
\hline $\min$ & Minuto \\
\hline $\min ^{-1}$ & Minuto menos um \\
\hline $\mathrm{mL}$ & Mililitro \\
\hline $\mathrm{mm}$ & Milímetro \\
\hline mol & Molaridade \\
\hline $\mathbf{N}$ & Normal \\
\hline $\mathrm{nm}$ & Nanômetro \\
\hline$p / p$ & Peso/peso \\
\hline seg & Segundo \\
\hline$v / v$ & Volume/volume \\
\hline
\end{tabular}


RESUMO 
NAZARETH JUNIOR, E. M. Desenvolvimento e caracterização de dispersões sólidas de efavirenz. 2020. 176 p. Dissertação (Mestrado) - Faculdade de Ciências Farmacêuticas, Universidade de São Paulo, São Paulo, 2020.

A baixa solubilidade aquosa dos insumos farmacêuticos ativos (IFA) é um grande desafio no desenvolvimento de formulações farmacêuticas, pois pode resultar em biodisponibilidade insuficiente e variável. Diversas estratégias de modificação do estado sólido dos compostos ativos, têm sido propostas para incrementar a solubilidade de fármacos pouco solúveis em água. Dentre as estratégias abordadas a dispersão sólida (DS) é uma das formas mais promissoras de aumentar a solubilidade, dissolução e a biodisponibilidade de IFAs com baixa solubilidade aquosa. O efavirenz (EFV) é um inibidor não nucleosídeo da transcriptase reversa (NNRTI) e um dos componentes da terapia antirretroviral de alta atividade (HAART), sendo parte da primeira linha de tratamento de infecções do vírus HIV tipo 1. O antirretroviral está classificado como pertencente à classe II do SCB, e exibe baixa solubilidade aquosa (solubilidade menor que $10 \mu \mathrm{g} / \mathrm{mL}$ ) e alta permeabilidade com absorção dependente da taxa de dissolução, resultando em biodisponibilidade oral baixa e variável. A administração de fármacos pouco solúveis na forma de DS é um método atraente para aumentar a biodisponibilidade in vivo. Neste estudo, um método de triagem rápida por evaporação de solvente foi empregado para preparar DS de EFV, variando-se proporções em misturas compostas pelos carreadores, polivinilpirrolidona K-28/32 (PVP K-28/32), copovidona (CoPVP), hidroxipropilmetilcelulose ftalato (HPMCP-50, HPMCP-55 e HPMCP-55s), poloxâmero 188 (P188) e poloxâmero 407 (P407). A solubilidade das DS foi avaliada por meio do método do equilíbrio (shake-flask), onde selecionou-se os polímeros P188 e P407 que conduziram a uma elevada capacidade de saturação em meio aquoso, superior a 1.000 vezes ao fármaco puro. As propriedades físico-químicas e do estado sólido das amostras foram avaliadas por meio de calorimetria exploratória diferencial (DSC); termogravimetria (TG); espectroscopia do infravermelho com transformada de Fourier (FTIR), difratometria de raios $\mathrm{X}$ pelo método do pó (DRXP) e ensaios de dissolução com emprego do aparato IV USP. Os resultados de DRXP demonstraram que os carreadores P188 e P407 foram capazes de estabilizar o EFV na forma amorfa nas DS, fato esse evidenciado pela ausência de picos característicos do antirretroviral.

Palavras-chave: Efavirenz; Dispersão sólida; Poloxâmero; Solubilidade; Fármacos pouco solúveis em água. 
ABSTRACT 
NAZARETH JUNIOR, E. M. Development and characterization of efavirenz solid dispersions. 2020. 176 p. Thesis (Masters) - Faculty of Pharmaceutical Sciences, University of São Paulo, São Paulo, 2020.

The low aqueous solubility of the active pharmaceutical ingredient (API) is a major challenge in the development of pharmaceutical formulations as it may result in insufficient and variable bioavailability. Several strategies for modifying the solid-state of the active compounds have been proposed to increase solubility of drugs that are poorly soluble in water. Among the strategies approaches, solid dispersion (SD) is one of the most promising ways to increase solubility, dissolution and bioavailability of APIs with low aqueous solubility. Efavirenz (EFV) is a non-nucleoside reverse transcriptase inhibitor (NNRTI) and one of the components of highly active antiretroviral therapy (HAART), being part of the first line of treatment of type 1 HIV virus infections. The antiretroviral is classified as belonging to BCS class II, and exhibits low aqueous solubility (solubility less than $10 \mu \mathrm{g} / \mathrm{mL}$ ) and high permeability with dissolution ratedependent absorption, resulting in low and variable oral bioavailability. Drug delivery of poorly aqueous soluble drugs in form SD is an appealing method to increase in vivo bioavailability. In this study, a fast screening method of solvent evaporation method was used to prepare EFV SD, varying the proportions in mixtures composed by the carriers polyvinylpyrrolidone K-28/32 (PVP K-28/32), copovidone (CoPVP), hydroxypropylmethylcellulose phthalate (HPMCP-50, HPMCP-55 e HPMCP-55s), poloxamer 188 (P188) e poloxamer 407 (P407). The solubility of the samples was evaluated by the method of equilibrium (shake-flask), wherein the polymers P188 and P407 were selected due to the capacity to promote high saturation in aqueous medium, 1,000 times superior to the pure drug. The physicochemical and solid-state properties of the samples were evaluated by differential scanning calorimetry (DSC); thermogravimetry (TG); Fourier transform infrared spectroscopy (FTIR), X-ray powder diffraction (XRPD) and dissolution assays using the IV USP apparatus. The results of XRPD demonstrated that the carriers P188 and P407 were able to stabilize the EFV in amorphous form in the SD, a fact evidenced by the absence of characteristic peaks of the antiretroviral.

Keywords: Efavirenz; Solid dispersion; Poloxamer; Solubility, Poorly water-soluble drugs 
1. INTRODUÇÃO 
O vírus da imunodeficiência humana (HIV) ainda permanece no mundo como um dos mais significantes desafios de saúde pública, particularmente nos países de baixa e média renda. Desde sua descoberta, no início dos anos 80 , tem sido atribuída ao HIV a morte de mais de 32 milhões de pessoas em todo o mundo, sendo atualmente responsável pela infecção de quase 38 milhões de pessoas (UNAIDS, 2020).

O HIV infecta células do sistema imunológico humano, denominadas de CD4 ou Células $\mathrm{T}$, levando à destruição das mesmas e tornando-as incapazes de combater infecções e doenças, o que resulta na síndrome da imunodeficiência adquirida (AIDS), deixando o indivíduo vulnerável a quaisquer tipos de doenças e infecções (UNAIDS, 2020).

A terapia antirretroviral de alta atividade (HAART; do inglês, "highly active antiretroviral therapy"), introduzida em 1996, combina pelo menos três fármacos antirretrovirais e, por mais de uma década, tem sido utilizada para prolongar a vida dos pacientes infectados pelo HIV. Com essa terapia, a antiga doença fatal associada ao HIV, a AIDS, tornou-se uma infecção crônica administrável na maioria dos países desenvolvidos (SOSNIK; CHIAPPETTA; CARCABOSO, 2009). Dados disponíveis no site UNAIDS Brasil, informam que em meados do ano de 2019, aproximadamente 25 milhões de pessoas receberam a HAART, o que representa aproximadamente $65 \%$ dos 38 milhões de infectados com o HIV. A HAART tem permitido aos pacientes com HIV uma condição de vida mais saudável, além de diminuir as chances de transmissão do vírus (UNAIDS, 2020).

Entre os fármacos mais utilizados na HAART está o efavirenz (EFV), um inibidor não-nucleosídeo da transcriptase reversa do HIV. Considerado como de primeira linha no tratamento de infecções do HIV tipo 1, o EFV age inibindo a enzima transcriptase reversa, o que impede o mecanismo de transcrição do RNA viral em DNA viral (BASTOS et al., 2016; HOFFMEISTER et al., 2017). Este antirretroviral está classificado como pertencente à classe II do sistema de classificação biofarmacêutica (SCB), uma vez que, apresenta alta permeabilidade e baixa solubilidade (solubilidade menor que $10 \mu \mathrm{g} / \mathrm{mL}$ ) e, consequentemente, baixa biodisponibilidade oral (40\% 50\%) (FANDARUFF et al., 2014a; HOFFMEISTER et al., 2017; KOMMAVARAPU; MARUTHAPILLAI; PALANISAMY, 2016; PAWAR et al., 2016). 
Os fármacos pouco solúveis em água apresentam desafios contínuos na produção de medicamentos viáveis, pois podem resultar em biodisponibilidade insuficiente e variável. Dados da literatura relatam que, cerca de $40 \%$ dos fármacos comercializados e $75 \%$ dos novos compostos, candidatos a fármacos, apresentam baixa solubilidade aquosa (BOYD et al., 2019; TIAN et al., 2017; WILLIAMS et al., 2013).

Nesse sentido, as propriedades do estado sólido dos fármacos exercem grande impacto no comportamento de dissolução da substância ativa e, como consequência, na sua biodisponibilidade. Esse fato é especialmente crítico no caso de fármacos pouco solúveis, para os quais, a estrutura cristalina e polimorfismo devem ser cuidadosamente controlados e monitorados na produção farmacêutica, conforme recomendação das agências reguladoras (FDA, 2007; FANDARUFF et al., 2015). Assim, a manipulação do estado sólido é uma das abordagens mais promissoras para aumentar a solubilidade, a dissolução e a biodisponibilidade de fármacos pouco solúveis em água. Entre das diversas abordagens está a preparação de sólidos amorfos (TIAN et al., 2017; WILLIAMS et al., 2013), uma vez que o processo de solubilização e de dissolução de um sólido cristalino passa primeiramente pelo rompimento da estrutura cristalina para, posteriormente, ocorrer a difusão molecular no solvente. Como, todavia, em fármacos amorfos, a primeira etapa é inexistente, uma menor energia é requisitada para promover a dissolução (VASCONCELOS et al., 2016; VASCONCELOS; SARMENTO; COSTA, 2007).

As formas amorfas são caracterizadas pela ausência de um padrão de organização estrutural ao nível intermolecular, pois não possuem estruturas cristalinas definidas, levando à baixa estabilidade termodinâmica. A solubilidade aparente de formas amorfas é maior, o que resulta em altos níveis de supersaturação em meio aquoso, quando em comparação com às formas cristalinas (NEWMAN; KNIPP; ZOGRAFI, 2012; VASCONCELOS et al., 2016).

Contudo, a amorfização dos insumos farmacêuticos ativos (IFA) é inevitavelmente acompanhada por um risco à estabilidade do produto, uma vez que, o composto amorfo possui a tendência de se recristalizar durante o armazenamento, devido a sua instabilidade termodinâmica. Nessas condições, o produto amorfo fica à mercê da umidade relativa do ar e da temperatura ambiente, desafiando os 
pesquisadores a inibir o processo de recristalização (NEWMAN; KNIPP; ZOGRAFI, 2012; XIE; TAYLOR, 2016).

A dispersão sólida (DS) é uma tecnologia farmacêutica que possui a função de melhorar a solubilidade de um fármaco pouco solúvel em água e estabilizá-lo fisicamente, com o emprego de um carreador hidrofílico (inerte) em estado sólido. Nesta condição, o composto ativo encontra-se disperso em um carreador e essa combinação faz com que a solubilidade e a dissolução do IFA sejam incrementadas. O fármaco nas DS pode ser disperso como moléculas separadas, partículas amorfas ou partículas cristalinas enquanto o carreador pode estar no estado cristalino ou amorfo (BAGHEL; CATHCART; O'REILLY, 2016; VASCONCELOS; SARMENTO; COSTA, 2007; VO; PARK; LEE, 2013).

Existem três principais métodos descritos na literatura empregados para a obtenção de DS, incluindo o método de fusão, método do solvente e método de fusãosolvente (BAGHEL; CATHCART; O'REILLY, 2016; LEUNER; DRESSMAN, 2000; VASCONCELOS; SARMENTO; COSTA, 2007; VO; PARK; LEE, 2013).

As propriedades físico-químicas das DS obtidas por diferentes meios estão diretamente relacionadas ao método utilizado. Portanto, é de extrema importância avaliar a interferência do método no desenvolvimento das DS, elegendo o que será mais eficiente em relação à solubilidade, dissolução e estabilidade do produto final (ALVES et al., 2012).

Diante do exposto, o presente trabalho teve como objetivo, melhorar a solubilidade e a dissolução do fármaco EFV por meio do desenvolvimento e caracterização de DS. Para isto, pretende-se empregar o método de evaporação do solvente e os seguintes carreadores: polivinilpirrolidona K-28/32 (PVP K-28/32), copovidona (CoPVP), hidroxipropilmetilcelulose ftalato (HPMCP-50, HPMCP-55 e HPMCP-55s), poloxâmero 188 (P188) e poloxâmero (P407). 
2. OBJETIVOS 


\subsection{Objetivo geral}

O presente trabalho teve como objetivo desenvolver e caracterizar dispersões sólidas de efavirenz, visando o incremento da solubilidade e dissolução do fármaco.

\subsection{Objetivos específicos}

I. Obtenção das dispersões sólidas de efavirenz por meio do método de evaporação do solvente, empregando os carreadores selecionados: Kollidon® 30 polivinilpirrolidona K-28/32 (PVP K-28/32), Kollidon® VA64 copovidona (CoPVP), hidroxipropilmetilcelulose ftalato (HPMCP-50, HPMCP-55 e HPMCP55s), Kolliphor® P188 poloxâmero 188 (P188) e Kolliphor® P407 poloxâmero (P407).

II. Avaliação da solubilidade do fármaco, quando puro, nas dispersões sólidas e nas misturas físicas, utilizando a técnica do shake-flask;

III. Avaliação da dissolução em condição sink do fármaco, quando puro, nas dispersões sólidas e nas misturas físicas, com emprego do aparato 4 Flow-Cell;

IV. Caracterização físico-química do estado sólido por DRXP, DSC, TG e FTIR do fármaco puro, dos carreadores, das dispersões sólidas e das misturas físicas de efavirenz. 
3. REVISÃO DA LITERATURA 


\subsection{Solubilidade aquosa do fármaco e as implicações na eficácia do medicamento}

A administração oral de fármacos é a via mais utilizada devido à sua facilidade de administração, maior comodidade para o paciente e sem necessidade de esterilidade (BAGHEL; CATHCART; O’REILLY, 2016). Adicionalmente, os medicamentos orais podem ser produzidos em uma ampla variedade de formas farmacêuticas e de dosagens, a custos comparativamente baixos em relação a outras vias de administração, tornando-os atraentes tanto para pacientes quanto para as empresas farmacêuticas (WILLIAMS III; WATTS; MILLER, 2016).

Quando um fármaco é administrado oralmente, essa substância precisa passar por certas barreiras dentro do sistema biológico, incluindo a dissolução em fluidos gastrointestinais, permeação através da membrana do trato gastrointestinal (TGI) e metabolismo de primeira passagem, para finalmente atingir seu local de ação via circulação sistêmica (BAGHEL; CATHCART; O'REILLY, 2016). Por essas razões, quando um fármaco possui baixa solubilidade aquosa, isso afetará sua absorção e, poderá resultar em alta variabilidade na biodisponibilidade (AMIDON et al., 1995; HUANG; WILLIAMS, 2018).

A baixa solubilidade aquosa dos IFAs é um grande desafio no desenvolvimento farmacêutico. Essa característica está se tornando cada vez mais comum entre os novos candidatos a medicamentos, provenientes de ferramentas de triagem combinatória e de alta produtividade, durante a fase de descoberta e seleção de potenciais agentes terapêuticos (VO; PARK; LEE, 2013).

O sistema de classificação biofarmacêutica (SCB) proposto por Amidon et al. (1995) e adotado por agências regulatórias de diversos países, permite classificar os fármacos com base em sua solubilidade e permeabilidade (Quadro 1). De acordo com o SCB, um fármaco é considerado de baixa solubilidade quando sua dosagem mais alta a ser administrada oralmente não for solúvel em $250 \mathrm{~mL}$ de meio aquoso nas faixas de $\mathrm{pH} 1,2$ - 6,8 a $37^{\circ} \mathrm{C}$; e um fármaco é considerado altamente permeável quando a extensão da absorção em humanos é determinada como $85 \%$ ou mais de uma dose oral administrada. A estimativa do volume de $250 \mathrm{~mL}$ é derivada de protocolos típicos dos estudos de bioequivalência, que prescrevem a administração de um medicamento à voluntários humanos sadios em jejum com um copo de água 
(AMIDON et al., 1995; EMA, 2010; KAWABATA et al., 2011; SAVJANI; GAJJAR; SAVJANI, 2012).

O SCB categoriza as substâncias medicamentosas em uma das quatro categorias com base em sua solubilidade e permeabilidade intestinal, e essas quatro categorias são definidas da seguinte maneira: alta solubilidade / alta permeabilidade (classe I), baixa solubilidade / alta permeabilidade (classe II), alta solubilidade / baixa permeabilidade (classe III) e baixa solubilidade / baixa permeabilidade (classe IV). Os compostos pertencentes às Classes II e IV do SCB, e se caracterizam pela baixa solubilidade aquosa, onde fármacos classificados como classe II apresentam variabilidades, devido as diferenças nas formulações e variáveis fisiológicas e para os da classe IV possuem alta variabilidade na velocidade e extensão de absorção (AMIDON et al., 1995; KAWABATA et al., 2011).

Quadro 1 - Sistema de classificação biofarmacêutica.

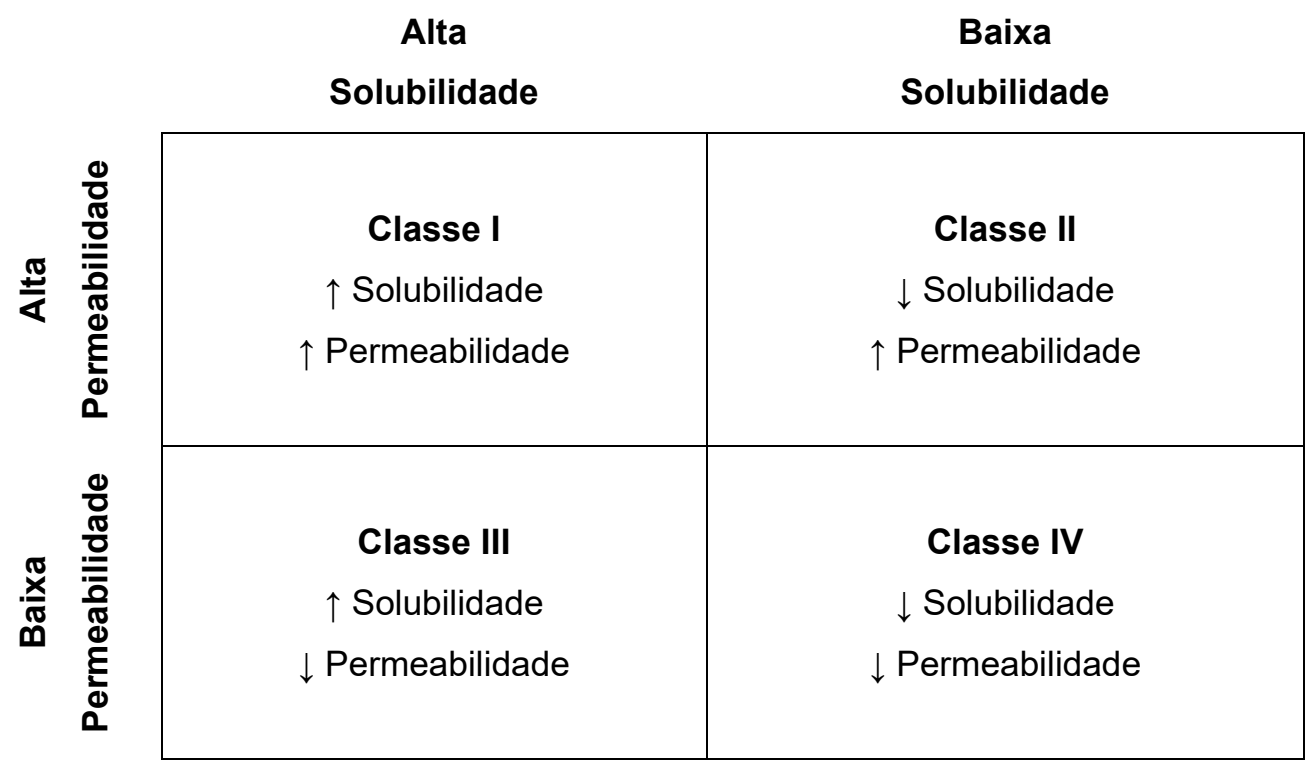

Fonte: Adaptação de (AMIDON et al., 1995).

A solubilidade, assim como a permeabilidade, são fatores determinantes da biodisponibilidade oral dos fármacos e da eficácia dos medicamentos, assim tais fatores são as principais características requeridas para novos compostos candidatos a fármaco e para o sucesso no desenvolvimento de formulações farmacêuticas 
(WILLIAMS III, WATTS; MILLER, 2016; LEUNER; DRESSMAN, 2000). Apesar das tentativas de contornar os problemas de solubilidade, aproximadamente $40 \%$ dos fármacos comercializados, e até $75 \%$ dos compostos ativos em desenvolvimento, têm sido sugeridos como sendo pouco solúveis em água (TIAN et al., 2017; WILLIAMS et al., 2013).

A solubilidade é definida em termos quantitativos como a concentração de soluto em uma solução saturada a uma determinada temperatura, podendo ser declarada em unidades de concentração, molaridade, fração molar, razão molar e outras unidades (WILLIAMS III; WATTS; MILLER, 2016; SAVJANI; GAJJAR; SAVJANI, 2012).

A solubilidade é a propriedade de uma substância química denominada soluto, e que pode se apresentar em um dos três estados da matéria sendo, sólido, líquido ou gasoso. O soluto pode ser dissolvido em solvente (sólido, líquido ou gasoso) formando uma solução homogênea do soluto no solvente. A solubilidade de um composto depende fundamentalmente do solvente utilizado, bem como da temperatura e pressão. A extensão da solubilidade de uma substância em um solvente específico é medida como a concentração de saturação em que a adição de mais soluto não aumenta sua concentração na solução (SAVJANI; GAJJAR; SAVJANI, 2012). A solubilidade está intimamente relacionada com a dissolução, que é um processo cinético e pode ser definida como o meio pelo qual um fármaco é liberado de sua forma farmacêutica, tornando-se disponível para ser absorvido pelo organismo através da camada de difusão (WILLIAMS III; WATTS; MILLER, 2016; LAVRA, 2016).

O coeficiente de partição (Log P) é uma medida de solubilidade diferencial de um composto em um solvente hidrofóbico (octanol) e um solvente hidrofílico (água), o logaritmo desses dois valores permitem que as substâncias sejam classificadas em termos de hidrofilicidade ou hidrofobicidade. As farmacopeias americana, britânica e brasileira classificam a solubilidade independentemente do solvente utilizado, apenas em termos de quantificação e definiram os critérios conforme apresentado no Quadro 2 (FARMACOPEIA BRASILEIRA, 2010; SAVJANI; GAJJAR; SAVJANI, 2012). 
Quadro 2 - Termo descritivo de solubilidade e seus significados.

\begin{tabular}{|ll|}
\hline \hline Solvente & Termo descritivo \\
\hline Muito solúvel & Menos de 1 parte* \\
Facilmente solúvel & De 1 a 10 partes \\
Solúvel & De 10 a 30 partes \\
Ligeiramente solúvel & De 30 a 100 partes \\
Pouco solúvel & De 100 a 1.000 partes \\
Muito pouco solúvel & De 1.000 a 10.000 partes \\
Praticamente insolúvel ou insolúvel & Mais de 10.000 partes \\
\hline \hline
\end{tabular}

*A expressão "partes" refere-se à dissolução de $1 \mathrm{~g}$ de um sólido no número de mililitros do solvente estabelecido no número de partes.

Fonte: (FARMACOPEIA BRASILEIRA, 2010).

Diversas técnicas que incrementam a solubilidade dos fármacos foram relatadas, e permitem a administração bem-sucedida de medicamentos pouco solúveis em água. Essas técnicas podem ser categorizadas em quatro estratégias distintas: solubilização do fármaco, modificação molecular, modificação da morfologia e modificação intermolecular conforme ilustrado na Figura 1 (HUANG; WILLIAMS, 2018).

A técnica de solubilização de fármacos emprega cossolventes, veículos lipídicos, micelas (tensoativos) e formação de complexos, é frequentemente utilizada e esta estratégia de formulação tem sido amplamente relatada na produção de formulações líquidas. A estratégia de modificação molecular normalmente compreende a alteração da estrutura química, ao ajustar a polaridade da molécula, a solubilidade e a permeabilidade de toda a molécula sofrem modificação, e isso normalmente altera seu comportamento farmacocinético. Exemplos de modificação molecular incluem: pró-fármaco, twin drug (associação de dois fármacos) e sais. Para a estratégia de modificação morfológica, aumento da área de superfície das partículas ao reduzir o tamanho das amostras podem beneficiar a taxa de dissolução do fármaco, aumentando assim, a biodisponibilidade dos compostos ativos com absorção limitada, conforme descrito pela equação de Noyes - Whitney (Eq. 1) (HUANG; WILLIAMS, 2018; NOYES; WHITNEY, 1897).

$$
\frac{d C}{d t}=\frac{D\left(C_{S}-C\right)}{V h}
$$


Onde $C$ é a quantidade de soluto na solução no tempo $t, d C / d t$ é a taxa de passagem do soluto na solução no tempo $t, D$ é o coeficiente de difusão do soluto no meio de dissolução, Cs é a solubilidade do soluto no equilíbrio na temperatura do experimento, $V$ é o volume de dissolução do líquido e $h$ é a largura da camada de difusão.

A estratégia de modificação intermolecular, como a formação de polimorfos, cocristais ou formulações amorfas, também podem ser utilizadas e afetam o processo de dissolução. Entre essas estratégias de formulação, a modificação intermolecular envolvendo uma dispersão sólida amorfa é muito utilizada. As formulações amorfas não apenas proporcionam melhores taxas de dissolução do fármaco e melhor solubilidade, mas também mantêm a possibilidade de produzir formas farmacêuticas sólidas sem alterar a estrutura química das moléculas do fármaco (HUANG; WILLIAMS, 2018).

Figura 1 - Diferentes formas de modificações físico-químicas e farmacotécnicas para fármacos de baixa solubilidade aquosa.

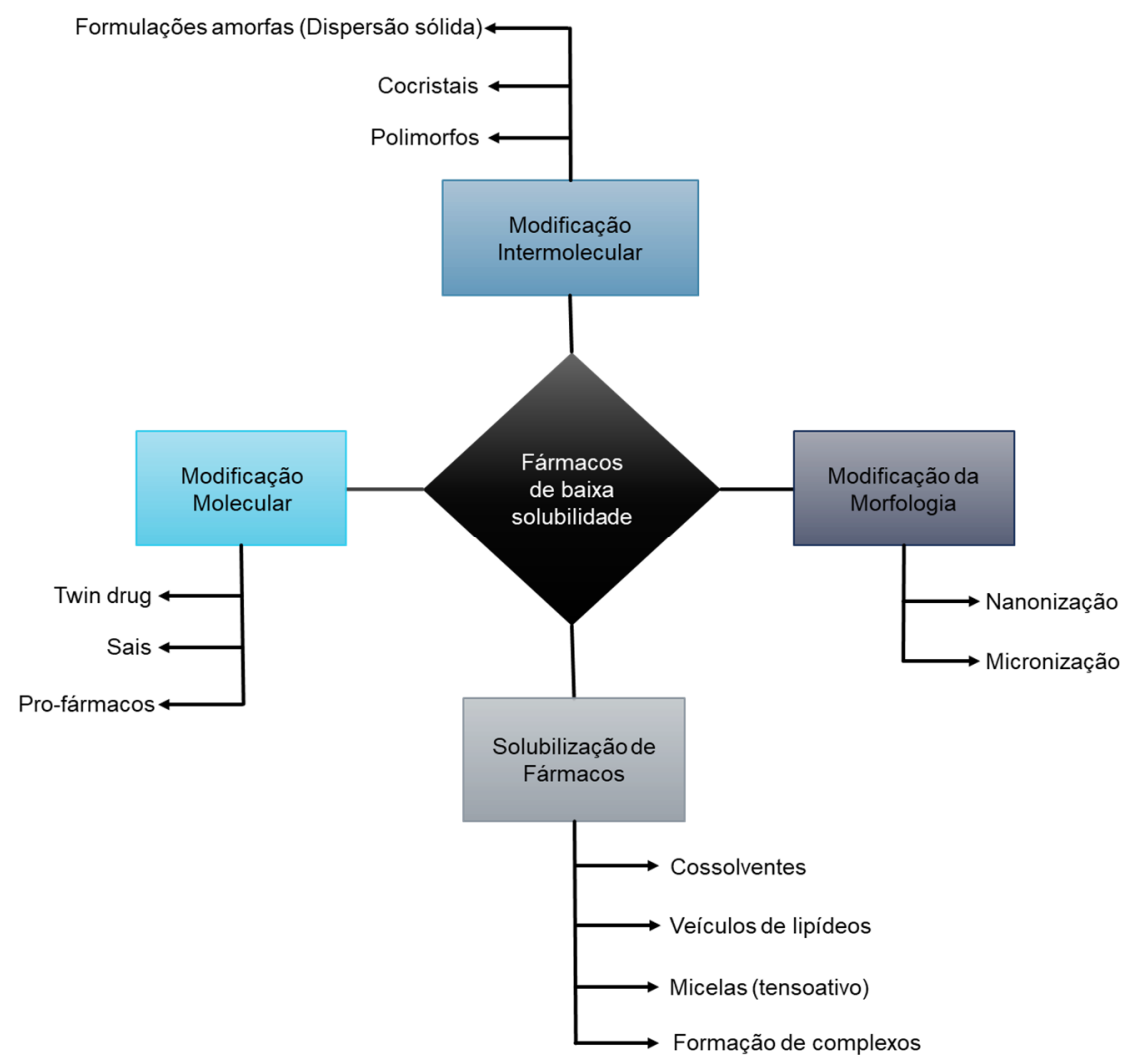

Fonte: Adaptação de (HUANG; WILLIAMS, 2018). 


\subsection{Estado sólido dos fármacos}

Os materiais farmacêuticos podem existir nos estados sólidos cristalino ou sólido amorfo. Os sólidos cristalinos podem existir sob diversas formas, tais como, anidratos, hidratos, solvatos e cocristais, assim como, várias formas polimórficas cristalinas e de sais. Todas essas formas são caracterizadas por um arranjo bem definido, de átomos e moléculas em uma simétrica rede cristalina de longa distância, isso ocorre através de celas unitárias que se repetem em três dimensões. A capacidade de formar cristais em uma rede bem definida é desejável para qualquer molécula, incluindo os IFAs, já que a cristalização geralmente leva a altos níveis de pureza e estabilidade no estado sólido (BYRN; ZOGRAFI; CHEN, 2017).

Os sólidos amorfos são caracterizados pela falta de ordem nos operadores de simetria de longa distância, (ordem translacional, orientacional e conformacional), fatores estes encontrados em sólidos cristalinos. A ausência de ordem de longa distância pode ser atribuída a uma distribuição aleatória de unidades moleculares, moléculas individuais são aleatoriamente orientadas umas às outras e existem em diversos estados conformacionais. As formas amorfas apresentam um excesso de energia livre, entalpia e entropia, comparadas aos estados cristalinos correspondentes, portanto, sua solubilidade no TGI pode ser maior, resultando assim em maior biodisponibilidade do fármaco (BYRN; ZOGRAFI; CHEN, 2017; SHAH et al., 2014; YU, 2001). A Figura 2 ilustra o estado cristalino (lado esquerdo) como um sólido perfeitamente ordenado com moléculas (círculos) matriz ordenada e o material amorfo (lado direito) como um material desordenado com apenas ordem de curto alcance (BYRN; ZOGRAFI; CHEN, 2017). 
Figura 2 - Representação esquemática do estado cristalino (lado esquerdo) e estado amorfo (lado direito), as moléculas são vistas como círculos.
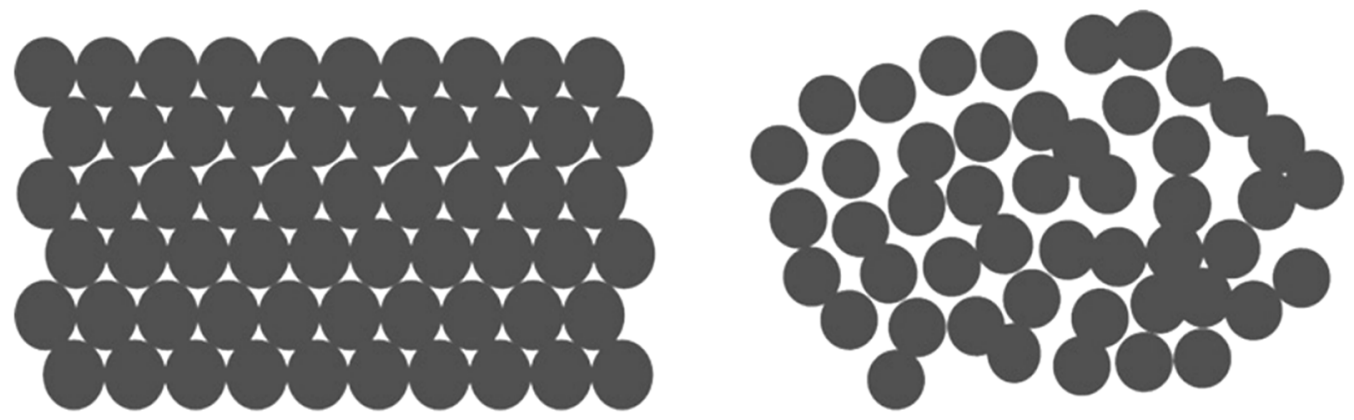

Fonte: Reproduzido com permissão de (BYRN; ZOGRAFI; CHEN, 2017).

\subsubsection{Sólidos amorfos}

A relação clássica de energia livre e temperatura, entre a forma cristalina de uma molécula e de sua forma líquida correspondente, conforme esquematicamente ilustrado na Figura 3 é utilizada para compreender as propriedades dos sólidos amorfos. Nessa imagem, podemos observar que a temperatura abaixo da temperatura de fusão (Tf), os sólidos existem com menor energia livre do que os líquidos e, portanto, o sólido é a forma termodinamicamente estável. Entretanto, a amostra passa a ser aquecida até exceder a Tf, onde o líquido passa no menor estado de energia livre, e o sólido se funde espontaneamente para formar o líquido (BYRN; ZOGRAFI; CHEN, 2017). A partir desse momento, se o líquido fosse esfriado lentamente abaixo da Tf, esperaríamos que ocorresse a cristalização, restaurando assim o estado cristalino. Contudo, conforme representado na Figura 3, se esfriarmos rapidamente o líquido evitando a formação de núcleos de cristais, é possível formar um líquido superresfriado, antes que qualquer cristalização possa ocorrer. Assim, neste processo, formamos um estado líquido super-resfriado que é metaestável em relação à forma cristalina (BYRN; ZOGRAFI; CHEN, 2017; HANCOCK; SHAMBLIN, 2001; NEWMAN, 2015).

Após o arrefecimento, à medida que a viscosidade do líquido super-resfriado aumenta e os movimentos difusivos das moléculas diminuem, o equilíbrio não pode mais ser mantido, gera uma descontinuidade distinta no diagrama de energia livre e temperatura com a formação do estado vítreo instável. Isto ocorre em uma temperatura diferente chamada de temperatura de transição vítrea $\left(T_{g}\right)$, temperatura 
onde o vidro se forma, característica única da estrutura química da molécula (HANCOCK; SHAMBLIN, 2001).

Figura 3 - Diagrama de temperatura e energia livre para um sistema de único componente.

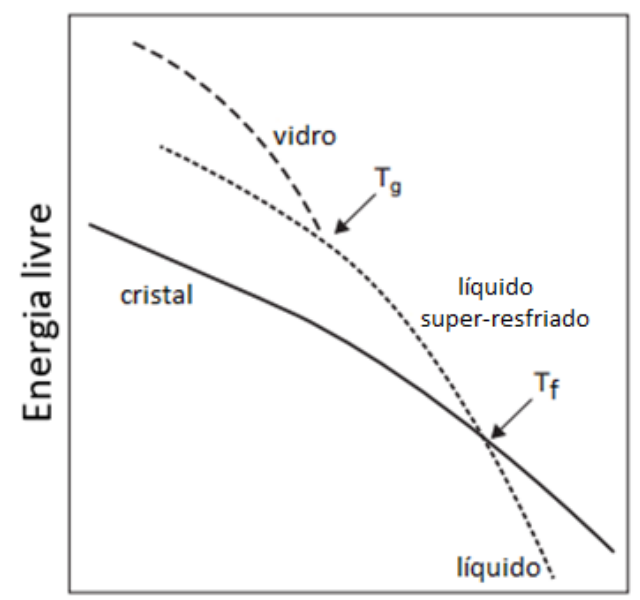

Temperatura

Fonte: Adaptação (e reproduzido com permissão) de (HANCOCK; SHAMBLIN, 2001).

Os sólidos amorfos podem existir em diversos produtos industrialmente importantes, tais como polímeros, cerâmicas, metais, materiais ópticos (vidro e fibras), alimentos e produtos farmacêuticos. No caso de produtos farmacêuticos, a importância do estado amorfo se deve a sólidos amorfos que apresentam maior solubilidade, maior taxa de dissolução e, em alguns casos, melhores características de compressão do que as formas cristalinas. Por outro lado, as substâncias amorfas são geralmente menos estáveis fisicamente e quimicamente do que os cristais. Os compostos amorfos podem ser produzidos por processos farmacêuticos padrão e são a forma comum de certos materiais, por exemplo, proteínas, peptídeos, polímeros e alguns açúcares (YU, 2001).

As substâncias amorfas são consideradas como vidro, pois possuem propriedades reológicas de sólidos e propriedades moleculares de líquidos. $O$ comportamento de vidro amorfos pode ser explicado pelo conteúdo de calor, ou mudanças de volume molar com as mudanças de temperatura. Quando o conteúdo de calor ou volume molar de uma amostra é deparado em relação à temperatura, essas variáveis mudam suavemente até chegar à região conhecida como temperatura de transição vítrea $\left(\mathrm{T}_{\mathrm{g}}\right)$, onde as variáveis mudam abruptamente (SHAH et al., 2014). 
A região abaixo da temperatura de $T_{g}$ é conhecida como "estado vítreo" e acima é conhecida como "estado borrachoso". As propriedades físico-químicas e físicomecânicas dos materiais são completamente diferentes entre essas duas regiões (SHAH et al., 2014).

$\mathrm{O}$ valor de $\mathrm{T}_{\mathrm{g}}$ é determinado experimentalmente de forma mais conveniente utilizando calorimetria exploratória diferencial (DSC), onde a capacidade de calor pode ser medida, em que, a temperatura da amostra é continuamente alterada a uma taxa constante de baixas temperaturas até a temperatura de fusão. Por causa das mudanças estruturais que provocam mudanças na taxa de movimentos moleculares, a capacidade de calor geralmente sofre nitidamente uma mudança abrupta na $T_{g}$, conforme ilustrado na Figura 4 (BYRN; ZOGRAFI; CHEN, 2017; NEWMAN, 2015).

Figura 4 - Mudança na capacidade calorífica durante a transição vítrea. No gráfico é indicado

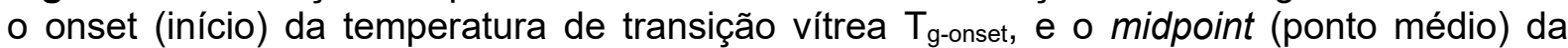
temperatura de transição vítrea $T_{g-m i d}$.

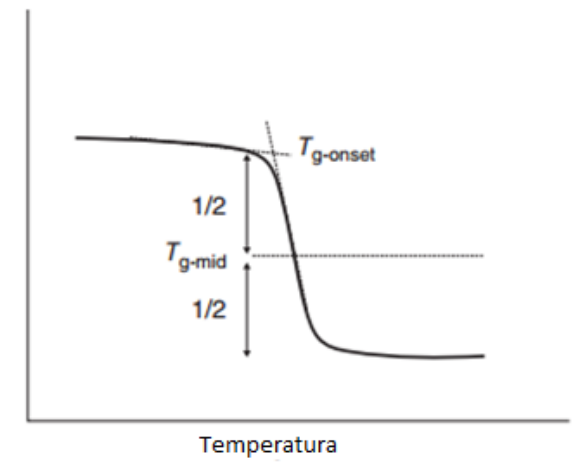

Fonte: Adaptação (e reproduzido com permissão) (BYRN; ZOGRAFI; CHEN, 2017).

Evidentemente para manter um estado condensado através de interação intermolecular, os sólidos amorfos devem reter certo nível de curta distância ou ordem "local" que é limitada a algumas dimensões moleculares, como no vizinho mais próximo (NN) e próximo vizinho mais próximo (NNN). Distâncias, tipicamente menores que 2,0 - 2,5 nm para moléculas orgânicas pequenas (BYRN; ZOGRAFI; CHEN, 2017; NEWMAN, 2015). A Figura 5 ilustra esquematicamente as diferenças gerais na ordem de longa distância para sólidos cristalinos e sólidos amorfos, respeitando a perda desta ordem no estado amorfo, mas com a retenção da ordem local (BYRN; ZOGRAFI; CHEN, 2017). 
Figura 5 - Representação esquemática dos arranjos dos átomos e moléculas nos estados cristalino e amorfo.

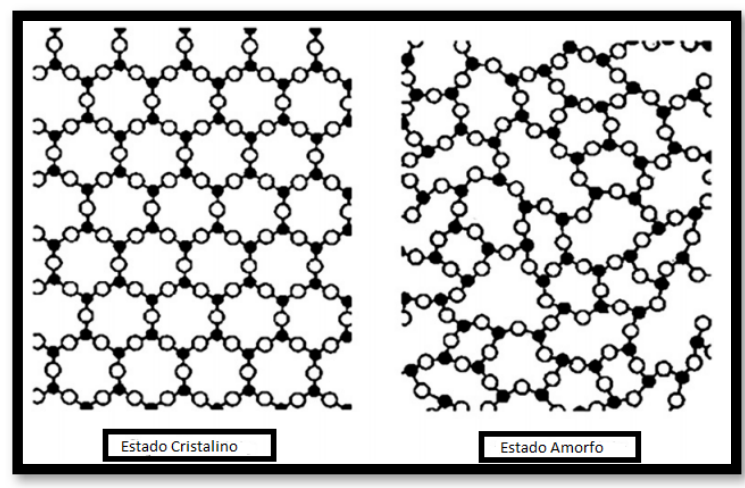

Fonte: Adaptação (e reproduzido com permissão) de (BYRN; ZOGRAFI; CHEN, 2017).

Uma forma de observar experimentalmente as diferenças entre a ordem de longa distância em cristais, e a perda da ordem de longa distância em sólidos amorfos, seria comparar os difratogramas pela técnica de difratometria de raios $\mathrm{X}$ pelo método do pó (DRXP), os padrões das formas cristalina e amorfa são ilustrados na Figura 6. Nessa figura, podemos evidenciar que os picos de difração característicos para os cristais representam os vários planos de simetria dentro da rede cristalina, e para os sólidos amorfos a perda completa dos picos de difração, devido à perda da ordem de longa distância da rede. Tipicamente, uma forma amorfa exibirá um amplo padrão de "halo", caracteristicamente ocorrendo em um ângulo de cerca de $20^{\circ} 2 \theta$ (dois theta). Além disso, um sólido amorfo ainda é caracterizado pela falta de propriedades distintas de ponto de fusão e birrefringência (BYRN; ZOGRAFI; CHEN, 2017; SHAH et al., 2014).

Para descrever a estrutura local de um sólido amorfo, é possível usar dados de espalhamento total de raios X para se obter o padrão Pair Distribution Function (PDF), que fornece uma distribuição de distâncias de pares atômicos na estrutura. Para o caso de fármacos, distâncias intramoleculares e que representam ordenamentos locais, estão presentes tanto em fases amorfas e cristalinas. Picos no padrão PDF que se estendem a altas distâncias (maiores do que cerca de $10 \AA$ para o caso de fármacos) estão relacionadas ao ordenamento tridimensional de longo alcance (distâncias intermoleculares) relacionado com a estrutura cristalina. Dessa forma, é possível se diferenciar e caracterizar estruturas de curto, médio e longo ordenamento (NEWMAN, 2015). 
Figura 6 - Comparação dos padrões de DRXP do fármaco efavirenz nos estados sólido cristalino e sólido amorfo.

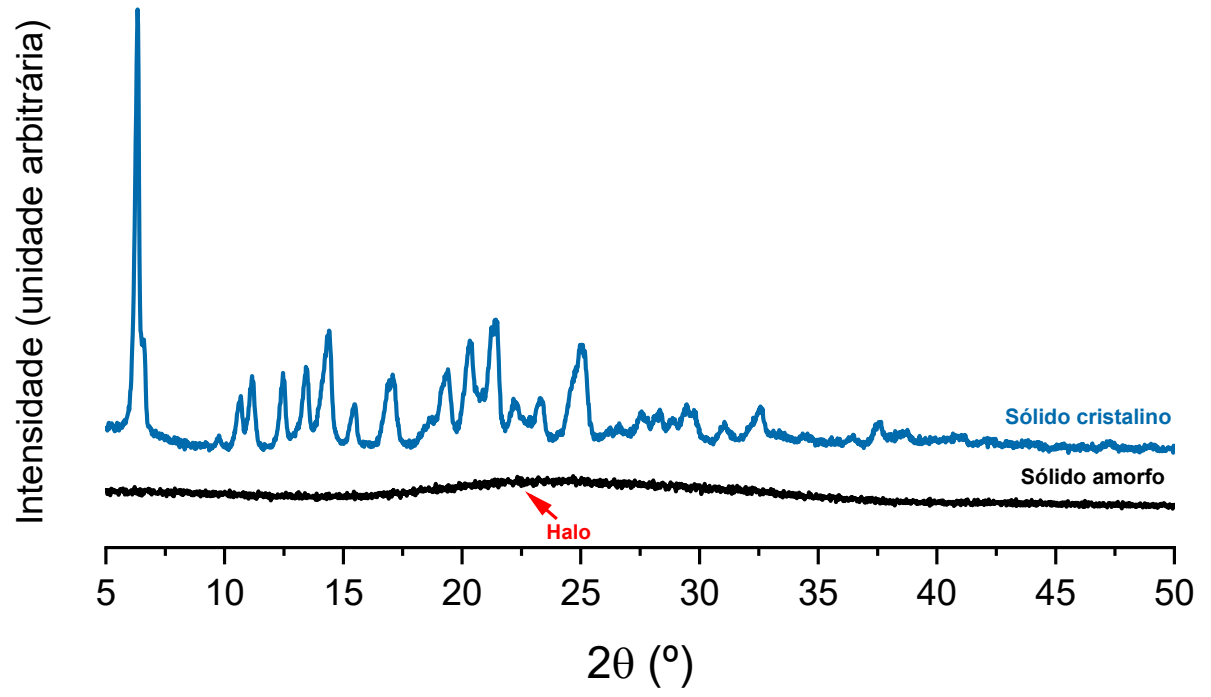

Fonte: Elaborado pelo autor.

Geralmente, produtos amorfos são classificados em dois grupos distintos, em fármaco molecularmente puro e dispersão sólida, sendo esta última um sistema binário de fármaco molecularmente disperso em carreadores. Ambos os tipos são caracterizados por natureza de estado sólido, sem estrutura cristalina, maior energia livre, entalpia, entropia e volume, em comparação com a forma cristalina. Devido às propriedades termodinâmicas, os produtos amorfos apresentam maior solubilidade aparente em água e maior taxa de dissolução, levando a uma melhor absorção oral. Além disso, menor energia é necessária para aumentar a taxa de dissolução do fármaco, apesar destas vantagens, os ingredientes ativos amorfos puros raramente são candidatos a fármacos no desenvolvimento da forma farmacêutica, devido às dificuldades de produção resultantes da instabilidade termodinâmica (RAMS-BARON et al., 2018).

O fármaco no estado amorfo puro representa a forma mais alta de energia (potencial químico) do princípio ativo no estado sólido, portanto a solubilidade teórica dessa substância amorfa pura, (em que o potencial químico do fármaco não dissolvido é igual ao seu correspondente dissolvido), é superior a quaisquer outras formas sólidas do IFA. Consequentemente seria de se esperar os benefícios desses compostos químicos em seu estado amorfo puro, em termos de aumento da solubilidade e taxas de dissolução (HUANG; WILLIAMS, 2018). 
Contudo, as características de estado sólido dos fármacos e as transformações entre diferentes estados no ambiente gastrointestinal, não são facilmente avaliadas em ambientes dinâmicos e complexos. As tendências mais recentes em relação às formas amorfas dos fármacos de alta energia, apresentam um problema de cristalização imprevisível, com consequências para a solubilização e a biodisponibilidade. A predisposição para a cristalização pode ser antecipada, no entanto, o meio complexo do TGI instala um nível de incerteza em torno disso (BOYD et al., 2019).

A empresa farmacêutica AstraZeneca em 1999 obteve a aprovação do FDA para a fabricação do zafirlucaste (Accolate $®)$ um medicamento amorfo puro. Esse IFA em sua forma cristalina, possui baixa solubilidade aquosa (isto é, cerca de $0,6 \mu \mathrm{g} / \mathrm{mL}$ em FaSSIF) e, consequentemente, baixa biodisponibilidade oral. Assim que o fármaco foi convertido para o estado amorfo, o composto ativo passou a exibir uma maior biodisponibilidade, contudo, o zafirlucaste (amorfo) apresentou recristalização na presença de umidade, convertendo-se na forma cristalina monoidratada, resultando assim em menor solubilidade e biodisponibilidade (HUANG; WILLIAMS, 2018). A conclusão obtida para esse caso foi que, devido ao seu estado inerente de alta energia do fármaco amorfo puro, relatou-se que esse produto possui problemas de instabilidade termodinâmica, que levam ao relaxamento, nucleação, cristalização e até degradação química, durante o armazenamento ou dentro do trato gastrointestinal. Portanto, a aplicação do sistema amorfo contendo fármacos amorfos puro tem sido limitada (HUANG; WILLIAMS, 2018; KONNO; TAYLOR, 2008).

\subsubsection{Métodos de preparo de sólidos amorfos}

Devido às razões termodinâmicas e cinéticas, preparações de sólidos amorfos são simples para alguns materiais (bons formadores de vidro), e mais difícil para outros (pobres formadores de vidro). Termodinamicamente, a capacidade de formação do vidro origina-se de um estado cristalino que não é substancialmente mais estável do que o estado amorfo, o que pode ser o caso de moléculas que empacotam mal ou contêm muitos graus internos de liberdade. Cineticamente, uma taxa lenta de cristalização permite que um material se torne um "líquido congelado" ou vitrifique sem cristalização (YU, 2001). 
Contudo, como descrito no Quadro 3, também é possível produzir formas amorfas por moléculas de condensação rápida, diretamente do estado de vapor a baixas temperaturas, ou fazendo com que moléculas precipitem rapidamente da solução, onde em ambos os casos a cristalização é cineticamente evitada. Embora a preparação a partir do estado de vapor não seja usada atualmente como um processo para formar produtos farmacêuticos amorfos, há evidências de que tal método pode levar a excepcionalmente vidros estáveis. A precipitação da solução para formar um sólido amorfo é a base para os processos amplamente utilizados de liofilização e secagem por pulverização (spray-drying), onde a liofilização se mostrou particularmente útil na formação de produtos proteicos amorfos estéreis, para uso parenteral e secagem por pulverização para o desenvolvimento de dispersões sólidas para uso oral e pulmonar (BYRN; ZOGRAFI; CHEN, 2017; HANCOCK, 2001; NEWMAN, 2015; YU, 2001).

Conforme evidenciado no Quadro 3, é possível formar o estado amorfo diretamente de um cristal, através da introdução de tensão mecânica que é suficiente para criar defeitos na estrutura cristalina, que eventualmente coalescem em uma forma completamente amorfa. Da mesma forma, foi demonstrado que as formas amorfas podem ser criadas pela desidratação de hidratos de cristais ou pela dessolvatação de solvatos cristalinos, onde em ambos os casos a rede cristalina dessolvatada colapsa por causa do volume livre deixado pela remoção do solvente da estrutura cristalina. Embora tais métodos que interrompam a rede cristalina, ainda não foram considerados práticos para a preparação de sistemas amorfos farmacêuticos em larga escala. A importância de tais fenômenos foi demonstrada em situações em que os sólidos cristalinos, são inadvertidamente tornados parcialmente amorfos por processos, tais com moagem e secagem, levando a pequenas quantidades de desordem e imprevistos no estado sólido. Em conclusão, dado que diferentes métodos utilizados para formar sólidos amorfos, podem levar a vidro com propriedades diferentes, é importante reconhecer que os vários processos farmacêuticos empregados para produzir produtos farmacêuticos amorfos, robustos, de alta qualidade e desempenho, devem estar sob cuidadoso controle em relação ao tempo, temperatura e outras condições do processo (HANCOCK, 2001; NEWMAN, 2015). 
Quadro 3 - Diversos métodos de produção do estado amorfo.

\begin{tabular}{|c|c|c|}
\hline Forma & Método & Exemplos \\
\hline \multirow{5}{*}{ Cristal } & \multirow{5}{*}{ Ruptura / entrada de energia } & Moagem ou trituração \\
\hline & & Compressão ou descompressão \\
\hline & & dessolvatação de solvatos e hidratos \\
\hline & & Irradiação \\
\hline & & Reação \\
\hline \multirow{7}{*}{ Solução } & \multirow{7}{*}{ Remoção de solvente } & Spray-drying \\
\hline & & Liofilização \\
\hline & & Precipitação \\
\hline & & Granulação úmida \\
\hline & & revestimento de película aquosa \\
\hline & & Polimerização \\
\hline & & Reação \\
\hline \multirow{3}{*}{ Líquido } & \multirow{3}{*}{ Refrigeração ou remoção de energia } & Extrusão a quente \\
\hline & & Polimerização \\
\hline & & Reação \\
\hline \multirow{2}{*}{ Vapor } & \multirow{2}{*}{ Refrigeração ou remoção de energia } & Sublimação \\
\hline & & Reação \\
\hline
\end{tabular}

Fonte: Adaptação de (HANCOCK, 2001; NEWMAN, 2015).

\subsection{Dispersão sólida}

Em meados dos anos 60 dois pesquisadores Sekiguti e Obi (1961) relataram pela primeira vez na literatura, que ao realizar formulações de misturas eutéticas, poderia levar a uma melhoria na taxa de dissolução de fármacos poucos solúveis e consequentemente o incremento de sua biodisponibilidade. A combinação eutética do experimento dos pesquisadores continha sulfatiazol como fármaco de baixa solubilidade e ureia como carreador hidrossolúvel. A preparação apresentou uma rápida liberação do fármaco e uma melhor biodisponibilidade, quando comparada à formulação convencional (LEUNER; DRESSMAN, 2000; SEKIGUCHI; OBI, 1961).

Atualmente a preparação de mistura eutética proposta pelos pesquisadores Sekiguti e Obi (1961) é conhecida como dispersão sólida (DS) (Figura 7). O termo dispersão sólida foi introduzido pelos pesquisadores Chiou e Riegelman em 1971, que definiram DS como uma dispersão de um ou mais ingredientes ativos em um carreador inerte no estado sólido, preparados pelos métodos de fusão, evaporação do solvente ou fusão-solvente (CHIOU; RIEGELMAN, 1971; SEKIGUCHI; OBI, 1961; SHAH et al., 2014). 
Figura 7 - Representação esquemática da classificação de dispersão sólida cristalina, dispersão sólida amorfa e solução sólida de moléculas de fármacos na matriz polimérica carreadora.

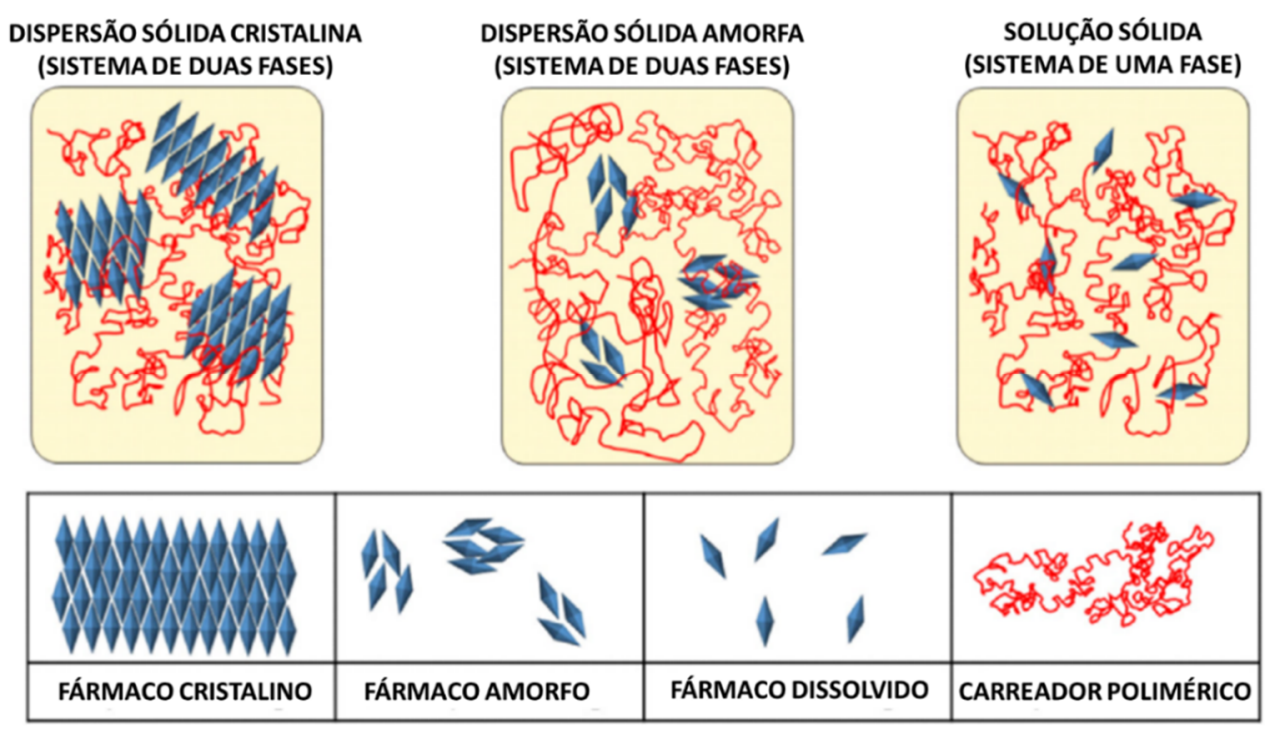

Fonte: Adaptação de (SUN; LEE, 2014).

As DS podem ser definidas como misturas moleculares de fármacos fracamente hidrossolúveis com carreadores hidrofílicos, responsáveis por modular o perfil de liberação dos compostos ativos. As DS são caracterizadas pela redução do tamanho das partículas a um nível molecular de solubilização ou dissolução em carreadores solúveis. No geral, as DS proporcionam melhor molhabilidade e dispersibilidade, uma vez que o fármaco está em seu estado supersaturado devido à solubilização forçada nos carreadores hidrofílicos (VASCONCELOS et al., 2016; VASCONCELOS; SARMENTO; COSTA, 2007).

As formas farmacêuticas orais convencionais à base de dispersão sólida amorfa (DSA) para medicamentos com baixa solubilidade em água, geralmente se concentram no aumento das taxas de dissolução, elevando o grau de supersaturação e estendendo sua duração. Trata-se de uma prática comum empregar polímeros solúveis como carreadores convencionais, para inibir a precipitação do fármaco do estado supersaturado (SUN; LEE, 2013).

Normalmente, a dissolução das DSA com base em polímeros solúveis em água é muito rápida, resultando em um aumento inicial da concentração do IFA no meio de dissolução, seguido por um declínio na concentração do composto ativo, devido aos eventos de nucleação e cristalização desencadeados pelo rápido acúmulo de 
supersaturação do fármaco. Dependendo da capacidade do polímero dissolvido em inibir a precipitação da substância ativa a partir do estado supersaturado, esse declínio na concentração do composto ativo pode ser retardado em diferentes graus. Em geral, quanto mais gradual o declínio na concentração do medicamento, melhor sua eficácia na inibição da precipitação, manutenção e da supersaturação da substância medicamentosa (SUN; LEE, 2013).

Os perfis típicos de dissolução desses sistemas binários amorfos, apresentam um rápido acúmulo inicial de supersaturação do IFA e subsequentemente retardo da precipitação, essa abordagem foi caracterizada como "mola e paraquedas" (Figura 8). Essa combinação de uma "mola" que se dissolve e supersatura rapidamente, e um "paraquedas" retardador da precipitação, essa estratégia foi adotada para produção de formulações mais eficazes para aumentar a taxa e a extensão da absorção oral. Embora esses dados de dissolução de "mola e paraquedas" tenham sido ajustados a equações empíricas, a interação entre esses processos na obtenção e manutenção da supersaturação ainda permanecem incompreendidas (BAGHEL; CATHCART; O'REILLY, 2016; SUN; LEE, 2013; WILLIAMS et al., 2013).

Figura 8 - Gráfico representativo do perfil de solubilidade do fármaco evidenciando o efeito mola e paraquedas ao comparar as formas amorfa e cristalina.

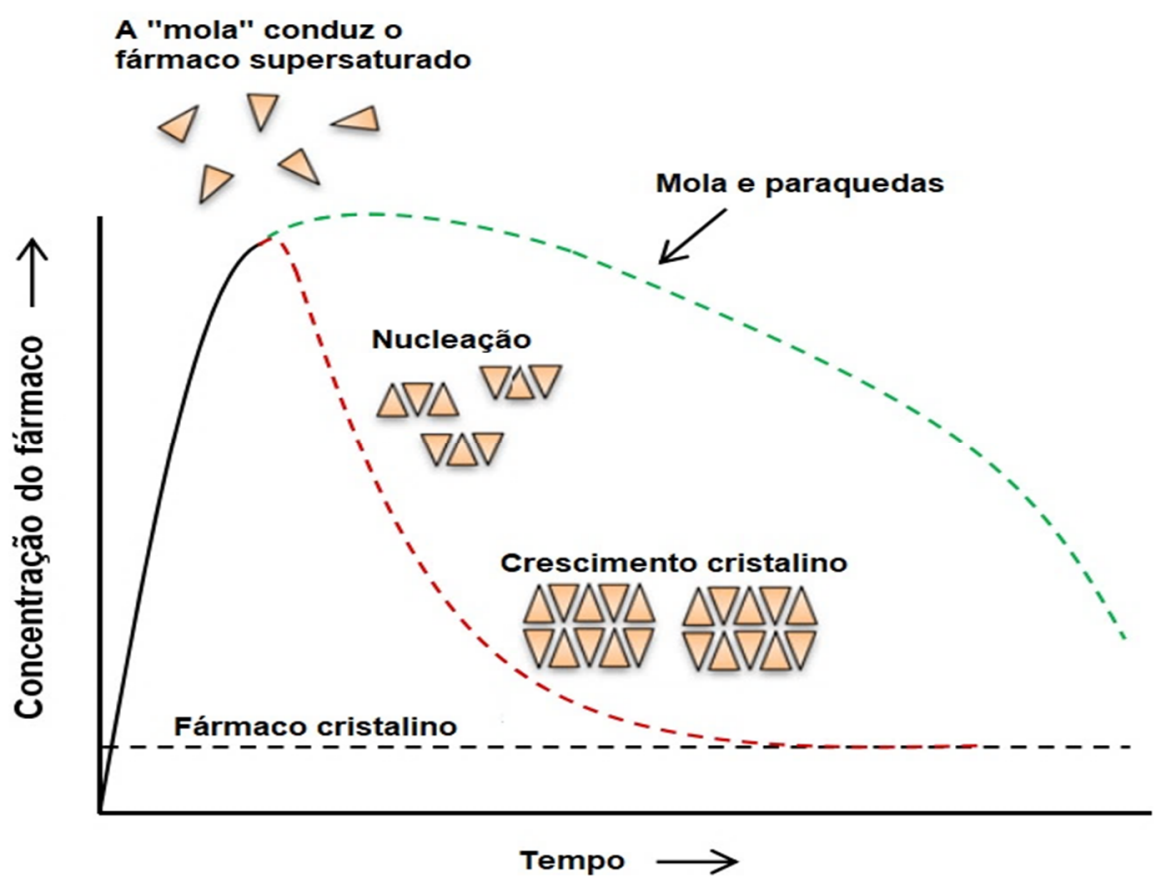

Fonte: Adaptação (e reproduzido com permissão) de (WILLIAMS et al., 2013). 
Atualmente, as DSA representam o campo de pesquisa e desenvolvimento mais interessante relacionado aos produtos farmacêuticos amorfos. Numerosos estudos sobre DSA foram publicados e demonstraram diversas propriedades vantajosas na melhoria na solubilidade e na taxa de dissolução de fármacos com baixa solubilidade aquosa. Estas vantagens incluem a redução do tamanho de partículas, possivelmente ao nível molecular, aumento da molhabilidade e porosidade, bem como alteração do estado cristalino do fármaco, preferencialmente para o estado amorfo (BERTONI et al., 2019; LI; TAYLOR, 2018; MESALLATI et al., 2017; SUN; LEE, 2015; VASCONCELOS et al., 2016; VASCONCELOS; SARMENTO; COSTA, 2007; VO; PARK; LEE, 2013; YU et al., 2018). A Figura 9 apresenta o número de publicações relativas ao tema de dispersões sólidas nos últimos 10 anos (2009-2019) e que foram obtidas a partir do site Web of Science, por meio do emprego das palavras chaves "Solid dispersion" (WEB OF SCIENCE, 2020).

Figura 9 - Número de publicações dos últimos 10 anos (2009-2019) do site Web of Science, sobre dispersões sólidas.

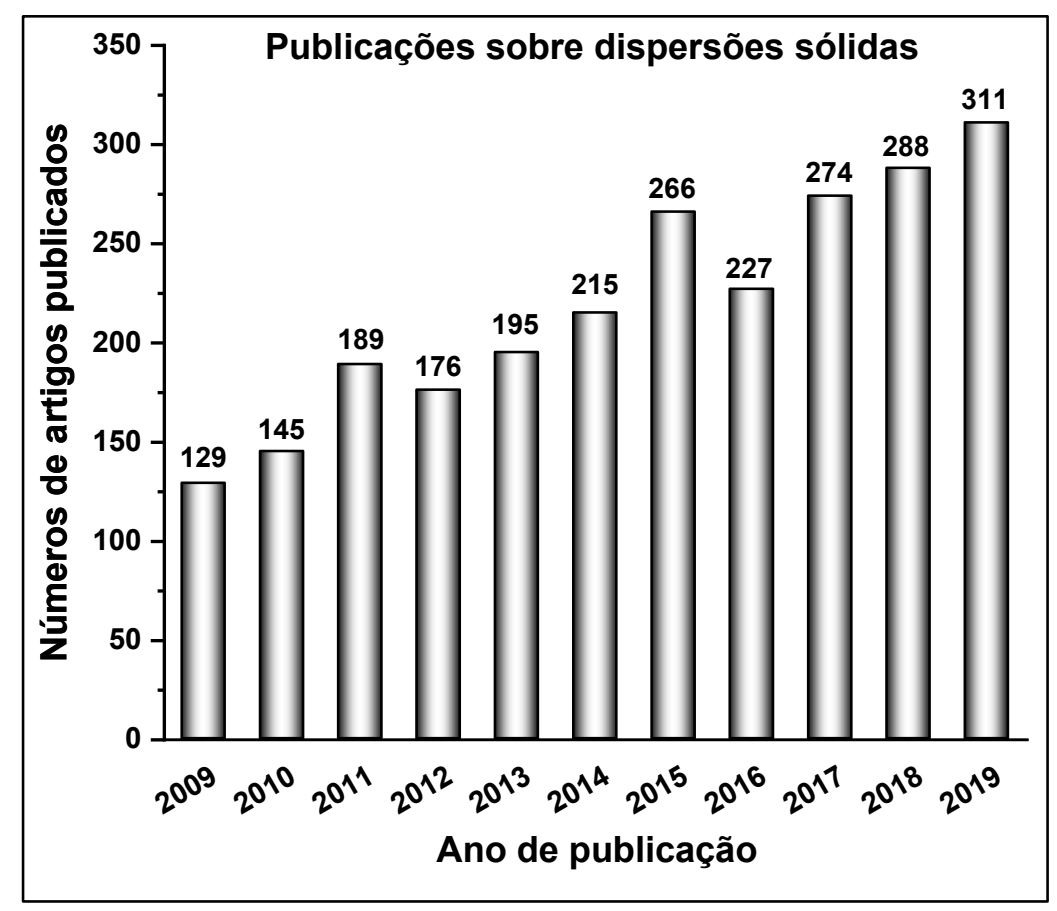

Fonte: Elaborado pelo autor. 


\subsubsection{Classificação das dispersões sólidas e tecnologia de obtenção}

O desenvolvimento de DS depende do acesso a carreadores farmacêuticos e a tecnologias adequadas para a preparação da dispersão. A classificação das DS em seus diferentes estágios de desenvolvimento é baseada nos excipientes farmacêuticos utilizados. Dependendo do estado físico do carreador seja cristalino ou amorfo, esses sistemas binários são divididos em DS cristalinas e DS amorfas, conforme ilustrado na Figura 7. As DS também podem ser classificadas em quatro gerações com base em sua composição, entretanto segundo os autores $\mathrm{Yu}$ et al. (2018) já se fala na existência da quinta geração de DS (VO; PARK; LEE, 2013; YU et al., 2018).

As DS de primeira geração foram baseadas principalmente em carreadores cristalinos, como ureia, sorbitol e manitol; onde um fármaco cristalino é disperso no carreador para formar uma mistura eutética ou monotética. No entanto, as dispersões resultantes desses processos possuem baixa estabilidade e baixa dissolução, comprometendo a biodisponibilidade do fármaco (VASCONCELOS; SARMENTO; COSTA, 2007; VO; PARK; LEE, 2013; YU et al., 2018).

As DS de segunda geração compreendem principalmente soluções binárias vítreas ou suspensões sólidas amorfas, com um fármaco pouco solúvel em água sendo disperso em um veículo adequado. Esses carreadores podem incluir: polímeros sintéticos como polivinilpirrolidona (PVP), polivinilpirrolidona-co-acetato de vinila (PVP-VA) e polietilenoglicol (PEG), polímeros de ocorrência natural, incluindo hidroxipropilmetilcelulose (HPMC) e hidroxipropilmetilcelulose ftalato (HPMCP) e outros tipos de dispersante de ocorrência natural como, amido de milho, amido de batata, trealose, sacarose e inulina. Nessa condição, o fármaco se apresenta em estado amorfo na DS e com solubilidade e dissolução elevadas, no entanto, quando se utilizam esses carreadores, as DS apresentam uma baixa estabilidade (VASCONCELOS; SARMENTO; COSTA, 2007; VO; PARK; LEE, 2013; YU et al., 2018).

As DS de terceira geração envolvem o uso combinado de vários excipientes farmacêuticos, como polímeros amorfos, tensoativos e / ou auto-emulsificantes (por exemplo, poloxâmero, Compritol 888 ATO, Soluplus $®$, Gelucire 44/14, lauril sulfato de sódio (LSS), Tween 80 e Inutec SP1. Apresentando uma maior liberação de fármaco, 
estabilidade a longo prazo e biodisponibilidade (VASCONCELOS; SARMENTO; COSTA, 2007; VO; PARK; LEE, 2013; YU et al., 2018).

As DS de quarta geração apresentam um sistema de liberação controlada, em consequência de empregarem nas formulações polímeros insolúveis em água ou intumescíeis como, etilcelulose, Eudragit ${ }^{\circledR} \mathrm{RS}$ ou $\mathrm{RL}$, carboxivinilpolímero (Carbopol囚) e poli (2-hidroxietilmetacrilato) reticulado (pHEMA). Estes carreadores apresentam as características de intumescerem e desta forma, retardam a liberação de fármacos no meio de dissolução. Assim, podem tanto melhorar a solubilidade de um fármaco, enquanto fornece um sistema de liberação estendida em uma forma farmacêutica de liberação controlada (VO; PARK; LEE, 2013; YU et al., 2018).

Nos últimos anos, as DS de quinta geração foram cada vez mais relatadas na literatura. Estas são caracterizadas pelo uso de micro ou nanoestruturas como um meio para melhorar o desempenho funcional de liberação da substância ativa. As DS são obtidas através das aplicações diretas de energia elétrica, a técnica electrospinning pode gerar DSA baseadas em nanofibras a partir de soluções carregadas de fármaco fundido, esses sistemas podem melhorar o comportamento de dissolução e fornecer perfis programáveis de liberação (YU et al., 2018).

As DS também podem ser classificadas de acordo com o arranjo molecular do fármaco na matriz transportadora e as propriedades do carreador. Em termos simples, o fármaco pode ser: 1) parcialmente dissolvido com excesso de fármaco suspenso no estado cristalino, 2) parcialmente dissolvido com excesso de fármaco suspenso no estado amorfo, ou 3) completamente dissolvido (isto é, disperso molecularmente). A matriz de DS pode ser cristalina ou amorfa, como tal, existem seis tipos principais de dispersões, estas são descritas no Quadro 4, e cada arranjo é apresentado esquematicamente na Figura 7 (WILLIAMS et al., 2013) 
Quadro 4 - Classificação dos subtipos das dispersões sólidas de acordo com a forma física do fármaco e o do carreador.

\begin{tabular}{|c|c|c|c|c|c|}
\hline Tipo & Dispersão sólida & Fármaco & Carreador & $\begin{array}{l}N^{0} \text { total } \\
\text { de fases }\end{array}$ & $\begin{array}{c}\text { Estabilidade física do } \\
\text { fármaco }\end{array}$ \\
\hline 1 & Mistura eutética & Partículas cristalinas & Cristalino & 2 & Estável. \\
\hline 2 & Suspensão sólida amorfa & Partículas amorfas & Cristalino & 2 & Instável, risco de cristalização. \\
\hline 3 & Solução sólida & $\begin{array}{l}\text { Molecularmente } \\
\text { disperso }\end{array}$ & Cristalino & 1 & $\begin{array}{l}\text { Estável (abaixo da solubilidade } \\
\text { cristalina); Instável (acima da } \\
\text { solubilidade cristalina); risco de } \\
\text { cristalização. }\end{array}$ \\
\hline 4 & Suspensão vítrea & Partículas cristalinas & Amorfo & 2 & Estável. \\
\hline 5 & Suspensão vítrea amorfa & Partículas amorfas & Amorfo & 2 & Instável, risco de cristalização. \\
\hline 6 & Solução vítrea & $\begin{array}{c}\text { Molecularmente } \\
\text { disperso }\end{array}$ & Amorfo & 1 & $\begin{array}{l}\text { Instável; risco de separação de } \\
\text { fase e cristalização. }\end{array}$ \\
\hline
\end{tabular}

Fonte: Adaptação de (WILLIAMS et al., 2013).

O mais simples desses sistemas consiste em fármaco cristalino, suspenso em um carreador cristalino e são referidos como misturas eutéticas (tipo 1 e 2 do Quadro 4). Misturas eutéticas são combinações de dois compostos cristalinos (fármaco e carreador) que são miscíveis no estado líquido fundido, mas apresentam pouca ou nenhuma miscibilidade no estado sólido. As misturas eutéticas sólidas são geralmente produzidas por resfriamento rápido de uma combinação dos dois compostos fundidos, a fim de obter uma mistura de partículas de cristais muito reduzidas, quanto menor for o tamanho de partícula melhor será a molhabilidade nessa suspensão, contribuindo assim para uma taxa de dissolução mais rápida (LEUNER; DRESSMAN, 2000; WILLIAMS et al., 2013).

Dentro da classe de DS descritas como soluções sólidas (tipo 3 do Quadro 4), existem dois subtipos: 1) Soluções sólidas contínuas: o fármaco e o carreador estão completamente miscíveis na DS; 2) Soluções sólidas descontínuas: o fármaco e o carreador estão parcialmente miscíveis na DS. A taxa de liberação do fármaco a partir de soluções sólidas é mais rápida que a de sistemas multifásicos equivalentes contendo partículas sólidas de fármaco em suspensão, independentemente do material em suspensão ser amorfo ou cristalino (LEUNER; DRESSMAN, 2000; WILLIAMS et al., 2013).

As DS que contêm fármacos dispersos em um carreador amorfo (tipos 4, 5 e 6 do Quadro 4), podem ser classificadas de maneira semelhante àquelas em que o carreador é cristalino, embora, neste caso, as DS sejam referidas como "vítreas" para enfatizar o caráter não cristalino do carreador. Assim, sistemas do tipo 4 , ou 
suspensão vítrea, é análogo aos sistema eutético e contém fármacos cristalinos suspensos em um carreador amorfo; sistemas do tipo 5, ou suspensão vítrea amorfa, está relacionado, mas contém partículas amorfas de fármaco suspensos em um carreador amorfo; as DS do tipo 6 ou as soluções vítrea são análogas às soluções sólidas e contêm uma dispersão molecular do fármaco em um carreador amorfo (LEUNER; DRESSMAN, 2000; WILLIAMS et al., 2013).

Para a obtenção de DS existem três principais métodos, incluindo o método de fusão, método do solvente e método de fusão-solvente. Contudo, o método de fusão e o método do solvente são mais comuns que o método de fusão-solvente. A Figura 10 apresenta os diversos métodos de preparo das DS (VO; PARK; LEE, 2013).

Conforme dito anteriormente, as formulações amorfas são obtidas principalmente por métodos à base de evaporação do solvente e fusão. Para o método do solvente, o fármaco e o polímero são dissolvidos em um solvente (ou combinação de solventes), formando um sistema de solução homogênea. Diferentes estratégias podem ser empregadas para remover rapidamente (por evaporação ou isolamento) o solvente da solução para formar a DS. Normalmente, o processo de secagem secundário em uma etapa descontínua é necessário para remover ainda mais o solvente residual. Quanto aos métodos baseados em fusão, calor e cisalhamento são aplicados para amolecer ou fundir o polímero e o fármaco, após a fusão dos compostos o fármaco pode ser incorporado ao polímero e passa por um processo de resfriamento para a solidificação e obtendo assim a DS. Contudo DS produzidas por diferentes métodos são expostas a diferentes condições, o que resulta em diversos níveis de estabilidade química, estabilidade física e desempenho in vitro ou in vivo (HUANG; WILLIAMS, 2018). 
Figura 10 - Fluxograma empregado para a produção de dispersões sólidas.

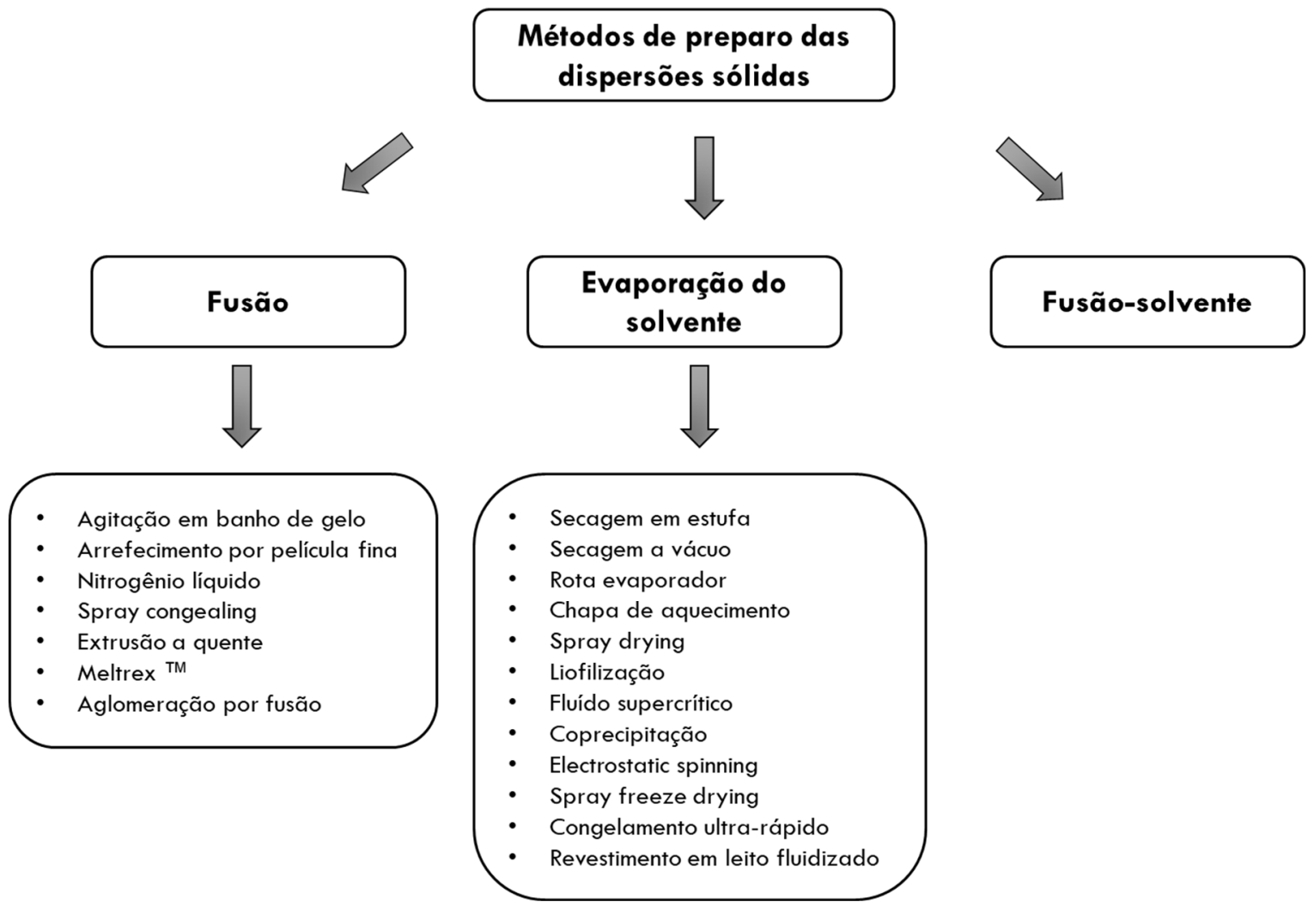

Fonte: Adaptação de (VO; PARK; LEE, 2013).

\subsubsection{Estabilidade física e inibição da cristalização das dispersões sólidas}

Nas DSA, o fármaco hidrofóbico é convertido em um estado amorfo de alta energia e disperso ao nível molecular em matrizes poliméricas. O polímero inibe a cristalização do fármaco por meio de interação física (por exemplo, ligações de hidrogênio e forças de Van der Waals), tanto no estado sólido quanto em ambientes aquosos (MENG; FERREIRA; ZHANG, 2019). Diversos fatores podem influenciar a propensão de cristalização de fármacos em DSA, tais quais, temperatura de transição vítrea, mobilidade molecular e miscibilidade entre fármaco-polímero (MA; WILLIAMS, 2019).

A cristalização é um processo de transição de fase através do qual uma fase ordenada e mais estável (cristalito), que emerge de um estado desordenado metaestável (por exemplo, uma solução supersaturada). A abordagem clássica trata esse fenômeno como um processo de duas etapas: nucleação e crescimento 
cristalino. A cristalização inicia com colisões aleatórias de monômeros de soluto (os blocos básicos de construção de cristais, isto é, átomos, íons ou moléculas) para formar agregados estáveis (núcleos), seguido do aumento desse núcleo (crescimento) por adição de bloco por bloco (HENRY TENG, 2013).

A Figura 11 ilustra o processo de nucleação de cristais, onde a linha azul ilustra a energia da superfície obtida pela criação de uma interface, a linha vermelha indica a perda de potencial químico associada à redução da concentração de solutos e a linha preta especifica a alteração da energia total à medida que cada átomo (esfera azul) é adicionado à fase sólida. Observe que o crescimento não pode ocorrer antes que o núcleo atinja seu tamanho crítico (núcleo crítico) em $r=r_{c}$ (HENRY TENG, 2013).

Figura 11 - Gráfico representativo do processo de nucleação e crescimento cristalino.

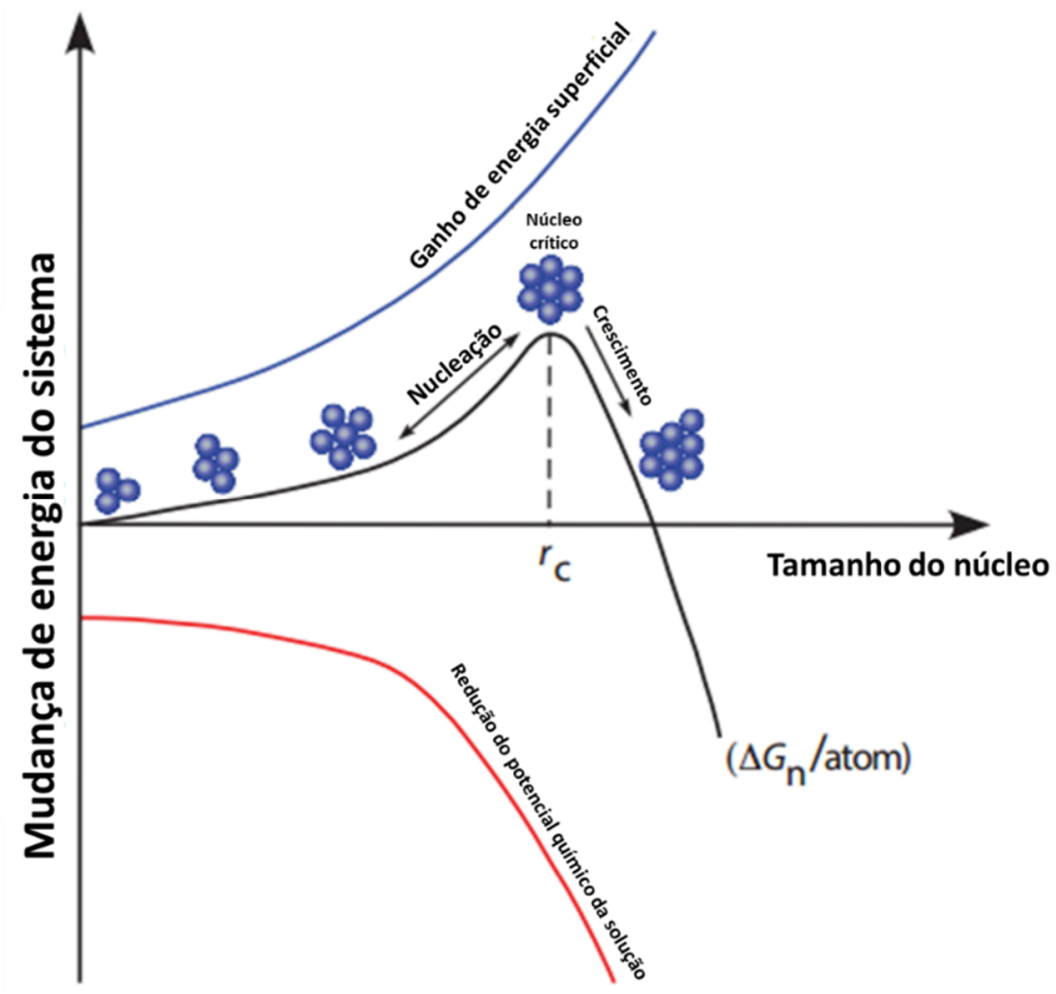

Fonte: Adaptação (e reproduzido com permissão) de (HENRY TENG, 2013). 
A miscibilidade apropriada entre fármacos e polímeros é considerada um prérequisito para sistemas amorfos binários estáveis. Quando a miscibilidade for fraca entre esses dois componentes, levará a um estado de supersaturação do fármaco no polímero, resultando assim, na cristalização do fármaco durante o armazenamento, sob condições de alta umidade e alta temperatura (SONG, 2015).

Polímeros também podem formar interações interespécies específicas com o fármaco, conforme dito anteriormente, tais como ligações de hidrogênio ou interações iônicas. A força de tais interações parece ter alguma correlação com a eficácia relativa dos polímeros como inibidores de cristalização. A inibição da cristalização no estado sólido ocorre quando o polímero está misturado com o fármaco amorfo ao nível molecular, pois a origem do efeito estabilizador dos polímeros é multifacetada. Acredita-se que os polímeros reduzem a mobilidade molecular do fármaco amorfo aumentando a temperatura de transição vítrea $\left(T_{g}\right)$ do sistema, habitualmente referido como efeito antiplastificante (XIE; TAYLOR, 2016).

\subsubsection{Características dos carreadores selecionados}

Conforme discutido previamente, existem grandes variedades de excipientes farmacêuticos que podem ser utilizados como carreadores farmacêuticos, dentre eles foram selecionados os seguintes tipos de carreadores para o desenvolvimento das DS: polivinilpirrolidona (PVP), copovidona (CoPvP), hidroxipropilmetilcelulose ftalato (HPMCP) e poloxâmero.

\subsubsection{Polivinilpirrolidona}

A polivinilpirrolidona (PVP), povidona ou Kollidon, sinônimos de 1-Ethenyl-2pirrolidinona homopolimer é descrita como um polímero sintético constituído essencialmente por grupos lineares de 1-vinil-2-pirrolidinona, cujo grau diferente de polimerização resulta em polímeros de vários pesos moleculares (Figura 12). Esse polímero é caracterizado pela sua viscosidade em solução aquosa, relativa à da água, expressa como valor K, nas faixas de 10 a 120. A PVP se apresenta como um pó higroscópico fino, de coloração branca a levemente amarelada, inodoro ou quase inodoro (ROWE; SHESKEY; QUINN, 2009). 
Embora a polivinilpirrolidona seja utilizada em várias formulações farmacêuticas como, desintegrante, intensificador de dissolução, agente de suspensão e aglutinante para comprimidos. A PVP é empregada também como solubilizante em formulações orais e parenterais e demonstrou aumentar a dissolução de fármacos pouco solúveis a partir de formas farmacêuticas sólidas (ROWE; SHESKEY; QUINN, 2009).

Figura 12 - Estrutura molecular da polivinilpirrolidona.

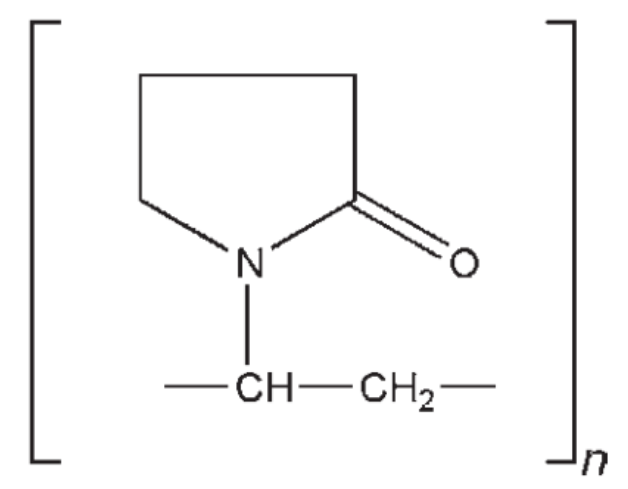

Fonte: (ROWE; SHESKEY; QUINN, 2009).

\subsubsection{Copovidona}

A copovidona (CoPVP) éster etenílico do ácido acético, polímero com 1-etenil2-pirrolidinona (Figura 13), é empregada como aglutinante para comprimidos, formador de filme e como parte do material da matriz aplicados nas formulações de liberação controlada. Esse polímero também pode ser chamado de Kollidon VA 64, Plasdone S-630 e PVP/VA e se apresenta como um pó amorfo branco a levemente amarelado, possuindo um leve odor e um sabor fraco. É normalmente produzido por spray dried com um tamanho de partícula relativamente fino (ROWE; SHESKEY; QUINN, 2009).

Nos comprimidos, a copovidona pode ser empregada como aglutinante para compressão direta e na granulação úmida. Esse polímero é frequentemente adicionado às soluções de revestimento como agente formador de filme, pois proporciona boa aderência, elasticidade e dureza e pode ser utilizado como barreira à umidade (ROWE; SHESKEY; QUINN, 2009). 
Figura 13 - Estrutura molecular da copovidona.

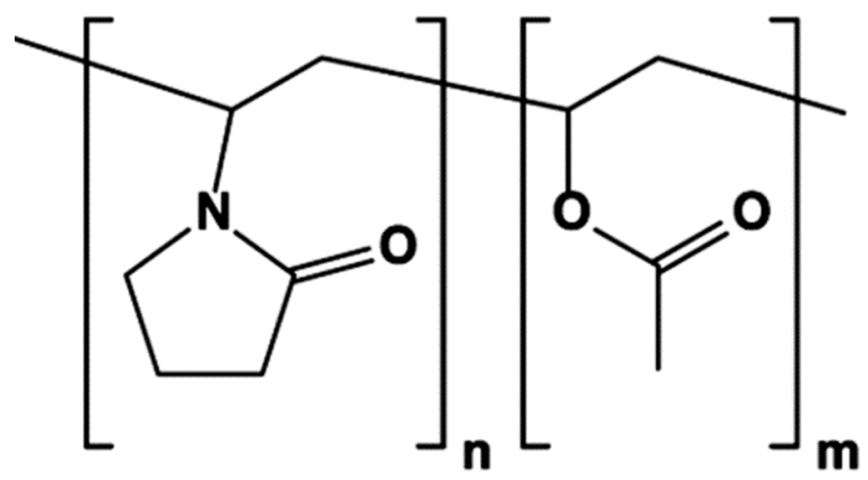

Fonte: Reproduzido com permissão de (SONG et al., 2015).

\subsubsection{Hidroxipropilmetilcelulose ftalato}

O polímero hidroxipropilmetilcelulose ftalato (HPMCP) é uma celulose na qual alguns dos grupos hidroxila são substituídos por éteres metílicos, éteres 2hidroxipropílicos ou ésteres ftálicos (celulose, 1,2-benzenodicarboxilato de hidrogênio, 2-hidroxipropil éter metílico), também pode ser conhecido como ftalato de hipromelose (Figura 14). Dois tipos de HPMCP com solubilidade diferente são comercializados (HPMCP-55 e HPMCP-50). Entretanto, existe o HPMCP-55s um tipo especial do HPMCP-55 que possui maior peso molecular, maior viscosidade, maior resistência do filme e maior resistência aos fluidos gástricos em comparação com os outros dois (ROWE; SHESKEY; QUINN, 2009; SHAH et al., 2014).

O ftalato de hipromelose se apresenta como flocos de fluxo livre brancos a levemente brancos, sendo inodoro ou com um odor levemente ácido e possui um sabor quase imperceptível. Esse polímero é amplamente empregado em formulações farmacêuticas orais como material de revestimento entérico para comprimidos ou grânulos, sendo insolúvel no líquido gástrico, entretanto intumesce e dissolve rapidamente no intestino superior. Como o HPMCP é insípido e insolúvel na saliva, também pode ser aplicado como revestimento para mascarar o sabor desagradável de algumas formulações de comprimidos. O excipiente também pode ser coprecipitado com um fármaco pouco solúvel para melhorar as características de dissolução (ROWE; SHESKEY; QUINN, 2009). 
Figura 14 - Estrutura molecular da Hidroxipropilmetilcelulose ftalato.

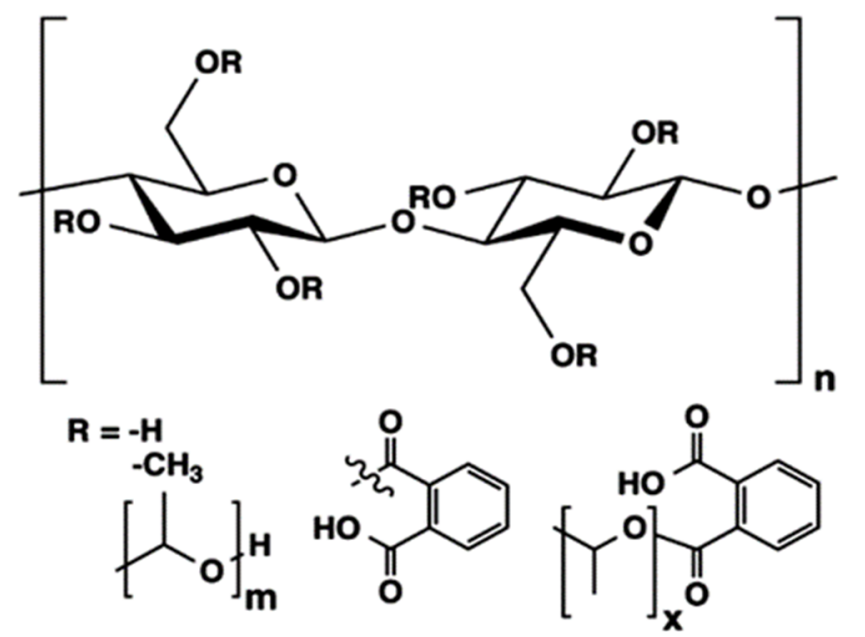

Fonte: Reproduzido com permissão de (SONG et al., 2015).

\subsubsection{Poloxâmero}

Os poloxâmeros (Figura 15) também comumente conhecidos como Kolliphor®, Lutrol $\circledast$ ou Pluronic $®$, são triblocos de copolímeros não iônicos de polioxietilenopolioxipropileno-polioxietileno (POE-POP-POE) com propriedades tensoativa. Estão disponíveis vários tipos dependendo dos valores de segmentos de "a" (POE) e "b" (POP), apresentados no Quadro 5 (CHAUDHARI; DUGAR, 2017).

Os excipientes são empregados principalmente em formulações farmacêuticas como, dispersantes, emulsificantes, solubilizantes, agente molhante e lubrificante para comprimidos. São uma série de copolímeros em blocos intimamente relacionados de óxido de etileno e óxido de propileno, de acordo com a fórmula geral $\mathrm{HO}\left(\mathrm{C}_{2} \mathrm{H}_{4} \mathrm{O}\right)_{a}\left(\mathrm{C}_{3} \mathrm{H}_{6} \mathrm{O}\right)_{b}\left(\mathrm{C}_{2} \mathrm{H} 4 \mathrm{O}\right)_{a} \mathrm{H}$. O segmento de polioxietileno (POE) (a) é hidrofílico, enquanto o segmento de polioxipropileno (POP) (b) é hidrofóbico. Todos os poloxâmeros são quimicamente similares em composição, diferindo apenas nas quantidades relativas de óxidos de propileno e etileno adicionados durante a fabricação. Suas propriedades físicas e ativas de superfície variam em uma ampla gama e vários tipos diferentes estão disponíveis comercialmente (ROWE; SHESKEY; QUINN, 2009).

Os poloxâmeros geralmente se apresentam como grânulos brancos, cerosos, com fluxo livre ou como sólidos fundidos, sendo praticamente inodoros e insípidos. À temperatura ambiente, o poloxâmero 124 se exibe como um líquido incolor. As 
propriedades de superfície ativa, baixo ponto de fusão, menor que $60^{\circ} \mathrm{C}$ e segurança oral, tornam os poloxâmeros adequados para a preparação de DS, particularmente pelo método de fusão (MEDAREVIĆ et al., 2016; ROWE; SHESKEY; QUINN, 2009)

Figura 15 - Estrutura molecular do poloxâmero.

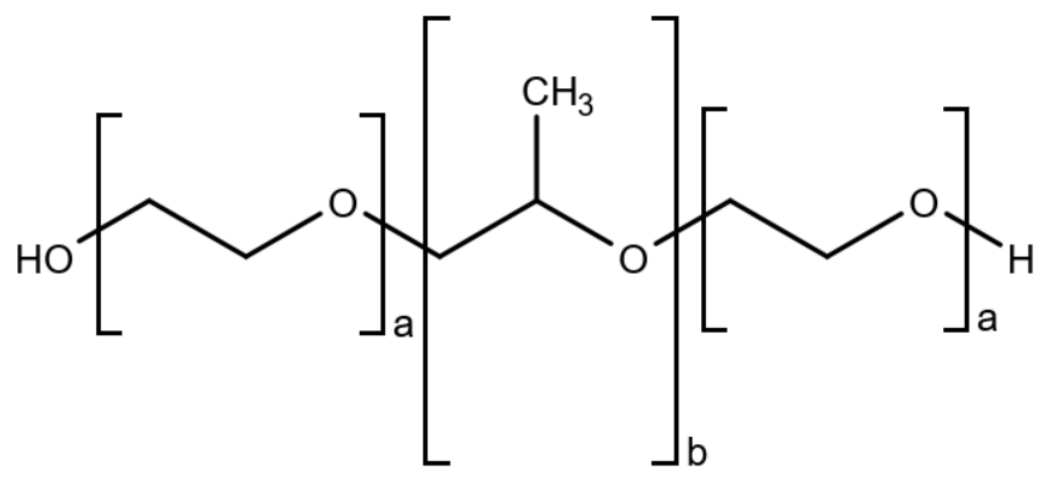

Fonte: Elaborado pelo autor.

Quadro 5 - Diferentes tipos de poloxâmeros s dependendo do número de segmentos de a e b.

\begin{tabular}{|ccccc|}
\hline \hline Poloxâmero & Forma física & $\begin{array}{c}\text { POE (a) } \\
\text { hidrofílico }\end{array}$ & $\begin{array}{c}\text { POP (b) } \\
\text { hidrofóbico }\end{array}$ & Peso molecular médio \\
\hline 124 & Líquida & 12 & 20 & $2090-2360$ \\
188 & Sólida & 80 & 27 & $7680-9510$ \\
237 & Sólida & 64 & 37 & $6840-8830$ \\
338 & Sólida & 141 & 44 & $12700-17400$ \\
407 & Sólida & 101 & 56 & $9840-14600$ \\
\hline \hline
\end{tabular}

Fonte: Adaptação de (ROWE; SHESKEY; QUINN, 2009).

\subsection{Efavirenz}

O efavirenz (EFV) [(4S)-6-cloro-4-(2-ciclopropiletinil)-4-(trifluorometil)-2,4dihidro-1H-3,1-benzoxazin-2-ona] fórmula $\left(\mathrm{C}_{14} \mathrm{H}_{9} \mathrm{ClF}_{3} \mathrm{NO}_{2}\right.$; massa molar, 315,676 g/mol), cuja estrutura molecular está ilustrada na Figura 16. Apresenta-se como um pó cristalino branco, ou quase branco, inodoro, com ponto de fusão na faixa de $136^{\circ} \mathrm{C}-141^{\circ} \mathrm{C}$, sendo praticamente insolúvel em água, e solúvel em acetona, etanol, metanol e diclorometano. Trata-se de um ácido fraco com pKa de 10,2, que apresenta coeficiente de partição octanol / água de 5,4, baixíssima taxa de dissolução intrínseca $\left(0,037 \mathrm{mg} / \mathrm{cm}^{2} / \mathrm{min}\right)$ e baixa biodisponibilidade oral (40\% - 50\%) (FARMACOPÉIA BRASILEIRA, 2010; CRISTOFOLETT et al., 2013; FANDARUFF et al., 2014; 
KOMMAVARAPU; MARUTHAPILLAI, PALANISAMY, 2016; SCHITTNY et al., 2020; HOFFMEISTER et al., 2017).

Figura 16 - Estrutura molecular do efavirenz.

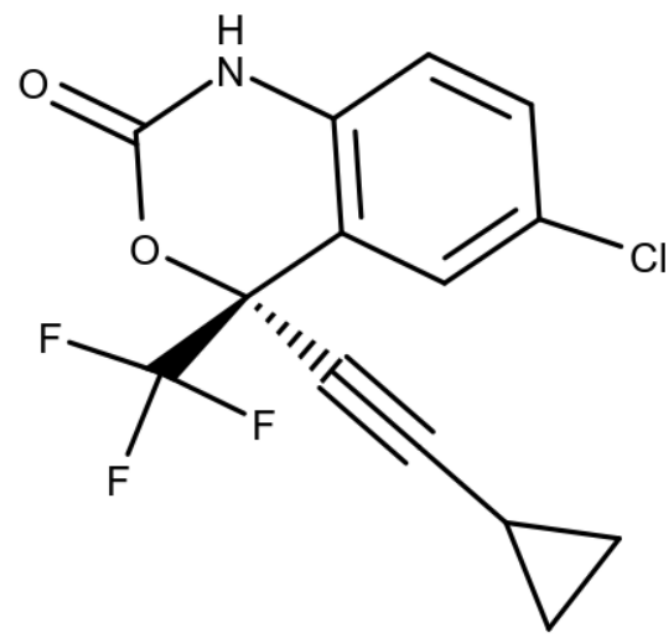

Fonte: Elaborado pelo autor.

O antirretroviral foi aprovado em 1998 pelo FDA e passou a ser produzido pelas empresas Bristol-Myers como Sustiva $®$ e pela Merck Sharp \& Dohme como Stocrin $®$. Trata-se de uma benzoxazinona pertencente à classe dos inibidores não nucleosídeo da transcriptase reversa (NNRTI), sendo parte da primeira linha de tratamento do vírus da imunodeficiência humana (HIV) tipo 1 (HIV-1). A enzima transcriptase reversa é importantíssima no ciclo de vida do HIV-1, em que, a enzima passa a recodificar o material genético do vírus convertendo o RNA viral em DNA viral. As principais classes de fármacos que bloqueiam a ação do vírus nesse estágio são os inibidores nucleosídeos da transcriptase reversa (NRTI) e os NNRTI (BASTOS et al., 2016; FANDARUFF et al., 2014a; HOFFMEISTER et al., 2017).

O EFV é um dos componentes da terapia antirretroviral de alta atividade (HAART), utilizado em combinações com outros medicamentos, sendo considerado uma excelente escolha no tratamento de crianças e adultos, pacientes com tuberculose, porém, é contraindicado para mulheres grávidas devido aos seus efeitos teratogênicos (CRISTOFOLETTI et al., 2013; FANDARUFF; ARAYA-SIBAJA, 2014; HOFFMEISTER et al., 2017). O fármaco é metabolizado pelo citocromo P450 e apesar 
de sua eficácia comprovada, um grande limitante do seu uso são devido aos seus efeitos neurotóxicos e hepatotóxicos (HARJIVAN et al., 2014).

A maioria dos autores e pesquisadores classificam o antirretroviral EFV como pertencente à classe II do SCB, devido a sua baixíssima solubilidade em água ( 4-9 $\mu \mathrm{g} / \mathrm{mL}$ ), o que dificulta a sua absorção oral e biodisponibilidade (FANDARUFF et al., 2014a; HOFFMEISTER et al., 2017; KOMMAVARAPU; MARUTHAPILLAI; PALANISAMY, 2016; PAWAR et al., 2016; SCHITTNY et al., 2020).

Entretanto, em função da indefinição em relação à permeabilidade, alguns autores (Cristofolett et al., 2013; Lindenberg; Kopp, Dressman, 2004) têm classificado o EFV como pertencente à classe II e IV do SCB. Segundo Cristofolett et al. (2013), não existem dados na literatura que demonstrem fração de absorção do antirretroviral em humanos $\geq 85 \%$, requisito para que um fármaco seja considerado de alta permeabilidade (CRISTOFOLETTI et al., 2013; LINDENBERG; KOPP; DRESSMAN, 2004; SCHITTNY et al., 2020).

\subsubsection{Polimorfos de efavirenz}

Diversos compostos orgânicos e inorgânicos podem apresentar diferentes formas sólidas, essas substâncias podem exibir o estado amorfo (desordenado) ou cristalino (ordenado). O polimorfismo de um composto é a capacidade da mesma substância de se cristalizar com mais de uma espécie cristalina distinta, no qual esses polimorfos apresentam as mesmas composições químicas e exibem estruturas internas diferentes. As estruturas internas podem diferir em dimensões de cela unitária, empacotamento de cristal e ou conformação molecular, entretanto substâncias como solvatos, hidratos, sais e cocristais o polimorfismo também está presente (BYRN; ZOGRAFI; CHEN, 2017; HILFIKER; RAUMER, 2019).

Diferenças nas estruturas internas dos polimorfos ilustrado na Figura 17, resultam em distintas propriedades físico-químicas, como solubilidade, dissolução, morfologia, densidade, atributos mecânicos e estabilidade. Consequentemente, essas propriedades desiguais podem ter um impacto significativo no desempenho e segurança do IFA e seus produtos formulados (BYRN; ZOGRAFI; CHEN, 2017) 
Figura 17 - Microscopia eletrônica de varredura dos polimorfos I (lado esquerdo) e polimorfo II (lado direito) do fármaco EFV.

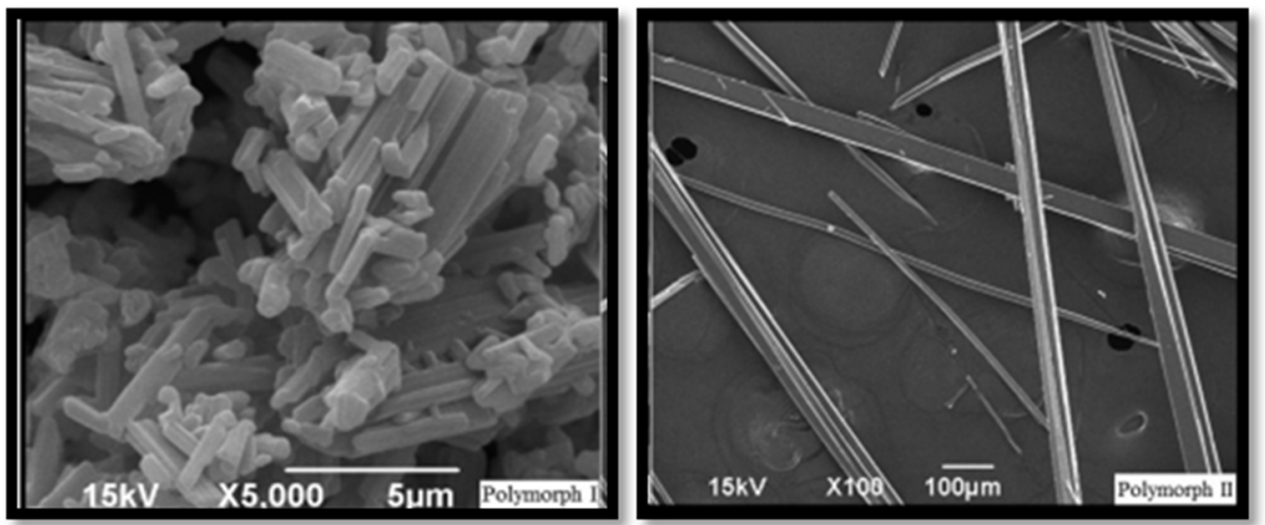

Fonte: Reproduzido com permissão de (FANDARUFF et al., 2014a).

Os polimorfos do EFV são descritos na literatura representados por três formas polimórficas distintas, polimorfo I (ortorrômbico), polimorfo II (ortorrômbico) e polimorfo III (monoclínico), esses compostos não exibem moléculas de solventes em suas estruturas cristalinas. O polimorfo I é o IFA mais utilizado na indústria farmacêutica, esse fármaco cristaliza no grupo espacial $P 2{ }_{1} 2{ }_{1} 2$ e apresenta três moléculas em sua unidade assimétricas. O polimorfo II cristaliza no grupo espacial $P 2{ }_{1}{ }_{1} 2_{1}$ com uma molécula independente, em contrapartida o polimorfo III cristaliza no grupo espacial C2. Os difratogramas apresentando os polimorfos do EFV estão ilustrados na Figura 18 (DE MELO et al., 2013; FANDARUFF et al., 2014a; MAHAPATRA et al., 2010; MARQUES et al., 2017; RAVIKUMAR; SRIDHAR, 2009).

O polimorfo I apresenta conformação synthon tipo A, enquanto os polimorfos II e III exibem conformação synthon tipo C. A conformação synthon tipo C justifica os altos valores de densidades encontrados nos polimorfos II e III $\left(1,486 \mathrm{~g} / \mathrm{cm}^{3}\right.$ e 1,501 $\mathrm{g} / \mathrm{cm}^{3}$ ) respectivamente, assim a presença de conformação synthon tipo A explica o alto grau de desordem conformacional no polimorfo I (FANDARUFF et al., 2014a; MARQUES et al., 2017).

Os estudos de Fandaruff et al. (2014) concluíram que o polimorfo II do EFV é mais estável termodinamicamente em temperatura ambiente que o polimorfo I, devido ao fato da forma II $\left(\mathrm{d}=1,486 \mathrm{~g} / \mathrm{cm}^{3}\right)$ possuir uma maior densidade em relação à forma I $\left(\mathrm{d}=1,395 \mathrm{~g} / \mathrm{cm}^{3}\right)$. No entanto, a avaliação da dissolução intrínseca demonstrou que 
a taxa de dissolução do polimorfo II $\left(0,149 \mathrm{mg} \cdot \mathrm{cm}^{-2} \mathrm{~min}^{-1}\right)$ é maior que a do polimorfo I (0,009 $\left.\mathrm{mg} \mathrm{cm}^{-2} \mathrm{~min}^{-1}\right)$ em mais de 10 vezes (FANDARUFF et al., 2014a).

Figura 18 - Comparação dos difratogramas de raios $X$ dos polimorfos descritos do EFV $(A=$ polimorfo I, B = polimorfo II e C = polimorfo III).

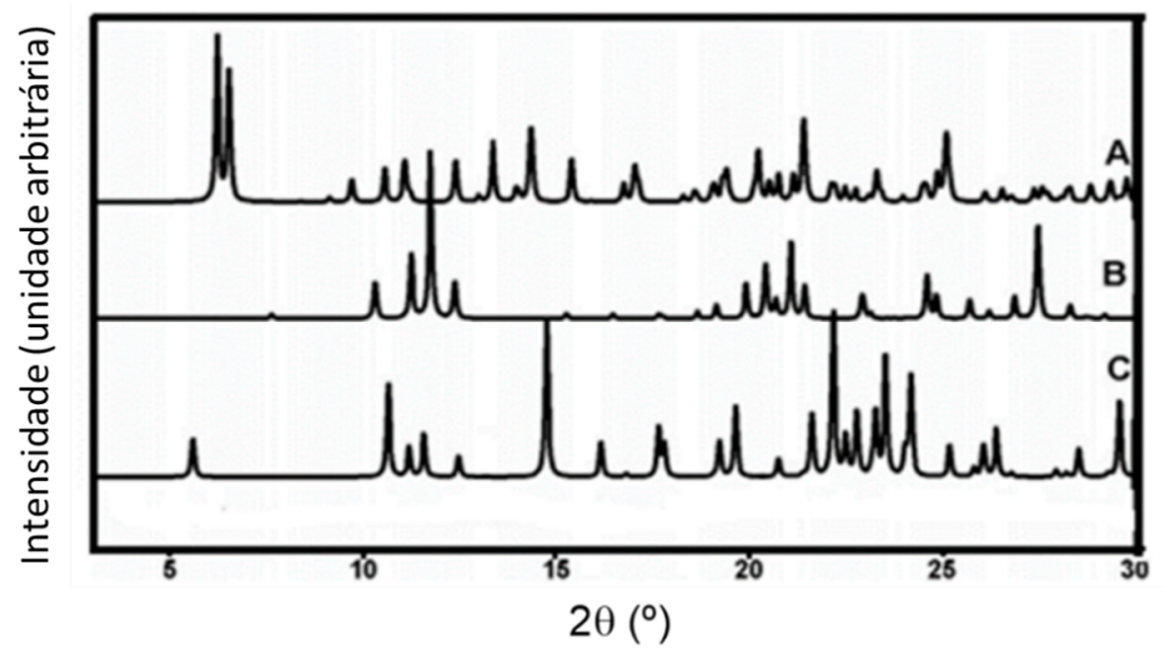

Fonte: Adaptação (e reproduzido com permissão) de (MARQUES et al., 2017).

\subsubsection{Dispersões sólidas de efavirenz}

Extenso levantamento da literatura foi realizado para verificar algumas abordagens desenvolvidas para melhorar a solubilidade, biodisponibilidade e outros problemas relacionados ao EFV, pois esse fármaco é comercializado na forma cristalina micronizada (LAVRA; PEREIRA DE SANTANA; RÉ, 2017; SENAPATI; SAHOO; SAHU, 2016).

Alguns estudos publicados com o objetivo de melhorar a solubilidade do EFV estão focados nas seguintes técnicas. Redução do tamanho de partículas utilizando moinho coloidal, comicronização com LSS ou polivinilpirrolidona (PVP), preparações utilizando nanotecnologia (nanossuspensões; nanoemulsões, nanopartículas, sistema de liberação de fármacos auto-nanoemulsificante), e outras técnicas como complexos de inclusão com ciclodextrinas, encapsulamento em micelas poliméricas, obtenção de novas formas polimórficas, crocristalização e obtenção de DS (ALVES et al., 2014; CHADHA et al., 2012; CHIAPPETTA et al., 2010; DA COSTA et al., 2013; HOFFMEISTER et al., 2017; KOMMAVARAPU; MARUTHAPILLAI; PALANISAMY, 2016; KOTTA et al., 2014; LAVRA; PEREIRA DE SANTANA; RÉ, 2017; MADHAVI et 
al., 2011; MAKWANA et al., 2015; PATEL et al., 2014; PAWAR et al., 2016; SATHIGARI et al., 2009; SENAPATI; SAHOO; SAHU, 2016).

A abordagem de desenvolvimento de formulações de DS de EFV com emprego de carreadores poliméricos, como inibidores de cristalização, tem demonstrado ser um campo promissor na pesquisa. Resultados de trabalhos publicados corroboram o grande interesse pela utilização de polímeros hidrofílicos. O emprego de polietilenoglicol (PEG), PVP K-30, hidroxipropilmetilcelulose acetato (HMPCAS), Eudragit ${ }$ EPO, HPMCP 55, HPMCP 50, Soluplus $®$, copovidona, assim como, novos amidos modificados denominados citrato de amido e fosfato de amido têm sido sugeridos como carreadores hidrofílicos (ALVES et al., 2012; COSTA et al., 2019; LAVRA; PEREIRA DE SANTANA; RÉ, 2017; MADHAVI et al., 2011; PAWAR et al., 2016; SATHIGARI et al., 2012; SCHITTNY et al., 2020)

Até o presente momento não foram relatados na literatura estudos de DS de EFV utilizando poloxâmeros como carreadores hidrofílicos. Contudo, os estudos de Chiappetta et al. (2011) demonstram experimentalmente que, ao encapsular o EFV em micelas poliméricas empregando o poloxâmero 407, os autores incrementaram a solubilidade do antirretroviral (CHIAPPETTA et al., 2011).

Entretanto, outros estudos demonstraram que, quando os tensoativos são intimamente misturados ao fármaco, isto é, quando são dissolvidos em um solvente comum e secos formando uma DS, demonstraram um efeito positivo na libertação dos compostos ativos (CHAUDHARI; DUGAR, 2017). Apesar dos progressos realizados, o desenvolvimento de um número considerável de formulações estáveis e eficientes ainda está por ser alcançado. O maior desafio é obter DS há um nível molecular restringindo interações intermoleculares entre EFV e carreadores (LAVRA; PEREIRA DE SANTANA; RÉ, 2017). 
4. MATERIAIS E MÉTODOS 


\subsection{Materiais}

\subsubsection{Padrão secundário}

- Efavirenz substância química de referência com grau de pureza de $100,3 \%$, fornecido gentilmente pela empresa Cristália Produtos Químicos e Farmacêutico (São Paulo, Brasil).

\subsubsection{Matérias-primas}

- Efavirenz matéria-prima de grau farmacêutico de pureza, fornecido gentilmente pela empresa Cristália Produtos Químicos e Farmacêutico (São Paulo, Brasil);

- Kollidon® 30 - Polivinilpirrolidona K 28/32 matéria-prima de grau farmacêutico de pureza, fornecido gentilmente pela empresa BASF (São Paulo, Brasil);

- Kollidon® VA64 - Copovidona matéria-prima de grau farmacêutico de pureza, fornecido gentilmente pela empresa BASF (São Paulo, Brasil);

- Kolliphor® P 188 micro - Poloxâmero 188 matéria-prima de grau farmacêutico de pureza, fornecido gentilmente pela empresa BASF (São Paulo, Brasil);

○ Kolliphor® P 407 - Poloxâmero 407 matéria-prima de grau farmacêutico de pureza, fornecido gentilmente pela empresa BASF (São Paulo, Brasil);

- Hidroxipropilmetilcelulose ftalato (HPMCP-50, HPMCP-55 e HPMCP55s), fornecido gentilmente pela empresa Shin-Etsu Chemical Company (Tóquio, Japão).

\subsubsection{Solventes e reagentes}

- Acetato de sódio trihidratado - Merck;

- Acetona P.A - Synth;

- Acetonitrila de pureza cromatográfica - Merck;

- Ácido acético glacial - Merck; 
- Ácido clorídrico P.A - Synth;

- Ácido o-Fosfórico P.A - Synth;

- Água ultra-puificada Milli-Q (Millipore Corporation, EUA);

- Etanol - Carlos Erba;

- Fosfato de potássio monobásico anidro P.A - Synth;

- Hidróxido de sódio micropérola P.A - Synth;

- Metanol de pureza cromatográfica - J.T Baker;

- Trietilamina P.S. - Vetec.

\subsubsection{Equipamentos e dispositivos diversos}

○ Micropipeta monocanal de 10 a $100 \mu \mathrm{L}$ - Eppendorf $\odot$;

- Micropipeta monocanal de 100 a $1000 \mu \mathrm{L}$ - Eppendorf $\AA$;

- Micropipeta monocanal de 500 a $5.000 \mu \mathrm{L}$ - Transferpette $®$;

- Filtros Millex LCR (com membrana PTFE) 0,45 $\mu \mathrm{m}$ e $13 \mathrm{~mm}$ para filtração de solventes orgânicos e aquosos (Millipore);

- Membranas Filtrantes Allcrom 0,47 mm de diâmetro e poros de 0,45 $\mu \mathrm{m}$ para filtração de solventes orgânicos e aquosos (Cobetter®);

- Cromatógrafo - Modelo Thermo Scientific Dionex UltiMate 3000 com bomba quartenária, degaseificador online, amostrador automático, aquecedor/resfriador de coluna e detector tipo UV e DAD (Diode-Array Dectector), equipamento com software Chromeleon versão 7.2;

- Bomba de vácuo isenta de óleo R-TE-0582 Tecnal;

- Coluna Gemini 5um C18 110A de fase reversa; 150 x 4,6 mm; Phenomenex $®$;

- Difratômetro Bruker Modelo D8 Advance Da Vinci com detector LYNXEYE e ótica TWIN-TWIN;

- Chapa de aquecimento - IKA® C-MAG HS 7;

- Termómetro infravermelho por imagem - Flir TG165;

- Lavadora Ultrassônica - Unique;

- Balança analítica A x 200 - Shimadzu;

- pHmetro digital PG2000 - Gehaka; 
- Plataforma de agitação orbital com temperatura controlada (Tecnal TE420, São Paulo, Brasil).

- Câmara climática - Nova Ética;

- Agitador magnético - Tecnal;

- Agitador de soluções AP56 - Phoenix Luferco;

○ Evaporador rotativo R-215 - Buchi;

- Bomba de vácuo V-710 - Buchi;

- Resfriador F-108 - Buchi;

- Banho de aquecimento B-491 - Buchi;

- Estufa - Nova Ética;

- Dissolutor aparato IV USP Flow-cell CE7 Smart - Sotax;

- DSC 4000 - PerkinElmer;

- Seladora de panelas - PerkinElmer;

- Panelas de alumínio 30 LL DSC - PerkinElmer;

- Tampas de alumínio DSC - PerkinElmer;

- Balança analítica AL204 - Mettler Toledo;

- DSC Q20 - TA Instruments;

- TG Q50 - TA Instruments;

○ Espectrofotômetro FTIR Nicolet iS10 - Thermo Fisher Scientific. 


\subsection{Métodos}

4.2.1 Desenvolvimento e validação do método de cromatografia líquida de alta eficiência (CLAE) para quantificação de efavirenz

\subsubsection{Preparo das soluções tampão e solução padrão}

Para o desenvolvimento do método analítico por CLAE, empregado nas análises das amostras (fármaco puro, misturas físicas e dispersões sólidas de EFV) obtidas a partir dos ensaios de solubilidade, dissolução e de teor de EFV, foram utilizados solução padrão de EFV e soluções tampão (meio aquoso) com diferentes valores de $\mathrm{pH}(1,2,4,5$ e 6,8). As soluções (soluções tampão e solução padrão de EFV) usadas nos ensaios cromatográficos foram preparadas conforme descrição do Quadro 6. Todas as soluções tampão foram preparadas com água ultrapurificada (equipamento Milli-Q) e filtradas sob vácuo, em filtro de membrana Nylon, com dimensões de $47 \mathrm{~mm}$ de diâmetro e poros de $0,45 \mu \mathrm{m}$. 
Quadro 6 - Descrição dos procedimentos para preparo das soluções empregadas para as análises por meio de CLAE do EFV (soluções tampão e solução padrão de EFV).

\begin{tabular}{|c|c|}
\hline Solução Tampão & Modo de Preparo \\
\hline Ácido clorídrico pH 1,2 & $\begin{array}{l}\text { Foram adicionados } 500 \mathrm{~mL} \text { da solução de cloreto de potássio } 0,2 \mathrm{~mol} / \mathrm{L}^{(1)} \mathrm{em} \text { um balão volumétrico de } 2 \mathrm{~L} \text {. Em seguida } \\
\text { acrescentaram-se } 850 \mathrm{~mL} \text { da solução de } \mathrm{HCl} 0,2 \mathrm{~mol} / \mathrm{L}^{(2)} \text { e completou-se o volume com água ultrapurificada (UNITED } \\
\text { STATES PHARMACOPEIA, 2017). }\end{array}$ \\
\hline Acetato $\mathrm{pH} \mathrm{4,5}$ & $\begin{array}{l}\text { Foram dissolvidos 5,98 g de acetato de sódio em um balão volumétrico de } 2 \mathrm{~L} \text {. Em seguida adicionaram-se } 28 \mathrm{~mL} \text { de } \\
\text { ácido acético } 2 \mathrm{~N}^{(3)} \text { e completou-se o volume com água ultrapurificada (UNITED STATES PHARMACOPEIA, 2017). }\end{array}$ \\
\hline Fosfato pH 6,8 & $\begin{array}{l}\text { Foram adicionados } 500 \mathrm{~mL} \text { de solução fosfato de potássio monobásico } 0,2 \mathrm{~mol} / \mathrm{L}^{(4)} \text { em um balão volumétrico de } 2 \mathrm{~L} \text {. } \\
\text { Em seguida adicionaram-se } 224 \mathrm{~mL} \text { de solução } \mathrm{NaOH} 0,2 \mathrm{~mol} / \mathrm{L}^{(5)} \text { e completou-se o balão com água ultrapurificada } \\
\text { (UNITED STATES PHARMACOPEIA, 2017). }\end{array}$ \\
\hline $\begin{array}{l}\text { (1) Solução de cloreto de } \\
\text { potássio } 0,2 \mathrm{~mol} / \mathrm{L}(1 \mathrm{~L})\end{array}$ & $\begin{array}{l}\text { Pesaram-se 14,91 g de cloreto de potássio em um balão volumétrico de } 1 \mathrm{~L} \text {. Em seguida completou-se o volume do } \\
\text { balão com água ultrapurificada (UNITED STATES PHARMACOPEIA, 2017). }\end{array}$ \\
\hline $\begin{array}{l}\text { (2) Solução de } \mathrm{HCl} 0,2 \mathrm{~mol} / \mathrm{L} \\
\text { (1L) }\end{array}$ & $\begin{array}{l}\text { Pipetaram-se } 16,72 \text { mL de HCI P.A em um balão volumétrico de } 1 \mathrm{~L} \text {. Em seguida completou-se o volume do balão com } \\
\text { água ultrapurificada (UNITED STATES PHARMACOPEIA, 2017). }\end{array}$ \\
\hline
\end{tabular}

(Continua) 


\begin{tabular}{|c|c|}
\hline Solução Tampão & Modo de Preparo \\
\hline $\begin{array}{l}\text { (3) Solução de ácido acético } 2 \\
\qquad N(1 L)\end{array}$ & $\begin{array}{l}\text { Adicionaram-se } 116 \mathrm{~mL} \text { de ácido acético glacial em um balão volumétrico de } 1 \mathrm{~L} \text {. Em seguida completou-se o volume } \\
\text { do balão com água ultrapurificada (UNITED STATES PHARMACOPEIA, 2017). }\end{array}$ \\
\hline $\begin{array}{l}\text { (4) Solução de fosfato de } \\
\text { potássio monobásico } 0,2 \\
\text { mol/L (1L) }\end{array}$ & $\begin{array}{l}\text { Foram dissolvidos } 27,22 \mathrm{~g} \text { de fosfato de potássio monobásico em um balão volumétrico de } 1 \mathrm{~L} \text { e completou-se com } \\
\text { água ultrapurificada (UNITED STATES PHARMACOPEIA, 2017). }\end{array}$ \\
\hline $\begin{array}{l}\text { (5) Solução de } \mathrm{NaOH} 0,2 \mathrm{~mol} / \mathrm{L} \\
\text { (1L) }\end{array}$ & $\begin{array}{l}\text { Foram dissolvidos } 8 \mathrm{~g} \text { de } \mathrm{NaOH} \text { em um balão volumétrico de } 1 \mathrm{~L} \text { e completou-se o volume com água ultrapurificada } \\
\text { (UNITED STATES PHARMACOPEIA, 2017). }\end{array}$ \\
\hline Solução de efavirenz & Modo de Preparo \\
\hline Solução mãe de EFV (SM) & $\begin{array}{l}\text { Foram pesados } 40,0 \mathrm{mg} \text { de EFV (pureza }=100,3 \% \text { ) em um balão de } 100 \mathrm{~mL} \text {, em seguida completou-se o volume do } \\
\text { balão ao adicionar a fase móvel (vide item 4.2.2.2 Condições cromatográficas), a fim de obter uma solução de } \\
\text { concentração de } 400,0 \mu \mathrm{g} / \mathrm{mL} \text { do fármaco (FARMACOPEIA BRASILEIRA, 2010). }\end{array}$ \\
\hline Solução padrão de EFV (SP) & $\begin{array}{l}\text { Foram pipetados } 5 \mathrm{~mL} \text { da SM de EFV para um balão volumétrico de } 100 \mathrm{~mL} \text { e em seguida completou-se o volume } \\
\text { do balão ao adicionar a fase móvel. (vide item 4.2.2.2 Condições cromatográficas), a fim de obter uma solução de } \\
\text { concentração de } 20,0 \mu \mathrm{g} / \mathrm{mL} \text { do fármaco (FARMACOPEIA BRASILEIRA, 2010). }\end{array}$ \\
\hline
\end{tabular}

Fonte: Elaborado pelo autor. 


\subsubsection{Condições cromatográficas}

O desenvolvimento do método para a quantificação do EFV, por CLAE foi baseado na Farmacopeia Brasileira, 2010. O Quadro 7 apresenta o resumo das condições cromatográficas empregadas para a quantificação do fármaco EFV. Como fase estacionária utilizou-se Coluna Gemini (características - $5 \mu \mathrm{m}$; C18 110A; 150 x 4,6 mm) equipada com uma pré-coluna Phenomenex®. A fase móvel usada foi constituída por uma mistura de acetonitrila, água e ácido ortofosfórico, nas proporções de 70:30:0,1 (v/v/v), respectivamente. A solução teve seu pH ajustado com trietilamina até a obtenção do valor de $\mathrm{pH}$ desejado de 3,3. A preparação foi filtrada sob vácuo, em filtro de membrana Nylon, com dimensões de $47 \mathrm{~mm}$ de diâmetro e poros de 0,45 $\mu \mathrm{m}$. Em seguida, a fase móvel foi levada ao banho de ultrassom para a degaseificação. Para detecção e quantificação do EFV empregou-se detector UV em $252 \mathrm{~nm}$, sob o fluxo de 1,0 mL/min, com volume de injeção de $20,0 \mu \mathrm{L}$, temperatura do forno de $25^{\circ} \mathrm{C}$ e tempo de corrida de 7 min (FARMACOPEIA BRASILEIRA, 2010).

Quadro 7 - Condições cromatográficas empregadas para análise e quantificação de EFV.

\begin{tabular}{|c|c|}
\hline \multicolumn{2}{|c|}{ Condições cromatográficas para análise do fármaco Efavirenz } \\
\hline Detector & UV \\
\hline Comprimento de onda $(\lambda)$ & $252 \mathrm{~nm}$ \\
\hline Fase móvel & Acetonitrila, água e ácido ortofosfórico (70:30:0,1) \\
\hline pH & 3,3 \\
\hline Fase estacionária & Coluna Gemini $5 \mu \mathrm{m}$ C18 110A 150 x 4,6 mm Phenomenex® \\
\hline Temperatura do forno & $25^{\circ} \mathrm{C}$ \\
\hline Fluxo & $1,0 \mathrm{~mL} / \mathrm{min}$ \\
\hline Tempo de corrida & $7 \mathrm{~min}$ \\
\hline Volume de injeção & $20,0 \mu \mathrm{L}$ \\
\hline
\end{tabular}

Fonte: Elaborado pelo autor. 


\subsubsection{Validação do método analítico}

O método descrito nos itens anteriores foi validado, conforme critérios estabelecidos pelo ICH (2005), para análise do fármaco em diferentes meios de soluções tampão com distintos valores de pH's (tampão $\mathrm{HCl}$ pH 1,2, tampão acetato $\mathrm{pH} 4,5$ e tampão fosfato $\mathrm{pH} 6,8)$, com emprego de solução padrão de EFV (400 $\mu \mathrm{g} / \mathrm{mL}$ ). O preparo de todas as soluções está descrito no Quadro 6.

\subsubsection{Especificidade}

A especificidade do método foi verificada por meio da comparação dos cromatogramas obtidos a partir das análises das soluções padrão (SP) de EFV, preparadas conforme descrição no Quadro 6. Para preparação das amostras para análises, alíquotas do fármaco foram diluídas em soluções tampão com distintos valores de pH's $(1,2,4,5$ e 6,8). Preparou-se também misturas entre fármaco e carreadores na proporção de 1:1, empregando separadamente os carreadores (PVP K-28/32, CoPVP, HPMCP-50, HPMCP-55, HPMCP-55s, P188 e P407) (ICH, 2005).

\subsection{Pesquisa de interferentes na análise do fármaco efavirenz}

A avaliação da interferência dos carreadores nas análises do EFV, foi determinada a partir de soluções contendo a mistura do EFV com os respectivos polímeros (PVP K-28/32, CoPVP, HPMCP-50, HPMCP-55, HPMCP-55s, P188 e P407). Para o preparo da solução padrão (SP) de EFV, procedeu-se conforme descrição no Quadro 6.

As soluções mãe (SM) de cada um dos polímeros foram preparadas transferindo-se cerca de 40 mg de cada uma das substâncias, separadamente, para balões volumétricos de $100 \mathrm{~mL}$, aos quais foram adicionados os solventes apropriados. Para os carreadores, PVP K-28/32, CoPVP, P188 e P407, utilizaram-se como solvente a água ultrapurificada (obtida com emprego do equipamento Milli-Q), enquanto que para os outros polímeros (HPMCP-50, HPMCP-55 e HPMCP-55s) empregou-se o metanol. Posteriormente os balões contendo os carreadores foram sonicados em banho de ultrassom, por 10 minutos, até obter a completa dissolução 
dos mesmos, em seguida completou-se o volume dos balões com os respectivos diluentes.

A partir das SM contendo os respectivos carreadores, foram preparadas soluções diluídas dos mesmos, tomando-se alíquotas de $5 \mathrm{~mL}$ de cada uma das preparações e transferindo-se separadamente para balão volumétrico de $100 \mathrm{~mL}$. Posteriormente o volume dos balões volumétricos foi completado com o respectivo solvente a fim de obter solução com concentração de $20,0 \mu \mathrm{g} / \mathrm{mL}$.

Soluções contendo o fármaco e os carreadores foram preparadas na proporção de 1:1, em tubos de ensaio, a partir da mistura das SM de EFV (3 mL) com as respectivas SM dos polímeros carreadores $(3 \mathrm{~mL})$, separadamente. Posteriormente os tubos de ensaio foram agitados em um agitador mecânico tipo vortex, por 15 segundos, e as misturas obtidas foram filtradas em filtros Millex LCR (Millipore, membrana PTFE, 0,45 $\mu \mathrm{m}, 13 \mathrm{~mm}$ ), para filtração de solventes orgânicos e aquosos e finalmente transferidas para os vials e analisadas por CLAE, conforme método descrito no item 4.2.1.2.

\subsubsection{Linearidade}

A linearidade foi determinada por meio da construção de curvas analíticas, obtidas a partir da análise do EFV nas soluções, em sete concentrações distintas, preparadas em um intervalo de 0,25 a $10,00 \mu \mathrm{g} / \mathrm{mL}$, conforme apresentadas no Quadro 8. As soluções foram obtidas a partir de diluições da SM de EFV (concentração de $400,0 \mu \mathrm{g} / \mathrm{mL}$, preparada conforme descrito no Quadro 6) em soluções tampão. com distintos valores de pH's (1,2, 4,5 e 6,8). O ensaio foi executado em três replicatas $(n=3)$, de acordo com as condições cromatográficas descritas no Quadro 7. As equações das retas foram obtidas por regressão linear por meio do método dos mínimos quadrados ( $\mathrm{ICH}, 2005)$. 
Quadro 8 - Descrição dos dados para o preparo dos pontos da curva analítica a partir da solução mãe de EFV de $400 \mu \mathrm{g} / \mathrm{mL}$.

\begin{tabular}{|cccc|}
\hline \hline Amostras & Alíquota da solução mãe $(\boldsymbol{\mu L})$ & Volume final $(\mathbf{m L})$ & $\begin{array}{c}\text { Concentração final } \\
\text { teórica }(\boldsymbol{\mu g} / \mathbf{m L})\end{array}$ \\
\hline $\mathbf{1}$ & 15,7 & 25,0 & 0,25 \\
$\mathbf{2}$ & 31,3 & 25,0 & 0,50 \\
$\mathbf{3}$ & 62,5 & 25,0 & 1,00 \\
$\mathbf{4}$ & 156,0 & 25,0 & 2,50 \\
$\mathbf{5}$ & 313,0 & 25,0 & 5,00 \\
$\mathbf{6}$ & 469,0 & 25,0 & 7,50 \\
$\mathbf{7}$ & 625,0 & 25,0 & 10,00 \\
\hline \hline
\end{tabular}

Fonte: Elaborado pelo autor.

\subsubsection{Precisão}

A precisão foi determinada analisando-se amostras de três concentrações diferentes do fármaco EFV em diferentes valores de $\mathrm{pH}$ 's $(0,50 \mu \mathrm{g} / \mathrm{mL}, 2,50 \mu \mathrm{g} / \mathrm{mL}$ e $7,50 \mu \mathrm{g} / \mathrm{mL}$ ), sendo que cada análise foi realizada com três repetições ( $n=3$ para cada concentração e para cada $\mathrm{pH}$ ), executadas em distintos meios compostos por soluções tampão nos pH's 1,2, 4,5 e 6,8, e este procedimento foi repetido para cada dia de análise. As análises foram realizadas no mesmo dia (repetibilidade), em três dias consecutivos (precisão intermediária) e para determinação do desvio padrão relativo (DPR) empregou-se a equação descrita a seguir (Eq. 2) (ICH, 2005).

$$
\operatorname{DPR}(\%)=\frac{\mathrm{DP}}{\mathrm{C} \text { média }} \times 100
$$

onde: DRP $(\%)$ = desvio padrão relativo em porcentagem;

DP = desvio padrão;

$\mathrm{C}$ média $=$ concentração média 


\subsubsection{Exatidão}

A exatidão foi verificada a partir de concentrações diferentes do fármaco EFV $(0,50 \mu \mathrm{g} / \mathrm{mL}, 2,50 \mu \mathrm{g} / \mathrm{mL}$ e $7,50 \mu \mathrm{g} / \mathrm{mL})$, em réplicas de três $(\mathrm{n}=3)$, e em três meios distintos compostos por soluções tampão nos pH's 1,2, 4,5 e 6,8. Os resultados foram calculados de acordo com a equação (Eq. 3) (ICH, 2005).

$$
\text { Exatidão }(\%)=\frac{\text { Concentração média experimental }}{\text { Concentração teórica }} \times 100
$$

\subsubsection{Limite de detecção e limite de quantificação}

O limite de detecção (LD) e o limite de quantificação (LQ) foram determinados a partir do desvio padrão da curva analítica $(\sigma)$ e da inclinação da curva analítica (IC). As curvas analíticas foram construídas conforme descrito no item 4.2.1.5. As soluções foram preparadas em sete concentrações distintas em três replicatas $(n=3)$, conforme apresentado no Quadro 8. Os resultados foram calculados conforme as equações (Eq. 4) e (Eq. 5) respectivamente (ICH, 2005).

$$
\begin{aligned}
& \mathrm{LD}=\frac{3,3 \cdot \sigma}{\mathrm{IC}} \\
& \mathrm{LQ}=\frac{10 \cdot \sigma}{\mathrm{IC}}
\end{aligned}
$$

\subsubsection{Desenvolvimento das formulações de dispersões sólidas de efavirenz por evaporação do solvente e avaliação da solubilidade}

As formulações para o desenvolvimento das DS de EFV foram obtidas a partir das misturas binárias contendo fármaco e carreador, nas proporções de 1:3 respectivamente, ambos solubilizados em solventes apropriados (conforme detalhamento a seguir). Foram empregados os seguintes carreadores: Kollidon® 30 
polivinilpirrolidona K-28/32 (PVP K-28/32), Kollidon® VA64 copovidona (CoPVP), hidroxipropilmetilcelulose ftalato (HPMCP-50, HPMCP-55 e HPMCP-55s) Kolliphor® P188 poloxâmero 188 (P188) e Kolliphor® P407 poloxâmero 407 (P407).

As misturas obtidas foram submetidas ao processo de secagem por meio do método de evaporação do solvente, que foi desenvolvida sob três formas distintas. A primeira forma de obtenção consistiu em um teste miniaturizado com emprego de lâmina de vidro e chapa de aquecimento. Nesta forma, designada de "seleção racional miniaturizada de solvente e carreadores", os solventes e carreadores foram selecionados em função da capacidade dos solventes em solubilizar tanto os carreadores como o fármaco e ainda garantir a amorfização e estabilidade do EFV. As outras duas formas de obtenção permitiram a produção das formulações em maior escala, e foram desenvolvidas apenas para as formulações selecionadas na primeira forma de obtenção. Para estas formas, para a evaporação do solvente foram empregados o rotaevaporador e a placa de aquecimento. Posteriormente as preparações tiveram sua solubilidade aquosa avaliada através do teste de shake flask.

\subsubsection{Seleção racional miniaturizada de solventes e carreadores}

Na primeira forma de obtenção o ensaio foi conduzido empregando lâmina de vidro virgem, misturas de solventes orgânicos (acetona - metanol 30:7 e acetona etanol 1:1), fármaco puro e carreadores (PVP K-28/32, CoPVP, HPMCP-50, HPMCP55, HPMCP-55s P188 e P407). Nesta etapa foram realizadas as misturas do fármaco e dos carreadores, na proporção 1:3, respectivamente, após solubilização de cada um deles separadamente, em solventes apropriados, conforme apresentado no Quadro 9.

Para a obtenção da lâmina com EFV amorfo, foram pesados $50 \mathrm{mg}$ do antirretroviral que foi solubilizado em tubo de ensaio em uma mistura de solvente contendo acetona - metanol, na proporção de 30:7 (v/v). Em seguida o composto foi agitado por 30 segundos em agitador mecânico, tipo vórtex e, alíquotas foram transferidas para a lâmina de vidro com o auxílio de uma pipeta tipo Pasteur.

As misturas binárias foram constituídas de uma combinação de fármaco e carreador na proporção de 1:3, para isso, pesaram-se $50 \mathrm{mg}$ do EFV e $150 \mathrm{mg}$ dos carreadores separadamente. As amostras foram transferidas individualmente para 
tubos de ensaio, onde posteriormente adicionaram-se entre 5 a $12 \mathrm{~mL}$ da mistura de solventes. Para o preparo das misturas binárias de EFV com os carreadores PVP K28/32, CoPVP, P188 e P407, empregou-se mistura dos solventes, acetona - metanol, na proporção de 30:7. Para o preparo das misturas binárias de EFV com os polímeros HPMCP-50, HPMCP-55 e HPMCP-55s, empregou-se mistura dos solventes, acetona - etanol, na proporção 1:1 (v/v). Após a adição dos solventes, os tubos foram agitados (entre 30 segundos e 5 minutos) em agitador mecânico, tipo vórtex e alíquotas destas misturas foram transferidas para lâminas de vidro com o auxílio de uma pipeta tipo Pasteur.

Posteriormente, estas lâminas foram submetidas ao aquecimento, por meio de uma chapa de aquecimento para evaporação do solvente, sob temperatura de $90^{\circ} \mathrm{C}$. Após a secagem, as amostras foram caracterizadas por difratometria de raios $\mathrm{X}$ pelo método do pó (DRXP), conforme descrito no item 4.2.4.3 (DAVIS et al., 2016).

Seguindo o protocolo descrito anteriormente, foram igualmente realizadas análises do fármaco puro, carreadores e da lâmina de vidro virgem (amostras designadas de padrão), para verificar o padrão amorfo apresentado. O fármaco puro e os carreadores foram transferidos para lâminas de vidro separadamente, e posteriormente as amostras foram analisadas por DRXP.

As lâminas contendo as misturas de materiais também foram destinadas ao estudo de estabilidade acelerada, empregando os seguintes intervalos de tempo: dia do preparo tempo 1 (T1) e após 30 dias do preparo tempo 2 (T2). O estudo foi conduzido de acordo com os critérios da resolução de estudo de estabilidade da ANVISA. As lâminas foram armazenadas em estufa com temperatura e umidade controladas $\left(40^{\circ} \mathrm{C} \pm 2{ }^{\circ} \mathrm{C} / 75 \%\right.$ UR $\pm 5 \%$ UR) por trinta dias (BRASIL, 2005).

Os resultados para os sistemas binários preparados nas lâminas de vidro foram expressos das seguintes formas, para os tempos 1 e 2: totalmente amorfo (AAAA), semicristalino (AACC) e totalmente cristalino (CCCC) (DAVIS et al., 2016). 
Quadro 9 - Descrição das amostras e das condições empregadas para obtenção do teste miniaturizado das misturas binárias (fármaco, carreador e solvente).

\begin{tabular}{|cccccc|}
\hline \hline Lâminas & Amostras & Solventes & $\begin{array}{c}\text { Quantidade } \\
\text { de solvente }\end{array}$ & $\begin{array}{c}\text { Tempo de } \\
\text { Agitação }\end{array}$ & $\begin{array}{c}\text { Temperatura de } \\
\text { aquecimento }\end{array}$ \\
\hline A & EFV amorfo $(50 \mathrm{mg})$ & Acetona - Metanol $30: 7$ & $5 \mathrm{~mL}$ & $30 \mathrm{seg}$ & $90^{\circ} \mathrm{C}$ \\
B & EFV $(50 \mathrm{mg})+$ PVP K-28/32 $(150 \mathrm{mg})$ & Acetona - Metanol $30: 7$ & $6 \mathrm{~mL}$ & $30 \mathrm{seg}$ & $90^{\circ} \mathrm{C}$ \\
C & EFV $(50 \mathrm{mg})+$ CoPVP $(150 \mathrm{mg})$ & Acetona - Metanol $30: 7$ & $5 \mathrm{~mL}$ & $30 \mathrm{seg}$ & $90^{\circ} \mathrm{C}$ \\
D & EFV $(50 \mathrm{mg})+$ HPMCP-50 $(150 \mathrm{mg})$ & Acetona - Etanol 1:1 & $12 \mathrm{~mL}$ & $5 \mathrm{~min}$ & $90^{\circ} \mathrm{C}$ \\
E & EFV $(50 \mathrm{mg})+$ HPMCP-55 $(150 \mathrm{mg})$ & Acetona - Etanol 1:1 & $8 \mathrm{~mL}$ & $1 \mathrm{~min}$ & $90^{\circ} \mathrm{C}$ \\
F & EFV $(50 \mathrm{mg})+$ HPMCP-55s $(150 \mathrm{mg})$ & Acetona - Etanol 1:1 & $8 \mathrm{~mL}$ & $3 \mathrm{~min}$ & $90^{\circ} \mathrm{C}$ \\
G & EFV $(50 \mathrm{mg})+$ P188 $(150 \mathrm{mg})$ & Acetona - Metanol $30: 7$ & $5 \mathrm{~mL}$ & $30 \mathrm{seg}$ & $90^{\circ} \mathrm{C}$ \\
H & EFV $(50 \mathrm{mg})+$ P407 $(150 \mathrm{mg})$ & Acetona - Metanol $30: 7$ & $5 \mathrm{~mL}$ & $30 \mathrm{seg}$ & $90^{\circ} \mathrm{C}$ \\
\hline \hline
\end{tabular}

Fonte: Elaborado pelo autor.

\subsubsection{Obtenção em maior escala das formulações de dispersões sólidas de efavirenz}

Para efetuar o preparo das formulações de DS de EFV em maiores escalas na proporção de 1:3 de fármaco e carreador, empregaram-se dois métodos distintos de evaporação do solvente. Para as misturas binárias do EFV com os carreadores PVP K-28/32, CoPVP, P188 e P407, utilizou-se o rotaevaporador, e para aquelas com os carreadores, HPMCP-50, HPMCP-55 e HPMCP-55s, empregou-se a chapa de aquecimento.

As formulações contendo os carreadores PVP K-28/32, CoPVP, P188 e P407 foram preparadas na proporção de 1:3 (fármaco e carreador). As matérias-primas que constituem as formulações foram pesadas separadamente em balança analítica. Para realizar a solubilização dos componentes sólidos foram aplicados solventes na forma de mistura nas seguintes proporções: acetona - metanol (30:7), conforme listado no Quadro 10.

Após a completa solubilização dos polímeros, procedimento realizado com o auxílio de um agitador magnético e uma barra de agitação magnética, posteriormente incorporou-se o fármaco EFV e agitou-se até a completa solubilização da substância ativa. Subsequentemente a solubilização, as soluções contendo as misturas binárias foram transferidas separadamente para um balão de fundo redondo, e evaporadas com o auxílio do equipamento Evaporador rotativo R-215 (Buchi, Suiça). Os 
parâmetros empregados no equipamento foram, temperatura do banho de $50{ }^{\circ} \mathrm{C}$, velocidade de rotação do balão de $50 \mathrm{rpm}$, e pressão reduzida de $370 \pm 2 \mathrm{mbar}$ durante todo o processo. Nessas condições, a evaporação completa do solvente transcorreu em cerca de 40 minutos (ALVES et al., 2014).

Após a completa evaporação do solvente, os balões contendo os precipitados com os respectivos carreadores (PVP K-28/32 e CoPVP), foram transferidos para uma estufa e submetidos à secagem, sob temperatura de $40^{\circ} \mathrm{C}$, por aproximadamente 12 horas. Em seguida as misturas binárias foram transferidas para um almofariz de vidro e trituradas manualmente com auxílio de pistilo. Posteriormente as preparações tiveram o tamanho de partícula padronizado utilizando um tamis com abertura de 0,42 $\mathrm{mm}$, em seguida as preparações foram armazenadas em frascos de vidro e devidamente seladas e levadas ao dessecador. A Figura 19 apresenta o fluxograma do processo de obtenção das formulações empregando os carreadores PVP K-28/32 e CoPVP.

Logo após passar pelo processo de evaporação do solvente, as misturas binárias contendo os seguintes carreadores poloxâmero 188 e 407, foram retiradas do balão de fundo redondo e transferidas separadamente para um béquer de plástico de $50 \mathrm{~mL}$. Posteriormente os béqueres contendo as preparações foram movidos para uma estufa e submetidas à secagem com temperatura de $40^{\circ} \mathrm{C}$ por aproximadamente 12 horas. As amostras foram devidamente protegidas por plástico filme e subsequentemente foram levadas e armazenadas no congelador. A Figura 20 resume o processo de obtenção das formulações utilizando os copolímeros P188 e P407.

Figura 19 - Fluxograma do método utilizado no preparo das formulações contendo os carreadores PVP K-28/32 e CoPVP.

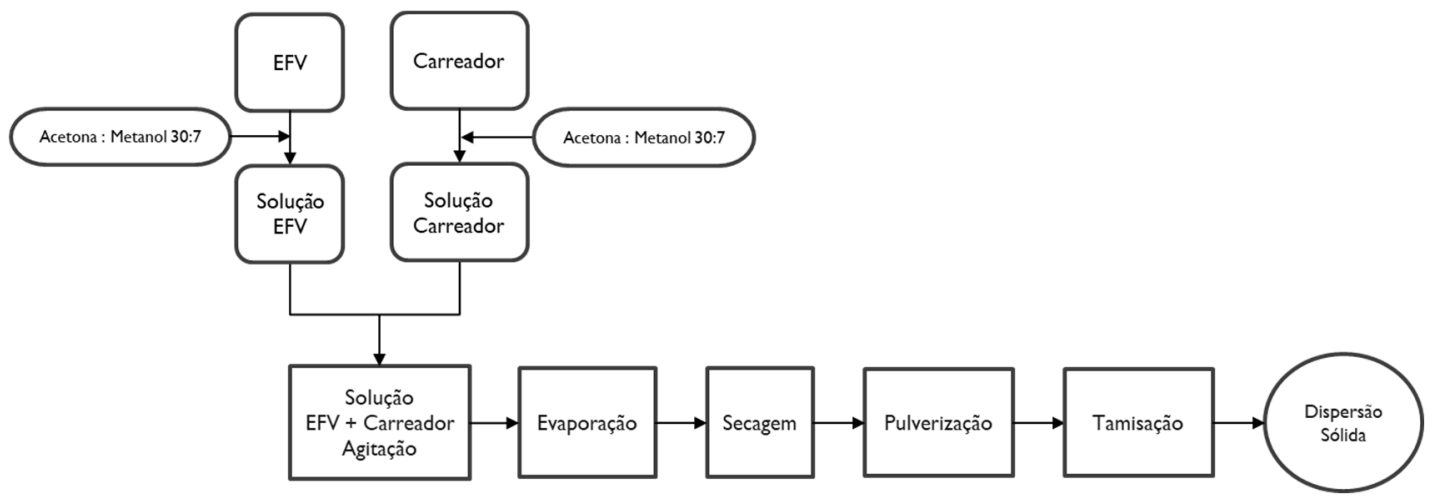

Fonte: Elaborado pelo autor. 
Figura 20 - Fluxograma do método utilizado no preparo das formulações contendo os carreadores P188 e P407.

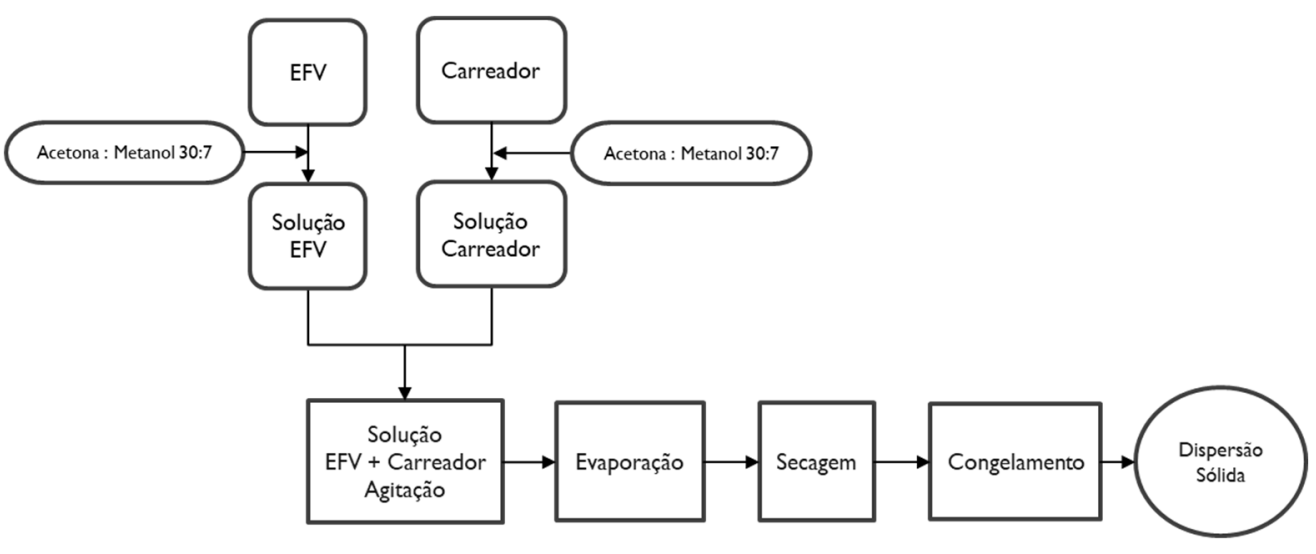

Fonte: Elaborado pelo autor.

As formulações contendo os carreadores HPMCP-50, HPMCP-55 e HPMCP55s foram preparadas na proporção de 1:3 (fármaco e carreador). As matérias-primas que constituem as formulações foram pesadas separadamente em balança analítica. Para realizar a solubilização dos componentes sólidos foram aplicados solventes na forma de mistura nas seguintes proporções: acetona - etanol (1:1), conforme listados no Quadro 10.

Após a completa solubilização dos polímeros, procedimento realizado com o auxílio de um agitador magnético e uma barra de agitação magnética, posteriormente incorporou-se o fármaco EFV e agitou-se até a completa solubilização da substância ativa. Subsequentemente a solubilização, as soluções contendo as misturas binárias foram transferidas separadamente em três placas de Petri distintas para cada polímero. Essas placas foram mantidas na chapa de aquecimento - IKA® C-MAG HS 7 à temperatura de $90{ }^{\circ} \mathrm{C}$, onde posteriormente transferiram-se as soluções aos poucos até a completa evaporação do solvente, permanecendo somente o precipitado considerado uma dispersão sólida.

Após a completa evaporação do solvente, as placas de petri contendo os precipitados, foram levadas para a estufa e submetidas à secagem na temperatura de $40{ }^{\circ} \mathrm{C}$, por aproximadamente 12 horas. Em seguida as preparações foram removidas das placas com o auxílio de um bisturi e armazenadas em dessecador. O processo de obtenção das formulações empregando os polímeros HPMCP-50, HPMCP-55 e HPMCP-55s está resumido na Figura 21. 
Figura 21 - Fluxograma do método utilizado no preparo das formulações contendo os carreadores HPMCP-50, HPMCP-55 e HPMCP-55s.

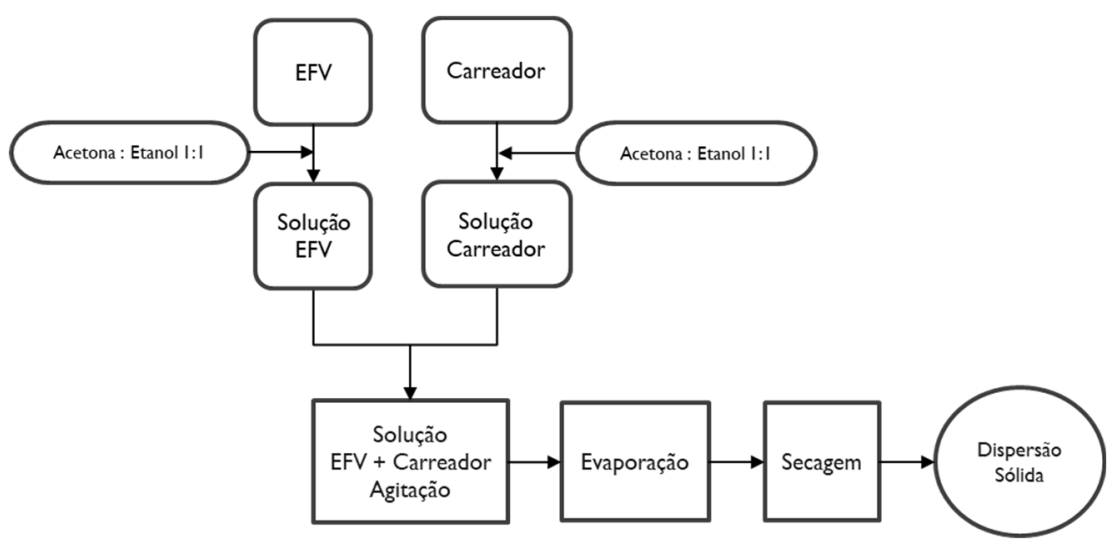

Fonte: Elaborado pelo autor.

Quadro 10 - Descrição das condições empregadas para obtenção das formulações (em maior quantidades empregando a proporção 1:3).

\begin{tabular}{|c|c|c|c|c|c|}
\hline Amostras & Formulações & Solventes & $\begin{array}{c}\text { Volume de } \\
\text { solvente }\end{array}$ & $\begin{array}{l}\text { Tempo de } \\
\text { Agitação }\end{array}$ & $\begin{array}{l}\text { Método de } \\
\text { preparo }\end{array}$ \\
\hline 1 & DS PVP K-28/32 (1:3) & Acetona - Metanol 30:7 & $120 \mathrm{~mL}$ & $5 \mathrm{~min}$ & Rotaevaporador \\
\hline 2 & DS CoPVP (1:3) & Acetona - Metanol 30:7 & $100 \mathrm{~mL}$ & $5 \mathrm{~min}$ & Rotaevaporador \\
\hline 3 & DS HPMCP-50 (1:3) & Acetona - Etanol 1:1 & $240 \mathrm{~mL}$ & $20 \mathrm{~min}$ & $\begin{array}{c}\text { Chapa de } \\
\text { aquecimento }\end{array}$ \\
\hline 4 & DS HPMCP-55 (1:3) & Acetona - Etanol 1:1 & $160 \mathrm{~mL}$ & $15 \mathrm{~min}$ & $\begin{array}{c}\text { Chapa de } \\
\text { aquecimento }\end{array}$ \\
\hline 5 & DS HPMCP-55s (1:3) & Acetona - Etanol 1:1 & $160 \mathrm{~mL}$ & $15 \mathrm{~min}$ & $\begin{array}{c}\text { Chapa de } \\
\text { aquecimento }\end{array}$ \\
\hline 6 & DS P188 (1:3) & Acetona - Metanol 30:7 & $100 \mathrm{~mL}$ & $5 \mathrm{~min}$ & Rotaevaporador \\
\hline 7 & DS P407 (1:3) & Acetona - Metanol 30:7 & $100 \mathrm{~mL}$ & $10 \min$ & Rotaevaporador \\
\hline
\end{tabular}

Fonte: Elaborado pelo autor.

\subsubsection{Obtenção das misturas físicas de efavirenz}

As misturas físicas (MF) foram obtidas paralelamente às DS, pela combinação simples do fármaco e dos carreadores $(p / p)$, nas proporções de $1: 3$, conforme apresentado no Quadro 9. Para realização do procedimento foram utilizados pistilo e gral de vidro. O EFV foi adicionado aos carreadores (PVP K-28/32, CoPVP, HPMCP50, HPMCP-55, HPMCP-55s, P188 e P407) separadamente por diluição geométrica, até a obtenção de uma mistura homogênea totalizando sete formulações distintas (MENG et al., 2015). 


\subsubsection{Determinação da solubilidade pelo método do equilíbrio (shake-flask)}

Os testes de solubilidade das amostras do EFV puro, MF e DS, foram determinadas através do método do equilíbrio, utilizando a técnica do shake-flask, com emprego da incubadora com plataforma de agitação orbital e temperatura controlada (Tecnal TE-420, São Paulo, Brasil).

Os ensaios foram conduzidos em triplicatas $(n=3)$ em diferentes meios de solubilização (solução tampão, $\mathrm{HCl}$ pH 1,2, acetato $\mathrm{pH} 4,5$ e fosfato $\mathrm{pH}$ 6,8), totalizando nove frascos por amostra. Dessa forma, excesso das formulações desenvolvidas conforme descrito no item 4.2.2.2, foram adicionadas aos frascos de vidro contendo $25 \mathrm{~mL}$ das respectivas soluções tampão (solução $\mathrm{HCl}$ pH 1,2, acetato $\mathrm{pH} 4,5$ e fosfato $\mathrm{pH} \mathrm{6,8)} \mathrm{preparadas} \mathrm{conforme} \mathrm{descrição} \mathrm{do} \mathrm{Quadro} \mathrm{6.} \mathrm{A} \mathrm{temperatura}$ das soluções foi mantida a $37 \pm 0,5{ }^{\circ} \mathrm{C}$ e posteriormente os frascos foram constantemente agitados a $150 \pm 3$ rpm durante 72 horas (DEZANI et al., 2013; EMA, 2010).

Após 72 horas de agitação, alíquotas destas amostras foram imediatamente filtradas em filtros Millex LCR (membrana PTFE; 0,45 $\mu \mathrm{m} ; 13 \mathrm{~mm}$ ), para filtração de solventes orgânicos e aquosos, com o auxílio de uma seringa. As soluções obtidas foram então transferidas para tubos de ensaios e em seguida diluídas conforme apresentadas no Quadro 11. A concentração do fármaco foi determinado pelo método cromatográfico, previamente desenvolvido e validado $(\mathrm{ICH}, 2005)$, conforme descrito no item 4.2.1. Os parâmetros de solubilidade foram comparados estatisticamente empregando-se a análise de variância (ANOVA) dois fatores, seguida de teste de Tukey. Valores de $p \leq 0,05$ foram considerados estatisticamente significativos. 
Quadro 11 - Descrição das condições empregadas para diluição do EFV puro, das misturas físicas (MF) e dispersões sólidas (DS), preparadas na proporção de 1:3.

\begin{tabular}{|ccccc|}
\hline \hline Amostras & Formulações & Alíquota pipetada & Volume final & Diluição \\
\hline $\mathbf{1}$ & EFV puro & $1 \mathrm{~mL}$ & $10 \mathrm{~mL}$ & $10 \mathrm{x}$ \\
$\mathbf{2}$ & DS PVP K-28/32 (1:3) & $1 \mathrm{~mL}$ & $10 \mathrm{~mL}$ & $10 \mathrm{x}$ \\
$\mathbf{3}$ & MF PVP K-28/32 (1:3) & $1 \mathrm{~mL}$ & $10 \mathrm{~mL}$ & $10 \mathrm{x}$ \\
$\mathbf{4}$ & DS CoPVP (1:3) & $1 \mathrm{~mL}$ & $10 \mathrm{~mL}$ & $10 \mathrm{x}$ \\
$\mathbf{5}$ & MF CoPVP (1:3) & $1 \mathrm{~mL}$ & $10 \mathrm{~mL}$ & $10 \mathrm{x}$ \\
$\mathbf{6}$ & DS HPMCP-50 (1:3) & $1 \mathrm{~mL}$ & $10 \mathrm{~mL}$ & $10 \mathrm{x}$ \\
$\mathbf{7}$ & MF HPMCP-50 (1:3) & $1 \mathrm{~mL}$ & $10 \mathrm{~mL}$ & $10 \mathrm{x}$ \\
$\mathbf{8}$ & DS HPMCP-55 (1:3) & $1 \mathrm{~mL}$ & $10 \mathrm{~mL}$ & $10 \mathrm{x}$ \\
$\mathbf{9}$ & MF HPMCP-55 (1:3) & $1 \mathrm{~mL}$ & $10 \mathrm{~mL}$ & $10 \mathrm{x}$ \\
$\mathbf{1 0}$ & DS HPMCP-55s (1:3) & $1 \mathrm{~mL}$ & $10 \mathrm{~mL}$ & $10 \mathrm{x}$ \\
$\mathbf{1 1}$ & MF HPMCP-55s (1:3) & $1 \mathrm{~mL}$ & $10 \mathrm{~mL}$ & $10 \mathrm{x}$ \\
$\mathbf{1 2}$ & DS P188 (1:3) & $50 \mu \mathrm{L}$ & $50 \mathrm{~mL}$ & $1000 \mathrm{x}$ \\
$\mathbf{1 3}$ & MF P188 (1:3) & $152 \mu \mathrm{L}$ & $50 \mathrm{~mL}$ & $328 \mathrm{x}$ \\
$\mathbf{1 4}$ & DS P407 (1:3) & $40 \mu \mathrm{L}$ & $100 \mathrm{~mL}$ & $2.500 \mathrm{x}$ \\
$\mathbf{1 5}$ & MF P407 (1:3) & $170 \mu \mathrm{L}$ & $100 \mathrm{~mL}$ & $588 \mathrm{x}$ \\
\hline \hline
\end{tabular}

Fonte: Elaborado pelo autor.

\subsubsection{Impactos nas alterações das proporções de polímeros nas formulações de dispersões sólidas de efavirenz}

Nessa etapa foram selecionadas as formulações que empregaram os carreadores P188 e P407, nas proporções de 1:3 de fármaco e carreador respectivamente, pois a combinação do EFV com esses compostos químicos demonstrou melhores resultados de solubilidade. O processo de alteração das formulações, consistiu em diminuir a proporção de polímeros utilizados no preparo das DS, passando de 1:3 para 1:1. Para analisar o impacto da alteração das proporções foram empregadas as análises de solubilidade por shake-flask, miscibilidade por calorimetria exploratória diferencial (DSC) e estabilidade por difratometria de raios $\mathrm{X}$ (DRXP), de acordo com a descrição no item 4.2.4.

\subsubsection{Avaliação da solubilidade}

O primeiro experimento consistiu em determinar a solubilidade do EFV empregando a metodologia apresentada no item 4.2.2.4. Foram produzidas MF de 
EFV nas proporções de 1:1 empregando os carreadores (P188 e P407) conforme descrição no item 4.2.2.3. As condições empregadas no ensaio estão descritas no Quadro 12, após a finalização do experimento as soluções foram diluídas e posteriormente analisadas por CLAE.

Quadro 12 - Descrição das condições empregadas para diluição do EFV puro e das MF preparadas na proporção de 1:1.

\begin{tabular}{|ccccc|}
\hline \hline Amostras & Formulações & Alíquota pipetada & Volume final & Diluição \\
\hline $\mathbf{1}$ & MF P188 (1:1) & $1 \mathrm{~mL}$ & $25 \mathrm{~mL}$ & $25 \mathrm{x}$ \\
$\mathbf{2}$ & MF P407 (1:1) & $300 \mu \mathrm{L}$ & $50 \mathrm{~mL}$ & $167 \mathrm{x}$ \\
\hline \hline
\end{tabular}

Fonte: Elaborado pelo autor.

\subsubsection{Avaliação da miscibilidade}

As curvas DSC foram obtidas empregando o equipamento PerkinElmer DSC 4000 conforme descrição do método no item 4.2.4.4.

O segundo procedimento para otimização das formulações, baseou-se na miscibilidade das misturas físicas (MF) preparadas em diferentes proporções com os respectivos carreadores P188 e P407. As MF foram obtidas pela combinação simples do fármaco e carreadores $(p / p)$, nas proporções de 1:1, 1:2, 1:3, 1:4, 1:5 e 3:1 respectivamente, totalizando 12 formulações (MENG et al., 2015). O procedimento do método está descrito no item 4.2.2.3.

\subsubsection{Avaliação da estabilidade}

Nesta terceira e última etapa de otimização das formulações, o experimento fundamentou-se na estabilidade das amostras. O ensaio foi conduzido empregandose lâmina de vidro virgem e misturas do fármaco e dos carreadores (P188 e P407) na proporção de 1:1 (50 mg) e posteriormente foram solubilizados em acetona - metanol (30:7), as misturas binárias foram preparadas conforme o método descrito no item 4.2.2.1, apresentado no Quadro 13 (DAVIS et al., 2016).

As lâminas contendo as preparações binárias também foram destinadas ao estudo de estabilidade nos seguintes intervalos de tempo: dia do preparo tempo 1 (T1) 
e após 30 dias do preparo tempo 2 (T2). As amostras foram armazenadas no congelador, pois a consistência delas era de um líquido muito viscoso semelhante a "mel de abelha", e quando armazenadas nesse compartimento as misturas binárias adquiriam uma propriedade mais consistente. Os resultados foram caracterizados por DRXP realizados conforme a descrição do item 4.2.4.3, expressos das seguintes formas para os tempos 1 e 2: totalmente amorfo (AAAA), semicristalino (AACC) e totalmente cristalino (CCCC) (DAVIS et al., 2016).

Quadro 13 - Descrição das amostras e das condições empregadas para obtenção das misturas binárias (fármaco, carreador e solvente) para verificar a estabilidade das formulações.

\begin{tabular}{|cccccc|}
\hline \hline Lâminas & Formulações & Solventes & $\begin{array}{c}\text { Quantidade de } \\
\text { solvente }\end{array}$ & $\begin{array}{c}\text { Tempo de } \\
\text { Agitação }\end{array}$ & $\begin{array}{c}\text { Temperatura de } \\
\text { aquecimento }\end{array}$ \\
\hline A & EFV $(50 \mathrm{mg})+\mathrm{P} 188(50 \mathrm{mg})$ & Acetona - Metanol $30: 7$ & $5 \mathrm{~mL}$ & $30 \mathrm{seg}$ & $90^{\circ} \mathrm{C}$ \\
B & $\mathrm{EFV}(50 \mathrm{mg})+\mathrm{P} 407(50 \mathrm{mg})$ & Acetona - Metanol $30: 7$ & $5 \mathrm{~mL}$ & $30 \mathrm{seg}$ & $90^{\circ} \mathrm{C}$ \\
\hline \hline
\end{tabular}

Fonte: Elaborado pelo autor.

\subsubsection{Caracterização físico-química das dispersões sólidas de efavirenz}

As amostras obtidas e selecionadas por meio das técnicas descritas nos itens 4.2.2 e 4.2.3 respectivamente, foram caracterizadas por meio dos ensaios de teor, dissolução, DRXP, DSC, TG e FTIR.

\subsubsection{Determinação do teor de efavirenz}

Para determinar o teor do EFV na matéria-prima e nas DS contendo os carreadores P188 e P407 na proporção de 1:3, foram transferidos separadamente o equivalente a $40 \mathrm{mg}$ do fármaco para um balão volumétrico de $100 \mathrm{~mL}$. No mesmo balão adicionaram-se $40 \mathrm{~mL}$ da fase móvel (ver item 4.2.1.2), posteriormente a solução foi submetida ao ultrassom por 15 minutos objetivando a completa solubilização do ativo. Após decorrer o tempo, completou-se o volume do balão com o mesmo solvente até o menisco e efetuando a homogeneização final. Executou-se o ensaio em triplicata $(n=3)$, e a concentração de EFV nas soluções resultantes foram analisadas pelo método cromatográfico, previamente validado, empregando o 
cromatógrafo Modelo Thermo Scientific Dionex UltiMate 3000 (FARMACOPEIA BRASILEIRA., 2010).

\subsubsection{Estudo de dissolução em condição sink pelo aparato 4 (Flow-Cell) e avaliação da eficiência de dissolução}

Nesta etapa as amostras de fármaco puro (EFV), formulações de DS obtidas com os carreadores P188 e P407 (conforme descrito no item 4.2.2.2) e as respectivas MF foram submetidas aos ensaios de dissolução por meio do equipamento do tipo Aparato USP IV Flow-Cell (Sotax AG, Suíça). Os ensaios foram conduzidos em triplicata, sob condições sink, e com o emprego de células de fluxo para pós e grânulos (Figura 22), em uma configuração aberta.

A parte cônica da célula foi preenchida com aproximadamente $800 \pm 50 \mathrm{mg}$ de esferas de vidro de $1 \mathrm{~mm}$ de diâmetro, e uma única esfera de rubi de aproximadamente $5 \mathrm{~mm}$ de diâmetro que foi posta na entrada do fluxo da célula (MUGHEIRBI et al., 2017).

Cada célula de fluxo foi composta sequencialmente de baixo para cima por: uma tela filtrante de metal (maior abertura), um filtro de microfibra de vidro GF/D 2.7 $\mu \mathrm{m}$, outra tela filtrante de metal (maior abertura), formando um sanduíche, e por fim acrescentou-se um anel de borracha. Após adicionar os filtros na parte inferior das células, pesaram-se separadamente sobre os filtros $10 \mathrm{mg}$ do EFV puro, $40 \mathrm{mg}$ da mistura física e $40 \mathrm{mg}$ da dispersão sólida para cada célula. Depois de pesadas as amostras, colocou-se um cesto acima das amostras com a parte cônica voltada para cima, com o objetivo de impedir a formação de grumos durante o ensaio.

Acima do cesto, adicionou-se um anel de metal para impedir que o cesto seja deslocado durante o experimento, na parte superior da célula inseriu-se uma tela de metal (maior abertura), um filtro de microfibra de vidro GF/F $0.7 \mu \mathrm{m}$ foi posto entre as duas telas de metal, uma segunda tela de metal (menor abertura) foi introduzida para reter particulas não dissolvidas, e por fim, adicionou-se um anel de borracha fechando o sistema (FOTAKI, 2011). 
Figura 22 - Célula de fluxo pós e grânulos

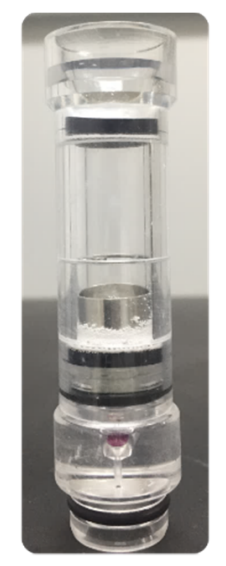

Fonte: Elaborado pelo autor.

As análises empregaram uma vazão pulsante de $8 \mathrm{~mL} / \mathrm{min}$ em temperatura de $37 \pm 0,5^{\circ} \mathrm{C}$, foram realizadas cinco coletas com intervalos de 25 min para cada solução tampão utilizada, totalizando 15 frascos por célula e um volume final de 50 $\mathrm{mL}$ e tempo de dissolução de $375 \mathrm{~min}$, realizando um split que é o descarte do volume excedente de 75\%. A programação está resumida no Quadro 14.

O total de células de fluxo utilizadas por experimento foram 6, pois conforme dito anteriormente os testes de dissolução foram executados em triplicata. $\mathrm{O}$ aparato IV é comprovadamente útil em estudos de dissolução, nos quais é requerido uma mudança de meio de dissolução (MUGHEIRBI et al., 2017).

Os meios de dissolução utilizado durante os ensaios foram as soluções tampão $\mathrm{pH}$ 1,2, 4,5 e 6,8 (ver item 4.2.1.1). Durante o experimento realizaram-se 5 coletas de 25 minutos para cada uma das soluções tampão, totalizando 125 min de análise para cada pH com um tempo total de 375 min de ensaio de dissolução. Foram gerados 15 frascos por célula de fluxo, e a somatória das 6 células produziu um montante de 90 frascos para ser analisados. As amostras foram analisadas pelo método cromatográfico, previamente desenvolvido e validado conforme item 4.2.1, empregando o cromatógrafo Modelo Thermo Scientific Dionex UltiMate 3000 (FARMACOPEIA BRASILEIRA, 2010; ICH 2005).

Os perfis de dissolução foram avaliados e comparados em relação a porcentagem de fármaco dissolvido $\left(Q_{\text {min }}\right)$, e por eficiência de dissolução (ED\%) que 
foi calculada a partir dos valores de área sob a curva, no intervalo de tempo de 0 e 375 min com o emprego do suplemento do Excel DDsolver® (ZHANG et al., 2010).

Quadro 14 - Programação do aparato IV (Flow-Cell) considerando o tipo de meio de dissolução, período e intervalo de coleta e quantidade recolhida e descartada.

\begin{tabular}{|ccccc|}
\hline \hline Meio de dissolução & Período & Intervalos & $\begin{array}{c}\text { Amostra } \\
\text { recolhida }\end{array}$ & $\begin{array}{c}\text { Amostra } \\
\text { descartada }\end{array}$ \\
\hline Tampão HCl pH 1,2 & $0-125$ min & 5 coletas de 25 min & $25 \%$ & $75 \%$ \\
Tampão acetato pH 4,5 & $125-250$ min & 5 coletas de 25 min & $25 \%$ & $75 \%$ \\
Tampão fosfato $\mathrm{pH} \mathrm{6,8}$ & $250-375$ min & 5 coletas de 25 min & $25 \%$ & $75 \%$ \\
\hline \hline
\end{tabular}

Fonte: Adaptação de (SILVA, 2014).

\subsubsection{Difratometria de raios $X$ pelo método do pó}

As análises de difratometria de raios $\mathrm{X}$ pelo método do pó (DRXP) das matériasprimas, das MF e das DS foram realizadas em um difratômetro (Bruker Massachusetts, EUA) modelo D8 Advance Da Vinci com detector LYNXEYE e ótica TWIN-TWIN, equipado com fonte de radiação Cu Ka $(\lambda=1,54 \AA)$, utilizando corrente de $40 \mathrm{~mA}$ e voltagem de $40 \mathrm{kV}$. A varredura foi realizada em um intervalo de $5^{\circ}$ a $40^{\circ}$ com velocidade de 0.02 29/seg (COSTA et al., 2019).

\subsubsection{Calorimetria exploratória diferencial}

As análises de calorimetria exploratória diferencial (DSC) do EFV, das MF e das DS empregando os carreadores P188 e P407 e suas respectivas matérias-primas, foram realizadas empregando dois equipamentos TA Instrument Q20 e PerkinElmer DSC 4000. Os instrumentos foram calibrados utilizado o elemento químico Índio (In) e uma panela de alumínio vazia foi empregada como padrão de referência. Os ensaios foram executados com aproximadamente $2 \mathrm{mg}$ das amostras e posteriormente as preparações foram pesadas separadamente dentro de panelas de alumínio em balança analítica, onde foram fechadas utilizando tampas de alumínio, em seguida, os recipientes foram selados empregando seladora manual. Os recipientes contendo amostras e a referência (vazio) foram aquecidos na faixa de temperatura ambiente até $180{ }^{\circ} \mathrm{C}$ empregando uma taxa de aquecimento de $10{ }^{\circ} \mathrm{C}$ por minuto. Atmosfera inerte 
de nitrogênio foi mantida com fluxo de $50 \mathrm{~mL} / \mathrm{min}^{-1}$, esses valores de fluxo foram mantidos para cada corrida de DSC (SUN; LEE, 2015).

\subsubsection{Termogravimetria}

As medidas das análises termogravimétricas (TG) do EFV, da MF, da DS empregando os carreadores P188 e P407 e suas respectivas matérias-primas, foram obtidas empregando o equipamento TA Instruments TG Q50. As análises foram executadas com aproximadamente $4,5 \mathrm{mg}$ das amostras pesadas separadamente dentro de panelas de platina. Os recipientes contendo as amostras foram aquecidos na faixa de temperatura ambiente até $600^{\circ} \mathrm{C}$ empregando uma taxa de aquecimento de $10{ }^{\circ} \mathrm{C}$ por minuto. Atmosfera inerte de nitrogênio foi mantida com fluxo de 50 $\mathrm{mL} / \mathrm{min}^{-1}$, esse valor de fluxo foi mantido para cada corrida de TG (FANDARUFF et al., 2014b).

\subsubsection{Espectroscopia na região do infravermelho com transformada de Fourier}

As análises de espectroscopia na região do infravermelho com transformada de Fourier (FTIR) do EFV, das MF, das DS empregando os carreadores P188 e P407 e suas respectivas matérias-primas, foram realizadas no equipamento Thermo Fisher Scientific Espectrofotômetro FTIR Nicolet iS10, empregando uma faixa de análise de $4000-600 \mathrm{~cm}^{-1}$. As amostras foram misturadas separadamente com $\mathrm{KBr}$ (brometo de potássio) empregando almofariz e pistilo e as pastilhas foram produzidas por compressão dos pós (FANDARUFF et al., 2014a). 
5. RESULTADOS E DISCUSSÃO 


\subsection{Validação do método por cromatografia líquida de alta eficiência (CLAE) para quantificação de efavirenz}

Para análise e determinação do EFV nas amostras obtidas a partir dos ensaios de teor, solubilidade e de dissolução, foi desenvolvido e validado método analítico por CLAE, com detecção em UV, conforme descrição no item 4.2.1. O método foi validado conforme os seguintes critérios preconizados no ICH (2005): especificidade, linearidade, precisão, exatidão e limites de detecção e de quantificação.

\subsubsection{Especificidade}

A especificidade refere-se à capacidade do método analítico de identificar ou quantificar o analito de interesse, inequivocamente na presença de componentes que podem estar presentes nas amostras a serem analisadas, como impurezas, diluentes e componentes da matriz ( $\mathrm{ICH}, 2005)$.

A Figura 23 apresenta o cromatograma obtido a partir da análise da solução padrão de EFV $(20,0 \mu \mathrm{g} / \mathrm{mL})$ utilizando como diluente a fase móvel. As Figuras 24 a 28, por sua vez, apresentam os resultados da pesquisa de interferentes (soluções tampão pH 1,2, 4,5 e 6,8; carreadores PVP K-28/32, CoPVP, HPMCP-50, HPMCP55, HPMCP-55s, P188 e P407) a partir das amostras preparadas conforme descrito no item 4.2.2.2, referente à validação do método. A comparação das Figuras $23 \mathrm{com}$ as demais, permitiu concluir que não foram evidenciados picos interferentes no tempo de retenção do EFV ( $t=4,48 \mathrm{~min}$ ) na presença dos interferentes investigados.

Figura 23 - Cromatograma obtido a partir da análise da solução padrão de EFV $(20,0 \mu \mathrm{g} / \mathrm{mL})$ utilizando como diluente a fase móvel.

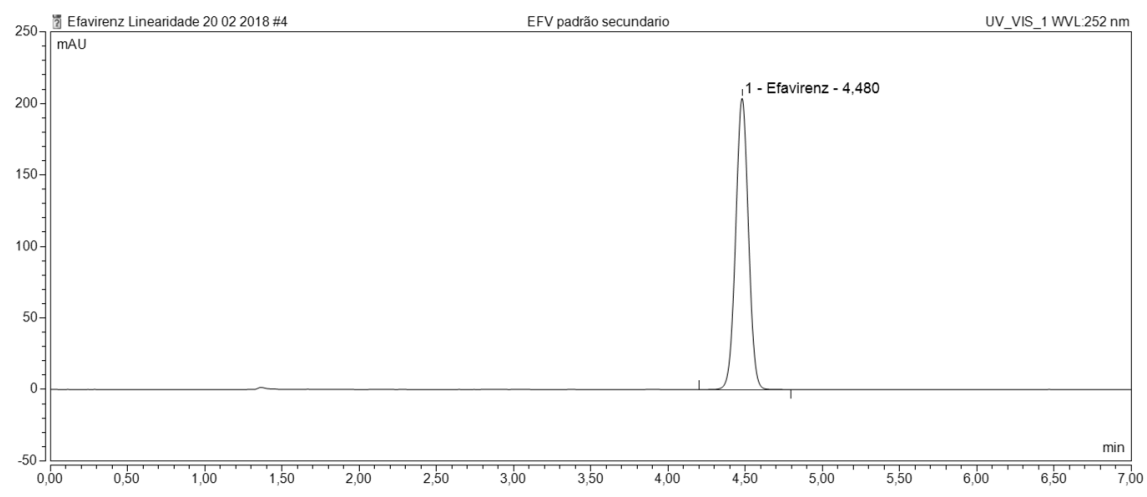

Fonte: Elaborado pelo autor. 
Figura 24 - Cromatogramas obtidos a partir das análises das amostras obtidas para avaliação da especificidade, designados conforme descrito a seguir: $\mathrm{A}$ - branco (tampão $\mathrm{HCl}$ pH 1.2); B - EFV $(10,0 \mu \mathrm{g} / \mathrm{mL}$ ) em diluente tampão $\mathrm{HCl} \mathrm{pH} 1.2(\mathrm{~B})$; $\mathrm{C}-$ branco (tampão acetato pH 4.5) e $\mathrm{D}-\mathrm{EFV}(10,0 \mu \mathrm{g} / \mathrm{mL})$ em diluente tampão acetato $\mathrm{pH} 4.5$.
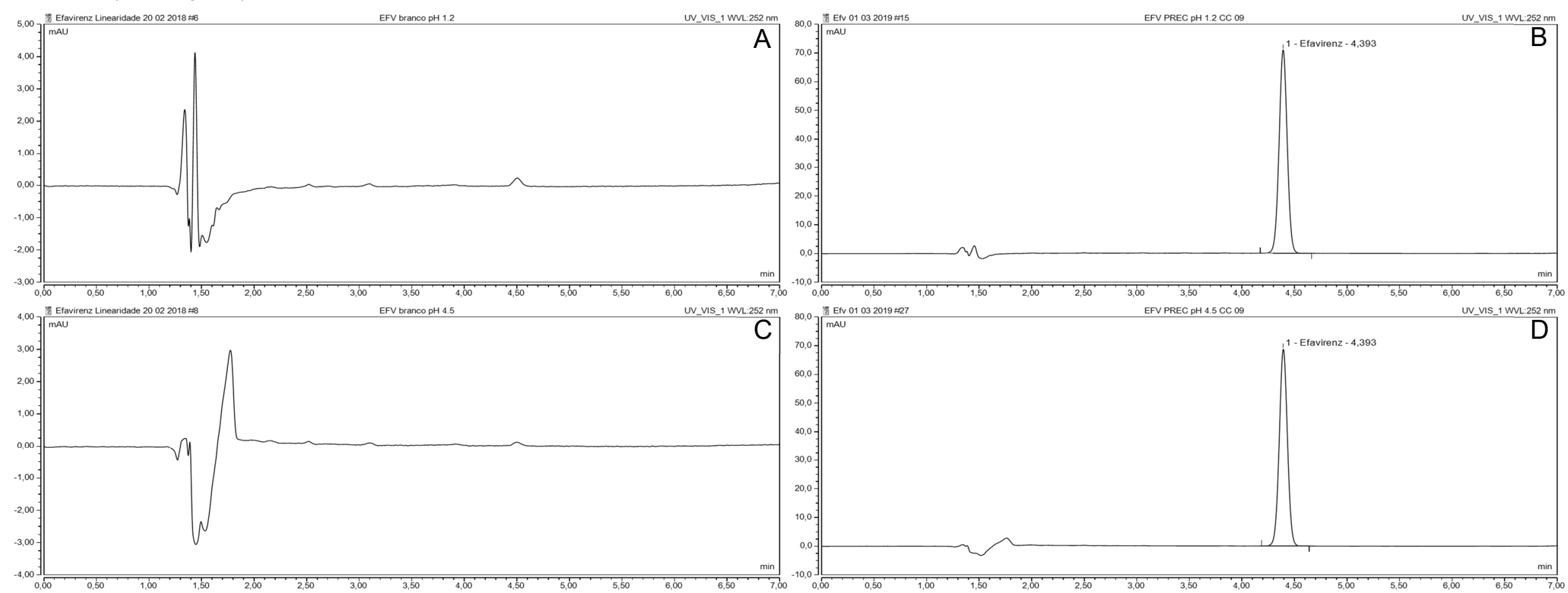

Fonte: Elaborado pelo autor. 
Figura 25 - Cromatogramas obtidos a partir das análises das amostras obtidas para avaliação da especificidade, designados conforme descrito a seguir: A - branco (tampão fosfato $\mathrm{pH} 6.8)$; B - EFV $(10,0 \mu \mathrm{g} / \mathrm{mL})$ em diluente tampão fosfato $\mathrm{pH} 6.8 ; \mathrm{C}-$ carreador PVP K-28/32 $(20,0 \mu \mathrm{g} / \mathrm{mL})$ em água ultrapurificada e D - mistura do EFV $(20,0 \mu \mathrm{g} / \mathrm{mL})$, diluído na fase móvel, e carreador PVP K-28/32 (20,0 $\mu \mathrm{g} / \mathrm{mL})$ utilizando como diluente água ultrapurificada.

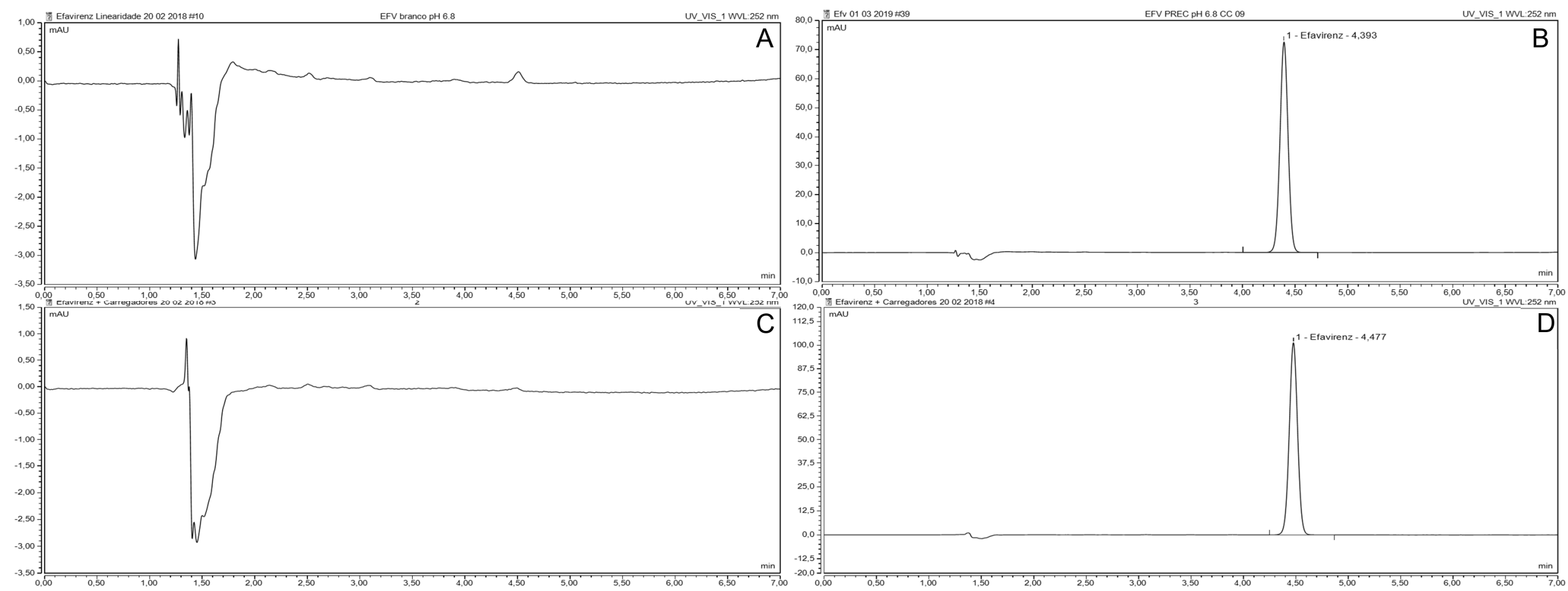

Fonte: Elaborado pelo autor. 
Figura 26 - Cromatogramas obtidos a partir das análises das amostras obtidas para avaliação da especificidade, designados conforme descrito a seguir: A - carreador CoPVP $(20,0 \mu \mathrm{g} / \mathrm{mL})$ em água ultrapurificada; $B$ - mistura do EFV $(20,0 \mu \mathrm{g} / \mathrm{mL})$, diluído na fase móvel, e carreador CoPVP $(20,0 \mu \mathrm{g} / \mathrm{mL})$ utilizando como diluente água ultrapurificada; C - carreador P188 ( (20,0 $\mu \mathrm{g} / \mathrm{mL})$ em água ultrapurificada; D - mistura do EFV (20,0 $\mu \mathrm{g} / \mathrm{mL})$, diluído na fase móvel, e carreador P188 $(20,0 \mu \mathrm{g} / \mathrm{mL})$ utilizando como diluente água ultrapurificada.

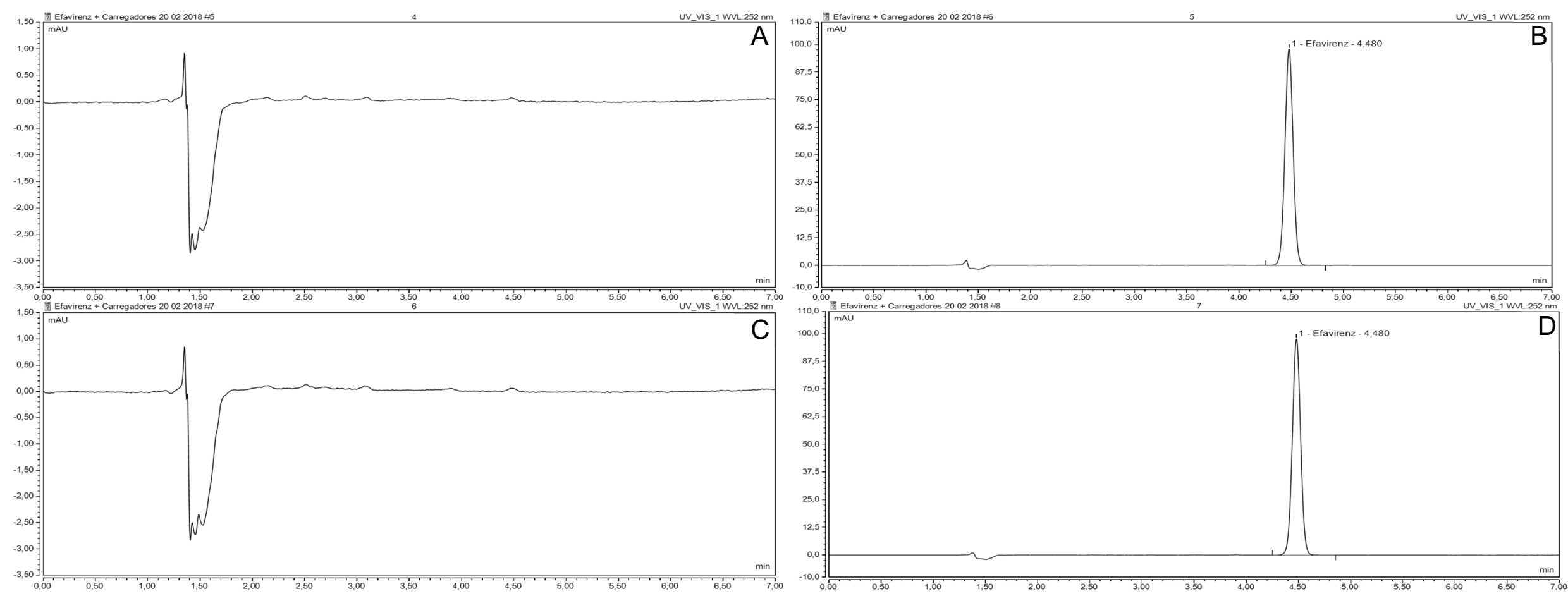

Fonte: Elaborado pelo autor. 
Figura 27 - Cromatogramas obtidos a partir das análises das amostras obtidas para avaliação da especificidade, designados conforme descrito a seguir: A - carreador P407 $(20,0 \mu \mathrm{g} / \mathrm{mL})$ em água ultrapurificada; $B$ - mistura do EFV $(20,0 \mu \mathrm{g} / \mathrm{mL})$, diluído na fase móvel, e carreador P407 $(20,0 \mu \mathrm{g} / \mathrm{mL})$ utilizando como diluente água ultrapurificada; C - carreador HPMCP-50 ( $(20,0 \mu \mathrm{g} / \mathrm{mL})$ em metanol; D - mistura do EFV (20,0 $\mu \mathrm{g} / \mathrm{mL})$, diluído na fase móvel, e carreador HPMCP-50 $(20,0 \mu \mathrm{g} / \mathrm{mL})$ utilizando como diluente metanol.
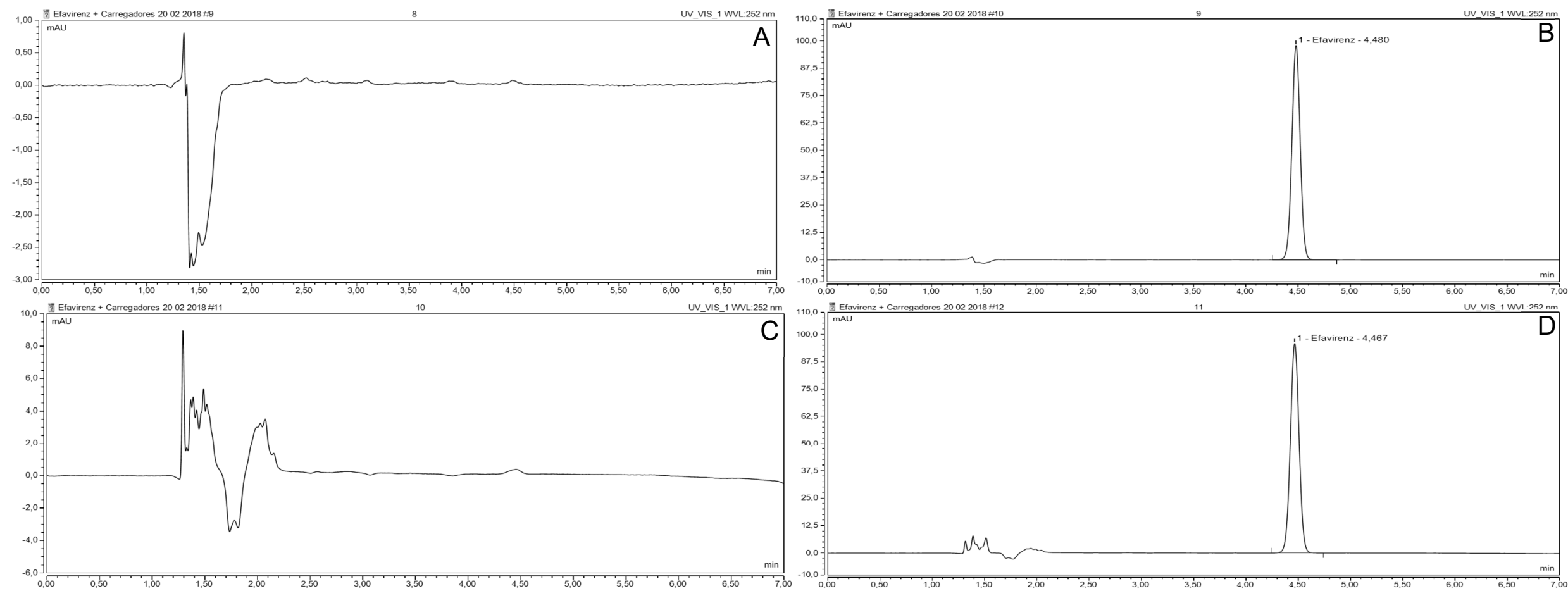

Fonte: Elaborado pelo autor. 
Figura 28 - Cromatogramas obtidos a partir das análises das amostras obtidas para avaliação da especificidade, designados conforme descrito a seguir: A - carreador HPMCP-55 $(20,0 \mu \mathrm{g} / \mathrm{mL})$ em metanol; B - mistura do EFV $(20,0 \mu \mathrm{g} / \mathrm{mL})$, diluído na fase móvel, e carreador HPMCP-55 $(20,0 \mu \mathrm{g} / \mathrm{mL})$ utilizando como diluente metanol; C - carreador HPMCP-55s (20,0 $\mu \mathrm{g} / \mathrm{mL})$ em metanol; D - mistura do EFV $(20,0 \mu \mathrm{g} / \mathrm{mL})$, diluído na fase móvel, e carreador HPMCP-55s $(20,0 \mu \mathrm{g} / \mathrm{mL})$ utilizando como diluente metanol.

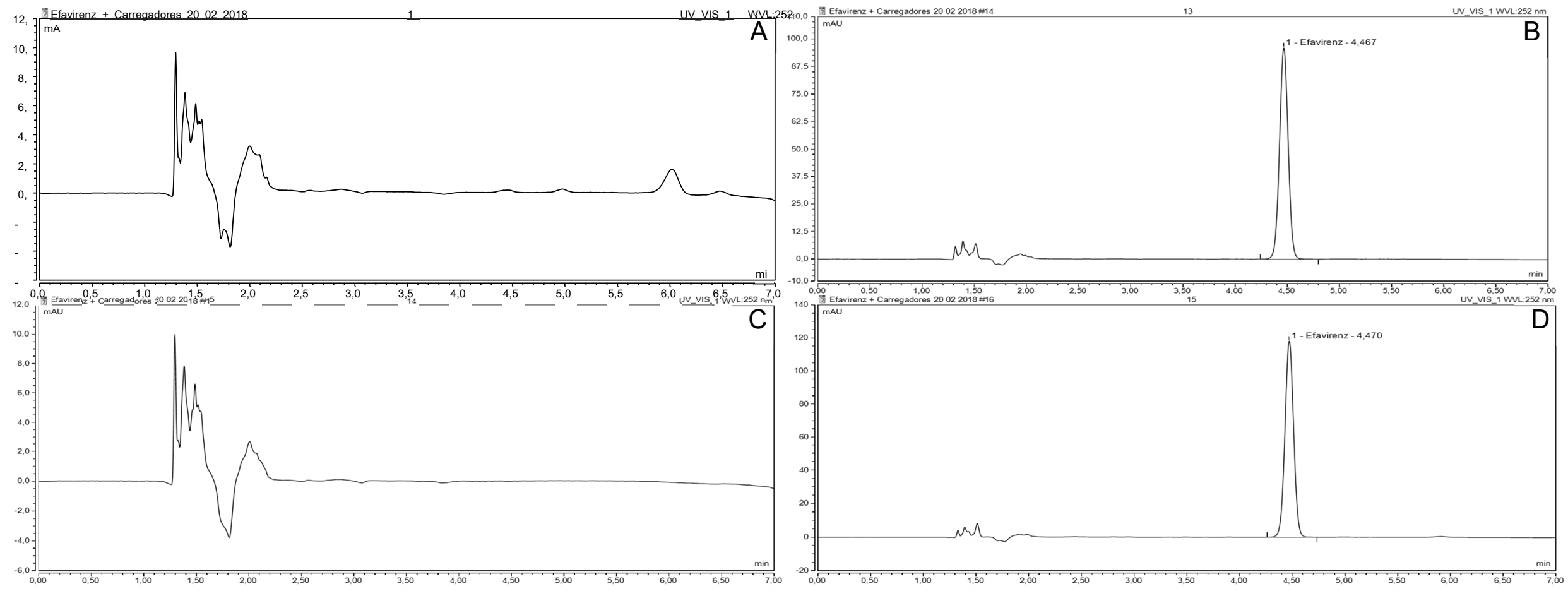

Fonte: Elaborado pelo autor. 


\subsubsection{Linearidade}

Para a determinação da linearidade, a análise por CLAE permitiu a detecção do EFV no comprimento de onda de $252 \mathrm{~nm}$. A faixa de concentração considerada foi de 0,25 a 10,0 $\mathrm{\mu g} / \mathrm{mL}$, conforme apresentado no Quadro 8. As curvas de linearidade, para cada solução tampão com distintos valores de pH's (1,2, 4,5 e 6,8), foram obtidas por meio de regressão linear. Estas relacionam as concentrações das soluções padrão contendo EFV (abcissa) com as áreas dos picos obtidos por meio dos cromatogramas (Figuras 29, 30 e 31). Conforme pode ser observado, o método demonstrou ser linear nos três meios com pH's distintos (1,2, 4,5 e 6,8), com coeficiente de determinação superior a 0,99 ( $R^{2} \geq$ a 0,99$)$.

Figura 29 - Curva analítica do método cromatográfico para análise do EFV obtida no tampão $\mathrm{HCl} \mathrm{pH} \mathrm{1,2.}$

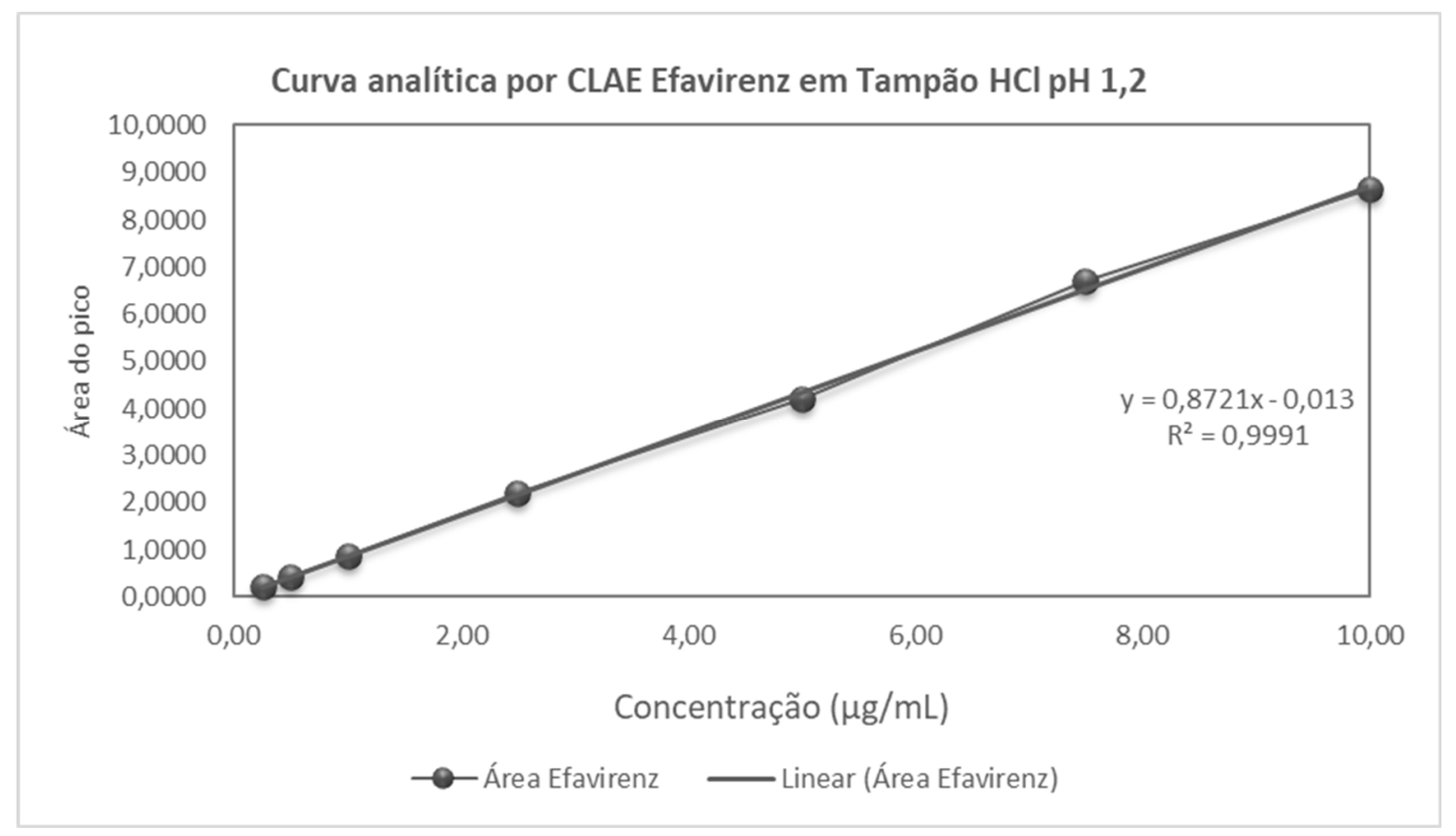

Fonte: Elaborado pelo autor. 
Figura 30 - Curva analítica do método cromatográfico para análise do EFV obtida no tampão acetato $\mathrm{pH} 4,5$.

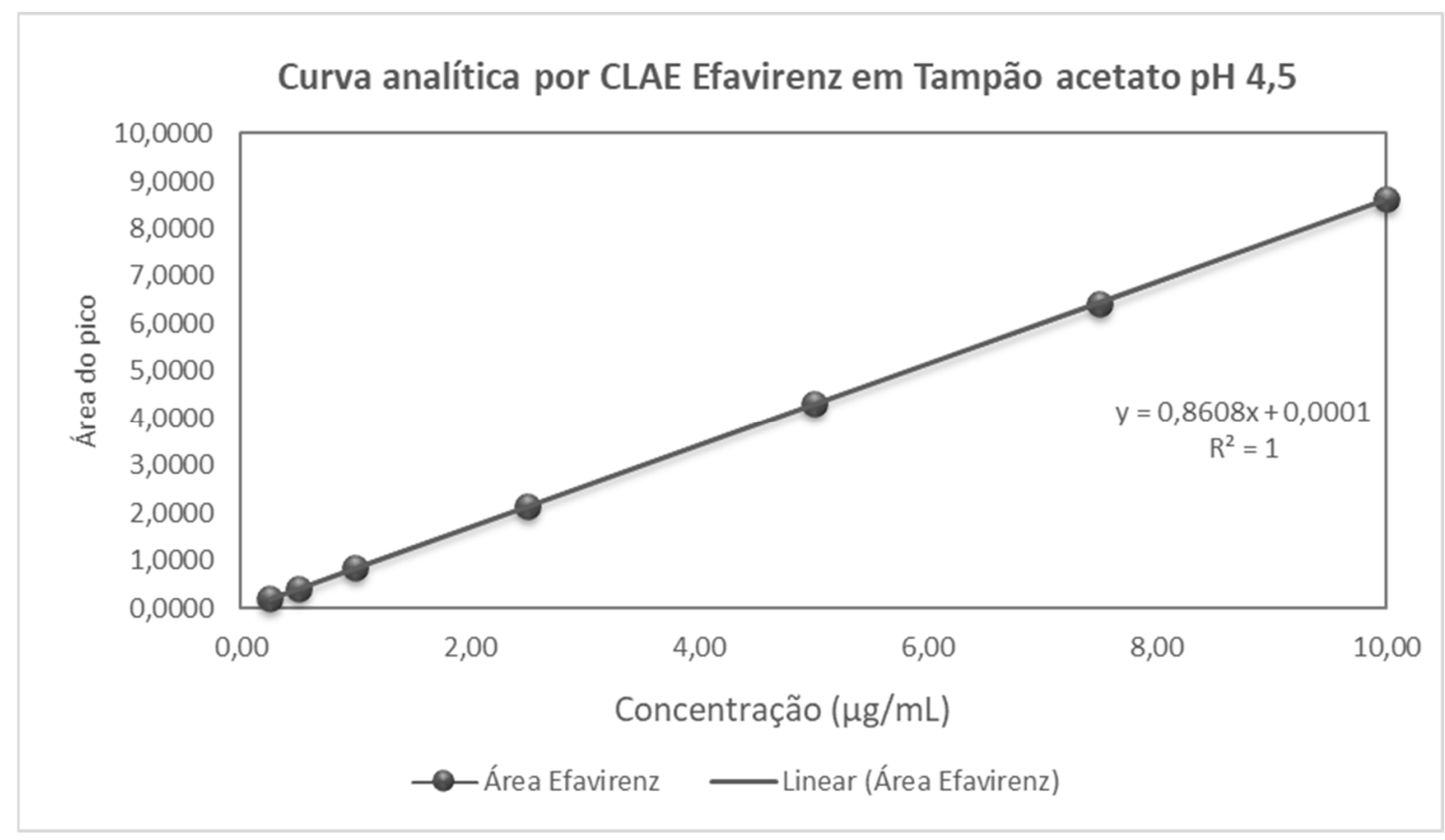

Fonte: Elaborado pelo autor.

Figura 31 - Curva analítica do método cromatográfico para análise do EFV obtida no tampão fosfato $\mathrm{pH} 6,8$.

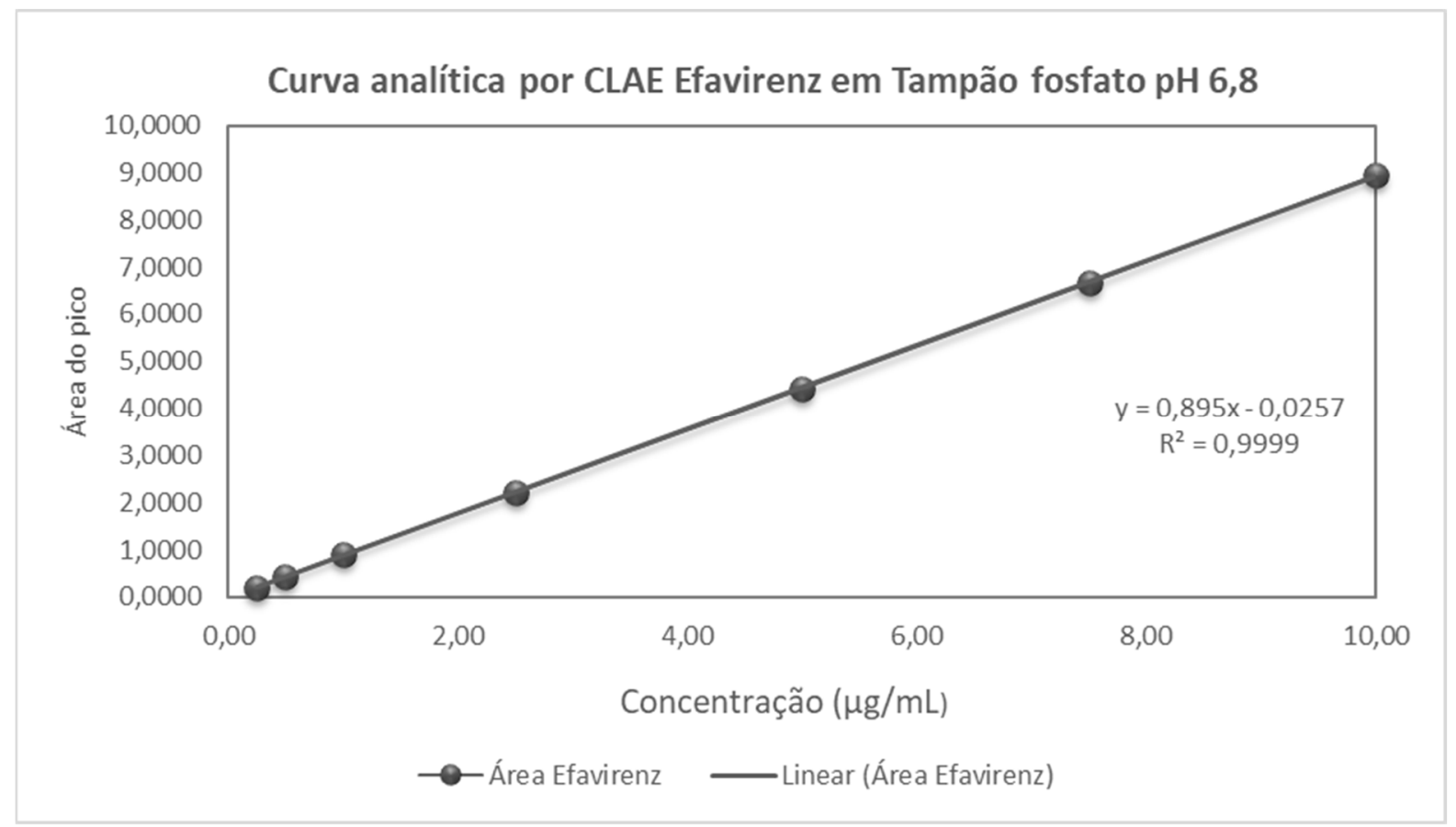

Fonte: Elaborado pelo autor. 


\subsubsection{Precisão}

As Tabelas 1, 2 e 3 apresentam os resultados obtidos para repetibilidade (mesmo dia) e precisão intermediária (dias consecutivos) do método desenvolvido, conforme descrito no item 4.2.1.6. Os resultados obtidos indicam que os valores de porcentagem (\%) do desvio padrão relativo (DPR), para a razão das áreas dos picos, foram inferiores a 5\%, nas três concentrações em distintas soluções tampão. Portanto as injeções das concentrações trabalhadas no mesmo dia e em dias consecutivos foram consideradas satisfatórias, segundo os critérios de aceitação (ICH, 2005).

Tabela 1 - Precisão (repetibilidade e precisão intermediária) do método analítico para a determinação de EFV em tampão $\mathrm{HCl}$ pH 1,2

\begin{tabular}{ccccc}
\hline \hline \multirow{2}{*}{$\begin{array}{c}\text { Concentração teórica } \\
(\boldsymbol{\mu g} / \mathbf{m L})\end{array}$} & \multicolumn{3}{c}{ Precisão DPR (\%) } & \multirow{2}{*}{ Precisão intermediária } \\
\cline { 2 - 4 } & Triplicata 1 & Triplicata 2 & Triplicata 3 & \\
\hline $\mathbf{0 , 5 0}$ & 1,69 & 1,73 & 1,74 & 1,18 \\
$\mathbf{2 , 5 0}$ & 1,38 & 0,21 & 0,98 & 0,50 \\
$\mathbf{7 , 5 0}$ & 2,08 & 2,63 & 1,12 & 1,55 \\
\hline \hline
\end{tabular}

Fonte: Elaborado pelo autor.

Tabela 2 - Precisão (repetibilidade e precisão intermediária) do método analítico para a determinação de EFV em tampão acetato pH 4,5

\begin{tabular}{ccccc}
\hline \hline \multirow{2}{*}{$\begin{array}{c}\text { Concentração teórica } \\
(\boldsymbol{\mu g} / \mathbf{m L})\end{array}$} & \multicolumn{3}{c}{ Precisão DPR (\%) } & \multirow{2}{*}{ Precisão intermediária } \\
\cline { 2 - 4 } & Triplicata 1 & Triplicatidade 2 & Triplicata 3 & \\
\hline $\mathbf{0 , 5 0}$ & 4,07 & 3,40 & 3,55 & 2,63 \\
$\mathbf{2 , 5 0}$ & 0,33 & 2,15 & 1,69 & 3,47 \\
$\mathbf{7 , 5 0}$ & 2,52 & 2,00 & 1,16 & 1,88 \\
\hline \hline
\end{tabular}

Fonte: Elaborado pelo autor.

Tabela 3 - Precisão (repetibilidade e precisão intermediária) do método analítico para a determinação de EFV em tampão fosfato pH 6,8

\begin{tabular}{ccccc}
\hline \hline \multirow{2}{*}{$\begin{array}{c}\text { Concentração teórica } \\
(\boldsymbol{\mu g} / \mathbf{m L})\end{array}$} & \multicolumn{3}{c}{ Precisão DPR (\%) } & \multirow{2}{*}{ Precisão intermediária } \\
\cline { 2 - 4 } & Triplicata 1 & Triplicatia 2 & Triplicata 3 & \\
\hline $\mathbf{0 , 5 0}$ & 2,65 & 4,95 & 3,91 & 4,65 \\
$\mathbf{2 , 5 0}$ & 0,58 & 2,55 & 0,80 & 3,56 \\
$\mathbf{7 , 5 0}$ & 2,58 & 1,99 & 2,37 & 2,83 \\
\hline \hline
\end{tabular}

Fonte: Elaborado pelo autor. 


\subsubsection{Exatidão}

As Tabelas 4, 5 e 6 apresentam os resultados obtidos para a exatidão do método cromatográfico, determinado por meio do ensaio de recuperação, em três níveis de concentrações diferentes, em distintos valores de pH's, conforme descrito no item 4.2.1.7. A recuperação encontrada para o EFV nas três soluções tampão variaram entre $99,52 \%$ a $103,34 \%$ indicando assim, uma boa concordância entre as quantidades adicionadas de solução padrão e as quantidades recuperadas $(\mathrm{ICH}$, 2005).

Tabela 4 - Exatidão do método analítico para a determinação de EFV em tampão $\mathrm{HCl}$ pH 1,2

\begin{tabular}{ccc}
\hline \hline $\begin{array}{c}\text { Concentração teórica } \\
(\boldsymbol{\mu g} / \mathrm{mL})\end{array}$ & $\begin{array}{c}\text { Concentração média experimental } \\
(\boldsymbol{\mu g} / \mathrm{mL})^{*}\end{array}$ & $\begin{array}{c}\text { Exatidão } \\
(\%)^{*}\end{array}$ \\
\hline $\mathbf{0 , 5 0}$ & 0,51 & 101,14 \\
$\mathbf{2 , 5 0}$ & 2,54 & 101,73 \\
$\mathbf{7 , 5 0}$ & 7,70 & 102,73 \\
\hline \hline
\end{tabular}

*Média de três determinações

Fonte: Elaborado pelo autor.

Tabela 5 - Exatidão do método analítico para a determinação de EFV em tampão acetato pH 4,5

\begin{tabular}{ccc}
\hline \hline $\begin{array}{c}\text { Concentração teórica } \\
(\boldsymbol{\mu g} / \mathrm{mL})\end{array}$ & $\begin{array}{c}\text { Concentração média experimental } \\
(\boldsymbol{\mu g} / \mathbf{m L})^{*}\end{array}$ & $\begin{array}{c}\text { Exatidão } \\
(\%)^{*}\end{array}$ \\
\hline $\mathbf{0 , 5 0}$ & 0,50 & 100,29 \\
$\mathbf{2 , 5 0}$ & 2,53 & 101,08 \\
$\mathbf{7 , 5 0}$ & 7,46 & 99,52 \\
\hline \hline
\end{tabular}

*Média de três determinações

Fonte: Elaborado pelo autor.

Tabela 6 - Exatidão do método analítico para a determinação de EFV em tampão fosfato $\mathrm{pH}$ 6,8

\begin{tabular}{ccc}
\hline \hline $\begin{array}{c}\text { Concentração teórica } \\
(\boldsymbol{\mu} \mathbf{g} / \mathrm{mL})\end{array}$ & $\begin{array}{c}\text { Concentração média experimental } \\
(\boldsymbol{\mu g} / \mathbf{m L})^{*}\end{array}$ & $\begin{array}{c}\text { Exatidão } \\
(\%)^{*}\end{array}$ \\
\hline $\mathbf{0 , 5 0}$ & 0,52 & 103,34 \\
$\mathbf{2 , 5 0}$ & 2,49 & 99,78 \\
$\mathbf{7 , 5 0}$ & 7,49 & 99,85 \\
\hline \hline
\end{tabular}

*Média de três determinações

Fonte: Elaborado pelo autor. 


\subsubsection{Limite de detecção e limite de quantificação}

A determinação dos limites de detecção e de quantificação seguiu a descrição do item 4.2.1.8. Os valores dos limites de detecção e limites de quantificação obtidos a partir das análises, considerando as três soluções tampão utilizadas $(\mathrm{pH} 1,2 ; 4,5 \mathrm{e}$ $6,8)$ encontram-se descritos na Tabela 7.

Tabela 7 - Limites de deteç̧ão e de quantificação para as três soluções tampão utilizados no experimento

\begin{tabular}{ccc}
\hline \hline Tampão & $\begin{array}{c}\text { Limite de Detecção } \\
(\mu \mathrm{g} / \mathrm{mL})\end{array}$ & $\begin{array}{c}\text { Limite de Quantificação } \\
(\boldsymbol{\mu g} / \mathbf{m L})\end{array}$ \\
\hline HCI 1,2 & 0,23 & 0,71 \\
Acetato 4,5 & 0,04 & 0,11 \\
Fosfato 6,8 & 0,06 & 0,18 \\
\hline \hline
\end{tabular}

Fonte: Elaborado pelo autor.

\subsection{Desenvolvimento das formulações de dispersões sólidas de efavirenz por evaporação do solvente e avaliação da solubilidade}

\subsubsection{Seleção racional miniaturizada de solventes e carreadores}

Esta etapa foi realizada em lâminas de vidro, com o objetivo de selecionar tanto solventes, quanto carreadores apropriados, para a obtenção de DS, assegurando assim, não somente, a solubilização da mistura fármaco e carreador, mas também a capacidade deste sistema em proporcionar a estabilização do fármaco na forma amorfa, sem que o composto ativo apresente recristalização. Para tanto, empregouse um sistema miniaturizado. As amostras obtidas nesta etapa foram analisadas por DRXP, conforme descrito no item 4.2.4.3.

Dessa forma, foram considerados nos experimentos apenas os solventes das classes II e III, segundo as normas de solventes residuais do ICH (2016), visando um menor risco de toxicidade tanto para o paciente, quanto para o ambiente (DAVIS et al., 2016).

Para este estudo foram incluídos como solventes, o metanol, acetona e etanol, empregados na forma de mistura, nas seguintes proporções: acetona - metanol (30:7) e acetona - etanol (1:1) ambas (v/v). Já para a seleção dos carreadores, foram 
elencados: PVP K-28/32, CoPVP, HPMCP-50, HPMCP-55, HPMCP-55s, P188 e P407. As amostras foram preparadas conforme descrição do item 4.2.2.1.

Conforme resultados obtidos por DRXP, apresentados na Tabela 8, pode-se determinar quais carreadores foram capazes de estabilizar o EFV na forma amorfa, após a conclusão do estudo de estabilidade.

Os difratogramas de raios $X$ obtidos estão ilustrados nas Figuras 32 e 33. O estudo foi conduzido comparativamente com os difratogramas das matérias-primas nas formas puras (Figura 32), e com os difratogramas das amostras do EFV amorfo e das formulações binárias (Figura 33).

Contudo, também foram realizadas comparações entre os difratogramas, obtidos em dois tempos distintos do estudo de estabilidade, conforme descrito no item 4.2.2.1. Os resultados de DRXP das lâminas de vidro contendo as formulações adquiridas no dia do preparo, foram designados de tempo 1 (T1), e denominados de tempo 2 (T2), após 30 dias do preparo. Os difratogramas do T1 não foram apresentados nas formas de figuras, com exceção do EFV amorfo que está ilustrado na Figura 33. Os resultados das matérias-primas, T1e T2 podem ser evidenciados na Tabela 8.

A Figura 32 apresenta os difratogramas da amostra designada como "padrão" do EFV puro, da lâmina de vidro virgem, e dos carreadores nas formas pura (PVP K28/32, CoPVP, HPMCP-50, HPMCP-55, HPMCP-55s, P188 e P407). Os difratogramas das lâminas de vidro virgem e daquelas com os carreadores poliméricos (PVP K-28/32, CoPVP, HPMCP-50, HPMCP-55 e HPMCP-55s) apresentaram um padrão de difração amorfo característico, exibindo um halo na faixa de $2 \theta$ nos espectros de DRXP (Figura 32). Já o EFV puro apresentou picos de difração característicos, próximos de $5^{\circ}, 10^{\circ}, 15^{\circ}, 20^{\circ}$ e $25^{\circ}(2 \theta)$. As posições desses picos foram comparadas com as descritas em estudos realizados por Mahapatra et al. (2010) e Fandaruff et al. (2014), onde constatou-se que correspondem a forma polimórfica I do EFV em sua condição pura (FANDARUFF et al., 2014a; MAHAPATRA et al., 2010).

Em relação aos carreadores, poloxâmeros 188 e 407, quando analisados na forma pura, apresentaram difratogramas com picos cristalinos entre $15^{\circ}$ e $25^{\circ}(2 \theta)$ (Figura 32), semelhantes aos descritos no estudo de Medarevic et al. (2016). 
A Figura 33 apresenta os resultados dos difratogramas do EFV amorfo (solubilizado em acetona - metanol (30:7)), nos tempos 1 e 2. Conforme dados de DRXP obtidos durante o T1, pôde-se confirmar a capacidade do processo de evaporação utilizando essa mistura de solventes em amorfizar o EFV. Moura Ramos et al. (2019) descrevem que o EFV possui uma alta capacidade de formação vítrea (isto é, de se amorfizar) a partir do arrefecimento após a fusão. Essa capacidade é atribuída em função a elevada rigidez da molécula, da baixa temperatura de transição vítrea $\left(T_{g}\right)$ e da entropia de fusão reduzida (MOURA RAMOS et al., 2019). Essa capacidade também foi constatada após os processos de evaporação, uma vez que a maioria das misturas e o fármaco puro se mantiveram amorfos em T1. Entretanto, após o estudo de estabilidade acelerada, o antirretroviral puro apresentou recristalização em T2 (30 dias após).

Provavelmente, a baixa estabilidade do EFV amorfo (puro) se deu pela baixa temperatura de $T_{g}$ e pela falta de um agente estabilizante (carreador), capaz de interagir com o fármaco e estabilizá-lo por meio de ligações intermoleculares como, por exemplo, ligações de hidrogênio. O processo de cristalização envolve dois eventos, nucleação para formar um cristal embrionário, seguido do crescimento desse cristal. A inibição da nucleação requer redução da mobilidade molecular e interações dos carreadores com grupos funcionais específicos dos fármacos. Essa redução de mobilidade ocorre ao se utilizar um excipiente amorfo com altos valores de temperatura de $T_{g}$ e miscibilidade suficiente entre o fármaco e o excipiente (carreador) utilizado. Assim, ao reduzir a mobilidade molecular da substância ativa, tem-se como consequência o aumento da estabilidade física da substância amorfa. Outro fator que pode contribui para a recristalização dos compostos amorfos é o armazenamento destes em locais sem a devida diferença de menos $50{ }^{\circ} \mathrm{C}$ entre a temperatura do local de armazenamento e a temperatura de $\mathrm{T}_{\mathrm{g}}$ da substância amorfa (HANCOCK; SHAMBLIN; ZOGRAFI, 1995; KONNO; TAYLOR, 2008; NEWMAN, 2015).

O valor da temperatura de $T_{g}$ para o EFV descrito nos estudos de Sathigari et al. (2012) foi de $33^{\circ} \mathrm{C}$. Os resultados do estudo de Hancock et al. (1995), corroboram com o baixo valor de $\mathrm{T}_{\mathrm{g}}$ do $\mathrm{EFV}$, onde segundo os autores, para uma substância se manter no estado amorfo, seria necessário um armazenamento sob temperatura com $50{ }^{\circ} \mathrm{C}$ inferior a temperatura de $\mathrm{T}_{\mathrm{g}}$ da substância amorfa. Por exemplo: o EFV possui 
temperatura de $\mathrm{T}_{\mathrm{g}}$ de $33{ }^{\circ} \mathrm{C}$ e foi armazenado durante o estudo de estabilidade sob temperatura de $40{ }^{\circ} \mathrm{C}$, assim, para que o EFV possa permanecer estável na forma amorfa, o armazenamento do mesmo deveria ser sob temperatura de $-17{ }^{\circ} \mathrm{C}$ (HANCOCK; SHAMBLIN; ZOGRAFI, 1995; NEWMAN, 2015; SATHIGARI et al., 2012).

Na avaliação comparativa dos difratogramas de EFV (Figura 33) observa-se o fármaco em estado amorfo (T1) e recristalizado (T2). A forma recristalizada do fármaco foi comparada com o intuito de verificar quais formas polimórficas do EFV foram obtidas no T2. A comparação dos picos do antirretroviral recristalizado (Figura 33) com a sua forma pura (Figura 32) permitiu evidenciar diferenças, visto que, houve um deslocamento e o surgimento de novos picos entre $5^{\circ}$ e $15^{\circ}(2 \theta)$ em T2 (Figura 33).

Após a constatação dessas diferenças, os picos obtidos na análise do fármaco recristalizado foram confrontados novamente com os dados descritos no estudo de Fandaruff et al. (2014), indicando portanto que, provavelmente a forma recristalizada da Figuras 33 pode se tratar do polimorfo I proposto pelo estudo dos autores Mahapatra et al. (2010) (FANDARUFF et al., 2014a; MAHAPATRA et al., 2010).

A Figura 33 apresenta os difratogramas em T2 (30 dias) das formulações de EFV preparadas na proporção de 1:3 de fármaco polímero. Evidenciou-se nos DRXP da Figura 33 a capacidade dos polímeros empregados (PVP K-28/32, CoPVP, HPMCP-50, HPMCP-55 e HPMCP-55s) em estabilizar o EFV na forma amorfa, nos diferentes intervalos de tempos avaliados, T1 e T2. Tal fato foi constatado pela ausência de picos indicando cristalinidade, mesmo após a conclusão do estudo de estabilidade acelerada (30 dias).

Segundo Kono e Taylor (2008) o efeito estabilizador dos polímeros tem sido atribuído ao efeito antiplastificante, pois as DSA típicas possuem temperaturas de $\mathrm{T}_{\mathrm{g}}$ mais elevadas do que a forma amorfa do fármaco puro, sugerindo que uma menor mobilidade molecular pode ser alcançada. Também tem sido proposto que a formação de interações específicas entre fármacos e polímeros, através das ligações de hidrogênio pode contribuir para a estabilização física do composto amorfo (KONNO; TAYLOR, 2008; MATSUMOTO; ZOGRAFI, 1999; NEWMAN et al., 2008). 
Os difratogramas dos sistemas binários da mistura de EFV, e dos copolímeros P188 e P407 obtidos na proporção de 1:3 com o emprego da mistura de solventes acetona - metanol (30:7) estão apresentados na Figura 33. As análises comparativas dos difratogramas com os do EFV puro, e dos poloxâmeros 188 e 407 puro (Figura 32), demonstrou que o método de evaporação do solvente não foi capaz de promover a completa amorfização das preparações, nos dois tempos do estudo de estabilidade (T1 e T2) conforme constatado pela presença de picos indicando cristalinidade (Figura 33).

Os picos cristalinos da Figuras 33 ocorreram entre $15^{\circ}$ e a $25^{\circ}(2 \theta)$ dos difratogramas, esses picos surgiram nas mesmas posições das respectivas formas puras da (Figura 32), conforme evidenciado nos estudos de Medarevic et al. (2016). Entretanto, os picos da mistura binária do P188 apresentaram uma atenuação da intensidade, em comparação com a sua forma pura. Já para a preparação contendo o P407 o primeiro pico apresentou uma intensidade superior, em relação a sua forma pura. (MEDAREVIĆ et al., 2016). Foi também possível observar que esses mesmos compostos foram eficazes em estabilizar o EFV na forma amorfa, visto que, não foram evidenciados nos difratogramas, os mesmos padrões cristalinos do antirretroviral das Figuras 32 e 33 nos dois tempos do estudo de estabilidade.

A Tabela 8 resume os resultados dos DRXP para todas as preparações desenvolvidas e avaliadas até o momento. Os polímeros (PVP K-28/32, CoPVP, HPMCP-50, HPMCP-55 e HPMCP-55s) demonstraram ser efetivos em estabilizar o EFV na forma amorfa, sendo eles classificadas como totalmente amorfo. Todavia, os copolímeros com características de tensoativos (P188 e P407) empregados no preparo das misturas binárias, apesar de, não exibirem estruturas totalmente amorfas nos difratogramas, também demonstraram ser efetivos em estabilizar o fármaco, portanto as misturas com os tensoativos foram classificadas como semicristalina. Assim sendo, prosseguiu-se com todos os carreadores testados, em virtude de que foram capazes de estabilizar o fármaco na forma amorfa. 
Figura 32 - Difratogramas de raios $X$ obtidos pelo método do pó a partir das análises das matérias-primas (EFV e carreadores: PVP K-28/32, CoPVP, HPMCP-50, HPMCP-55, HPMCP-55s, P188 e P407) e da lâmina de vidro virgem.

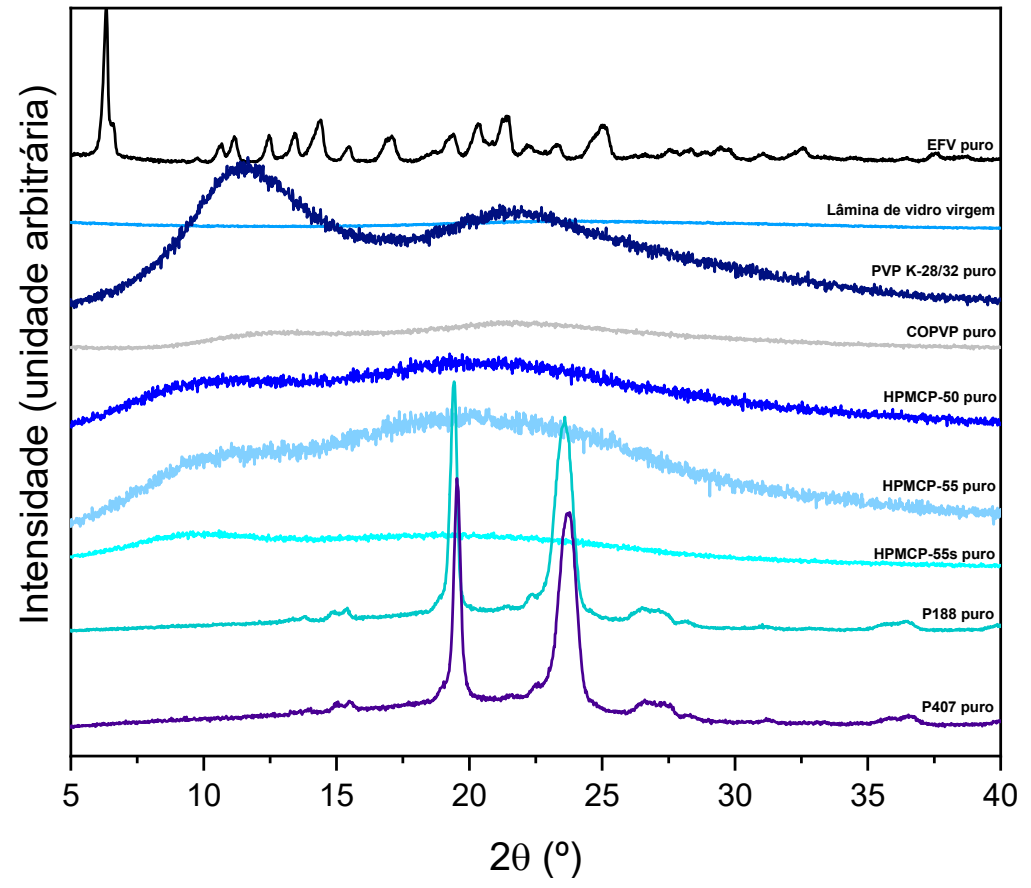

Fonte: Elaborado pelo autor.

Figura 33 - Difratogramas de raios X pelo método do pó do EFV amorfo em T1 e T2 e das misturas binárias com os carreadores obtidos na proporção de 1:3 em T2: DS PVP K-28/32, DS CoPVP, DS HPMCP-50, DS HPMCP-55, DS HPMCP-55s, DS P188 e DS P407.

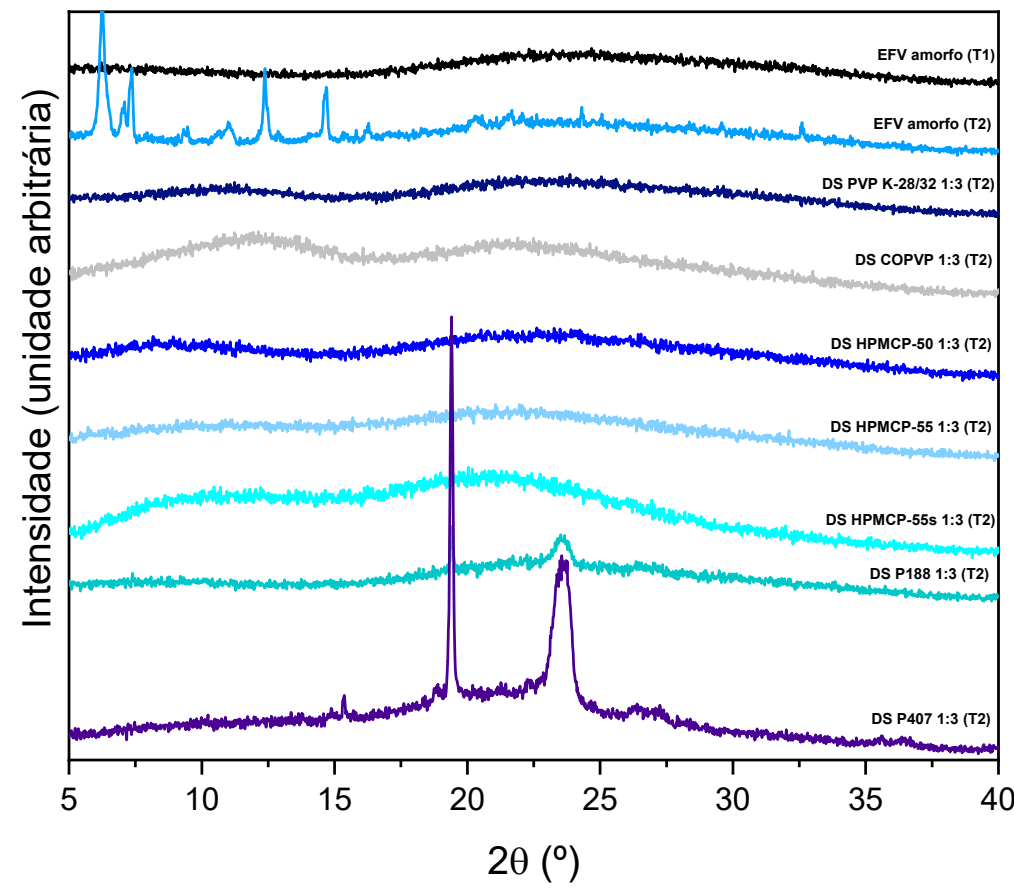

Fonte: Elaborado pelo autor. 
Tabela 8 - Resultados dos difratogramas de raios X das matérias-primas (pura) e do EFV puro amorfizado e das misturas binárias, após o estudo de estabilidade acelerado onde foram classificadas como: totalmente amorfo (AAAA), semicristalino (AACC) e totalmente cristalino (CCCC)

\begin{tabular}{cccc}
\hline \hline Lâminas & Formulações & $\begin{array}{c}\text { T1 } \\
\text { dia do preparo }\end{array}$ & $\begin{array}{c}\text { T2 } \\
\text { trinta dias após o preparo }\end{array}$ \\
\hline A & EFV puro & CCCC & - \\
B & PVP K-28/32 puro & AAAA & - \\
C & CoPVP puro & AAAA & - \\
$\mathbf{D}$ & HPMCP-50 puro & AAAA & - \\
$\mathbf{E}$ & HPMCP-55 puro & AAAA & - \\
$\mathbf{F}$ & HPMCP-55s puro & AAAA & - \\
$\mathbf{G}$ & P188 puro & AACC & - \\
$\mathbf{H}$ & P407 puro & AACC & - \\
$\mathbf{I}$ & EFV amorfo & AAAA & AACC \\
J & DS PVP K-28/32 1:3 & AAAA & AAAA \\
$\mathbf{K}$ & DS CoPVP 1:3 & AAAA & AAAA \\
$\mathbf{L}$ & DS HPMCP-50 1:3 & AAAA & AAAA \\
$\mathbf{M}$ & DS HPMCP-55 1:3 & AAAA & AAAA \\
$\mathbf{N}$ & DS HPMCP-55s 1:3 & AAAA & AAAA \\
$\mathbf{O}$ & DS P188 1:3 & AACC & AACC \\
$\mathbf{P}$ & DS P407 1:3 & AACC & AACC \\
\hline \hline
\end{tabular}

Fonte: Elaborado pelo autor.

A Figura 34 exibe as fotografias das lâminas de vidro contendo o fármaco puro amorfizado e as misturas binárias, as imagens foram obtidas após o estudo de estabilidade acelerado e referem-se às amostras do tempo T2. A lâmina "A" contendo o EFV puro amorfizado sem o auxílio de carregadores, apresentou um processo de recristalização do fármaco durante o estudo de estabilidade, fator esse comprovado pelo difratograma de raios X (Figura 33). A aparência da lâmina A, anteriormente ao estudo de estabilidade, era idêntica aos das lâminas B, C e D, ou seja, sem a presença das manchas brancas e dos cristais evidentes ao lado direito da lâmina.

As lâminas B, C D, E e F contendo os respectivos polímeros PVP, CoPVP, HPMCP-55, HPMCP-55s e HPMCP-50, permaneceram exatamente com o mesmo aspecto de antes de serem submetidas ao estudo de estabilidade acelerado. A única diferença visível foi observada nas lâminas $E$ e $F$ em função da viscosidade dos 
carreadores HPMCP-55s e HPMCP-50, respectivamente. Esses materiais sobressalientes com características plásticas, surgiram imediatamente durante a evaporação do solvente.

As lâminas $\mathrm{G}$ e H, que contêm as misturas binárias com poloxâmeros $188 \mathrm{e}$ 407, respectivamente, exibiram um aspecto de cera, que surgiu após o estudo de estabilidade acelerado em no T2. Essa cera, não era evidenciada no T1, onde foi constatado que não houve impacto na estabilidade do fármaco conforme discutido anteriormente.

Figura 34 - Fotografias das lâminas de vidro contendo o fármaco puro amorfizado e as misturas binárias após a finalização do estudo de estabilidade. A - EFV puro, EFV e carreadores (B - DS PVP K-28/32, C - DS CoPVP, D - DS HPMCP-55, E - DS HPMCP-55s, F - DS HPMCP-50, G - DS P188 e H - DS P407).
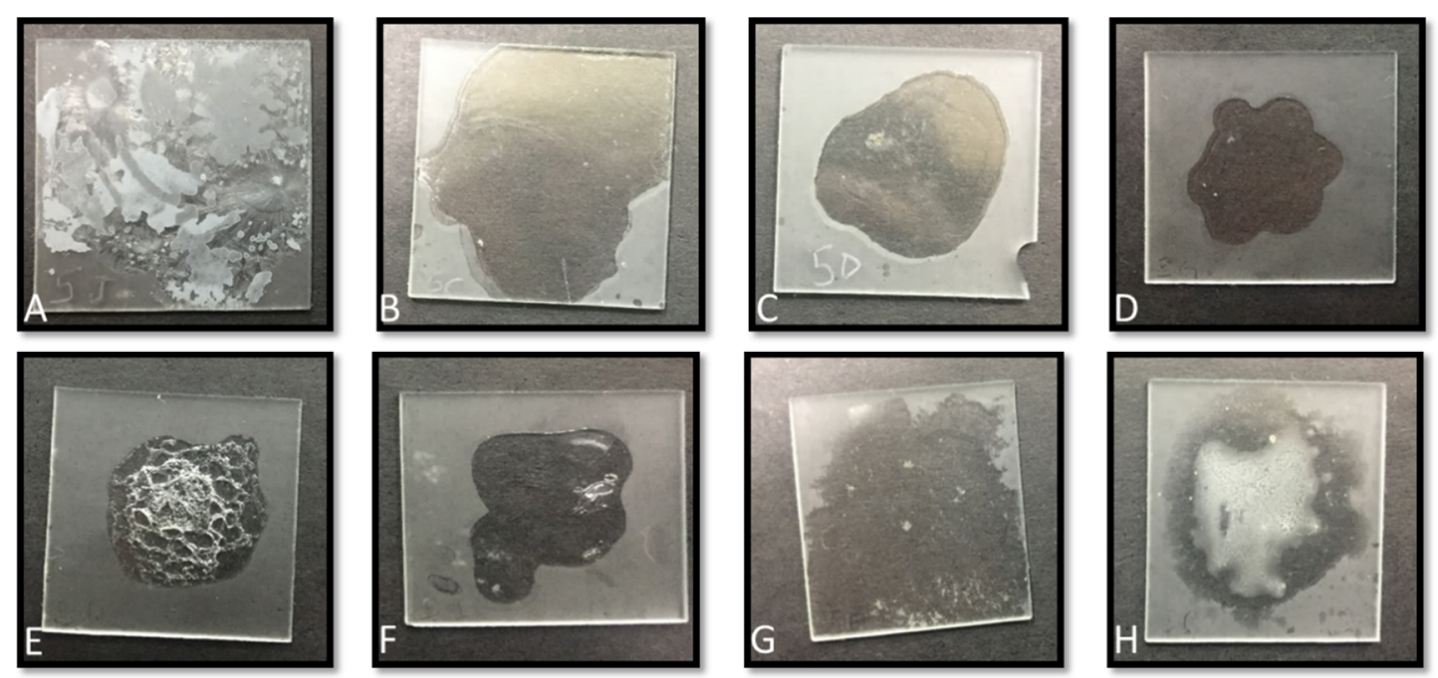

Fonte: Elaborado pelo autor.

\subsubsection{Obtenção em maior escala das formulações de dispersões sólidas de efavirenz}

Conforme descrito anteriormente, todas as formulações foram selecionadas e produzidas de acordo com a descrição do item 4.2.2.2. A Figura 35 apresenta as fotografias das formulações de DS nas proporções de fármaco e carreador 1:3 (A DS PVP K-28/32, B - DS CoPVP, C - DS HPMCP-50, D - DS HPMCP-55, E - DS HPMCP-55s, F - DS P188 e G - DS P407). 
As formulações empregando os carreadores PVP K-28/32 e CoPVP se apresentaram como um pó fino levemente amarelado e inodoro. As preparações contendo os carreadores HPMCP-50, HPMCP-55 e HPMCP-55s (Figura 35) exibiram características de lâminas de plástico inodoro e de coloração quase branco translucido.

As misturas binárias obtidas com o emprego dos carreadores P188 e P407, após submetidas ao resfriamento no congelador sob temperatura de $-20{ }^{\circ} \mathrm{C}$, apresentaram consistência semissólida semelhante a "pomada", de colocação quase branca a levemente amarelada, com característica inodora. Antes do resfriamento as preparações mostraram consistência de líquido viscoso, semelhante a "mel de abelha" (Figura 35). 
Figura 35 - Fotografias das dispersões sólidas nas proporções de fármaco e carreador 1:3 (A - DS PVP K-28/32, B - DS CoPVP, C - DS HPMCP-50, D - DS HPMCP-55, E - DS HPMCP-55s, F - DS P188 e G - DS P407).
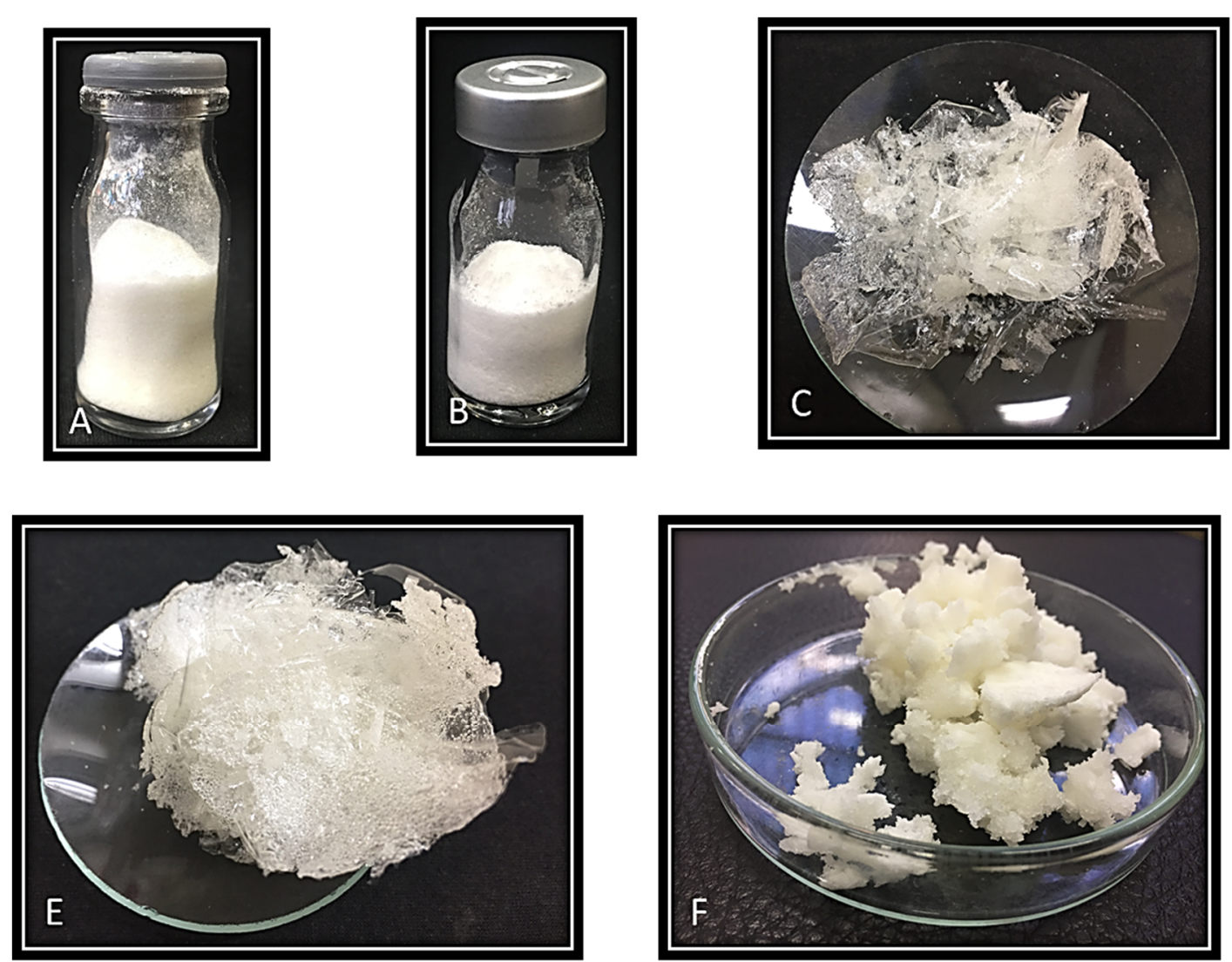

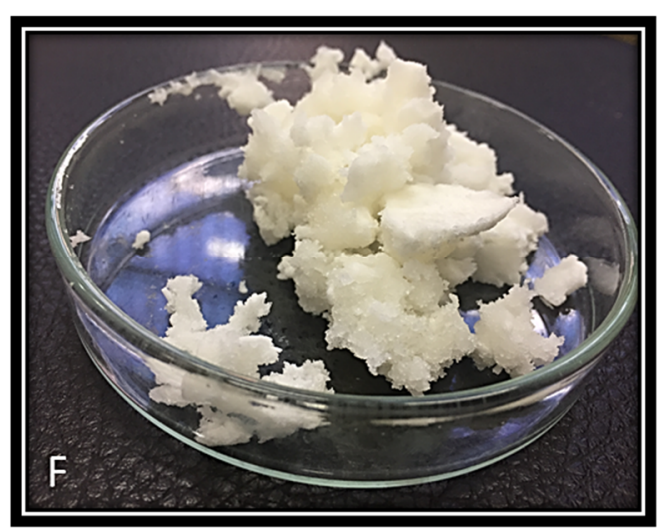

Fonte: Elaborado pelo autor.
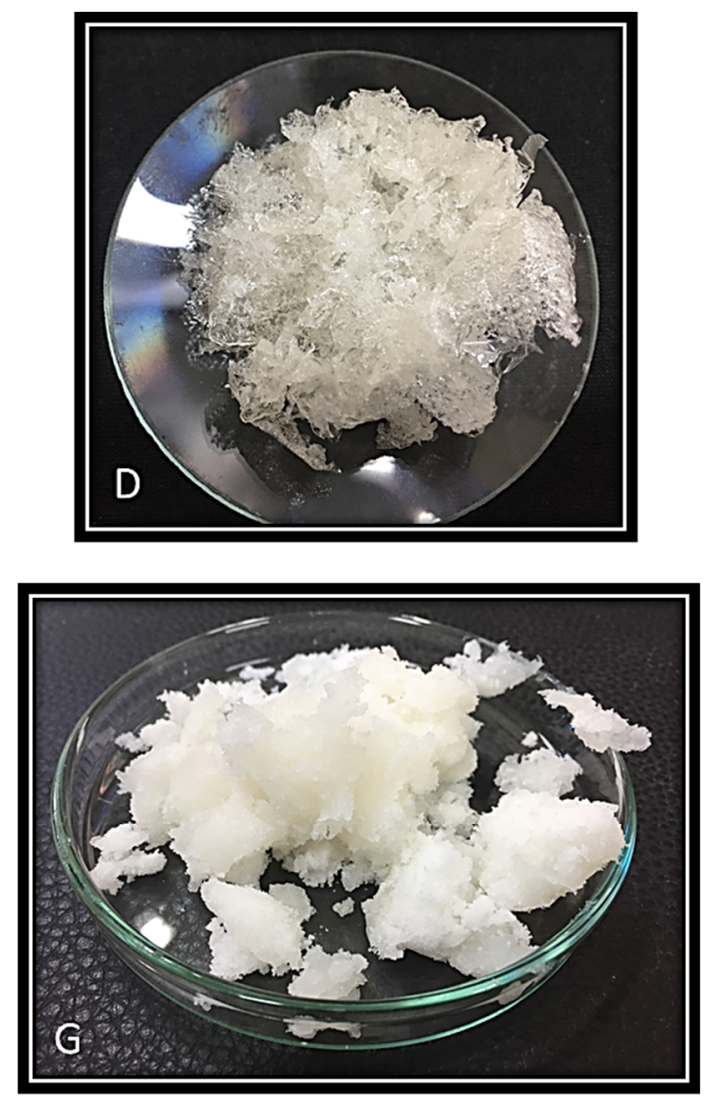
O processo de obtenção das DS pelo método de evaporação do solvente é relativamente longo, pois é necessário o cumprimento de duas etapas (evaporação e secagem) para os carreadores PVP K-28/32, CoPVP, HPMCP-50, HPMCP-55 e HPMCP-55s, e três etapas (evaporação, secagem e resfriamento) para os carreadores P188 e P407. A Figura 36 apresenta os valores de rendimentos das DS amorfas produzidas com o emprego do fármaco EFV com os respectivos polímeros, na proporção de 1:3.

Ao empregar os carreadores PVP K-28/32 e CoPVP, os rendimentos das DS foram de $79 \%$ e $69 \%$ respectivamente. O processo utilizado de evaporação leva aproximadamente 40 minutos no equipamento rotaevaporador, e, posteriormente, mais 12 horas de secagem em estufa. O baixo rendimento das preparações resultou da aderência do produto no fundo do balão empregado para a evaporação do solvente, o que dificultou a remoção do produto na íntegra. Posteriormente as preparações foram pulverizadas e tamisadas reduzindo ainda mais os seus rendimentos.

As formulações obtidas com os polímeros, HPMCP-50, HPMCP-55 e HPMCP55 s tiveram rendimento de $71 \%$, 79\% e 99\%, respectivamente. Essas preparações foram obtidas por evaporação do solvente em placa de Petri empregando chapa de aquecimento, o tempo total de evaporação foi de aproximadamente de 1 hora e mais 12 horas de secagem em estufa. Para realizar a remoção das amostras das placas, as mesmas necessitavam estar devidamente secas e a extração das preparações se deu com o emprego de um bisturi. O rendimento das formulações com o carreador HPMCP-55s foi maior, em consequência de o polímero apresentar maior viscosidade, o que facilitou a secagem do produto e a remoção da placa. As formulações com os outros dois carreadores (HPMCP-50, HPMCP-55) tiveram uma maior aderência na vidraria, resultando assim em um menor rendimento. Não foi possível realizar a tamisação em virtude dessas formulações apresentarem um formato de "lâmina plásticas", um material resistente, o que não favorecia a pulverização com o emprego do grau de vidro.

A produção das formulações com os copolímeros P188 e P407 foi o processo mais longo, pois conforme dito anteriormente é necessário o cumprimento de três etapas (evaporação, secagem e resfriamento em congelador). Os rendimentos para 
ambas as preparações foram de $92 \%$ para o P188 e de $94 \%$ para o P407. Para obtenção destas formulações empregou-se o equipamento rotaevaporador e o tempo total de evaporação foi de aproximadamente $40 \mathrm{~min}$. Posteriormente as amostras foram submetidas a secagem em estufa por aproximadamente 12 horas e subsequentemente os produtos foram destinados ao congelador por 48 horas, sob a temperatura de $-20^{\circ} \mathrm{C}$. O rendimento nesse caso foi relativamente alto, em razão de se tratar de um líquido viscoso, a remoção das preparações do balão de evaporação foi relativamente fácil, pois foi necessário apenas verter a vidraria e aguardar a completa remoção do produto.

Figura 36 - Gráfico do rendimento do processo de produção das DS amorfas de EFV em (\%), nas proporções de fármaco e carreador 1:3 (A - DS PVP K-28/32, B - DS CoPVP, C - DS HPMCP-50, D - DS HPMCP-55, E - DS HPMCP-55s, F - DS P188 e G - DS P407).

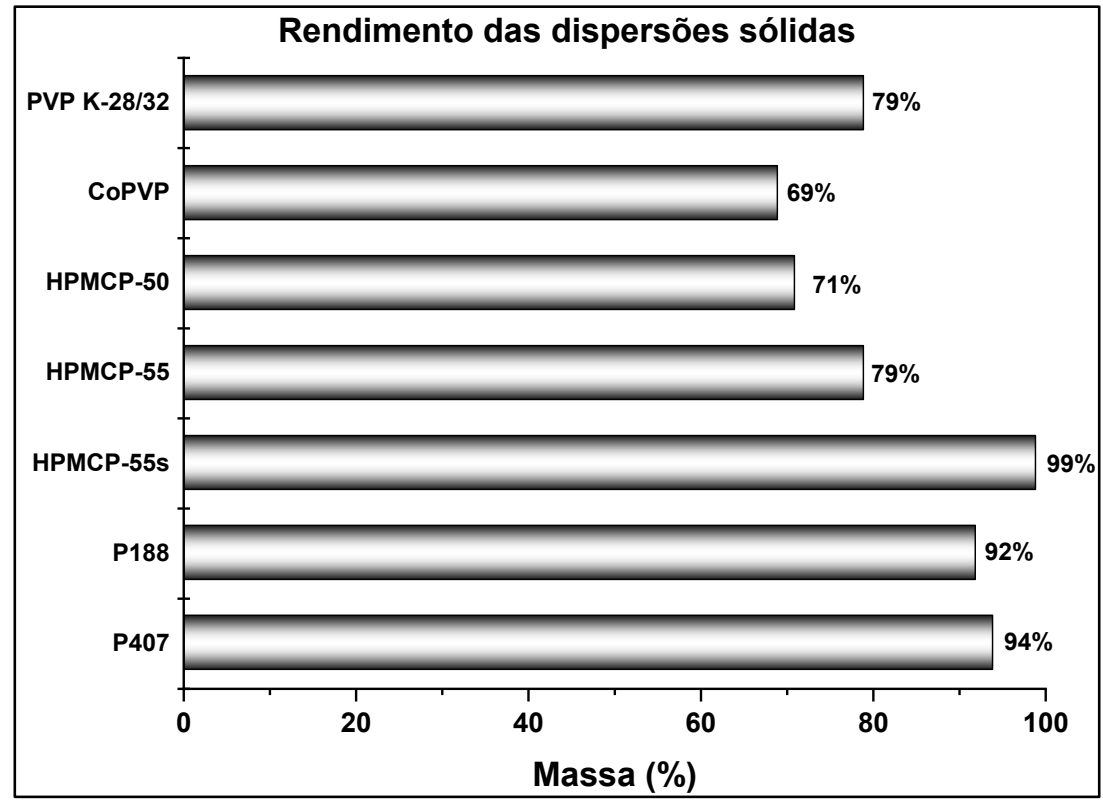

Fonte: Elaborado pelo autor. 


\subsubsection{Determinação da solubilidade pelo método do equilíbrio (shake-flask)}

Os dados do estudo de solubilidade obtidos pelo método do equilíbrio (shakeflask), conforme descrito no item 4.2.2.4, para EFV puro, misturas físicas (MF) e dispersões sólidas (DS) de EFV, em soluções tampão com distintos valores de pHs $(1,2,4,5$ e 6,8$)$ foram analisados utilizando-se a ANOVA dois fatores seguida de Tukey e estão ilustrados na Figura 37 e resumidos nas Tabelas 9 e 10.

Os resultados obtidos referentes a solubilidade para o EFV (puro) foram similares aos valores encontrados na literatura (CRISTOFOLETTI et al., 2013). O EFV é descrito na literatura por apresentar valores de solubilidades em meios aquosos abaixo de $10 \mu \mathrm{g} / \mathrm{mL}$ (COSTA et al., 2019; CRISTOFOLETTI et al., 2013; HOFFMEISTER et al., 2017; MARQUES et al., 2017). Observou-se no presente estudo o comportamento da solubilidade do antirretroviral em meios aquosos com distintos valores de pHs, em tampão $\mathrm{HCl}$ pH 1,2 (9,58 $\pm 0,01 \mu \mathrm{g} / \mathrm{mL})$, em tampão acetato $\mathrm{pH} 4,5(10,08 \pm 0,04 \mu \mathrm{g} / \mathrm{mL})$ e em tampão fosfato $\mathrm{pH} 6,8(9,49 \pm 0,04 \mu \mathrm{g} / \mathrm{mL})$. Constatou-se um ligeiro aumento da concentração em microgramas por mililitro de EFV no tampão acetato, em comparação aos valores obtidos com as demais soluções tampão, contudo, esse valor demonstrou não ser estatisticamente significante (valor$p>0,05)$. A razão dose-solubilidade nas faixas de $\mathrm{pHs}$ avaliadas excedeu em muito os $250 \mathrm{~mL}$, indicando assim, que o EFV não pode ser classificado como "altamente solúvel" de acordo com o SCB (FDA, 2000; CRISTOFOLETTI et al., 2013).

Conforme apresentado na Tabela 9 e 10, as formulações de DS obtidas com os polímeros PVP K-28/32, CoPVP, HPMCP-50, HPMCP-55, HPMCP-55s, P188 e P407 apresentaram dados de solubilidade em todos os meios empregados $(1,2 ; 4,5 \mathrm{e}$ $6,8)$ significativamente superiores aos dados de solubilidade do EFV puro, indicando portanto que os polímeros P188 e P407, permitiram a obtenção do incremento da solubilidade do EFV.

As formulações obtidas com o emprego do carreador PVP K-28/32 não apresentaram diferenças significativas entre os valores de solubilidade dos compostos avaliados (MF e DS) nos diferentes meios empregados ( $\mathrm{pH} 1,2 ; 4,5$ e 6,8) , ou seja, a solubilidade destas formulações não demonstrou ser pH dependente (Figura 37). No entanto, observou-se que o PVP K-28/32 proporcionou valores de solubilidade significativamente superiores (valor-p < 0,05) em relação aqueles observados para o 
EFV puro, porém não foram observadas diferenças significativas entre os sistemas binários (MF e DS) (Tabelas 9 e 10), o que indica que o polímero PVP K-28/32 foi responsável por melhorar a solubilidade do fármaco e não o processo de obtenção de DS. Ainda, os resultados apresentados na Tabela 10 mostram que as MF, para o PVP $\mathrm{K}-28 / 32$, apresentaram maiores valores de solubilidade nos meios com $\mathrm{pH} 1,2(15,13$ \pm 0,29 $\mu \mathrm{g} / \mathrm{mL}), \mathrm{pH} 4,5(16,37 \pm 0,27 \mu \mathrm{g} / \mathrm{mL})$ e $\mathrm{pH}$ 6,8 $(14,00 \pm 0,32 \mu \mathrm{g} / \mathrm{mL})$, em relação àqueles observados para as formulações de DS nos meios com os distintos pH's $(\mathrm{pH} 1,2$ - 14,17 \pm 0,05 $\mu \mathrm{g} / \mathrm{mL} ; \mathrm{pH} 4,5-14,78 \pm 0,16 \mu \mathrm{g} / \mathrm{mL}$ e $\mathrm{pH}$ 6,8 -13,83 \pm 0,09 $\mu \mathrm{g} / \mathrm{mL}$ ), todavia, vale ressaltar que esses valores não foram considerados estatisticamente significativos (Tabelas 9 e 10). Esse episódio, da distinção dos valores de solubilidade por saturação das MF serem maiores em comparação aos valores das DS foi igualmente evidenciado nos estudos de dissolução de Alves et al. (2014).

Nesse estudo, os autores sugeriram que ao desenvolver as DS de EFV pelo método de evaporação do solvente com o emprego do carreador PVP K-30, uma malha de polímero foi formada, assumindo assim, a forma de uma camada de "pseudo-gel", que intumesce para controlar a liberação do fármaco, que passou a ser liberado da matriz polimérica preferencialmente por erosão. Os resultados de dissolução das MF foram maiores em relação aos das DS, evidenciando a influência negativa do método de evaporação do solvente utilizado para produzi-las. A mistura simples entre o EFV e o PVP K-28/32 propicia uma melhor dissolução e essa circunstância pode ser atribuída principalmente ao efeito hidrofílico do carreador, que atua reduzindo a tensão interfacial entre a partícula e o meio de dissolução, contribuindo para a molhabilidade da substância ativa por meio da formação de um microambiente que facilita a solubilização em torno das partículas (ALVES et al., 2014).

As formulações (MF e DS) obtidas com o polímero copovidona (CoPVP) apresentaram resultados de solubilidade significativamente diferentes (valor-p $<0,05$ ) nos meios com valores de $\mathrm{pH} 4,5$ e 6,8, evidenciando que as preparações foram $\mathrm{pH}$ dependente. Por outro lado, os ensaios não revelaram diferenças significativas entre os dados de solubilidade das MF $(14,58 \pm 0,24 \mu \mathrm{g} / \mathrm{mL})$ e DS $(16,97 \pm 0,15 \mu \mathrm{g} / \mathrm{mL})$ ao utilizar o tampão $\mathrm{HCl} \mathrm{pH} \mathrm{1,2,} \mathrm{contudo,} \mathrm{essas} \mathrm{duas} \mathrm{amostras} \mathrm{demonstraram} \mathrm{distinções}$ 
significativas (valor-p < 0,05) ao serem comparadas com o EFV puro 9,58 \pm 0,01 $\mu \mathrm{g} / \mathrm{mL}$.

Os resultados de solubilidade obtidos para as soluções tampão pH 4,5 e 6,8 são semelhantes entre si, pois as amostras de MF e DS indicaram ser pH dependente, e as MF apresentaram maiores valores de solubilidade em comparação com as DS para ambos os valores de $\mathrm{pH}$, demonstrando distinção estatisticamente significativa entre o valor-p < 0,05 para o EFV puro e as MF e as DS e entre as MF e DS. Para o tampão pH 4,5 os valores para EFV puro, MF e DS foram respectivamente $(10,08 \pm$ $0,04 \mu \mathrm{g} / \mathrm{mL}),(25,61 \pm 0,16 \mu \mathrm{g} / \mathrm{mL})$ e $(19,53 \pm 0,20 \mu \mathrm{g} / \mathrm{mL})$ e tampão $\mathrm{pH} 6,8$ os valores foram para EFV puro 9,49 $\pm 0,04 \mu \mathrm{g} / \mathrm{mL}$, MF 24,51 $\pm 0,27 \mu \mathrm{g} / \mathrm{mL}$ e DS 18,11 \pm 0,29. Portanto, concluiu-se que o polímero copovidona melhora a solubilidade do fármaco EFV e não o processo de DS por evaporação do solvente.

Não foram evidenciados na literatura resultados semelhantes com o emprego do carreador CoPVP e EFV, onde a MF apresentou maiores valores de solubilidade em relação às DS. Entretanto, o trabalho de Sathigari et al. (2012) demonstrou que ao preparar DS de EFV com o mesmo carreador, na proporção de 1:1, os valores de dissolução em 120 min foram superiores para as DS (82\% de liberação) em relação à MF (47\% de liberação) e ao EFV puro (43\% de liberação) (SATHIGARI et al., 2012). Nesse estudo, a DS foi preparada pelo método de extrusão a quente (hot melt extrusion) e permitiu resultados mais eficazes do que foi aqui observado pelo método de evaporação do solvente.

Os estudos de Zhao et al. (2019) corroboram com a ideia inicial da ineficiência do método de evaporação do solvente, onde os autores comprovaram que ao preparar DS de ritonavir, empregando como carreador a CoPVP obtida por dois métodos distintos (evaporação do solvente e extrusão a quente) na proporção de 1:5 (p/p), apresentaram distinção entre os valores de solubilidade dos métodos empregados. Os resultados de solubilidade por saturação foram performados em água destilada a $37^{\circ} \mathrm{C}$ por 120 minutos, para as amostra obtidas via evaporação do solvente os valores de solubilidade foram de $10 \mu \mathrm{g} / \mathrm{mL}$ e para os compostos obtidos via extrusão a quente os valores foram de $14 \mu \mathrm{g} / \mathrm{mL}$ (ZHAO et al., 2019). Segundo o estudo de Lavra (2016), o polímero CoPVP foi introduzido como carreador polimérico nos processos exclusivos de obtenção por extrusão a quente, devido a sua temperatura de transição 
vítrea $\left(\mathrm{T}_{\mathrm{g}}=106^{\circ} \mathrm{C}\right)$, termoplasticidade e compatibilidade com a maioria dos fármacos (LAVRA, 2016).

Os ensaios de solubilidade empregando os carreadores hidroxipropilmetilcelulose ftalato (HPMCP-50, HPMCP-55 e HPMCP-55s), demonstraram ser $\mathrm{pH}$ dependente, pois esses carreadores poliméricos são praticamente insolúveis em valores baixos de pH (LI; TAYLOR, 2018).

Os resultados de solubilidade para as preparações de MF e DS obtidas separadamente com os carreadores, HPMCP-50, HPMCP-55 e HPMCP-55s, demonstraram que tais polímeros não proporcionaram incremento ou alteração estatisticamente significativa (valor-p < 0,05) em relação ao EFV puro nos meios com pH's 1,2 e 4,5 (Tabelas 9 e 10). Por outro lado, os resultados de solubilidade obtidos em solução tampão fosfato $\mathrm{pH} \mathrm{6,8,} \mathrm{para} \mathrm{as} \mathrm{formulações} \mathrm{com} \mathrm{esses} \mathrm{polímeros,}$ demonstraram que apenas as MF (HPMCP-50 - 39,90 \pm 2,44 $\mu \mathrm{g} / \mathrm{mL}$; HPMCP-55 $60,14 \pm 2,91 \mu \mathrm{g} / \mathrm{mL}$ e HPMCP-55s - 65,03 \pm 0,91 $\mu \mathrm{g} / \mathrm{mL}$ ) apresentaram valores significativamente superiores aos obtidos para o EFV puro $(9,49 \pm 0,04 \mu \mathrm{g} / \mathrm{mL})$ e para as DS (HPMCP-50 -7,24 \pm 0,54 $\mu \mathrm{g} / \mathrm{mL}$, HPMCP-55 - 7,19 \pm 0,14 $\mu \mathrm{g} / \mathrm{mL}$ e HPMCP$55 \mathrm{~s}-17,55 \pm 1,50 \mu \mathrm{g} / \mathrm{mL})$. Esses dados das DS evidenciaram a incapacidade do processo em incrementar a solubilidade do fármaco EFV, onde pôde-se concluir que, quem melhorou a solubilidade do composto ativo foram os polímeros e não a DS no tampão fosfato $\mathrm{pH} \mathrm{6,8,} \mathrm{fato} \mathrm{este} \mathrm{semelhante} \mathrm{ao} \mathrm{observado} \mathrm{em} \mathrm{relação} \mathrm{às} \mathrm{formulações}$ empregando os carreadores PVP K-28/32 e CoPVP, anteriormente apresentadas e discutidas.

Contudo, acredita-se que a ineficiência do processo de obtenção das DS empregando os carreadores, HPMCP-50, HPMCP-55 e HPMCP-55s, seja atribuída ao fato do EFV possuir um pKa elevado (pKa = 10,2) e não formar ligações iônicas com esses polímeros de características ácidas (CRISTOFOLETTI et al., 2013; DE ARAUJO et al., 2017). Estudos de Song et al. (2015) que descrevem a obtenção de DS do lapatinib com o carreador HPMCP-55, na proporção de 1:1, através do método de evaporação do solvente por spray drying, evidenciaram aumento significativo da dissolução do fármaco. Os autores descrevem dissolução de aproximadamente $70 \%$ para as DS em comparação com a liberação de apenas 5\% para o fármaco puro. Os autores concluíram que o método por spray drying demonstrou ser efetivo no preparo 
das misturas binárias com o emprego do polímero HPMCP-55 pelo fato do fármaco ser uma base fraca com pKa =7,26 e ocorrer uma interação do tipo ácido-base com o polímero (SONG et al., 2015).

Os dados de solubilidade para as formulações obtidas com o carreador P188 apresentaram diferenças estatisticamente significativas (valor-p <0,05) entre si (EFV puro, MF e DS), conforme pode ser observado nas Tabelas 9 e 10 e Figura 37. Os valores de solubilidade no meio com pH 1,2 apresentaram diferenças significativas entre os grupos: DS $(5799,46 \pm 1,36 \mu \mathrm{g} / \mathrm{mL})$, MF $(760,08 \pm 1,64 \mu \mathrm{g} / \mathrm{mL})$ e EFV puro $(9,58 \pm 0,01 \mu \mathrm{g} / \mathrm{mL})$. No entanto, não foram evidenciados nos cálculos estatísticos distinção significativa entre os grupos de EFV puro e MF; contudo, é possível evidenciar nas Tabelas 9 e 10 que o polímero proporcionou um aumento da solubilidade do fármaco. Comportamento semelhante foi observado quando se empregou como meio solução tampão pH 4,5. Os grupos comparados foram, DS e MF $(5230,79 \pm 0,50$ e $888,31 \pm 0,25 \mu \mathrm{g} / \mathrm{mL}$, respectivamente) e DS e EFV puro $(5230,79 \pm 0,50$ e 9,58 $\pm 0,01 \mu \mathrm{g} / \mathrm{mL}$, respectivamente) demonstraram diferenças

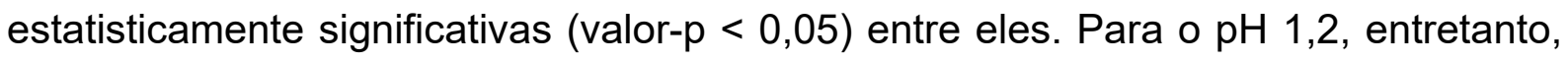
os grupos EFV puro e MF (9,58 \pm 0,01 e 888,31 $\pm 0,25 \mu \mathrm{g} / \mathrm{mL})$ não demonstraram diferenças estatisticamente significantes, apesar de apresentar uma indiscutível melhora na solubilidade do fármaco na mesma faixa de $\mathrm{pH}$.

Os resultados de solubilidade obtidos no meio pH 6,8 (solução tampão fosfato), para as formulações com carreador P188 evidenciaram diferenças estatisticamente significativas (valor-p < 0,05) entre as amostras avaliadas (EFV puro: 9,58 \pm 0,01, MF: $2272,39 \pm 1,42$ e DS: $7167,86 \pm 2,77 \mu \mathrm{g} / \mathrm{mL}$ ). Os valores observados para as formulações DS evidenciaram a capacidade do processo em incrementar a solubilidade do fármaco EFV, onde pôde-se concluir que, quem foi responsável por melhorar a solubilidade do composto ativo foi de fato a dispersão sólida e não apenas o P188 isoladamente.

Resultados semelhantes foram observados quando as formulações com 0 carreador P407 foram avaliadas. Os valores de solubilidade das formulações apresentaram diferenças estatisticamente significativas (valor-p <0,05) para todas as amostras avaliadas e comparadas (EFV puro, MF e DS) nos três meios distintos (pH $1,2 ; 4,5$ e 6,8$)$. Evidenciou-se que o processo de produção de DS pelo método de 
evaporação do solvente demonstrou ser efetivo no incremento da solubilidade do fármaco e não apenas a utilização do poloxâmero isoladamente.

Os valores de solubilidade obtidos a partir das amostras (EFV puro, MF e DS) no três meios empregados $(1,2 ; 4,5$ e 6,8) demonstraram ser $\mathrm{pH}$ dependente, onde os maiores valores são apresentados no meio de pH 4,5 (EFV puro - 10,08 \pm 0,04; MF $6171,97 \pm 2,14$ e DS - 23071,37 $\pm 0,45 \mu \mathrm{g} / \mathrm{mL}$ ), em relação aos meios de $\mathrm{pH} 1,2$ (EFV puro - 9,58 \pm 0,01; MF - 4273,77 $\pm 1,94$ e DS - 17331,61 $\pm 1,42 \mu \mathrm{g} / \mathrm{mL})$ e pH 6,8 (EFV puro - 9,49 \pm 0,04; MF - 5716,13 $\pm 0,07$ e DS - 21296,46 \pm 0,78 $\mu \mathrm{g} / \mathrm{mL}$ ).

Os poloxâmeros 188 e 407 são copolímeros não iônicos triblocos de polioxietileno-polioxipropileno-polioxietileno (POE-POP-POE). O óxido de etileno hidrofílico e o óxido de propileno hidrofóbico fornecem ao poloxâmero uma estrutura anfifílica, o que significa que possui um grupo polar, solúvel em água, ligado a uma cadeia de hidrocarbonetos não polar e insolúvel em água. As moléculas dos copolímeros se convertem em micelas (uma cadeia de moléculas compactadas) em solução aquosa. A formação de micelas depende da temperatura pois, abaixo de uma certa temperatura característica conhecida como "temperatura micelar crítica, os blocos de POE e POP são hidratados, onde o óxido de propileno se torna solúvel em meio aquoso (FUSCO; BORZACCHIELLO; NETTI, 2006; SHIRWAIKER; PURSER; WYSK, 2014).

As micelas poliméricas se comportam como "cavalo de Tróia" para incorporar fármacos hidrofóbicos solúveis em água, destinados à administração oral. Os blocos de copolímeros de poli (óxido de etileno) - poli (óxido de propileno) (POE - POP) com resposta térmica são os anfifilos mais populares para formação de micelas (CHIAPPETTA et al., 2011). Assim, o núcleo hidrofóbico (óxido de propileno) das micelas incorporou o EFV, aumentando sua solubilidade. Além disso, as propriedades hidrofílicas e tensoativas dos poloxâmeros incrementaram a molhabilidade do antirretroviral, diminuindo assim, a tensão interfacial entre o EFV e a água (COLOMBO et al., 2019).

A partir dos resultados evidenciados nos estudos de solubilidade empregando o fármaco EFV, foi concluído que, o copolímero P407 melhora consideravelmente a solubilidade do EFV em comparação com o carreador P188, onde os valores de saturação das DS obtidas com o P407 foram quatro vezes superiores. Pode-se 
presumir que, quanto mais segmento de POE-POP-POE o poloxâmero possuir, melhor será a saturação do fármaco EFV no meio aquoso devido a formação de micelas. Com base nos resultados de solubilidade, os poloxâmeros 188 e 407 foram selecionados para investigações de dissolução. 
Tabela 9 - Valores de solubilidade de saturação $(\mu \mathrm{g} / \mathrm{mL})$ do EFV puro e das DS com os polímeros PVP K-28/32, CoPVP, HPMCP-50, HPMCP55, HPMCP-55s, P188 e P407, na proporção 1:3. Os resultados representam a média e desvio padrão de três análises

\begin{tabular}{|c|c|c|c|c|c|c|c|c|}
\hline \multirow{2}{*}{$\begin{array}{l}\text { Soluções } \\
\text { tampão }\end{array}$} & \multicolumn{8}{|c|}{$\begin{array}{l}\text { Solubilidade }(\mu \mathrm{g} / \mathrm{mL}) \\
\text { Dispersão sólida }(1: 3)\end{array}$} \\
\hline & EFV puro & DS PVP K-28/32 & DS CoPVP & DS HPMCP-50 & DS HPMCP-55 & DS HPMCP-55s & DS P188 & DS P407 \\
\hline pH 1.2 & $9,58 \pm 0,01$ & $14,17 \pm 0,05$ & $16,97 \pm 0,15$ & $10,52 \pm 0,14$ & $7,79 \pm 0,09$ & $7,73 \pm 0,10$ & $5799,46 \pm 1,36$ & $17331,61 \pm 1,42$ \\
\hline pH 4.5 & $10,08 \pm 0,04$ & $14,78 \pm 0,16$ & $19,53 \pm 0,20$ & $15,55 \pm 0,41$ & $10,72 \pm 0,09$ & $10,22 \pm 0,05$ & $5230,79 \pm 0,50$ & $23071,37 \pm 0,45$ \\
\hline pH 6.8 & $9,49 \pm 0,04$ & $13,83 \pm 0,09$ & $18,11 \pm 0,29$ & $7,24 \pm 0,54$ & $7,19 \pm 0,14$ & $17,55 \pm 1,50$ & $7167,86 \pm 2,77$ & $21296,46 \pm 0,78$ \\
\hline
\end{tabular}

Fonte: Elaborado pelo autor.

Tabela 10 - Valores de solubilidade de saturação $(\mu \mathrm{g} / \mathrm{mL})$ do EFV puro e das MF com os polímeros PVP K-28/32, CoPVP, HPMCP-50, HPMCP55, HPMCP-55s, P188 e P407, na proporção 1:3. Os resultados representam a média e desvio padrão de três análises

\begin{tabular}{|c|c|c|c|c|c|c|c|c|}
\hline \multirow{2}{*}{$\begin{array}{l}\text { Soluções } \\
\text { tampão }\end{array}$} & \multicolumn{8}{|c|}{$\begin{array}{c}\text { Solubilidade }(\mu \mathrm{g} / \mathrm{mL}) \\
\text { Mistura física }(1: 3)\end{array}$} \\
\hline & EFV puro & MF PVP K-28/32 & MF CoPVP & MF HPMCP-50 & MF HPMCP-55 & MF HPMCP-55s & MF P188 & MF P407 \\
\hline pH 1.2 & $9,58 \pm 0,01$ & $15,13 \pm 0,29$ & $14,58 \pm 0,24$ & $11,79 \pm 0,26$ & $8,92 \pm 0,06$ & $7,82 \pm 0,26$ & $760,08 \pm 1,64$ & $4273,77 \pm 1,94$ \\
\hline pH 4.5 & $10,08 \pm 0,04$ & $16,37 \pm 0,27$ & $25,61 \pm 0,16$ & $10,73 \pm 0,06$ & $8,96 \pm 0,12$ & $5,70 \pm 0,03$ & $888,31 \pm 0,25$ & $6171,97 \pm 2,14$ \\
\hline pH 6.8 & $9,49 \pm 0,04$ & $14,00 \pm 0,32$ & $24,51 \pm 0,27$ & $39,90 \pm 2,44$ & $60,14 \pm 2,91$ & $65,03 \pm 0,91$ & $2272,39 \pm 1,42$ & $5716,13 \pm 0,07$ \\
\hline
\end{tabular}

Fonte: Elaborado pelo autor. 
Figura 37 - Resultados das solubilidades obtidas através do método do equilíbrio do EFV puro, das MF e das DS na proporção 1:3. As barras de erros indicam o desvio padrão dos testes realizados em triplicatas.
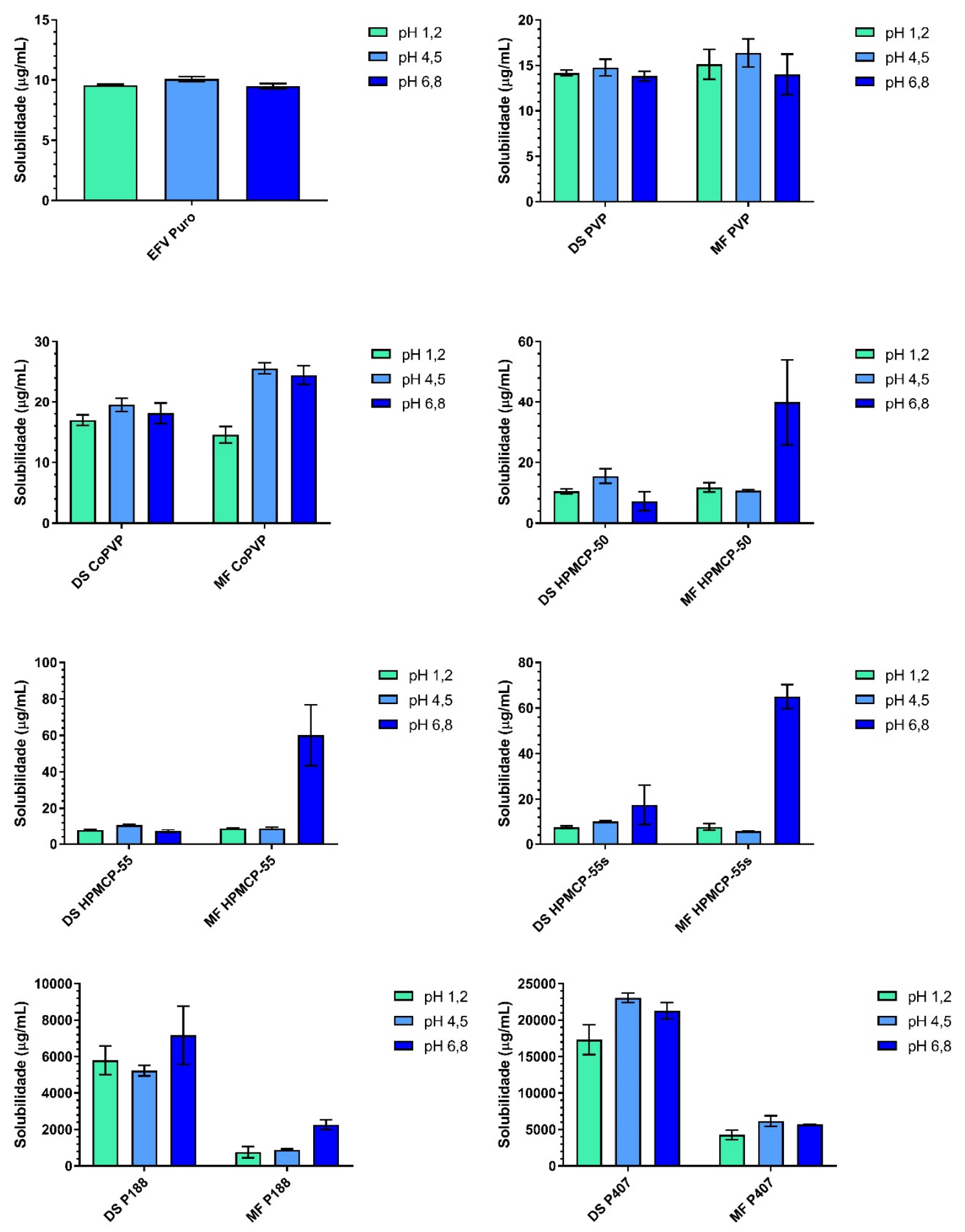

Fonte: Elaborado pelo autor 


\subsection{Impactos nas alterações das proporções de polímeros nas formulações de dispersões sólidas de efavirenz}

A partir dos resultados obtidos, descritos e discutidos nos itens anteriores, selecionaram-se as formulações que melhores resultados apresentaram em relação ao incremento de solubilidade nos meios empregados ( $\mathrm{pH} 1,2,4,5$ e 6,8). Assim, as formulações obtidas com os carreadores P188 e P407 foram as selecionadas para a etapa de verificação dos impactos nas alterações das proporções das formulações. Nesta etapa reduziu-se a proporção dos polímeros, e as formulações foram desenvolvidas na proporção de 1:1 (EFV:carreador). Os ensaios de solubilidade, termoanálise e difração foram empregados para avaliar o impacto da redução dos polímeros na formulação final.

\subsubsection{Avaliação da solubilidade}

A partir dos resultados anteriormente descritos, selecionaram-se para continuidade dos estudos, as formulações que apresentaram os melhores resultados de solubilidade. Dessa forma, conforme descrito no item 4.2.2.4, formulações com os polímeros P188 e P407 (MF e DS) foram preparadas na proporção de 1:1, com o objetivo de avaliar o impacto da redução dos polímeros nos resultados de solubilidade.

Não foi possível realizar o teste de solubilidade com as DS dos carreadores P188 e P407 nas proporções de 1:1, devido ao fato das preparações apresentarem consistência de um líquido viscoso semelhante a "mel de abelha". Inviabilizando assim a saturação visual das soluções tampão empregadas no ensaio.

Assim, resultados médios $(n=3)$ obtidos a partir dos estudos de solubilidade das formulações de EFV com os carreadores P188 e P407 (MF) com emprego do método do equilíbrio (shake-flask), nos diferentes meios (soluções tampão pH's 1,2, 4,5 e 6,8) foram analisados e comparados com aqueles obtidos para as MF e FP utilizando-se a ANOVA dois fatores seguida de Tukey, e encontram-se apresentados na Tabela 11 e Figura 38.

Conforme pode ser observado, os resultados de solubilidade para as misturas binárias com o carreador P188 (MF e DS), na proporção de 1:1, não apresentaram diferenças estatisticamente significativas quando foram comparados àqueles 
observados para o EFV puro, nos três meios empregados (soluções tampão pH's 1,2, $4,5$ e 6,8$)$. Contudo, foi evidenciado incremento da solubilidade do EFV, nos três meios aquosos, pH 1,2 (EFV puro - 9,58 $\pm 0,01$ e MF -102,14 $\pm 0,37 \mu \mathrm{g} / \mathrm{mL}$ ), pH 4,5 (EFV puro - 10,08 $\pm 0,04$ e MF - 47,96 $\pm 0,31 \mu \mathrm{g} / \mathrm{mL}$ ) e pH 6,8 (EFV puro - 9,49 $\pm 0,04$ e MF $-102,97 \pm 4,02 \mu \mathrm{g} / \mathrm{mL}$ ).

Por outro lado, quando foram avaliadas as formulações obtidas com o carreador P407 (MF), observou-se aumento significativo da solubilidade do EFV na comparação dos resultados da MF, nos três meios de solução tampão ( $\mathrm{pH} 1,2$ $1648,76 \pm 1,57 \mu \mathrm{g} / \mathrm{mL} ; \mathrm{pH} 4,5-1836,31 \pm 3,19 \mu \mathrm{g} / \mathrm{mL}$ e pH 6,8 $-1229,10 \pm 1,19$ $\mu \mathrm{g} / \mathrm{mL}$ ), com aqueles obtidos para o EFV puro (pH 1,2 - 9,58 $\pm 0,01 ; \mathrm{pH} \mathrm{4,5-10,08 \pm}$ 0,04 e pH 6,8 - 9,49 $\pm 0,04$ ) (valor-p < 0,05).

Os resultados de solubilidade indicam que o maior incremento foi obtido com o emprego do carreador P407, em relação ao P188, nas proporções de 1:1. Os valores estão em concordância com o item 5.2.3, onde conforme discutido anteriormente os sistemas binários empregando o P407 apresentam maiores valores de saturação do EFV, provavelmente devido ao número de segmentos de POE-POP-POE, contudo ao diminuir a proporção de ambos poloxâmeros, evidenciou-se uma diminuição na solubilidade do EFV. A conclusão para esse experimento foi que, quanto maior a proporção dos carreadores empregados nas misturas binárias, maior será a concentração do EFV solubilizado no meio aquoso devido a formação de micelas. 
Tabela 11 - Valores de solubilidade de saturação $(\mu \mathrm{g} / \mathrm{mL})$ do EFV puro e das MF com os polímeros P188 e P407, na proporção 1:1. Os resultados representam a média e desvio padrão de três análises

\begin{tabular}{cccc}
\hline \hline \multirow{2}{*}{$\begin{array}{c}\text { Soluções } \\
\text { tampão }\end{array}$} & \multicolumn{3}{c}{$\begin{array}{c}\text { Solubilidade }(\boldsymbol{\mu g} / \mathbf{m L}) \\
\text { Mistura física (1:1) }\end{array}$} \\
\cline { 2 - 4 } & EFV puro & MF P188 & MF P407 \\
\hline pH 1.2 & $9,58 \pm 0,01$ & $102,14 \pm 0,37$ & $1648,76 \pm 1,57$ \\
pH 4.5 & $10,08 \pm 0,04$ & $47,96 \pm 0,31$ & $1836,31 \pm 3,19$ \\
pH 6.8 & $9,49 \pm 0,04$ & $102,97 \pm 4,02$ & $1229,10 \pm 1,19$ \\
\hline \hline
\end{tabular}

Fonte: Elaborado pelo autor.

Figura 38 - Resultados das solubilidades obtidas através do método do equilíbrio do EFV puro e das MF na proporção 1:1. As barras de erros indicam o desvio padrão dos testes realizados em triplicatas.
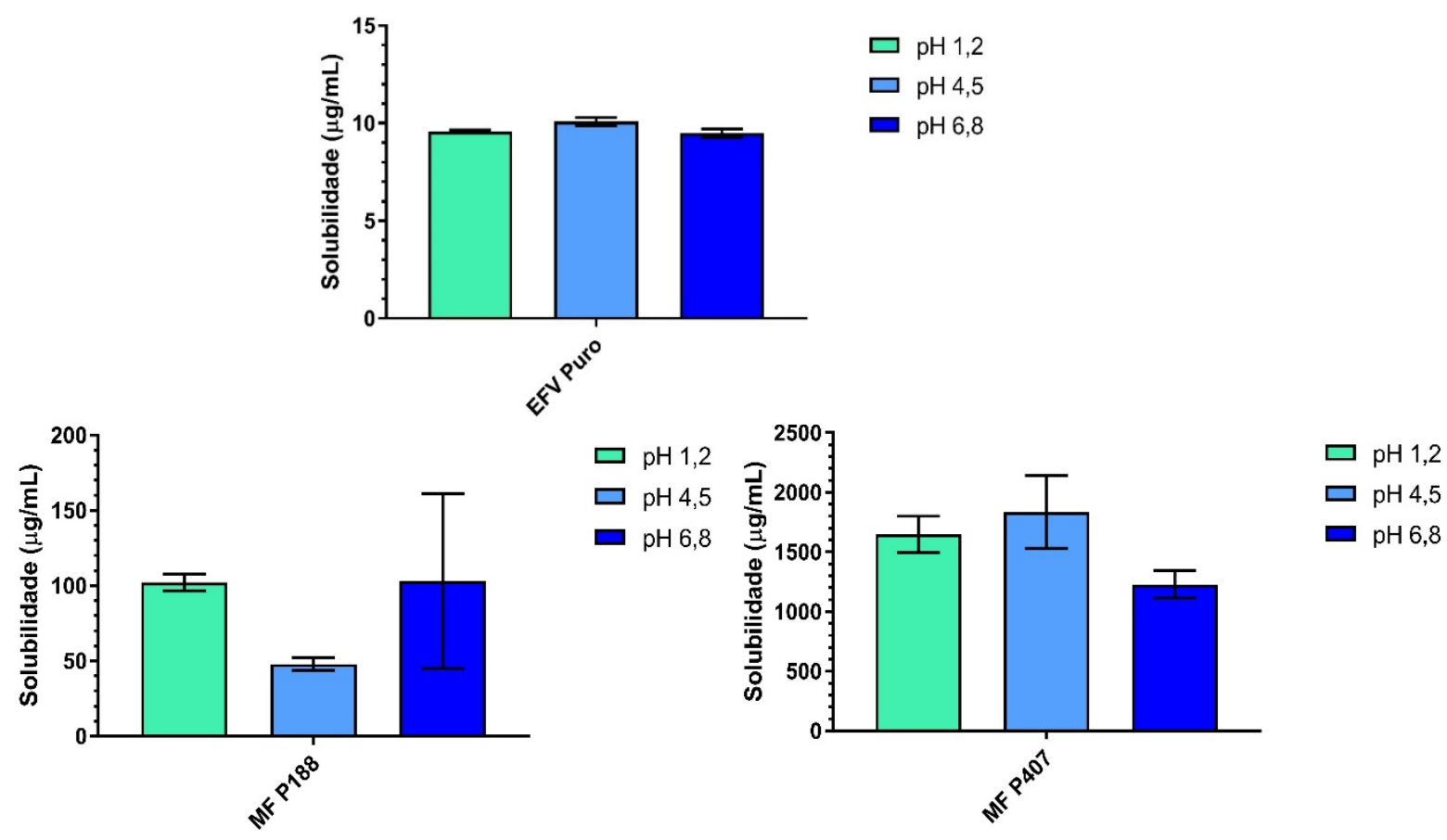

Fonte: Elaborado pelo autor. 


\subsubsection{Avaliação da miscibilidade}

Nesta etapa as formulações preparadas com os polímeros P188 e P407 (MF) nas proporções de 1:1, 1:2, 1:3, 1:4, 1:5 e 3:1, conforme descrito no item 4.2.2.3, foram analisadas e comparadas com os dados do EFV puro e dos carreadores puros por meio da calorimetria exploratória diferencia (DSC), conforme descrito no item 4.2.4.4. Os resultados estão apresentados nas Figuras 39 e 40.

A curva DSC do antirretroviral apresentou um nítido pico endotérmico de fusão em $138,5^{\circ} \mathrm{C}$, indicando a natureza cristalina do composto ativo. O resultado obtido está em concordância com a literatura, pois a faixa de fusão do EFV está entre $136{ }^{\circ} \mathrm{C}$ a $141{ }^{\circ} \mathrm{C}$ (COSTA et al., 2019; FANDARUFF et al., 2014a; PAWAR et al., 2016).

As curvas DSC das MF contendo o P188 estão ilustradas na Figura 39, onde é possível evidenciar a fusão do polímero $\mathrm{P} 188$ puro a $57,6{ }^{\circ} \mathrm{C}$, como um distinto e nítido pico endotérmico (MEDAREVIĆ et al., 2016; SONG; YOON; KIM, 2016). A MF P188 1:1 (fármaco e carreador) apresentou uma atenuação e um deslocamento do pico de fusão do EFV, onde a fusão ocorreu em $134,8^{\circ} \mathrm{C}$ e uma diminuição no valor de $\Delta \mathrm{H}$ que passou de $\Delta \mathrm{H}=59,6 \mathrm{~J} / \mathrm{g}$ para $\Delta \mathrm{H}=0,3 \mathrm{~J} / \mathrm{g}$ em comparação com o EFV puro. As MF preparadas nas proporções de 1:2, 1:3, 1:4 e 1:5 não apresentaram evidências da fusão do EFV, ou seja, ocorreu um desaparecimento do pico devido ao aumento da quantidade do polímero. A preparação MF P188 3:1 apresentou um deslocamento da fusão do pico do EFV, passando para $136,8{ }^{\circ} \mathrm{C}$ e houve uma atenuação no valor de $\Delta \mathrm{H}(4,8 \mathrm{~J} / \mathrm{g})$ em comparação com o valor do fármaco puro $\Delta \mathrm{H}(59,6 \mathrm{~J} / \mathrm{g})$.

A Figura 40 apresenta as análises das preparações empregando o carreador P407, onde é possível evidenciar a fusão do polímero P407 puro através de um pico endotérmico ocorrendo em 58,7 ${ }^{\circ} \mathrm{C}$ (COLOMBO et al., 2019; DUGAR; GAJERA; DAVE, 2016; KAROLEWICZ et al., 2017; MEDAREVIĆ et al., 2016).

A mistura binária MF P407, na proporção 1:1, apresentou um deslocamento do pico do EFV para $134,0^{\circ} \mathrm{C}$ e uma diminuição no valor para $\Delta \mathrm{H}=0,2 \mathrm{~J} / \mathrm{g}$, a preparação MF P407 3:1 também apresentou um deslocamento do pico de fusão do EFV para $136,5^{\circ} \mathrm{C}$ e uma atenuação do valor de $\Delta \mathrm{H}=0,9 \mathrm{~J} / \mathrm{g}$, valores esses comparados com a curva DSC do EFV puro. As MF nas proporções de 1:2, 1:3, 1:4 e 1:5 apresentaram desaparecimento do pico de fusão do EFV em suas respectivas curvas DSC. 
Os resultados revelados a partir das curvas DSC indicam que os poloxâmeros 188 e 407 foram estáveis até aproximadamente $160^{\circ} \mathrm{C}$, e após essa temperatura houve uma depressão na linha base da curva DSC indicando uma reação exotérmica, os estudos de Li et al. (2015) evidenciaram o mesmo evento exotérmico no P188, o que provavelmente se trata de uma possível recristalização (LI et al., 2015).

As curvas DSC das misturas binárias nas proporções 1:1 e 3:1 (fármaco e carreador), para ambos os carreadores, indicam que não houve uma quantidade suficiente de polímero, pois nessa proporção é possível ainda evidenciar o pico de fusão do EFV. O desaparecimento do pico do EFV das MFs empregando as proporções de 1:2 a 1:5 para ambos os carreadores, é ocasionado devido à solubilização do EFV nos polímeros fundidos, pois os poloxâmeros fundem em temperaturas significantemente mais baixas que o antirretroviral (COLOMBO et al., 2019; MEDAREVIĆ et al., 2016). Esse desaparecimento do pico de fusão, mais acentuado na mistura com o P407, também reforça uma maior miscibilidade com o EFV e é congruente com o maior poder de solubilização observado.

Contudo pode-se concluir que, ao aumentar a quantidade de fármaco no polímero é provável que possa ocasionar uma cristalização do composto amorfo durante o armazenamento do produto, sob condições de alta temperatura e umidade (BAIRD; TAYLOR, 2012; NEWMAN; KNIPP; ZOGRAFI, 2012; XIE; TAYLOR, 2016). Por conta desses resultados, optou-se em prosseguir com as formulações na proporção de 1:3, pois acredita-se que há elevado risco de cristalização do EFV na proporção de 1:2. 
Figura 39 - Curvas DSC do EFV puro, P188 puro e MF nas proporções de 1:1, 1:2, 1:3, 1:4, 1:5 e $3: 1$ obtidas a $10^{\circ} \mathrm{C} / \mathrm{min}$ e atmosfera dinâmica de nitrogênio com vazão de $50 \mathrm{~mL} \mathrm{~min}{ }^{-1}$.

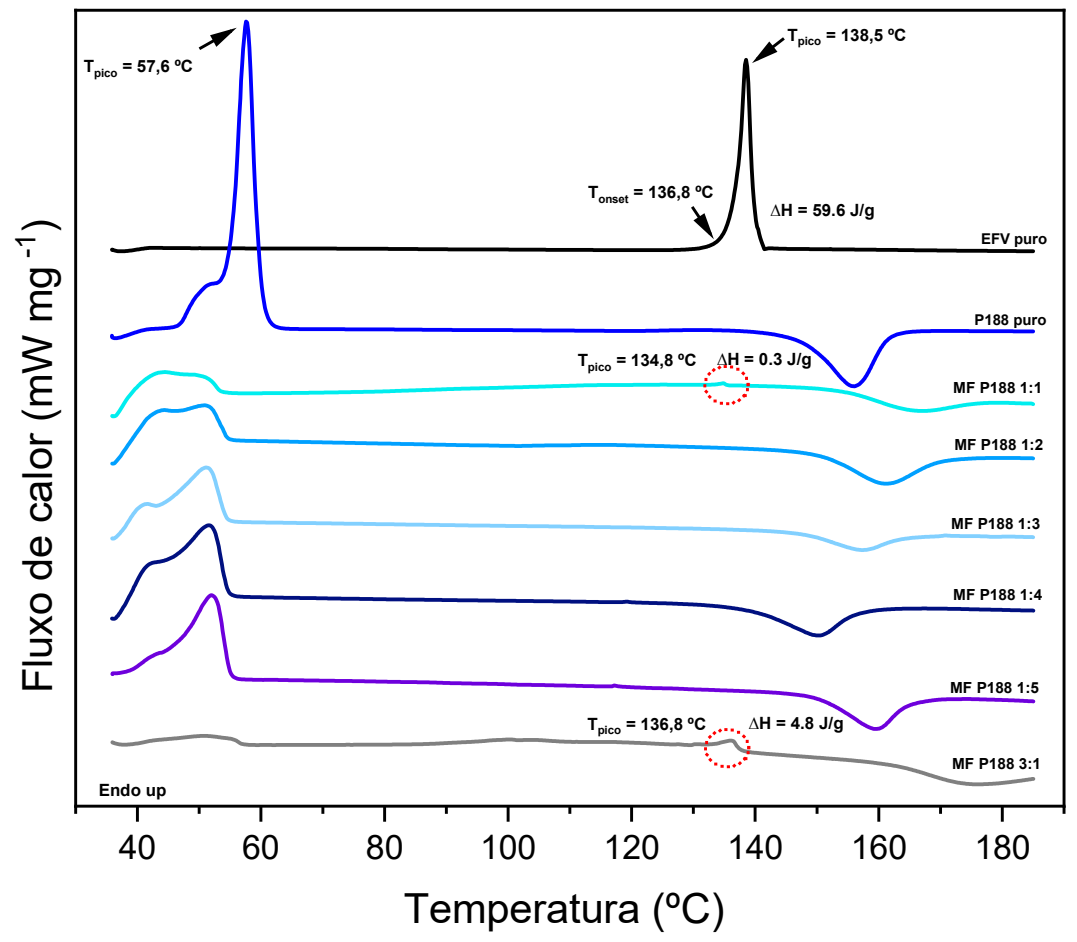

Fonte: Elaborado pelo autor.

Figura 40 - Curvas DSC do EFV puro, P407 puro e MF nas proporções de 1:1, 1:2, 1:3, 1:4, 1:5 e 3:1 obtidas a $10^{\circ} \mathrm{C} / \mathrm{min}$ e atmosfera dinâmica de nitrogênio com vazão de $50 \mathrm{~mL} \mathrm{~min}{ }^{-1}$.

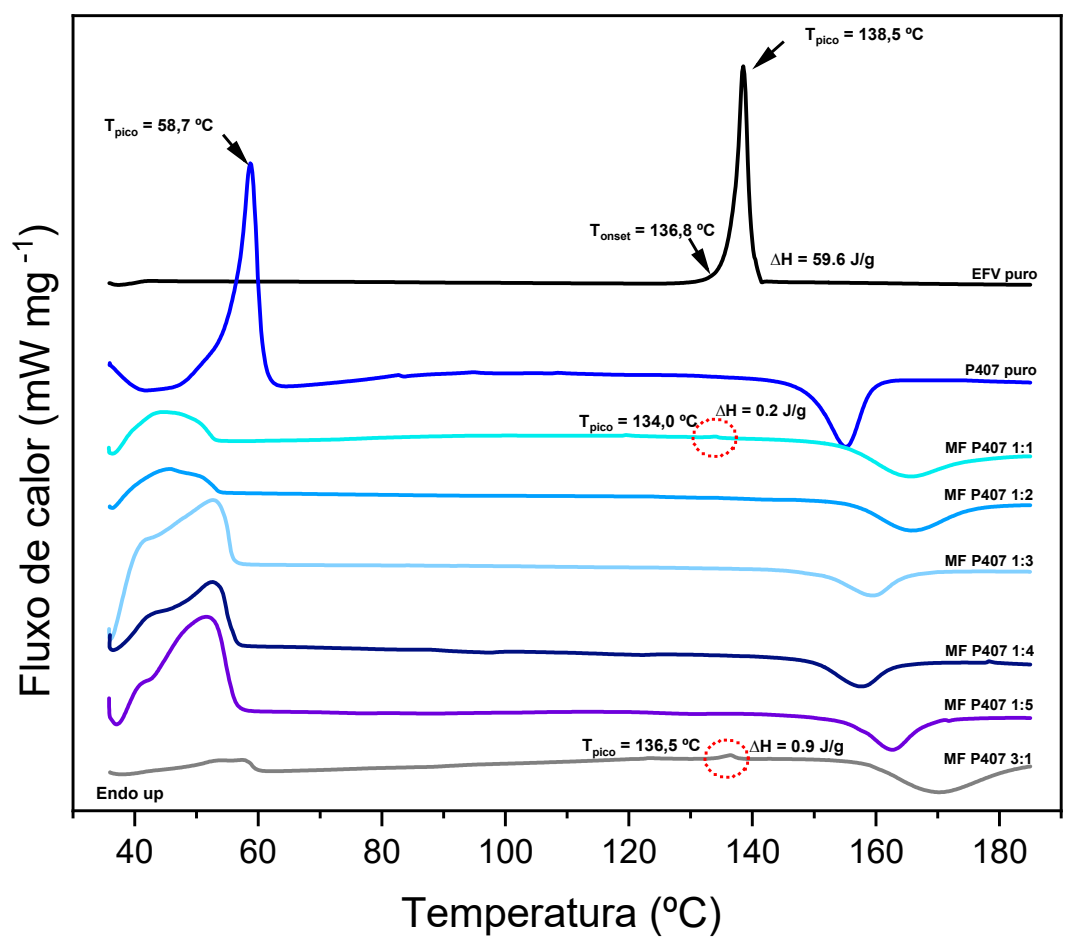

Fonte: Elaborado pelo autor. 


\subsubsection{Avaliação da estabilidade}

Nesta etapa as formulações preparadas com os polímeros P188 e P407 (MF e DS) proporção de 1:1, conforme descrito no item 4.2.2, foram analisadas e comparadas com os dados do EFV puro e dos carreadores puros por meio da difratometria de raios $X$ pelo método do pó (DRXP), conforme descrito no item 4.2.4.3.

O estado sólido das amostras foi caracterizado por análise de DRXP, os resultados obtidos estão ilustrados nas Figuras 41 e 42 e na Tabela 12.

Os valores do EFV puro, P188 puro e P407 puro foram previamente discutidos no item 5.2.1. As MF obtidas com o emprego dos carreadores P188 e P407, demonstraram padrões de difração semelhantes aos dos compostos puros, indicando que a cristalinidade do fármaco não foi afetada pelo processo de preparação.

A DS obtida no tempo 1 (T1) dia do preparo DS P188 1:1 (T1) (Figura 41), foi caracterizada por uma completa ausência de picos e presença do halo próximo de $20^{\circ}$ $(2 \theta)$, características típicas de compostos amorfos. Entretanto esse mesmo composto amorfo quando analisado no tempo 2 (T2), após trinta dias de preparo DS P188 1:1 (T2) apresentou recristalização, devido ao armazenamento no congelador durante o estudo de estabilidade. O difratograma da DS P407 1:1 (T1) (Figura 42) evidenciou a incapacidade do sistema em amorfizar completamente a preparação, pois em $10^{\circ}(2 \theta)$ é possível visualizar a presença do pico indicando cristalinidade. Os picos de Bragg dos sistemas binários surgiram entre $10^{\circ}$ a $25^{\circ}(2 \theta)$, para ambas as preparações, entretanto os picos da DS P407 1:1 (T2) demonstraram maior intensidade em comparação com a DS P188 1:1 (T2). Esse acontecimento indica provavelmente o surgimento da formação de uma fase desconhecida do fármaco EFV, pois esses picos oriundos da recristalização, não coincidem com as outras formas polimórficas do antirretroviral comparadas na literatura (FANDARUFF et al., 2014a; MARQUES et al., 2017).

Os resultados obtidos por DRXP estão em concordância com os dados adquiridos por DSC no item 5.3.2, onde é possível afirmar que ao diminuir a quantidade dos carreadores a estabilidade do fármaco no estado amorfo é comprometida, ocasionando a recristalização do composto ativo durante o armazenamento. 
A Tabela 12 resume os resultados dos DRXP para ambas as preparações, empregando os carreadores P188 e P407. As DS foram classificadas antes do estudo de estabilidade como totalmente amorfa e semicristalina para os carreadores P407 e P188 respectivamente na proporção de 1:1. Posteriormente ao estudo de estabilidade, as amostras passaram a ser consideradas semicristalinas. Com base nos resultados de estabilidade, foram descartadas quaisquer possibilidades de prosseguir com futuras investigações, pois ao diminuir a quantidade de poloxâmero as preparações recristalizaram.

A Figura 43 exibe as fotografias das lâminas de vidro contendo as misturas binárias, as imagens foram obtidas após as lâminas serem armazenadas em congelador por um período de 30 dias (esse armazenamento foi designado de estabilidade). As lâminas A e B contendo as DS com poloxâmeros 188 e 407 respectivamente, apresentavam o aspecto de um material translúcido e viscoso antes do armazenamento, e posteriormente ao estudo de estabilidade, as lâminas passaram a exibir um aspecto esbranquiçado semelhante a cera. Suponha-se que essas manchas sejam ocasionadas pela recristalização do EFV, pois conforme o experimento realizado anteriormente com o antirretroviral amorfo puro, o mesmo apresentou recristalização, comportamento semelhante conforme discutido no item 5.2.1. A recristalização pode ser evidenciada nos difratogramas das Figuras 41 e 42 para ambos os carreadores.

As DS obtidas na proporção de 1:3 empregando os dois copolímeros, apresentaram resultados semelhantes, ou seja, foram classificadas como semicristalinas no T2 de estabilidade, contudo, o referido sistema binário foi capaz de amorfizar e estabilizar o EFV, uma vez que, os picos evidenciados foram ocasionados pelos poloxâmeros que é um composto semicristalino.

Com base nas informações apresentadas dos testes de otimização, foi possível concluir que, seria inviável diminuir a quantidade dos copolímeros das formulações, uma vez que, os dados dos três experimentos solubilidade, DSC e DRXP, evidenciaram uma diminuição nos valores de saturação e recristalização do EFV, provenientes da imiscibilidade fármaco-polímero. 
Figura 41- Difratogramas de raios $\mathrm{X}$ pelo método do pó do EFV puro, do $\mathrm{P} 188$ puro, da MF P188 1:1 e das DS P188 1:1 nos tempos (T1 e T2).

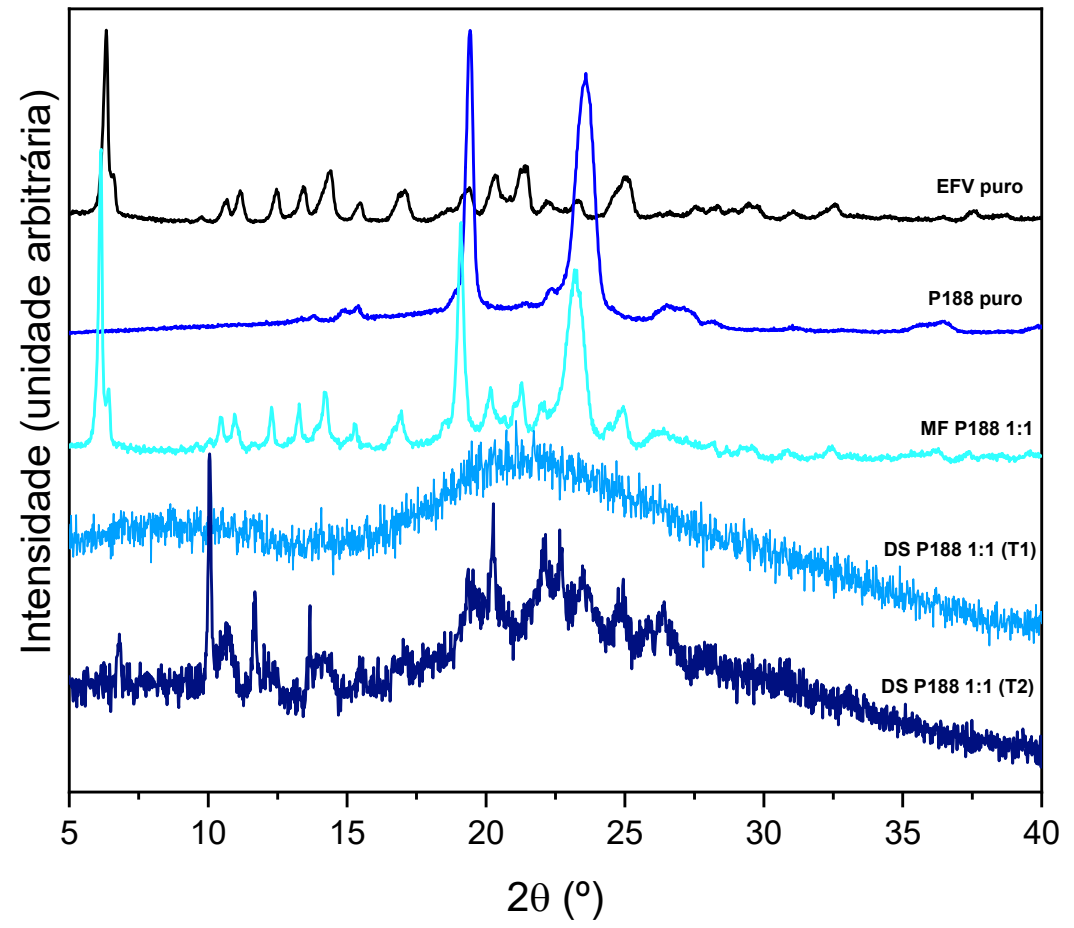

Fonte: Elaborado pelo autor.

Figura 42 - Difratogramas de raios X pelo método do pó do EFV puro, do P407 puro, da MF P407 1:1 e das DS P407 1:1 nos tempos (T1 e T2).

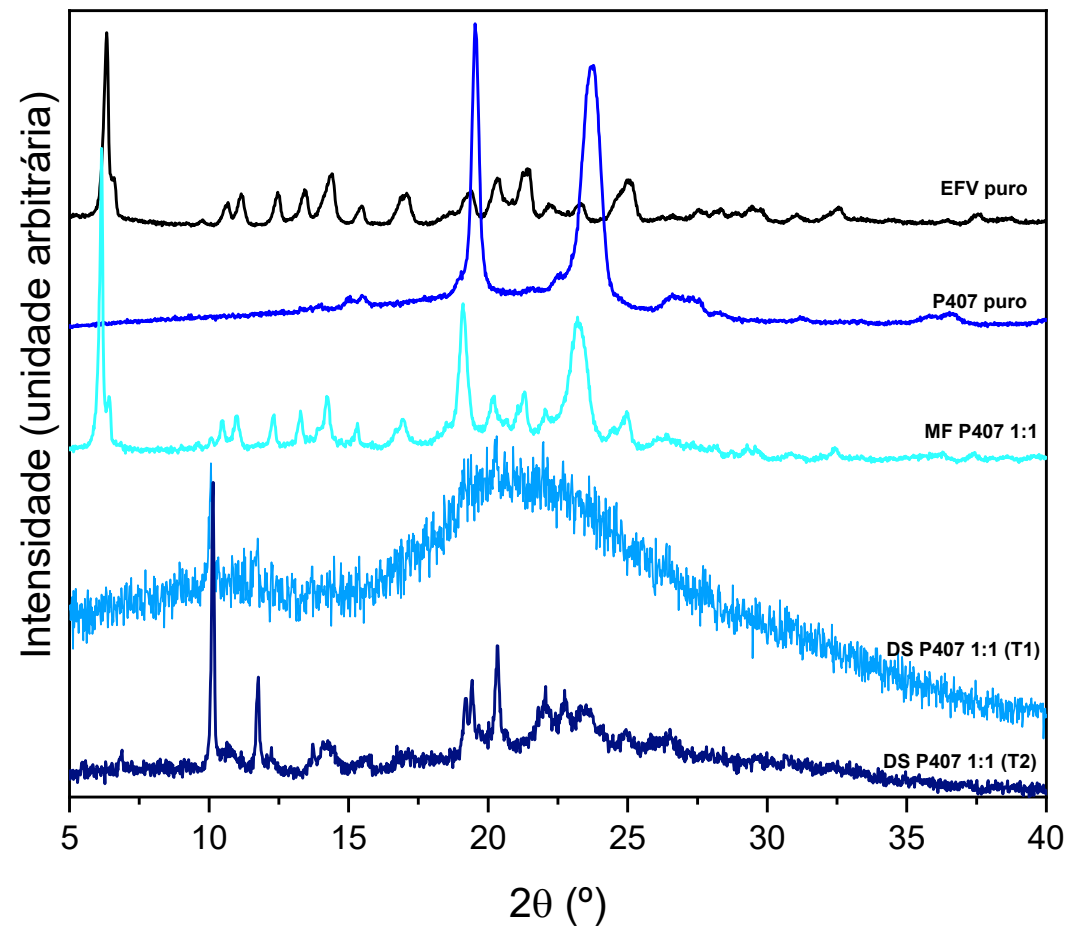

Fonte: Elaborado pelo autor. 
Tabela 12 - Resultados dos difratogramas de raios $X$ das matérias-primas (pura) e das misturas binárias, após o estudo de estabilidade onde foram classificadas como: totalmente amorfo (AAAA), semicristalino (AACC) e totalmente cristalino (CCCC)

\begin{tabular}{cccc}
\hline \hline Lâminas & Formulações e matérias-primas & $\begin{array}{c}\text { T1 } \\
\text { dia do preparo }\end{array}$ & $\begin{array}{c}\text { T2 } \\
\text { trinta dias após o preparo }\end{array}$ \\
\hline A & DS P188 1:1 & AAAA & AACC \\
B & DS P407 1:1 & AACC & AACC \\
C & EFV puro & CCCC & - \\
D & P188 puro & AACC & - \\
E & P407 puro & AACC & - \\
\hline \hline
\end{tabular}

Fonte: Elaborado pelo autor.

Figura 43 - Fotografias das lâminas de vidro contendo as misturas binárias, após a finalização do estudo de estabilidade. A - DS P188 e B - DS P407.

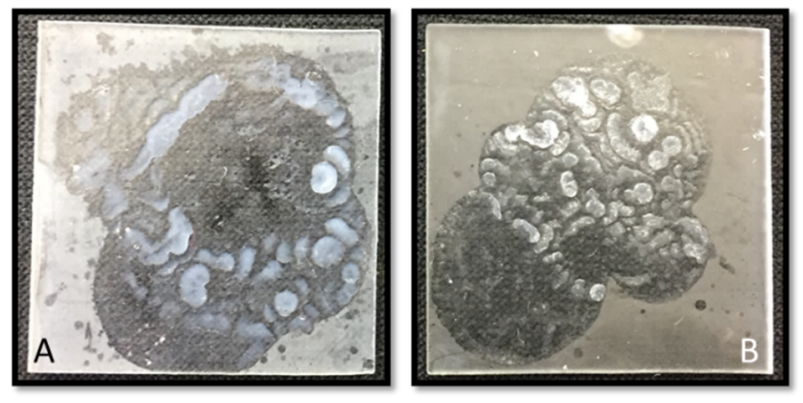

Fonte: Elaborado pelo autor.

\subsection{Caracterização físico-química das dispersões sólidas de efavirenz}

Para verificar o estado sólido final das DS, as análises de teor, dissolução, DRXP, DSC, TG e FTIR foram empregadas para caracterizar as propriedades físicoquímicas dos sistemas binários de poloxâmeros e EFV, comparadas com o EFV puro, copolímeros puros e MF. 


\subsubsection{Determinação do teor de efavirenz}

Os resultados obtidos da determinação do teor do EFV na matéria-prima e DS, preparadas por rotaevaporador na proporção de 1:3, estão apresentados na Tabela 13. Onde é possível evidenciar que a quantidade recuperada de fármaco das misturas binárias foi de $67,34 \%$ e de $63,30 \%$, para as DS P188 e DS P407, respectivamente. Esses valores estão em concordância com os resultados obtidos experimentalmente da matéria-prima (EFV puro) com recuperação de $65,38 \%$. A proximidade entre os valores de teor, indica uma boa eficiência da técnica empregada de evaporação do solvente no preparo das DS.

Tabela 13 - Valores de teor de EFV presente na matéria-prima e nas DS. Resultados representam os valores médios de três determinações e os respectivos desvios-padrão (DP)

\begin{tabular}{cc}
\hline \hline Amostra & Teor de EFV (\% \pm DP) \\
\hline EFV puro & $65,38 \pm 0,13$ \\
DS P188 & $67,34 \pm 0,65$ \\
DS P407 & $63,30 \pm 0,36$ \\
\hline \hline
\end{tabular}

Fonte: Elaborado pelo autor.

\subsubsection{Estudo de dissolução em condição sink pelo aparato 4 (Flow-Cell) e avaliação da eficiência de dissolução}

Os perfis de dissolução do EFV puro, das MF e das DS, sistemas binários produzidos com o auxílio dos carreadores P188 e P407 na proporção de 1:3, foram obtidos com o emprego do aparato IV Flow-Cell. O equivalente a $10 \mathrm{mg}$ do fármaco foi pesado e introduzido nas células de pós e grânulos, os resultados estão ilustrados na Figura 44 e resumidos na Tabela 14.

A determinação da taxa de dissolução em comparação com os estudos de solubilidade, não depende da concentração de saturação do IFA no meio aquoso, onde é menos sensível aos erros relacionados as possíveis mudanças de fase na formulação (KAROLEWICZ et al., 2017).

O ensaio foi realizado sob condições sink com emprego do Aparato USP tipo IV, com gradiente de $\mathrm{pH} 1,2$ nos primeiros $125 \mathrm{~min}, \mathrm{pH} 4,5$ nos próximos $125 \mathrm{~min}$ e pH 6,8 nos 125 min finais do ensaio, conforme descrito no item 4.2.4.2. O EFV em sua 
forma pura apresentou uma baixa taxa de dissolução cumulativa ( $\left.Q_{375} 21,93 \%\right)$, valor este atribuído principalmente à sua baixa solubilidade em água e propriedades de molhabilidade limitadas. Conforme discutido anteriormente o EFV é conhecido como fármaco pertencente a classe II do SCB, ou seja, apresenta alta permeabilidade e baixa solubilidade em água (menor que $10 \mu \mathrm{g} / \mathrm{mL}$ ) em sua forma cristalina (COSTA et al., 2019).

Contudo, optou-se por não utilizar o LSS, em consequência do equipamento possuir um fluxo intenso e continuo, pois o emprego do tensoativo, poderia propiciar uma acentuada formação de bolhas nas células de fluxo e prejudicar a dissolução. $O$ antirretroviral demonstrou não ser pH dependente e o valor de dissolução obtido está em concordância com os resultados do experimento de Pawar et al. (2016), onde os autores obtiveram uma taxa de dissolução menor que $20 \%$ em 90 min de ensaio, ao determinar o perfil de dissolução de $100 \mathrm{mg}$ de EFV em capsulas gelatinosas. Para o ensaio, os autores empregaram o Aparato USP tipo II, meio de dissolução constituído por $1000 \mathrm{~mL}$ de solução de $0,1 \mathrm{~N} \mathrm{HCl}$ contendo $0,2 \%$ de LSS para manter a condição sink do experimento (PAWAR et al., 2016).

Os perfis de dissolução das misturas binárias (MF e DS) de EFV com os carreadores P188 e P407, apresentaram os respectivos valores acumulativos de dissolução: MF P188 - Q375 89,39\%, MF P407 - Q375 104,35\%; DS P188 - Q375 80,59\% e DS P407 - Q Q 1015 103\%. A partir desses valores de dissolução, é possível evidenciar que as MF aparentaram uma maior capacidade de liberação do EFV, do que suas respectivas DS, contudo, ambas as preparações demonstraram melhores resultados em relação ao EFV puro.

O aumento na taxa de dissolução das formulações em relação ao fármaco puro cristalino, foi devido ao arranjo dos blocos de óxido de etileno e óxido de propileno presentes nos poloxâmeros, pois existe um autoarranjo da estrutura anfifilica em micelas em soluções aquosas. Essas micelas monomoleculares se associam para formar agregados de tamanhos variados, com a capacidade de solubilizar o fármaco (ELOY; MARCHETTI, 2014).

Em relação ao mecanismo de solubilização, pode-se dizer que, no estado seco, as partículas do composto ativo estão em contato próximo ou aderem às partículas do polímero como resultado da mistura. Quando a MF entra em contato com a água, as 
partículas de polímero são rapidamente hidratadas, solubilizando as partículas adjacentes do fármaco e liberando-as subsequentemente no meio aquoso (ELOY; MARCHETTI, 2014).

Contudo, a taxa de liberação da MF P407 foi superior ao da MF P188, onde ambas as preparações apresentaram uma liberação imediata do ativo, esse fenômeno foi discutido anteriormente no item 5.2.3, no qual é possível atribuir esse acontecimento ao maior número de segmentos de POE-POP-POE presente no P407, ver Quadro 5 (CHAUDHARI; DUGAR, 2017). Apesar disso, a DS P407 apresentou um comportamento de produto de liberação controlada, em comparação com a MF P407.

Os estudos de Karolewicz et al. (2017), investigaram que a presença do P407 em pH 1,2 na DS, ocasiona um retardo na liberação do fármaco imatinib devido à formação de uma camada viscosa de gel, enquanto que, em pH 6,8 foi observado um aumento significativo na taxa de dissolução do fármaco, a partir das DS em comparação com o imatinib puro. À medida que a concentração do polímero aumenta, a dissolução diminui devido à formação de uma camada viscosa de gel, o que dificulta a penetração da água no sistema binário, controlando e retardando a liberação do composto ativo (KAROLEWICZ et al., 2017).

A partir das informações citadas acima, é possível concluir que, a MF P407 no estado seco, facilita a liberação do fármaco, pois as partículas de polímero são rapidamente hidratadas. Já a DS P407 se apresenta no estado semissólido, o que propicia a formação de uma camada viscosa de gel ocasionando um controle e retardo na liberação do EFV em pH 1,2 (ELOY; MARCHETTI, 2014; KAROLEWICZ et al., 2017).

O P407 demonstrou mais uma vez, uma taxa de liberação maior do EFV em relação ao P188, contudo, nesse estudo as MF apresentaram uma maior taxa de dissolução do fármaco em relação as DS. No estudo de solubilidade por shake-flask, os resultados evidenciados foram o oposto, ou seja, as DS apresentaram uma maior taxa de saturação do que as MF. 
Tabela 14 - Porcentagem de EFV dissolvida em função do tempo a partir do EFV puro, das MF e das DS empregando os carreadores P188 e P407, em experimento utilizando o aparato IV, fluxo de $8 \mathrm{~mL} / \mathrm{min}$ e gradiente de $\mathrm{pH}$ como apresentado a seguir: solução tampão de $\mathrm{HCl}$ $\mathrm{pH} 1,2$ nos primeiros 125 minutos, solução tampão de acetado pH 4,5 de 125-250 minutos e solução tampão fosfato $\mathrm{pH}$ 6,8 de 250-375 minutos finais do ensaio

\begin{tabular}{|c|c|c|c|c|c|}
\hline \multirow{2}{*}{$\begin{array}{c}\text { Tempo } \\
(\min )\end{array}$} & \multicolumn{5}{|c|}{ Amostras } \\
\hline & $\begin{array}{c}\text { EFV puro } \\
(\% \pm D P)\end{array}$ & $\begin{array}{l}\text { MF P188 } \\
(\% \pm \text { DP) }\end{array}$ & $\begin{array}{l}\text { MF P407 } \\
(\% \pm D P)\end{array}$ & $\begin{array}{l}\text { DS P188 } \\
(\% \pm D P)\end{array}$ & $\begin{array}{l}\text { DS P407 } \\
\text { (\% } \pm \text { DP) }\end{array}$ \\
\hline $0-25$ & $1,30 \pm 0,56$ & $14,74 \pm 0,35$ & $69,92 \pm 2,42$ & $12,90 \pm 1,89$ & $7,62 \pm 2,20$ \\
\hline $25-50$ & $2,57 \pm 0,61$ & $28,87 \pm 1,25$ & $79,80 \pm 2,86$ & $29,61 \pm 3,23$ & $17,08 \pm 4,40$ \\
\hline $50-75$ & $3,73 \pm 0,66$ & $41,44 \pm 3,39$ & $85,87 \pm 3,26$ & $46,31 \pm 4,43$ & $27,09 \pm 5,62$ \\
\hline $75-100$ & $4,86 \pm 0,63$ & $51,29 \pm 6,21$ & $89,86 \pm 3,73$ & $56,76 \pm 3,42$ & $33,00 \pm 5,38$ \\
\hline $100-125$ & $6,03 \pm 0,59$ & $59,58 \pm 8,77$ & $92,35 \pm 4,03$ & $64,24 \pm 10,17$ & $39,22 \pm 5,63$ \\
\hline $125-150$ & $7,26 \pm 0,60$ & $65,30 \pm 8,18$ & $94,41 \pm 4,63$ & $69,42 \pm 15,22$ & $45,10 \pm 4,82$ \\
\hline $150-175$ & $8,63 \pm 0,57$ & $69,90 \pm 8,25$ & $96,00 \pm 4,81$ & $72,58 \pm 17,94$ & $51,94 \pm 4,70$ \\
\hline $175-200$ & $10,07 \pm 0,53$ & $73,49 \pm 8,62$ & $97,65 \pm 4,77$ & $73,36 \pm 17,79$ & $59,87 \pm 4,62$ \\
\hline $200-225$ & $11,63 \pm 0,50$ & $77,86 \pm 7,22$ & $98,87 \pm 4,92$ & $75,41 \pm 17,64$ & $69,59 \pm 5,08$ \\
\hline $225-250$ & $13,33 \pm 0,48$ & $81,30 \pm 6,61$ & $100,01 \pm 5,16$ & $77,34 \pm 17,48$ & $77,27 \pm 5,81$ \\
\hline $250-275$ & $14,93 \pm 0,70$ & $82,99 \pm 6,44$ & $100,96 \pm 5,31$ & $78,45 \pm 17,18$ & $85,13 \pm 6,83$ \\
\hline $275-300$ & $16,61 \pm 0,84$ & $84,56 \pm 6,46$ & $101,89 \pm 5,48$ & $79,08 \pm 17,16$ & $89,83 \pm 7,79$ \\
\hline $300-325$ & $18,31 \pm 0,99$ & $86,13 \pm 6,51$ & $102,67 \pm 5,57$ & $79,75 \pm 17,15$ & $93,83 \pm 9,32$ \\
\hline $325-350$ & $20,06 \pm 1,17$ & $87,78 \pm 6,54$ & $103,52 \pm 5,72$ & $80,16 \pm 17,12$ & $97,47 \pm 11,54$ \\
\hline $350-375$ & $21,93 \pm 1,25$ & $89,39 \pm 6,46$ & $104,35 \pm 5,84$ & $80,59 \pm 17,23$ & $101,03 \pm 13,74$ \\
\hline
\end{tabular}

Os resultados representam a média de três determinações $(n=3)$. O DP obteve um valor elevado, devido ao fato do filtro do equipamento Aparato USP tipo IV apresentar uma saturação, que impediu a degaseificação do sistema ocasionando bolhas nas células de fluxo, e assim dificultando a molhabilidade das amostras.

Fonte: Elaborado pelo autor. 
Figura 44 - Perfis médios de dissolução do EFV em função do tempo obtidos a partir do EFV puro, das MF e das DS empregando os carreadores P188 e P407, preparadas na proporção de 1:3, em experimento utilizando o aparato IV Flow-Cell, fluxo de $8 \mathrm{~mL} / \mathrm{min}$ e gradiente de $\mathrm{pH}$ como apresentado a seguir: solução tampão de $\mathrm{HCl}$ pH 1,2 nos primeiros 125 minutos, solução tampão de acetado $\mathrm{pH}$ 4,5 de 125-250 minutos e solução tampão fosfato pH 6,8 de 250-375 minutos finais do ensaio.

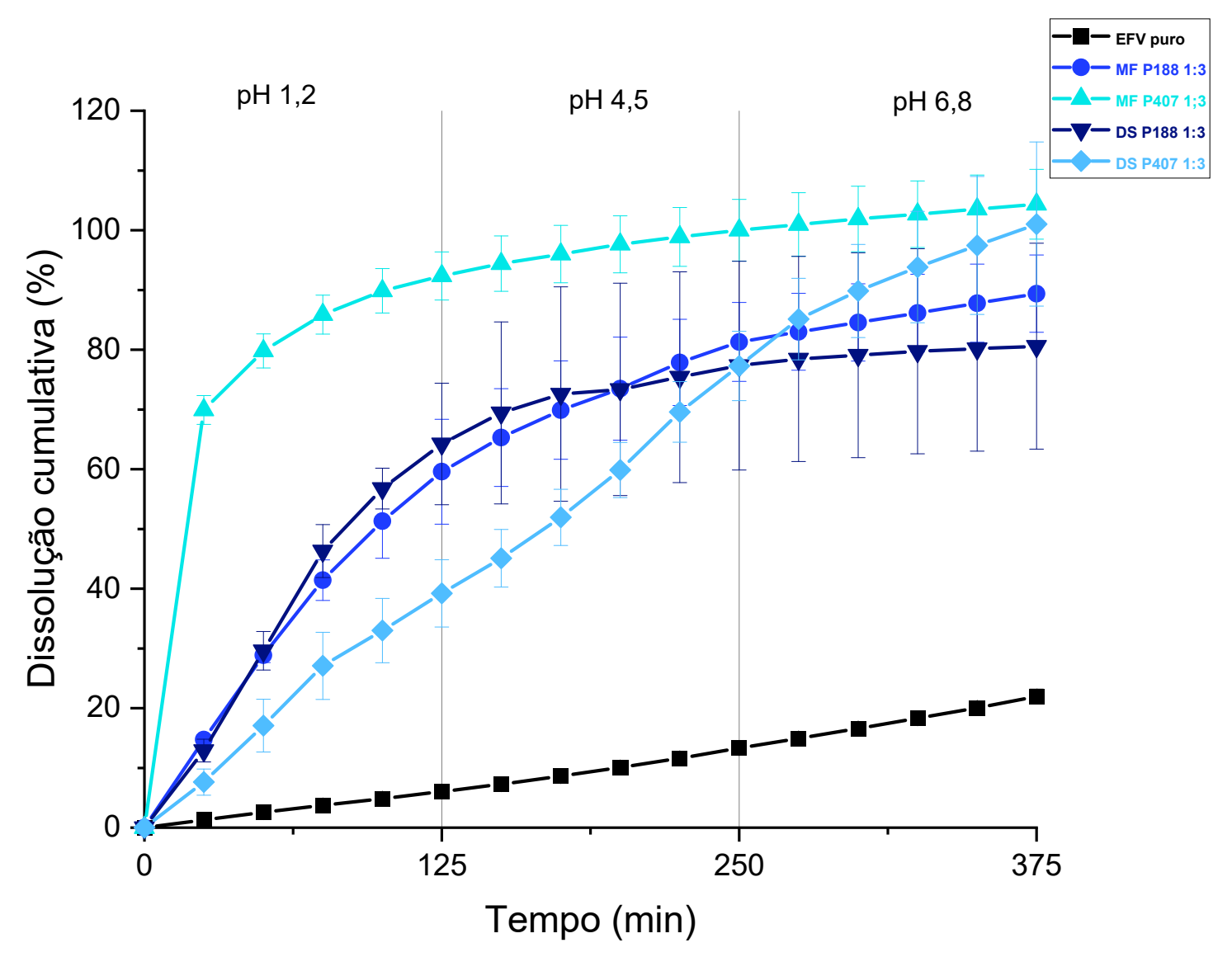

Fonte: Elaborado pelo autor.

Segundo Serra e Storpirtis (2007) a eficiência de dissolução (ED\%) foi estabelecida como a área sob a curva de dissolução em um determinado intervalo de tempo. Onde esse parâmetro permite comparações genuínas entre dois produtos. Contudo, a ED\% está associada com a quantidade real de fármaco que se encontra dissolvida no meio e, desta forma, é possível prever resultados in vivo (SERRA; STORPIRTIS, 2007).

A ED\% do EFV puro, das MF e das DS utilizando os carreadores P188 e P407, foi calculada com o auxílio do suplemento do Excel DDsolver $®$, e os resultados obtidos com o emprego do Aparato IV estão descritos na Tabela 15. 
O EFV puro demonstrou uma baixa ED\% (10,02\%), pois o antirretroviral pertence à classe II do SCB, ou seja, apresenta alta permeabilidade e baixa solubilidade (COSTA et al., 2019). Os resultados de ED\% das preparações binárias de MF e de DS de EFV com o carreador P188 foram comparadas e apresentaram valores semelhantes (MF P188 - 63,33\%; DS P188 - 62,38\%). A partir desses valores é possível evidenciar que, a MF P188 obteve uma porcentagem maior de ED\% em relação a DS P188. Os sistemas binários obtidos com o copolímero P407, apresentaram uma indiscutível discrepância nos resultados, onde a MF P407 exibiu resultados de ED\% igual a 91,06\%, enquanto a DS P407 apresentou ED\% igual a $56,30 \%$. Contudo, vale ressaltar que, os valores de dissolução da MF P407 e DS P407 realizada sob condição sink foram próximos entre si.

$\mathrm{Na}$ comparação dos resultados com o EFV puro, todas as formulações obtiveram uma maior taxa de ED\%. A conclusão obtida para o fenômeno de maior liberação do EFV das MF, foi em virtude, das preparações se apresentarem no estado seco e as partículas do polímero são rapidamente hidratadas, facilitando a liberação do composto ativo. Para as DS a conclusão se deu por conta do estado semissólido da formulação, o que favorece a formação de uma camada viscosa de gel ocasionando um controle e retardo na liberação do EFV em pH 1,2 (ELOY; MARCHETTI, 2014; KAROLEWICZ et al., 2017).

O carreador P407 possui maiores números de segmentos de POE-POP-POE, em comparação ao P188, esses segmentos são triblocos não iônico de copolímeros com propriedades tensoativas, capazes de incorporar fármacos lipofílicos, resultando em melhores taxas de liberação do EFV (CHAUDHARI; DUGAR, 2017; COLOMBO et al., 2019).

Apesar dos resultados de ED\% se demonstrarem favoráveis para as MF, vale ressaltar que, quando preparadas na proporção de 1:3 apresentaram cristalinidade do EFV, dados observados através da DRXP (item 5.4.3). Esses resultados de DRXP, podem corroborar com a baixa capacidade de saturação do antirretroviral empregando as MF P407 na proporção de 1:3 (item 5.2.3). Contudo, a cristalinidade do EFV não foi evidenciada nas DS empregando os carreadores P188 e P407 na proporção de $1: 3$, onde as misturas binárias foram capazes de amorfizar e estabilizar o EFV e apresentaram expressivos valores de saturação em comparação com as MF. 
Tabela 15 - Valores de eficiência de dissolução (ED\%) do EFV puro, das MF e das DS empregando os carreadores P188 e P407 obtidos na proporção de 1:3, avaliados em tempo de ensaio de 375 minutos em gradiente de $\mathrm{pH}$

\begin{tabular}{cc}
\hline \hline Amostra & Eficiência de Dissolução (\%) \\
\hline EFV puro & 10,02 \\
MF P188 & 63,33 \\
MF P407 & 91,06 \\
DS P188 & 62,38 \\
DS P407 & 56,30 \\
\hline \hline
\end{tabular}

Fonte: Elaborado pelo autor.

\subsubsection{Difratometria de raios $X$ pelo método do pó}

As análises das amostras foram realizadas conforme a descrição do item 4.2.4.3. Os padrões de DRXP do EFV puro (polimorfo I), dos copolímeros puros, das MF e das DS amorfas finais, obtidas na proporção de 1:3 estão ilustrados na Figura 45. O EFV cristalino, o P188 e o P407 exibiram picos característicos na faixa de $2 \theta$ nos espectros de DRXP.

Enquanto que, as MF apresentam uma mescla dos picos do EFV e dos poloxâmeros, contudo, é possível evidenciar uma atenuação na intensidade dos picos característicos do antirretroviral, devido a proporção fármaco-carreador. As duas formulações de DS empregando os copolímeros, demonstraram ausência de quaisquer picos de Bragg do EFV e a capacidade do sistema em amorfizar e estabilizar o fármaco. 
Figura 45 - Difratogramas de raios $X$ pelo método do pó do polimorfo I do EFV puro, do P188 puro, P 407 puro, das MF e das DS obtidas na proporção de 1:3.

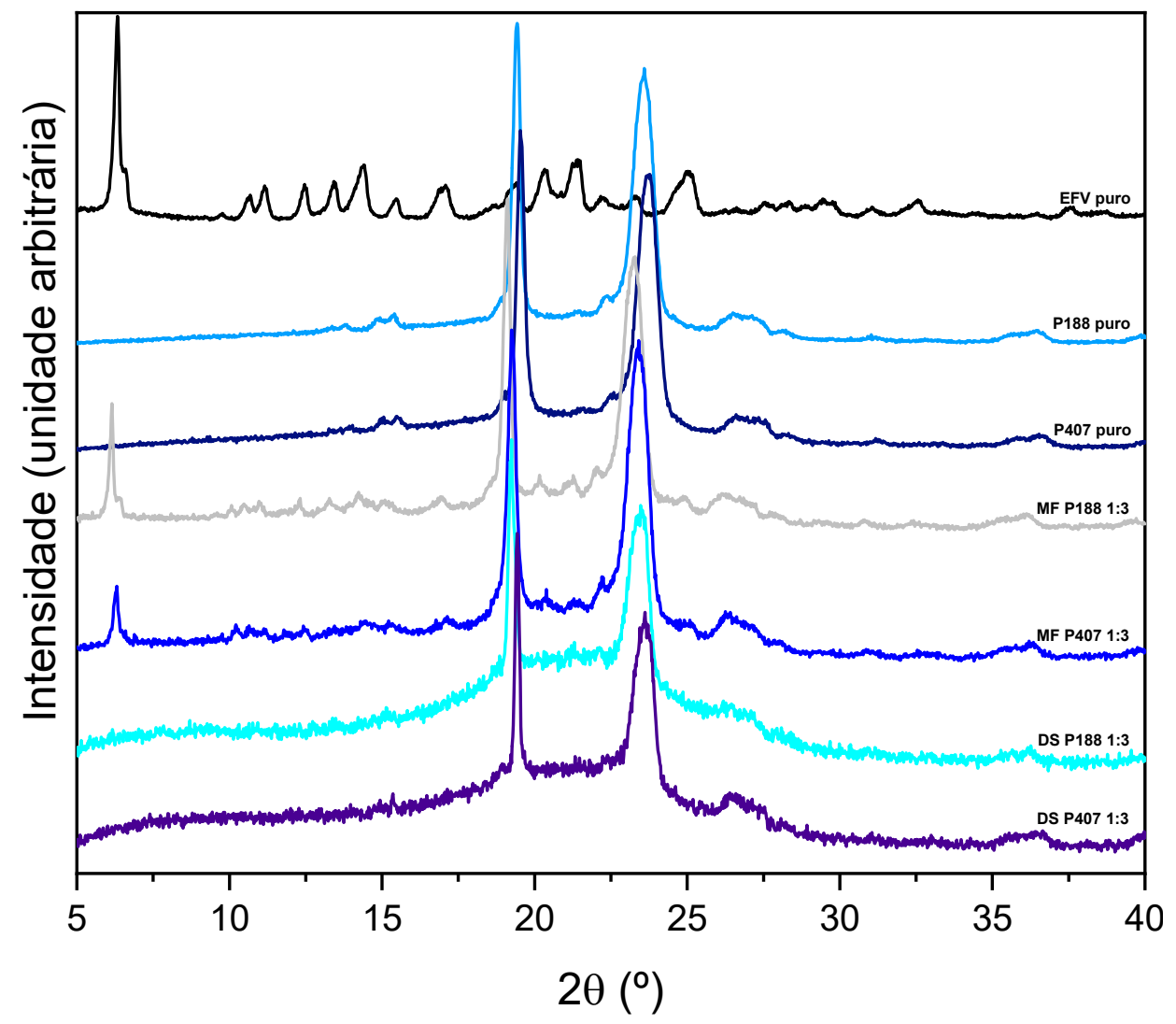

Fonte: Elaborado pelo autor.

\subsubsection{Calorimetria exploratória diferencial}

As curvas DSC do fármaco puro, dos carreadores puro e das MF foram obtidas empregando o equipamento PerkinElmer DSC 4000 e as curvas DSC das DS foram obtidas através do equipamento DSC Q20 TA Instruments, conforme descrição do método no item 4.2.4.4.

As Figuras 46 e 47 ilustram as curvas DSC do EFV puro, dos P188 e P407, das MF e das DS obtidas nas proporções de 1:3. As análises do EFV, do P188 e do P407, além de suas respectivas MF foram amplamente discutidas no item 5.3.2.

Nos ensaios das DS, foi possível evidenciar uma completa ausência do pico endotérmico do EFV nas formulações, esse evento indica uma provável amorfização do antirretroviral nas DS, ou mesmo uma possível formação de solução sólida. Evidenciou-se nas curvas DSC das preparações da DS P188 e da DS P407 um 
deslocamento dos pontos de fusão dos copolímeros. Os picos endotérmicos dos polímeros surgiram abaixo dos $40{ }^{\circ} \mathrm{C}$ para ambas as amostras, sendo que, os poloxâmeros são sólidos semicristalinos em suas formas puras, onde a fusão transcorreu por volta dos $55^{\circ} \mathrm{C}$. Provavelmente esse episódio pode ser justificado pela consistência das DS, que passaram para o estado semissólido e consequentemente menos energia foi necessário para promover a fusão do sistema binário durante a varredura DSC. Os picos acima mencionados são deslocados para temperaturas mais baixas, em comparação com a forma pura dos carreadores, que é um provável indicador de algum grau de miscibilidade entre fármaco-polímeros (MARSAC; LI; TAYLOR, 2009; MEDAREVIĆ et al., 2016).

A curva DSC da DS P188 apresentou um evento exotérmico por volta dos $140{ }^{\circ} \mathrm{C}$, o que provavelmente indica uma possível recristalização do sistema binário. Contudo, esse fenômeno apresentou um deslocamento de aproximadamente $20{ }^{\circ} \mathrm{C}$ ao se comparar com o P188 puro, e por sua vez, a curva DSC da DS P407 exibiu um desaparecimento do mesmo evento térmico. Para Baird e Taylor:

O comportamento de fusão do fármaco cristalino foi alterado pela presença do polímero, esse acontecimento se manifestou pela redução do ponto de fusão, denominado de "depressão do ponto de fusão". Termodinamicamente, as mudanças no comportamento de fusão surgem porque, à medida que o polímero se mistura espontaneamente com a fase líquida do fármaco, existe uma energia livre negativa da mistura, e o potencial químico do composto ativo na mistura é reduzido em relação ao fármaco líquido puro. Isso, por sua vez, torna o processo de fusão mais favorável termodinamicamente, levando à depressão do ponto de fusão. Conceitualmente, a depressão do ponto de fusão na presença do polímero é igual à dissolução do fármaco no polímero (BAIRD; TAYLOR, 2012, p. 410). 
Figura 46 - Curvas DSC do EFV puro, do P188 puro, da MF P188 e da DS P188 (1:3) obtidas a $10^{\circ} \mathrm{C} / \mathrm{min}$ e atmosfera dinâmica de nitrogênio com vazão de $50 \mathrm{~mL} \mathrm{~min}{ }^{-1}$.

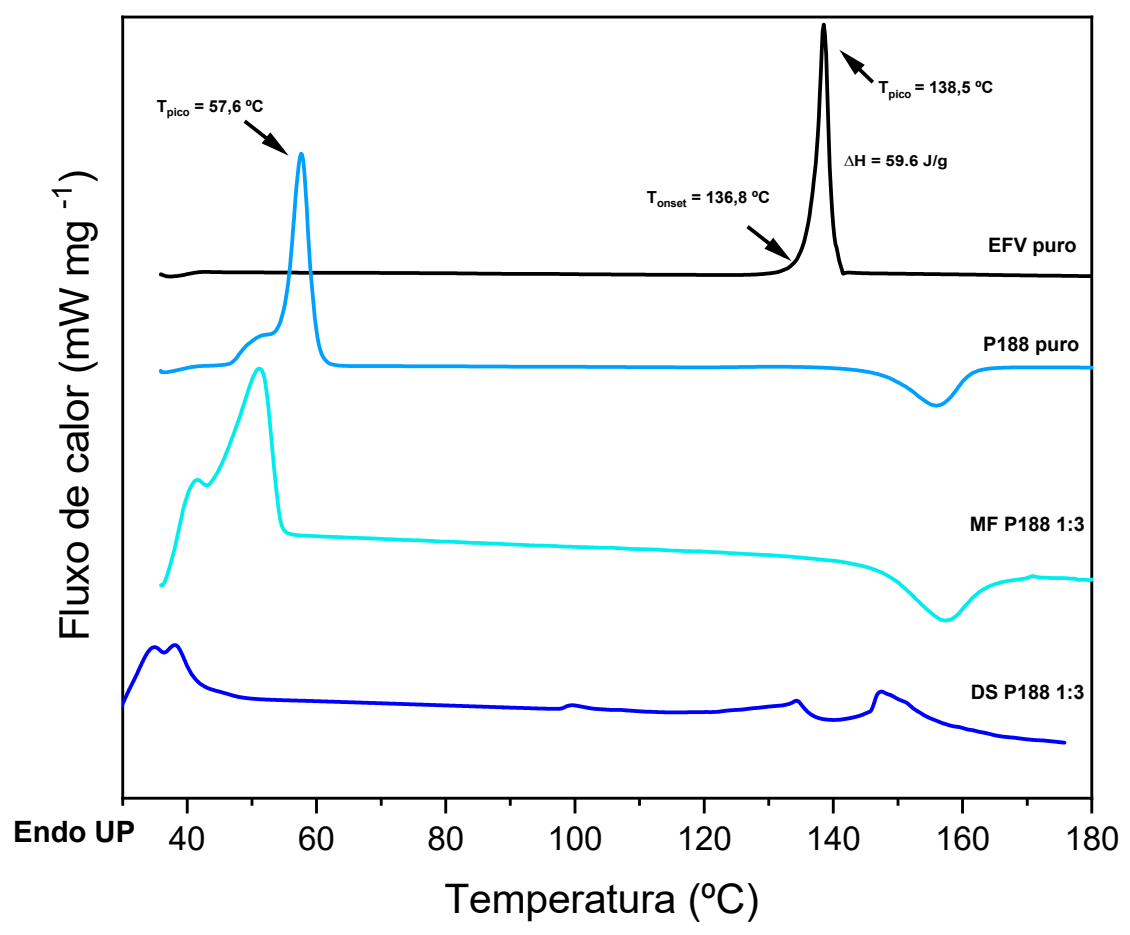

Fonte: Elaborado pelo autor.

Figura 47 - Curvas DSC do EFV puro, do P407 puro, da MF P407 e da DS P407 (1:3) obtidas a $10^{\circ} \mathrm{C} / \mathrm{min}$ e atmosfera dinâmica de nitrogênio com vazão de $50 \mathrm{~mL} \mathrm{~min}^{-1}$.

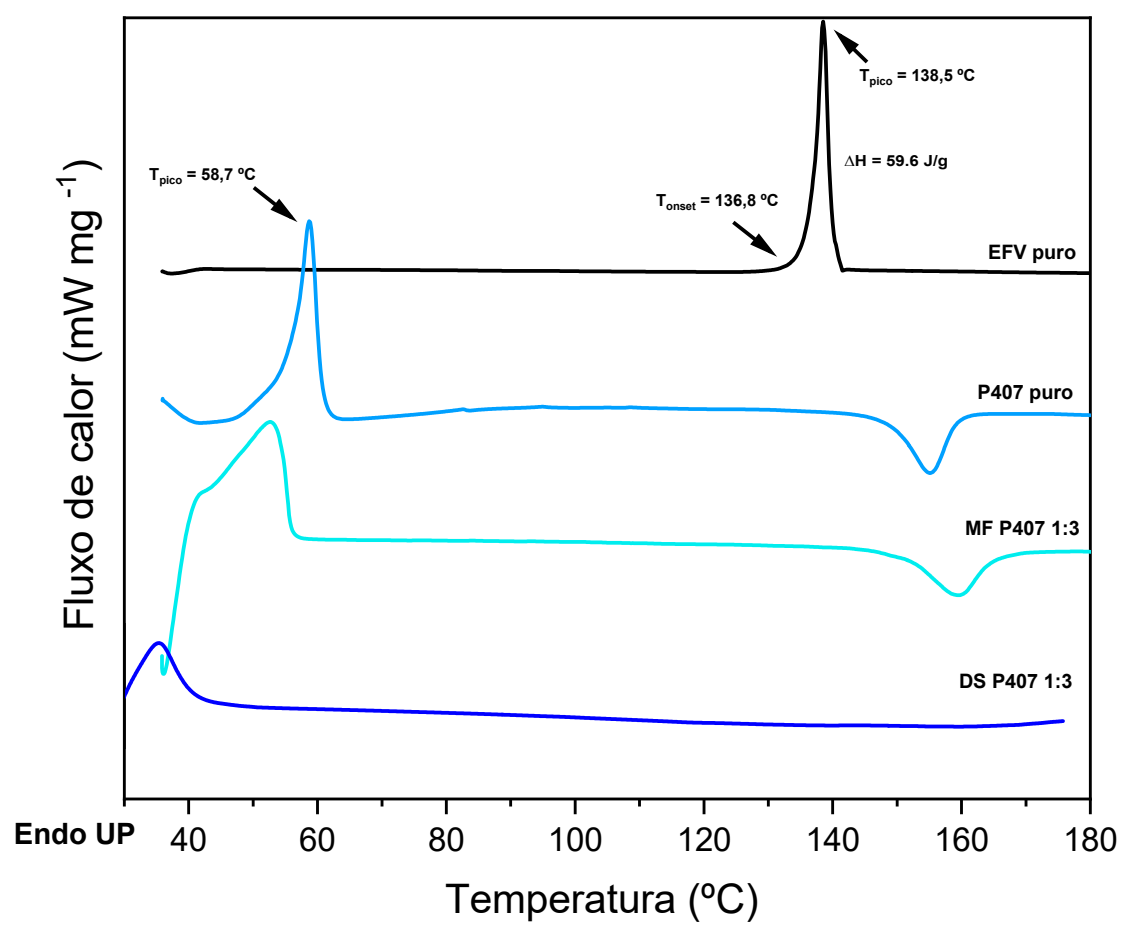

Fonte: Elaborado pelo autor. 


\subsubsection{Termogravimetria}

O estado sólido das amostras do EFV puro, das MF e das DS empregando os carreadores P188 e P407, foi caracterizado por análises termogravimétricas os resultados obtidos estão ilustrados nas Figuras 48 e 49. As preparações foram analisadas conforme o item 4.2.4.5.

A curva TG do EFV não demonstrou perda de massa até aproximadamente $200{ }^{\circ} \mathrm{C}$ e a decomposição completa do antirretroviral ocorreu por volta dos $260{ }^{\circ} \mathrm{C}$, apresentando uma redução da massa do composto ativo em torno de $95 \%$, conforme evidenciado na literatura (FANDARUFF et al., 2014b). As curvas TG dos poloxâmeros 188 e 407 puros se mostraram estáveis até aproximadamente $250^{\circ} \mathrm{C}$, onde a decomposição térmica completa dos copolímeros ocorreu por volta dos $400{ }^{\circ} \mathrm{C}$ com uma degradação química de $99 \%$ para ambos os carreadores (LI et al., 2015).

As MF apresentaram os mesmos comportamentos térmico dos poloxâmeros, pois é possível evidenciar que as curvas TG não exibiram diminuição de massa em até $220^{\circ} \mathrm{C}$ para a MF P188 e MF P407; contudo, uma segunda decomposição térmica iniciou-se por volta dos $350^{\circ} \mathrm{C}$ e finalizando por volta dos $400^{\circ} \mathrm{C}$, demonstrando uma redução de massa de $99 \%$ para ambas as formulações.

As curvas TG das DS empregando os carreadores P188 e P407, exibiram uma perda de massa de aproximadamente $5 \%$ entre $25^{\circ} \mathrm{C}$ e $200^{\circ} \mathrm{C}$, muito provavelmente devido à evaporação de solventes provenientes da obtenção dos sistemas binários. Para ambas as DS uma segunda etapa de composição é observada entre aproximadamente $350^{\circ} \mathrm{C}$ e $400{ }^{\circ} \mathrm{C}$, com uma perda de massa de aproximadamente $70 \%$. 
Figura 48 - Curvas TG do EFV puro, do P188 puro, da MF P188 e da DS P188 (1:3) obtidas a $10^{\circ} \mathrm{C} / \mathrm{min}$ e atmosfera dinâmica de nitrogênio com vazão de $50 \mathrm{~mL} \mathrm{~min}^{-1}$.

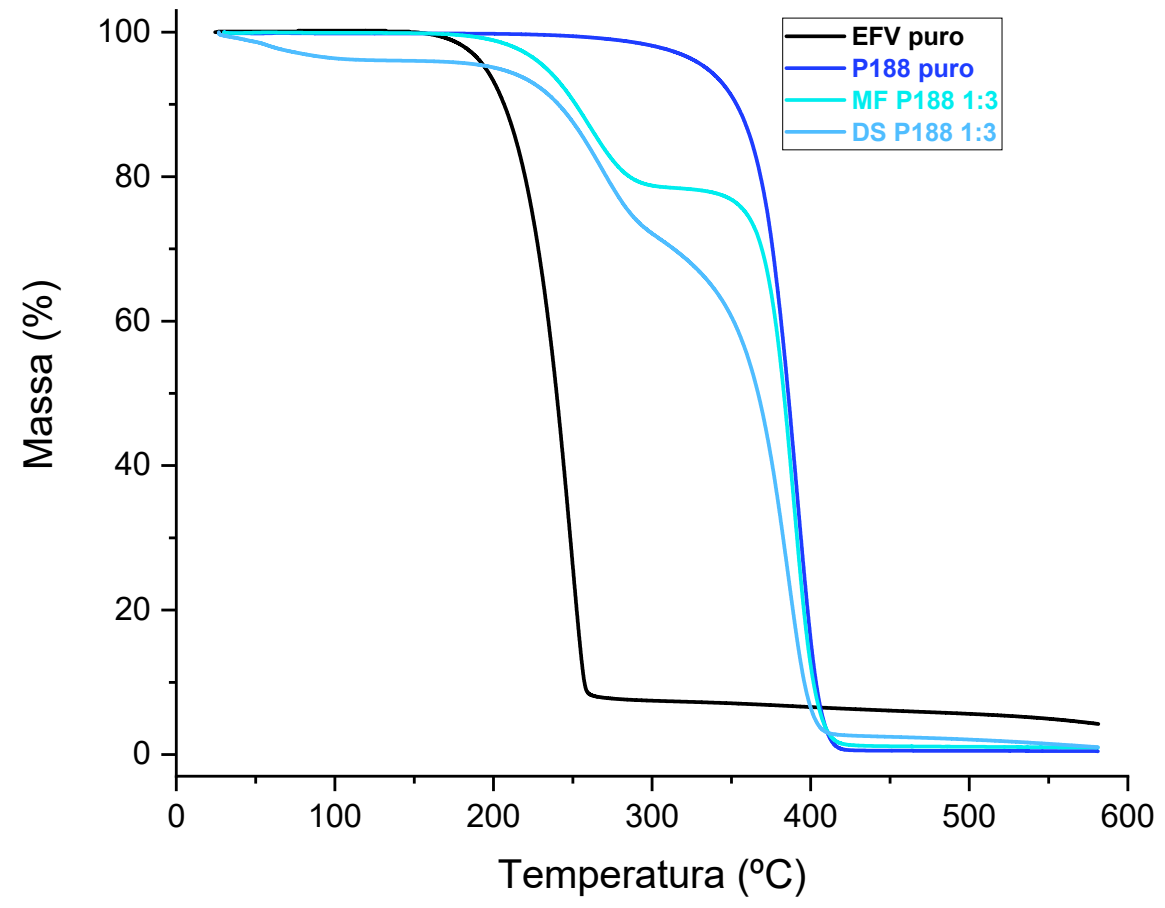

Fonte: Elaborado pelo autor.

Figura 49 - Curvas TG do EFV puro, do P407 puro, da MF P407 e da DS P407 (1:3) obtidas a $10^{\circ} \mathrm{C} / \mathrm{min}$ e atmosfera dinâmica de nitrogênio com vazão de $50 \mathrm{~mL} \mathrm{~min}^{-1}$.

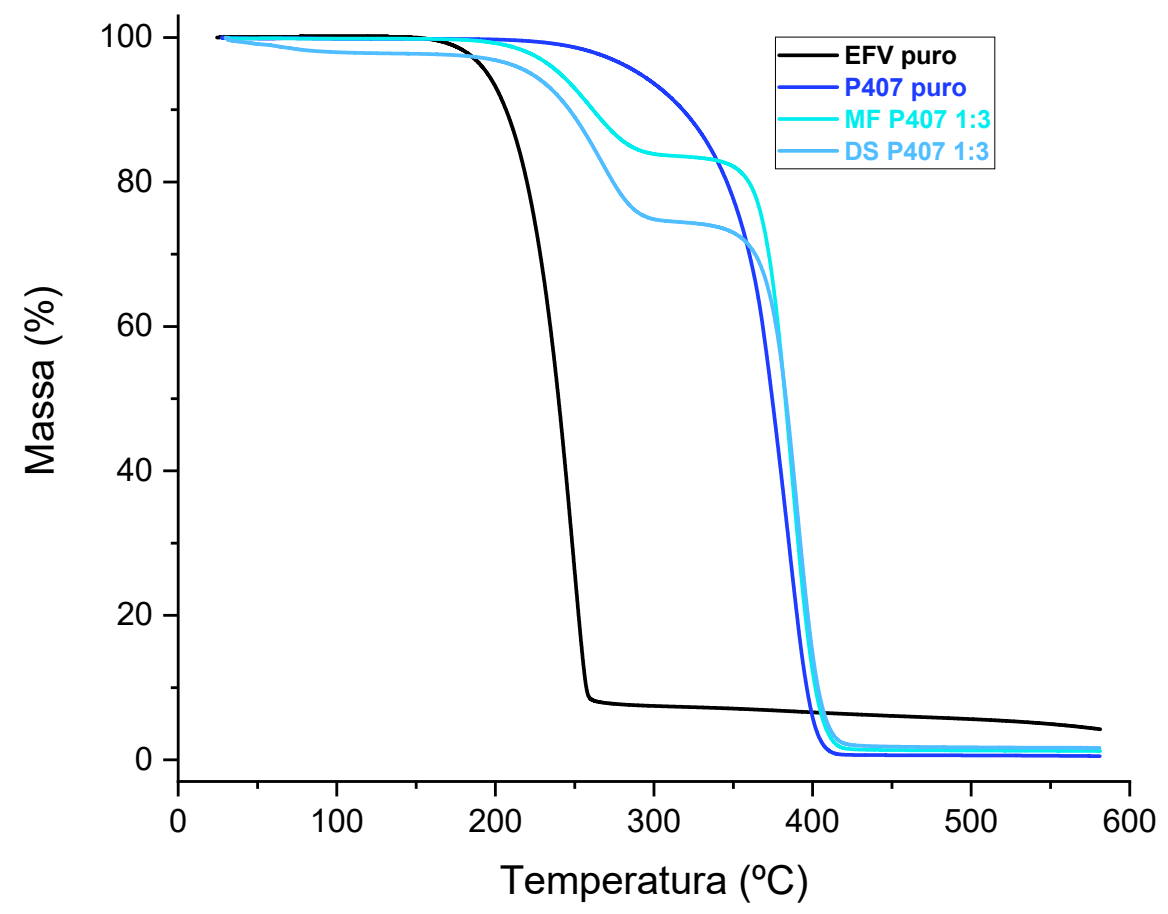

Fonte: Elaborado pelo autor. 


\subsubsection{Espectroscopia na região do infravermelho com transformada de Fourier}

Os espectros de FTIR do EFV, dos carreadores (P188 e P407), das MF e das DS, estão ilustradas nas Figuras 50 e 51 . As preparações foram analisadas conforme o item 4.2.4.6.

O espectro do EFV puro exibiu bandas características e bem definidas na região do infravermelho de 1074 - $1097 \mathrm{~cm}^{-1}$ vibração do estiramento de $\mathrm{C}-\mathrm{Cl}$, 1185 - $1198 \mathrm{~cm}^{-1}$ vibração do estiramento de C-F, 1495 e $1602 \mathrm{~cm}^{-1}$ vibração do estiramento de $\mathrm{C}=\mathrm{C}$ anel de benzeno, $1746 \mathrm{~cm}^{-1}$ vibração do estiramento de $\mathrm{C}=\mathrm{O}$, $2250 \mathrm{~cm}^{-1}$ vibração do estiramento de $\mathrm{C} \equiv \mathrm{C}$ e $3317 \mathrm{~cm}^{-1}$ vibração do estiramento de N-H (ALVES et al., 2014; MARQUES et al., 2017; MISHRA; TANDON; AYALA, 2012).

Os espectros dos poloxâmeros 188 e 407 apresentaram bandas semelhantes e características em $1103 \mathrm{~cm}^{-1}, 1342 \mathrm{~cm}^{-1}$ e $2884 \mathrm{~cm}^{-1}$, onde foram evidenciados vibração dos planos, estiramento de $\mathrm{C}-\mathrm{O}$, dobramento planar de $\mathrm{O}-\mathrm{H}$ e estiramento de C-H alifático respectivamente (COLOMBO et al., 2019; GARALA et al., 2013; KAROLEWICZ et al., 2017; MEDAREVIĆ et al., 2016).

As análises espectrais confirmaram que, a maioria das bandas originárias do EFV e polímeros P188 e P407 mantiveram suas posições nos espectros das MF e das DS, com exceção do grupamento amina ( $\mathrm{N}-\mathrm{H}$ em $\left.3317 \mathrm{~cm}^{-1}\right)$ presente no EFV, que apresentou desaparecimento nas misturas binárias para ambos os carreadores. Esse desaparecimento sugere que ocorreu uma provável interação intermolecular no estado sólido entre fármaco-polímero.

Os estudos de Lavra (2016), evidenciaram o mesmo desaparecimento da vibração de estiramento do $\mathrm{N}-\mathrm{H}$ em $3317 \mathrm{~cm}^{-1}$ da molécula do $E F V$, ao obter DS amorfas empregando os carreadores Soluplus ${ }^{\circledR}$, PVPVA64 e HMPCAS. A autora concluiu que, esse fenômeno foi em decorrência de interações de ligações de $\mathrm{H}^{+}$entre o grupo N-H (LAVRA., 2016). A pesquisa de Lavra (2016) informa que, o trabalho de Koh et al. (2013) reportaram o mesmo evento, no qual os autores atribuíram esse fenômeno de desaparecimento ao prepararem DS ternárias de EFV empregando os carreadores PVP-K30 e PEG 8000. Os autores evidenciaram que a região de vibração do estiramento do $\mathrm{N}-\mathrm{H}$ do EFV desapareceu em todos os sistemas de DS, o espectro de FTIR apresentou redução no pico e ligeira alteração da banda do estiramento do $\mathrm{C}=\mathrm{O}$ em todas as formulações investigadas. Esse fato pode ser devido as interações 
físicas entre fármaco e os polímeros, sugerindo ligação intermolecular de hidrogênio. Pois a partir da estruturas de EFV, pôde-se supor que uma possível interação seria através de ligação de hidrogênio entre os grupos $\mathrm{C}=\mathrm{O}$ e $\mathrm{N}-\mathrm{H}$ do antirretroviral, com o par solitário de elétrons do átomo de oxigênio ( $\mathrm{KOH}$ et al., 2013).

Fontes et al. (2016) observaram que, ao preparar sistemas binários de EFVLDH (Layered double hydroxides), os espectros de FTIR apresentaram desaparecimento da vibração do estiramento de $\mathrm{N}-\mathrm{H}$, redução da vibração de estiramento $\mathrm{C}=\mathrm{O}$ e redução da vibração de estiramento de $\mathrm{C}=\mathrm{C}$ no anel aromático (em 1600 e $1495 \mathrm{~cm}^{-1}$ ), com predominância das bandas em relação ao LDH. Os autores concluíram que, os resultados demostraram uma possível interação entre EFV e $\mathrm{LDH}$ em radicais como $\mathrm{N}-\mathrm{H}$ e $\mathrm{C}=\mathrm{O}$ presentes no antirretroviral, tornando esses sinais de ligação menos evidentes no espectro de FTIR (FONTES et al., 2016).

O trabalho de Sathigari et al. (2012), atribuíram o desaparecimento da banda de estiramento do $\mathrm{N}-\mathrm{H}$, devido a uma provável interação entre os grupos doadores de prótons $(\mathrm{N}-\mathrm{H})$ do $\mathrm{EFV}$, com os grupos receptores de prótons $(\mathrm{C}=\mathrm{O})$ presente na molécula do polímero Plasdone S-630. Ao obter DS amorfas de EFV utilizando o carreador Plasdone S-630, empregando a técnica de extrusão a quente (SATHIGARI et al., 2012).

A partir dessas informações, é possível evidenciar nas Figuras 50 e 51 uma diminuição na vibração de estiramento do $\mathrm{C}=\mathrm{O}$ em $2250 \mathrm{~cm}^{-1}$ do $\mathrm{EFV}$, onde é plausível supor que houve uma interação com ligação de $\mathrm{H}^{+}$entre o grupo aceptor de prótons $(\mathrm{C}=\mathrm{O})$, e do grupo doador de prótons do grupamento $\mathrm{N}-\mathrm{H}$ do $\mathrm{EFV}$. Dessa forma, uma banda larga em torno de $3500 \mathrm{~cm}^{-1}$ sobressaiu no espectros de ambas as DS, atribuída provavelmente à presença de estiramento de $-\mathrm{OH}$ (PAWAR et al., 2016). A ausência de deslocamento das bandas, foi evidenciada devido a semelhança à sobreposição dos espectros dos componentes individuais, enquanto, as intensidades foram atenuadas possivelmente devido à menor proporção do EFV nas formulações. 
Figura 50 - Espectros de infravermelho com transformada de Fourier do EFV puro, do P188 puro, da MF P188 e da DS P188 obtidas na proporção de 1:3.

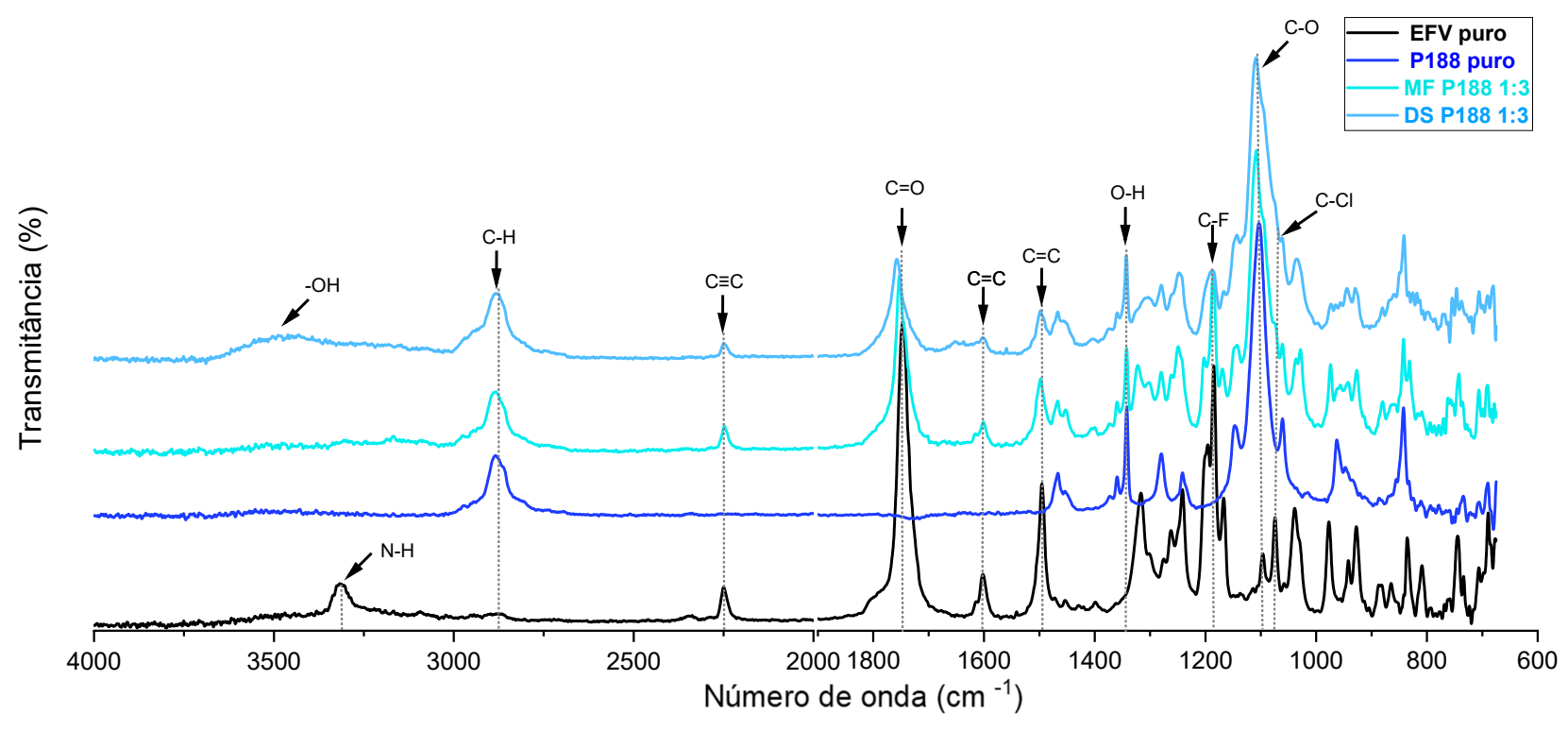

Fonte: Elaborado pelo autor.

Figura 51 - Espectros de infravermelho com transformada de Fourier do EFV puro, do P407 puro, da MF P407 e da DS P407 obtidas na proporção de 1:3.

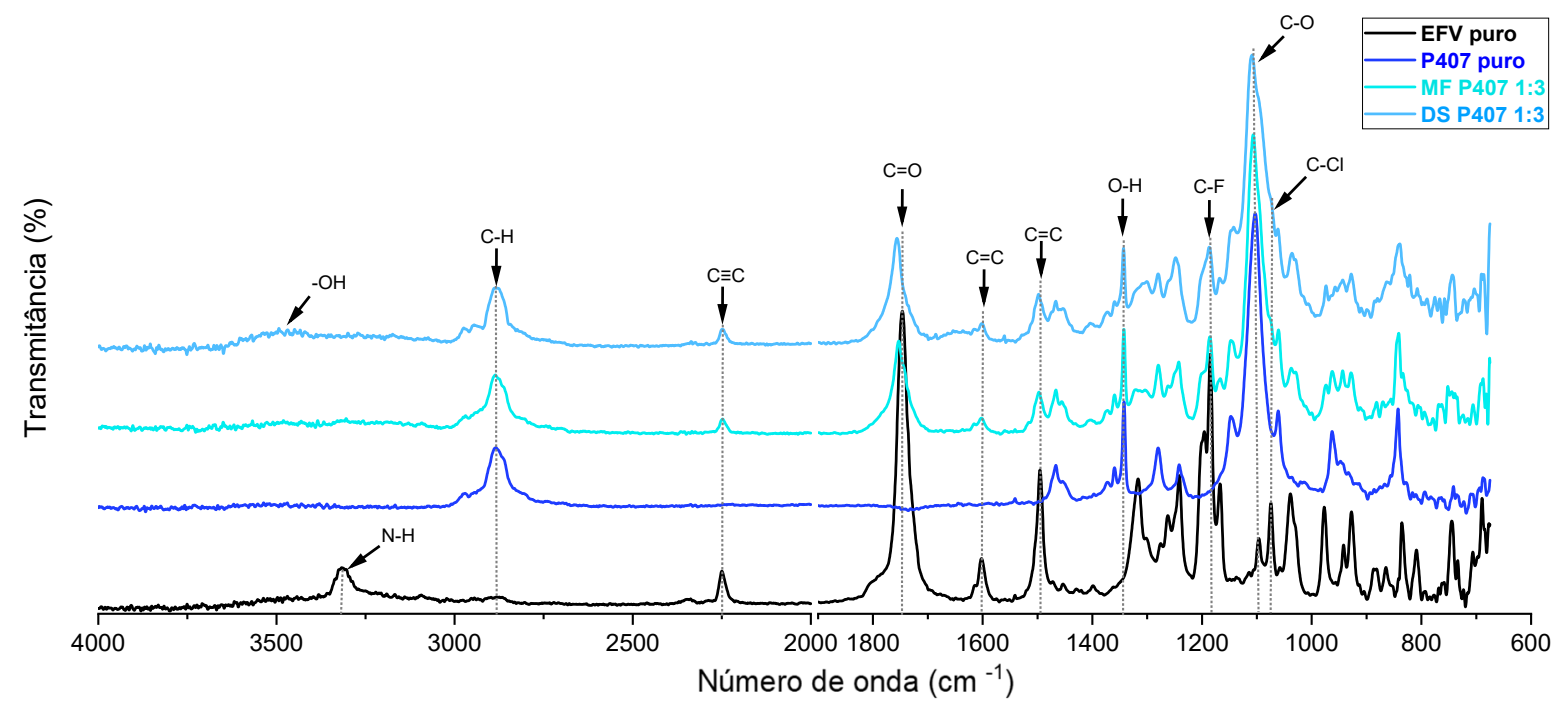

Fonte: Elaborado pelo autor. 
6. CONCLUSÃO 
O presente estudo possibilitou o desenvolvimento das dispersões sólidas de efavirenz com o emprego de dois carreadores, poloxâmero 188 e poloxâmero 407 . Ambos os carreadores utilizados incrementaram a solubilidade e a dissolução do fármaco $E F V$ em meio aquoso.

$O$ método analítico desenvolvido e validado para quantificar o EFV nas formulações binárias, cumpriram com as exigências estabelecidas pelo ICH 2005, quanto à: especificidade, linearidade, precisão, exatidão e limites de detecção e quantificação.

A seleção racional miniaturizada proporcionou a constatação de que todos os polímeros (PVP K-28/32, CoPVP, HPMCP-50, HPMCP-55 e HPMCP-55s) testados demonstraram ser efetivos em estabilizar o EFV na forma amorfa, sendo as formulações binárias classificadas como totalmente amorfa. Os copolímeros com características de tensoativos (P188 e P407) foram classificados como semicristalino, em razão de não exibiram estruturas totalmente amorfas nos difratogramas, contudo, os poloxâmeros também demonstraram ser efetivos em estabilizar o fármaco. Assim sendo, prosseguiu-se com todos os carreadores testados, em consequência de que foram capazes de estabilizar o fármaco na forma amorfa.

Observou-se que, a metodologia de evaporação do solvente empregada para a preparação das DS em maior escala, teve uma influência significativa nas características físico-químicas do estado sólido do composto ativo, no qual foi possível evidenciar que, apesar da estabilização do EFV na forma amorfa, os carreadores descartados (PVP K-28/32, CoPVP, HPMCP-50, HPMCP-55 e HPMCP-55s) não favoreceram a liberação do antirretroviral em solução aquosa.

A incorporação do copolímero P407 na DS de EFV na proporção de 1:3, obtido através do método de evaporação do solvente por rotaevaporador, apresentou melhores resultados ao incrementar a solubilidade e dissolução aquosa, assim como, levou à estabilização do antirretroviral na forma amorfa.

A redução da proporção dos poloxâmeros 188 e 407 nas DS demonstrou que, a estabilidade do EFV no estado amorfo é comprometida, ocasionando recristalização posterior do composto ativo durante o armazenamento.

A ausência de quaisquer transformações polimórficas do EFV, revelou que o método de obtenção aplicado é adequado para a preparação de DS, sem afetar a 
estabilidade física do antirretroviral. Contudo, através das análises de FTIR, foi possível evidenciar que houve desaparecimento do grupamento amina do EFV, e essa reação química entre o EFV e ambos os poloxâmeros, poderia impactar no desempenho in vivo da formulação.

Diante dos promissores resultados obtidos para incremento da solubilidade do EFV, trabalhos futuros como a realização de estudos estabilidade química, a avaliação de perfil de impurezas e estudos farmacocinéticos poderão ser explorados para a viabilização no desenvolvimento de um futuro medicamento, empregando a dispersão sólida obtida com o carreador poloxâmero 407. 
ALVES, L. D. S. et al. Avanços, propriedades e aplicações de dispersões sólidas no desenvolvimento de formas farmacêuticas sólidas. Revista de Ciências Farmacêuticas Básica e Aplicada, v. 33, n. 1, p. 17-25, 2012.

ALVES, L. D. S. et al. Solid dispersion of efavirenz in PVP K-30 by conventional solvent and kneading methods. Carbohydrate Polymers, v. 104, n. 1, p. 166-174, 2014.

AMIDON, G. L. et al. A Theoretical Basis for a Biopharmaceutic Drug Classification: The Correlation of in Vitro Drug Product Dissolution and in Vivo Bioavailability Pharmaceutical Research: An Official Journal of the American Association of Pharmaceutical Scientists, 1995.

BAGHEL, S.; CATHCART, H.; O'REILLY, N. J. Polymeric Amorphous Solid Dispersions: A Review of Amorphization, Crystallization, Stabilization, Solid-State Characterization, and Aqueous Solubilization of Biopharmaceutical Classification System Class II Drugs. Journal of Pharmaceutical Sciences, v. 105, n. 9, p. 25272544, 2016.

BAIRD, J. A.; TAYLOR, L. S. Evaluation of amorphous solid dispersion properties using thermal analysis techniques. Advanced Drug Delivery Reviews, v. 64, n. 5, p. 396-421, 2012.

BASTOS, M. M. et al. Efavirenz a nonnucleoside reverse transcriptase inhibitor of firstgeneration: Approaches based on its medicinal chemistry. European Journal of Medicinal Chemistry, v. 108, p. 455-465, 2016.

BERTONI, S. et al. Exploring the use of spray congealing to produce solid dispersions with enhanced indomethacin bioavailability: In vitro characterization and in vivo study. European Journal of Pharmaceutics and Biopharmaceutics, v. 139, n. March, p. 132-141, 2019.

BOYD, B. J. et al. Successful oral delivery of poorly water-soluble drugs both depends on the intraluminal behavior of drugs and of appropriate advanced drug delivery systems. European Journal of Pharmaceutical Sciences, v. 137, n. May, p. 104967, 2019.

BRASIL. Agência Nacional de Vigilância Sanitária. Resolução RE n. 1, de 29 de julho de 2005. Guia para realização de estudo de estabilidade. Diário Oficial da União, Brasília, s.1,n.

BYRN, S. R.; ZOGRAFI, G.; CHEN, X. (SEAN). SOLID-STATE PROPERTIES OF PHARMACEUTICAL MATERIALS. 1. ed. New Jersey, USA: John Wiley \&Sons, Inc, 2017.

CHADHA, R. et al. Cocrystals of efavirenz with selected conformers: Preparation and characterization. International Journal of Pharmacy and Pharmaceutical Sciences, v. 4, n. 2, p. 244-250, 2012. 
CHAUDHARI, S. P.; DUGAR, R. P. Application of surfactants in solid dispersion technology for improving solubility of poorly water-soluble drugs. Journal of Drug Delivery Science and Technology, v. 41, p. 68-77, 2017.

CHIAPPETTA, D. A et al. Efavirenz-loaded polymeric micelles for pediatric anti-HIV pharmacotherapy with significantly higher oral bioavailability [corrected]. Nanomedicine (London, England), v. 5, n. 1, p. 11-23, 2010.

CHIAPPETTA, D. A. et al. Synergistic encapsulation of the anti-HIV agent efavirenz within mixed poloxamine/poloxamer polymeric micelles. Nanomedicine: Nanotechnology, Biology, and Medicine, v. 7, n. 5, p. 624-637, 2011.

CHIOU, W. L.; RIEGELMAN, S. Pharmaceutical applications of solid dispersion systems. Journal of Pharmaceutical Sciences, 1971.

COLOMBO, M. et al. Solid Dispersion of Kaempferol: Formulation Development, Characterization, and Oral Bioavailability Assessment. AAPS PharmSciTech, v. 20, n. 3, 2019.

COSTA, B. L. A. et al. Determination of drug-polymer solubility from supersaturated spray-dried amorphous solid dispersions: A case study with Efavirenz and Soluplus $₫$. European Journal of Pharmaceutics and Biopharmaceutics, v. 142, n. April, p. 300-306, 2019.

CRISTOFOLETTI, R. et al. Biowaiver Monographs for Immediate Release Solid Oral Dosage Forms: Efavirenz. Journal of Pharmaceutical Sciences, v. 102, n. 2, p. 318329, 2013.

DA COSTA, M. A. et al. Efavirenz dissolution enhancement I: Co-micronization. Pharmaceutics, v. 5, n. 1, p. 1-22, 2013.

DAVIS, M. T. et al. Amorphous solid dispersions of BCS class II drugs: A rational approach to solvent and polymer selection. Chemical Engineering Research and Design, v. 110, p. 192-199, 2016.

DE ARAUJO, G. L. B. et al. Local Structure of Ion Pair Interaction in Lapatinib Amorphous Dispersions characterized by Synchrotron X-Ray diffraction and Pair Distribution Function Analysis. Scientific Reports, v. 7, n. January, p. 1-10, 2017.

DE MELO, A. C. C. et al. Toward novel solid-state forms of the anti-HIV drug efavirenz: From low screening success to cocrystals engineering strategies and discovery of a new polymorph. Crystal Growth and Design, v. 13, n. 4, p. 1558-1569, 2013.

DEZANI, A. B. et al. Equilibrium solubility versus intrinsic dissolution: Characterization of lamivudine, stavudine and zidovudine for BCS classification. Brazilian Journal of Pharmaceutical Sciences, v. 49, n. 4, p. 853-863, 2013.

DUGAR, R. P.; GAJERA, B. Y.; DAVE, R. H. Fusion Method for Solubility and Dissolution Rate Enhancement of lbuprofen Using Block Copolymer Poloxamer 407. AAPS PharmSciTech, v. 17, n. 6, p. 1428-1440, 2016. 
ELOY, J. O.; MARCHETTI, J. M. Solid dispersions containing ursolic acid in Poloxamer 407 and PEG 6000: A comparative study of fusion and solvent methods. Powder Technology, v. 253, p. 98-106, 2014.

EUROPEAN MEDICINES AGENCY. EMA. Committee for Medicinal Products for Human use (CHMP). Guideline on the investigation of bioequivalence, 2010. Disponível em: https://www.ema.europa.eu/en/documents/scientificguideline/guideline-investigation-bioequivalence-rev1_en.pdf. Acesso em: $20 \mathrm{fev}$, 2020.

FANDARUFF, C. et al. Correlation between microstructure and bioequivalence in AntiHIV Drug Efavirenz. European Journal of Pharmaceutics and Biopharmaceutics, v. 91, p. $52-58,2015$.

FANDARUFF, C. et al. Polymorphism of anti-HIV drug efavirenz: Investigations on thermodynamic and dissolution properties. Crystal Growth and Design, v. 14, n. 10, p. 4968-4975, 2014a.

FANDARUFF, C. et al. Thermal behavior and decomposition kinetics of efavirenz under isothermal and non-isothermal conditions. Journal of Thermal Analysis and Calorimetry, v. 115, p. 2351-2356, 2014b.

FANDARUFF, C.; ARAYA-SIBAJA, A. Interaction and compatibility studies of efavirenz with pharmaceutical excipients. Journal of Excipients and Food Chemistry, v. 5, n. September, p. 152-160, 2014.

FARMACOPEIA BRASILEIRA, 5. ed. Brasília: Agência de Vigilância Sanitária/Fundação Oswaldo Cruz, 2010, volume 1 e 2, p. 56, 359 - 361.

FDA. Center for Drug Evaluation and Research. Guidance for Industry: ANDAs:Pharmaceutical Solid Polymorphism: Chemistry, Manufacturing, and Controls Information. Rockville: FDA, 2007. 13p. Disponível em: https://www.fda.gov/regulatory-information/search-fda-guidancedocuments/andaspharmaceutical-solid-polymorphism-chemistry-manufacturing-andcontrols-information. Acesso em: 18 set. 2019.

FONTES, D. A. F. et al. CaAl-layered double hydroxide as a drug delivery system: effects on solubility and toxicity of the antiretroviral efavirenz. Journal of Inclusion Phenomena and Macrocyclic Chemistry, v. 85, p. 281-288, 2016.

FOTAKI, N. Flow-through cell apparatus (USP Apparatus 4): Operation and features. Dissolution Technologies, v. 18, n. 4, p. 46-49, 2011.

FUSCO, S.; BORZACCHIELLO, A.; NETTI, P. A. Perspectives on: PEO-PPO-PEO triblock copolymers and their biomedical applications. Journal of Bioactive and Compatible Polymers, v. 21, n. 2, p. 149-164, 2006.

GARALA, K. et al. Formulation and evaluation of periodontal in situ gel. International Journal of Pharmaceutical Investigation, v. 3, n. 1, p. 29, 2013. 
HANCOCK, B. C. Disordered drug delivery: Destiny, dynamics and the Deborah number. Pharmaceutical Journal, v. 267, n. 7169, p. 520, 2001.

HANCOCK, B. C.; SHAMBLIN, S. L. Molecular mobility of amorphous pharmaceuticals determined using differential scanning calorimetry. Thermochimica Acta, v. 380, n. 2, p. 95-107, 2001.

HANCOCK, B. C.; SHAMBLIN, S. L.; ZOGRAFI, G. Molecular Mobility of Amorphous Pharmaceutical Solids Below Their Glass Transition Temperatures Pharmaceutical Research: An Official Journal of the American Association of Pharmaceutical Scientists, 1995.

HARJIVAN, S. G. et al. The phenolic metabolites of the anti-HIV drug efavirenz: Evidence for distinct reactivities upon oxidation with Frémy's salt. European Journal of Medicinal Chemistry, v. 74, p. 7-11, 2014.

HENRY TENG, H. How ions and molecules organize to form crystals. Elements, v. 9, n. 3, p. 189-194, 2013.

HILFIKER, R.; RAUMER, M. VON. Polymorphism in the Pharmaceutical Industry Solid Form and Drug Development. 1. ed. Weinheim, Germany: Wiley-VCH, 2019.

HOFFMEISTER, C. R. D. et al. Efavirenz dissolution enhancement III: Colloid milling, pharmacokinetics and electronic tongue evaluation. European Journal of Pharmaceutical Sciences, v. 99, p. 310-317, 2017.

HUANG, S.; WILLIAMS, R. O. Effects of the Preparation Process on the Properties of Amorphous Solid Dispersions. AAPS PharmSciTech, 2018.

INTERNATIONAL CONFERENCE ON HARMONISATION OF TECHNICAL REQUIREMENTS FOR REGISTRATION OF PHARMACEUTICALS FOR HUMAN USE. Quality Guidelines. Analytical Validation Q2. Validation of analytical rocedures: text and methodology: Q2(R1). S.I.: ICH, 2005. 17p. Disponível em: https://www.ich.org/fileadmin/Public_Web_Site/ICH_Products/Guidelines/Quality/Q2 R1/Step4/Q2_R1_Guideline.pdf. Acesso em: 27 mar. 2018.

INTERNATIONAL CONFERENCE ON HARMONISATION OF TECHNICAL REQUIREMENTS FOR REGISTRATION OF PHARMACEUTICALS FOR HUMAN USE ICH - Q3C(R6) Impurities: Guideline for residual solvents, 2016. 40p. Disponível em:

http://www.ich.org/fileadmin/Public_Web_Site/ICH_Products/Guidelines/Quality/Q3C/ Q3C_R6__Step_4.pdf. Acesso em: 27 mar. 2018.

KAROLEWICZ, B. et al. Pluronic F127 as a suitable carrier for preparing the imatinib base solid dispersions and its potential in development of a modified release dosage forms: Thermal, spectroscopic, microscopic, and dissolution studies. Journal of Thermal Analysis and Calorimetry, v. 130, n. 1, p. 383-390, 2017. 
KAWABATA, Y. et al. Formulation design for poorly water-soluble drugs based on biopharmaceutics classification system: Basic approaches and practical applications. International Journal of Pharmaceutics, v. 420, n. 1, p. 1-10, 2011.

$\mathrm{KOH}, \mathrm{P}$. T. et al. Formulation development and dissolution rate enhancement of efavirenz by solid dispersion systems. Indian Journal of Pharmaceutical Sciences, v. 75 , n. 3, p. 291-301, 2013.

KOMMAVARAPU, P.; MARUTHAPILLAI, A.; PALANISAMY, K. Preparation and characterization of Efavirenz nanosuspension with the application of enhanced solubility and dissolution rate. HIV and AIDS Review, v. 15, n. 4, p. 170-176, 2016.

KONNO, H.; TAYLOR, L. S. Ability of different polymers to inhibit the crystallization of amorphous felodipine in the presence of moisture. Pharmaceutical Research, v. 25, n. 4, p. 969-978, 2008.

KOTTA, S. et al. Anti HIV nanoemulsion formulation: Optimization and in vitro-in vivo evaluation. International Journal of Pharmaceutics, v. 462, n. 1-2, p. 129-134, 2014.

LAVRA, Z. M. M. Incremento da solubilidade e da cinética de dissolução do fármaco efavirenz através da obtenção de misturas binárias amorfas com matrizes poliméricas. 2016. 255 p. Tese (Doutorado) - Centro de Ciências da Saúde, Universidade Federal de Pernambuco, Recife, 2016.

LAVRA, Z. M. M.; PEREIRA DE SANTANA, D.; RÉ, M. I. Solubility and dissolution performances of spray-dried solid dispersion of Efavirenz in Soluplus. Drug Development and Industrial Pharmacy, v. 43, n. 1, p. 42-54, 2017.

LEUNER, C.; DRESSMAN, J. Improving drug solubility for oral delivery using solid dispersions. European journal of pharmaceutics and biopharmaceutics, v. 50, n. 1, p. 47-60, 2000.

LI, N.; TAYLOR, L. S. Tailoring supersaturation from amorphous solid dispersions. Journal of Controlled Release, v. 279, n. February, p. 114-125, 2018.

$\mathrm{LI}, \mathrm{Y}$. et al. Preparation and characterization of paclitaxel nanosuspension using novel emulsification method by combining high speed homogenizer and high pressure homogenization. International Journal of Pharmaceutics, v. 490, n. 1-2, p. 324333, 2015.

LINDENBERG, M.; KOPP, S.; DRESSMAN, J. B. Classification of orally administered drugs on the World Health Organization Model list of Essential Medicines according to the biopharmaceutics classification system. European Journal of Pharmaceutics and Biopharmaceutics, v. 58, n. 2, p. 265-278, 2004.

MA, X.; WILLIAMS, R. O. Characterization of amorphous solid dispersions: An update. Journal of Drug Delivery Science and Technology, v. 50, n. November 2018, p. 113-124, 2019. 
MADHAVI, BB. et al. Dissolution enhancement of efavirenz by solid dispersion and PEGylation techniques. International Journal of Pharmaceutical Investigation, $v$. 1, n. 1, p. 29, 2011.

MAHAPATRA, S. et al. New solid-state forms of the anti-HIV drug efavirenz. Conformational flexibility and high $Z^{\prime}$ issues. Crystal Growth and Design, v. 10, n. 7 , p. 3191-3202, 2010.

MAKWANA, V. et al. Solid lipid nanoparticles (SLN) of Efavirenz as lymph targeting drug delivery system: Elucidation of mechanism of uptake using chylomicron flow blocking approach. International Journal of Pharmaceutics, v. 495, n. 1, p. 439446, 2015.

MARQUES, M. M. et al. New solid forms of efavirenz: Synthesis, vibrational spectroscopy and quantum chemical calculations. Journal of Molecular Structure, v. 1137, p. 476-484, 2017.

MARSAC, P. J.; LI, T.; TAYLOR, L. S. Estimation of drug-polymer miscibility and solubility in amorphous solid dispersions using experimentally determined interaction parameters. Pharmaceutical Research, v. 26, n. 1, p. 139-151, 2009.

MATSUMOTO, T.; ZOGRAFI, G. Physical Properties of Solid Molecular Dispersions of Indomethacin with Poly(vinylpyrrolidone) and Poly(vinylpyrrolidone-co-vinyl-acetate) in Relation to Indomethacin Crystallization. Pharmaceutical Research, v. 16, n. 11, p. 1722-1728, 1999.

MEDAREVIĆ, D. P. et al. Dissolution rate enhancement and physicochemical characterization of carbamazepine-poloxamer solid dispersions. Pharmaceutical Development and Technology, v. 21, n. 3, p. 268-276, 2016.

MENG, F. et al. Investigation and correlation of drug polymer miscibility and molecular interactions by various approaches for the preparation of amorphous solid dispersions. European Journal of Pharmaceutical Sciences, v. 71, p. 12-24, 2015.

MENG, F.; FERREIRA, R.; ZHANG, F. Effect of surfactant level on properties of celecoxib amorphous solid dispersions. Journal of Drug Delivery Science and Technology, v. 49, n. October 2018, p. 301-307, 2019.

MESALLATI, H. et al. Amorphous Polymeric Drug Salts as lonic Solid Dispersion Forms of Ciprofloxacin. Molecular Pharmaceutics, v. 14, n. 7, p. 2209-2223, 2017.

MISHRA, S.; TANDON, P.; AYALA, A. P. Study on the structure and vibrational spectra of efavirenz conformers using DFT: Comparison to experimental data. Spectrochimica Acta - Part A: Molecular and Biomolecular Spectroscopy, v. 88, p. 116-123, 2012.

MOURA RAMOS, J. J. et al. Thermal Behavior and Slow Relaxation Dynamics in Amorphous Efavirenz: A Study by DSC, XRPD, TSDC, and DRS. Journal of Pharmaceutical Sciences, v. 108, n. 3, p. 1254-1263, 2019. 
MUGHEIRBI, N. A. et al. A Comparative Study on the Performance of Inert and Functionalized Spheres Coated with Solid Dispersions Made of Two Structurally Related Antifungal Drugs. Molecular pharmaceutics, v. 14, n. 11, p. 3718-3728, 2017.

NEWMAN, A. et al. Characterization of Amorphous API:Polymer Mixtures Using X-Ray Powder Diffraction. Journal of Pharmaceutical Sciences, v. 97, n. 11, p. 4840-4856, 2008.

NEWMAN, A. Pharmaceutical amorphous solid dispersions. 1. ed. New Jersey, USA: John Wiley \& Sons, Inc., Hoboken, 2015.

NEWMAN, A.; KNIPP, G.; ZOGRAFI, G. Assessing the Performance of Amorphous Solid Dispersions. Journal of Pharmaceutical Sciences, v. 101, n. 4, p. 1355-1377, 2012.

NOYES, A. A.; WHITNEY, W. R. The rate of solution of solid substances in their own solutions. Journal of the American Chemical Society, v. 19, n. 12, p. 930-934, 1897.

PATEL, G. V. et al. Nanosuspension of efavirenz for improved oral bioavailability: formulation optimization, in vitro, in situ and in vivo evaluation. Drug Development and Industrial Pharmacy, v. 40, n. 1, p. 80-91, 2014.

PAWAR, J. et al. Solubility and dissolution enhancement of efavirenz hot melt extruded amorphous solid dispersions using combination of polymeric blends: A QbD approach. European Journal of Pharmaceutical Sciences, v. 88, p. 37-49, 2016.

RAMS-BARON, M. et al. Amorphous Drugs. 1. ed. Cham, Switzerland: Springer International Publishing, 2018.

RAVIKUMAR, K.; SRIDHAR, B. Molecular and crystal structure of efavirenz, a potent and specific inhibitor of HIV-1 reverse transcriptase, and its monohydrate. Molecular Crystals and Liquid Crystals, v. 515, n. July 2014, p. 190-198, 2009.

ROWE, R. C.; SHESKEY, P. J.; QUINN, M. E. Handbook of Pharmaceutical Excipients. 6. ed. London UK /Grayslake USA: Pharmaceutical Press, 2009.

SATHIGARI, S. et al. Physicochemical characterization of efavirenz-cyclodextrin inclusion complexes. AAPS PharmSciTech, v. 10, n. 1, p. 81-87, 2009.

SATHIGARI, S. K. et al. Amorphous-state characterization of efavirenz-polymer hotmelt extrusion systems for dissolution enhancement. Journal of Pharmaceutical Sciences, v. 101, n. 9, p. 3456-3464, 2012.

SAVJANI, K. T.; GAJJAR, A. K.; SAVJANI, J. K. Drug Solubility: Importance and Enhancement Techniques. ISRN Pharmaceutics, v. 2012, n. 100 mL, p. 1-10, 2012.

SCHITTNY, A. et al. Mechanistic insights into effect of surfactants on oral bioavailability of amorphous solid dispersions. Journal of Controlled Release, v. 320, n. January, p. 214-225, 2020. 
SEKIGUCHI, K.; OBI, N. Studies on Absorption of Eutectic Mixture. I. A Comparison of the Behavior of Eutectic Mixture of Sulfathiazole and that of Ordinary Sulfathiazole in Man. Chemical \& Pharmaceutical Bulletin, v. 9, n. 11, p. 866-872, 1961.

SENAPATI, P. C.; SAHOO, S. K.; SAHU, A. N. Mixed surfactant based (SNEDDS) self-nanoemulsifying drug delivery system presenting efavirenz for enhancement of oral bioavailability. Biomedicine and Pharmacotherapy, v. 80, p. 42-51, 2016.

SERRA, C. H. DOS R.; STORPIRTIS, S. Comparação de perfis de dissolução da cefalexina através de estudos de cinética e eficiência de dissolução (ED \%). Brazilian Journal of Pharmaceutical Sciences, v. 43, p. 79-88, 2007.

SHAH, N. et al. Amorphous Solid Dispersion - Theory and Practice. 1. ed. [s.I.] Controlled Release Society, Springer, 2014.

SHIRWAIKER, R. A.; PURSER, M. F.; WYSK, R. A. Scaffolding hydrogels for rapid prototyping based tissue engineering. [s.I.] Woodhead Publishing Limited, 2014.

SILVA, M.F. Correlação in vitro - in vivo de comprimidos matriciais de furosemida complexada à hidroxipropil- $\beta$-ciclodextrina: métodos in vitro, in vivo e in sílico. 2014. 257 f. Tese (Doutorado) - Faculdade de Ciências Farmacêuticas, Universidade de São Paulo, São Paulo, 2014.

SONG, C. K.; YOON, I. S.; KIM, D. D. Poloxamer-based solid dispersions for oral delivery of docetaxel: Differential effects of F68 and P85 on oral docetaxel bioavailability. International Journal of Pharmaceutics, v. 507, n. 1-2, p. 102-108, 2016.

SONG, Y. Acid-base interactions in amorphous solid dispersions: formulation strategy for tyrosine kinase inhibitors. 2015. $147 \mathrm{f}$. Tese (Doutorado) - Purdue University, Indiana, 2015.

SONG, Y. et al. Investigation of Drug-Excipient Interactions in Lapatinib Amorphous Solid Dispersions Using Solid-State NMR Spectroscopy. Molecular Pharmaceutics, v. 12, n. 3, p. 857-866, 2015.

SOSNIK, A.; CHIAPPETTA, D. A.; CARCABOSO, Á. M. Drug delivery systems in HIV pharmacotherapy: What has been done and the challenges standing ahead. Journal of Controlled Release, v. 138, n. 1, p. 2-15, 2009.

SUN, D. D.; LEE, P. I. Crosslinked hydrogels-a promising class of insoluble solid molecular dispersion carriers for enhancing the delivery of poorly soluble drugs. Acta Pharmaceutica Sinica B, v. 4, n. 1, p. 26-36, 2014.

SUN, D. D.; LEE, P. I. Evolution of supersaturation of amorphous pharmaceuticals: The effect of rate of supersaturation generation. Molecular Pharmaceutics, v. 10, n. 11, p. 4330-4346, 2013. 
SUN, D. D.; LEE, P. I. Probing the mechanisms of drug release from amorphous solid dispersions in medium-soluble and medium-insoluble carriers. Journal of Controlled Release, v. 211, p. 85-93, 2015.

TIAN, B. et al. Impact of polymers on the melt crystal growth rate of indomethacin polymorphs. Crystal Growth and Design, v. 17, n. 12, p. 6467-6476, 2017.

UNAIDS Brasil, Informações básicas sobre a AIDS. Disponível em: http://unaids.org.br/informacoes-basicas/. Acesso em: 20 fev. 2020.

UNITED STATES PHARMACOPEIA. UNITED STATES PHARMACOPEIA39/National Formulary 34. RockvilleUSP, 2017.

VASCONCELOS, T. et al. Amorphous solid dispersions: Rational selection of a manufacturing process. Advanced Drug Delivery Reviews, v. 100, p. 85-101, 2016.

VASCONCELOS, T.; SARMENTO, B.; COSTA, P. Solid dispersions as strategy to improve oral bioavailability of poor water-soluble drugs. Drug Discovery Today, v. 12, n. 23-24, p. 1068-1075, 2007.

VO, C. L.-N.; PARK, C.; LEE, B.-J. Current trends and future perspectives of solid dispersions containing poorly water-soluble drugs. European Journal of Pharmaceutics and Biopharmaceutics, v. 85, n. 3, p. 799-813, 2013.

Web of Science. Número de publicações dos últimos 10 anos (2009-2019) do site Web of Science, sobre dispersões sólidas. Disponível em: http://appswebofknowledge.ez67.periodicos.capes.gov.br/WOS_GeneralSearch_input.do?prod uct=WOS\&search_mode=GeneralSearch\&SID=7BN429QRr3T1AoVNfYs\&preferenc esSaved=. Acesso em: 19 jun.2020.

WILLIAMS, H. D. et al. Strategies to Address Low Drug Solubility in Discovery and Development. Pharmacological Reviews, v. 65, n. 1, p. 315-499, 2013.

WILLIAMS III, R. O; WATTS, A. B.; MILLER, D. A. Formulating Poorly Water-Soluble Drugs. 2. ed. Texas USA: American Association of Pharmaceutical Scientists, 2016.

XIE, T.; TAYLOR, L. S. Effect of Temperature and Moisture on the Physical Stability of Binary and Ternary Amorphous Solid Dispersions of Celecoxib. Journal of Pharmaceutical Sciences, p. 1-11, 2016.

YU, D. G. et al. Electrospun amorphous solid dispersions of poorly water-soluble drugs: A review. Journal of Controlled Release, v. 292, n. May, p. 91-110, 2018.

YU, L. Amorphous pharmaceutical solids preparation, characterization and stabilization. Advanced Drug Delivery Reviews, v. 48, p. 27-42, 2001.

ZHANG, Y. et al. DDSolver: An add-in program for modeling and comparison of drug dissolution profiles. AAPS Journal, v. 12, n. 3, p. 263-271, 2010. 
ZHAO, Y. et al. Effect of plasticizers on manufacturing ritonavir/copovidone solid dispersions via hot-melt extrusion: Preformulation, physicochemical characterization, and pharmacokinetics in rats. European Journal of Pharmaceutical Sciences, v. 127, n. June 2018, p. 60-70, 2019. 
8. ANEXOS 


\section{Anexo - Licenças de Reprodução}

\begin{tabular}{|c|c|c|c|c|c|}
\hline $\begin{array}{l}\text { Copyright } \\
\text { Clearance } \\
\text { Center }\end{array}$ & RightsLink & $\underset{\text { Home }}{\hat{\boldsymbol{n}}}$ & $\begin{array}{l}? \\
\text { Help }\end{array}$ & $\begin{array}{c}\boldsymbol{\Xi} \\
\text { Email Support }\end{array}$ & $\stackrel{2}{2}$ \\
\hline
\end{tabular}

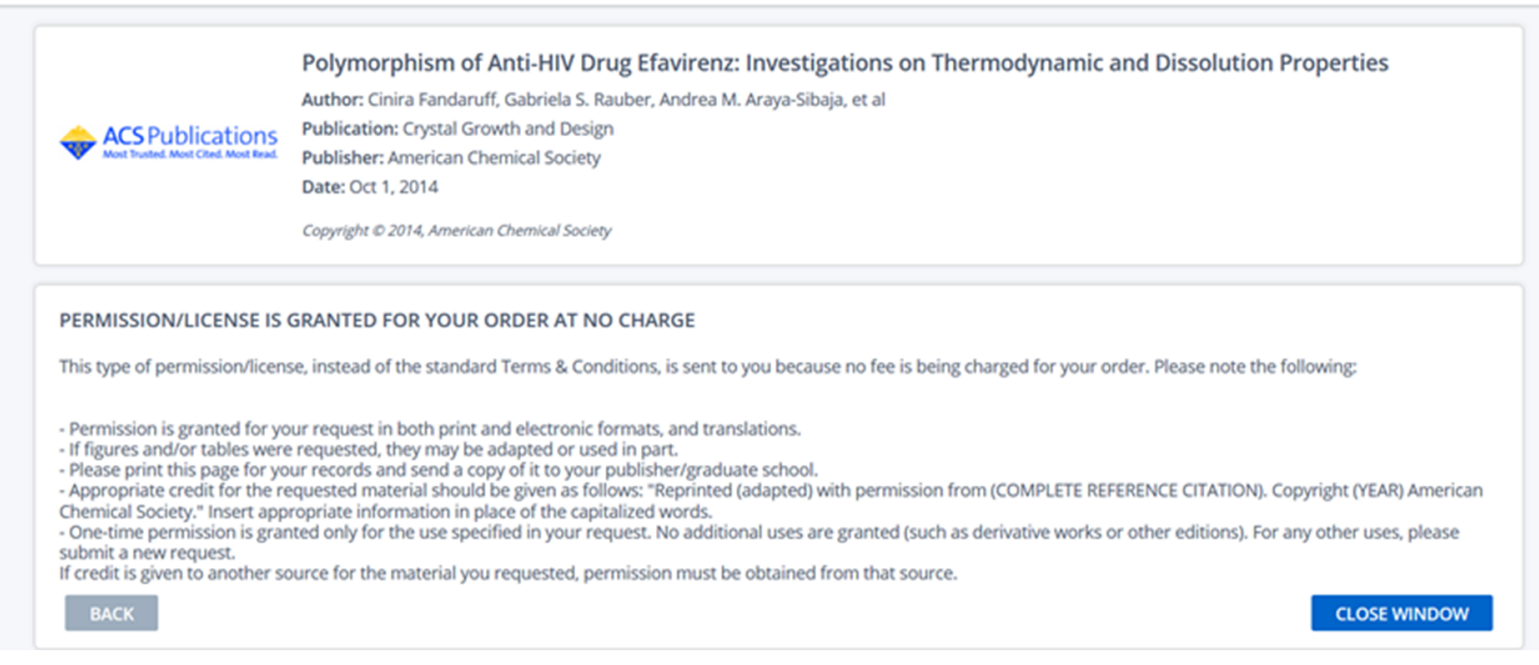

\begin{tabular}{|c|c|c|c|c|c|}
\hline $8 \begin{array}{l}\text { Copyright } \\
\text { Clearance } \\
\text { Center }\end{array}$ & RightsLink ${ }^{\circledR}$ & $\underset{\text { Home }}{\widehat{\hat{H}}}$ & $\begin{array}{l}? \\
\text { Help }\end{array}$ & $\underset{\text { Email Support }}{\bar{\square}}$ & Edilson Nazareth Junior v \\
\hline
\end{tabular}

\begin{tabular}{|c|c|}
\hline \multirow{6}{*}{ 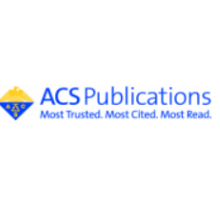 } & $\begin{array}{l}\text { Investigation of Drug-Excipient Interactions in Lapatinib Amorphous Solid Dispersions Using Solid-State NMR } \\
\text { Spectroscopy }\end{array}$ \\
\hline & Author: Yang Song, Xinghao Yang, Xin Chen, et al \\
\hline & Publication: Molecular Pharmaceutics \\
\hline & Publisher: American Chemical Society \\
\hline & Date: Mar 1, 2015 \\
\hline & Copyright 12015 , American Chemical Society \\
\hline \multicolumn{2}{|c|}{ PERMISSION/LICENSE IS GRANTED FOR YOUR ORDER AT NO CHARGE } \\
\hline \multicolumn{2}{|c|}{ This type of permission/license, instead of the standard Terms \& Conditions, is sent to you because no fee is being charged for your order. Please note the following: } \\
\hline \multicolumn{2}{|c|}{$\begin{array}{l}\text { - Permission is granted for your request in both print and electronic formats, and translations. } \\
\text { - If figures and/or tables were requested, they may be adapted or used in part. } \\
\text { - Please print this page for your records and send a copy of ft to your publisher/graduate school. } \\
\text { - Appropriate credit for the requested material should be given as follows: "Reprinted (adapted) with permission from (COMPLETE REFERENCE CITATION). Copyright (YEAR) American } \\
\text { Chemical Society." Insert appropriate information in place of the capitalized words. } \\
\text { - One-time permission is granted only for the use specified in your request. No additional uses are granted (such as derivative works or other editions). For any other uses, please } \\
\text { submit a new request. } \\
\text { If credit is given to another source for the material you requested, permission must be obtained from that source. }\end{array}$} \\
\hline BACK & CLOSE WINDOW \\
\hline
\end{tabular}




\begin{tabular}{|c|c|}
\hline My Orders & Welcome edizath@gmail.com.br ㄴogout \\
\hline \multicolumn{2}{|l|}{ My Orders > Orders > All Orders } \\
\hline \multicolumn{2}{|l|}{ License Details } \\
\hline \multicolumn{2}{|c|}{$\begin{array}{l}\text { This Agreement between Dr. Edilson Nazareth Junior ("You") and Elsevier ("Elsevier") consists of your license details and the terms and conditions provided by Elsevi } \\
\text { Copyright Clearance Center. }\end{array}$} \\
\hline \multicolumn{2}{|l|}{ Print Copy } \\
\hline License Number & 4818010801243 \\
\hline License date & Apr 29,2020 \\
\hline Licensed Content Publisher & Elsevier \\
\hline Licensed Content Publication & Journal of Molecular Structure \\
\hline Licensed Content Title & New solid forms of efavirenz: Synthesis, vibrational spectroscopy and quantum chemical calculations \\
\hline Licensed Content Author & $\begin{array}{l}\text { Marcelo M. Marques,Carlos A. Rezende,Gabriel C. Lima,Andressa C.S. Marques,Lívia D. Prado,Kátia Z. Leal,Helvécio V.A. } \\
\text { Rocha,Gláucio B. Ferreira,Jackson A.L.C. Resende }\end{array}$ \\
\hline Licensed Content Date & Jun 5,2017 \\
\hline Licensed Content Volume & 1137 \\
\hline Licensed Content Issue & $\mathrm{n} / \mathrm{a}$ \\
\hline Licensed Content Pages & 9 \\
\hline Type of Use & reuse in a thesis/dissertation \\
\hline Portion & figures/tables/illustrations \\
\hline $\begin{array}{l}\text { Number of figures/tables } \\
\text { fillustrations }\end{array}$ & 1 \\
\hline Format & both print and electronic \\
\hline $\begin{array}{l}\text { Are you the author of this Elsevier } \\
\text { article? }\end{array}$ & No \\
\hline Will you be translating? & No \\
\hline Title & Development and characterization of efavirenz solid dispersions \\
\hline Institution name & Universidade de São Paulo \\
\hline Expected presentation date & Jun 2020 \\
\hline Portions & Figure 2 , on page 478 \\
\hline \multirow[t]{2}{*}{ Requestor Location } & $\begin{array}{l}\text { Dr. Edilson Nazareth Junior } \\
\text { Rua Trajano Reis } \mathrm{n}^{\circ} 186 \text { ap } 32 \text { bl } 04\end{array}$ \\
\hline & $\begin{array}{l}\text { São Paulo, São Paulo } 05541030 \\
\text { Brazil } \\
\text { Attn: Dr. Edilson Nazareth Junior } \\
\text { GB } 494627212\end{array}$ \\
\hline Total & 0.00 USD \\
\hline BACK & \\
\hline
\end{tabular}


Copyright

Clearance

Center

RightsLink

My Orders

My Library

My Profile

Welcome edizath@gmail.com.br Logout I Help

My Orders $>$ Orders $>$ All Orders

\section{License Details}

This Agreement between Dr. Edilson Nazareth Junior ("You") and John Wiley and Sons ("John Wiley and Sons") consists of your license details and the terms and conditions provided by John Wiley and Sons and Copyright Clearance Center.

\section{Print Copy}

License date

4817991232505

Licensed Content Publisher

Apr 28, 2020

Licensed Content Publication

John Wiley and Sons

Licensed Content Date

Wiley Books

Licensed Content Pages

Type of Use

Dec 31, 1969

Requestor type

Dissertation/Thesis

University/Academic

Format

Print and electronic

Portion

Figure/table

Number of figures/tables

Will you be translating?

Number of languages

Yes, including English rights

Development and characterization of efavirenz solid dispersions

Institution name

Expected presentation date

Portions

Specific Languages

Requestor Location

Universidade de São Paulo

Jun 2020

$1.1,6.1,6.6$ on pages $2,70,73$

portuguese

Dr. Edilson Nazareth Junio

Rua Trajano Reis $n^{\circ} 186$ ap 32 bl 04

São Paulo, São Paulo 05541030

Brazil

Attn: Dr. Edilson Nazareth Junior

Publisher Tax ID

EU826007151

Total

0.00 USD

BACK

Copyright @ 2020 Copyright Clearance Center, Inc. All Rights Reserved. Privacy statement. Terms and Conditions . Comments? We would like to hear from you. E-mail us at customercare@copyright.com 
Copyright
Clearance
Center

\section{Center}

My Library My Profile

My Orders > Orders > All Orders

\section{License Details}

This Agreement between Dr. Edilson Nazareth Junior ("You") and Elsevier ("Elsevier") consists of your license details and the terms and conditions provided by Elsevier and Copyright Clearance Center.

\section{Print copy}

License Number
License date
Licensed Content Publisher
Licensed Content Publication
Licensed Content Title
Licensed Content Author
Licensed Content Date
Licensed Content Volume
Licensed Content Issue
Licensed Content Pages
Type of Use
Portion
Number of figures/tables
fillustrations
Format
Are you the author of this Elsevier
article?
Will you be translating?
Number of translations
Title
Institution name
Expected presentation date
Portions
Specific Languages
Requestor Location

Requestor Location

Publisher Tax ID

Total

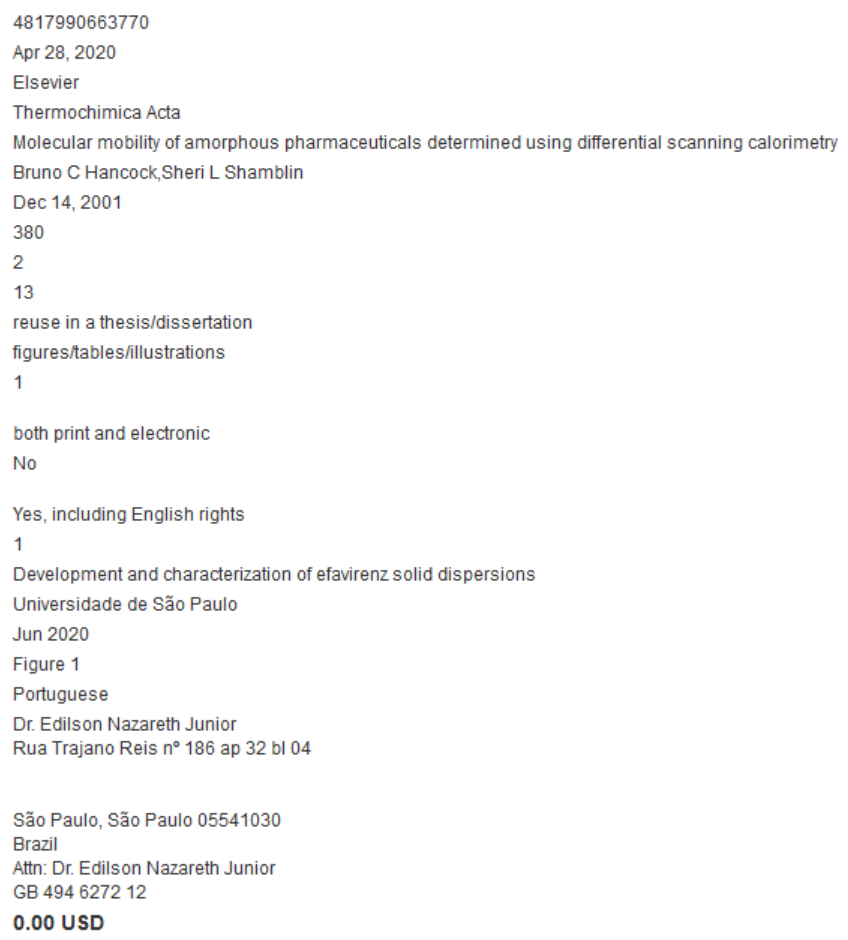




\section{Mineralogical Society of AMERICA}

3635 Concorde Pkwy Ste 500 • Chantilly VA 20151-1110 • USA

Tel: 1 (703) 652-9950 - Fax: 1 (703) 652-9951 - Internet: www.minsocam.org

11 May 2020

Mr. Edilson Marcelo Nazareth Jr.

Faculdade de Ciências Farmacêuticas da Universidade de São Paulo

Av. Prof. Lineu Prestes, 580 bl 15

São Paulo São Paulo 05508-000

Brazil

Email edizath@gmail.com

Dear Mr. Nazareth:

I received your e-mail message requesting permission to reproduce the following figure from Elements:

Figure 2 from Teng, H. Henry. (2013). How Ions and Molecules Organize to Form Crystals, Elements, Volume 9, 190.

It is with pleasure that we grant you permission to reproduce this figure for inclusion without cost and all subsequent editions of the work, its ancillaries, and other derivative works, in any form or medium, whether now known or hereafter developed, in all languages, for distribution throughout the world on the conditions that reference is given to the original publication of the Mineralogical Society of America.

Sincerely,

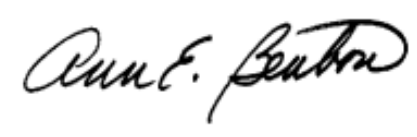

Ann E. Benbow, Ph.D.

Executive Director, MSA 


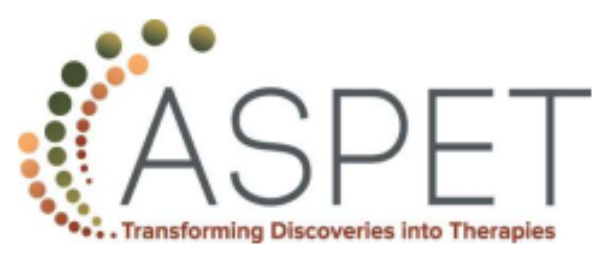

Wayne L. Backes

President

Louisiana State University Health

Sciences Center

Charles P. France

President-Elect

University of Texas Health Science

Center

Edward T. Morgan

Past President

Emory University School of

Medicine

Jin Zhang

Secretary/Treasurer
University of California, San Diego

Mary-Ann Bjornsti

Secretary/Treasurer-Elect

University of Alabama, Birmingham

Margaret E. Gnegy

Past Secretary/Treasurer

University of Michigan Medical

School

Alan V. Smrcka

Councilor

University of Michigan Medical

School

Kathryn A. Cunningham

Councillor

Councilor

Universty

Namandjé N. Bumpus

Councllor

Johns Hopkins University School

of Medicine

Mary E. Vore

Chair, Board of Publications

Trustees

University of Kentucky

Catherine M. Davis

FASEB Board Representative

Johns Hopkins University School

of Medicine

April 29, 2020

Edilson Marcelo Nazareth Junior

Pharmacy

Universidade de São Paulo

Av. Prof. Lineu Prestes, $\mathbf{5 8 0}$

Butantã

São Paulo

Brazil

Email: edizath@gmail.com

Dear Edilson Nazareth:

This is to grant you permission to include the following figure in your thesis titled "Development and characterization of efavirenz solid dispersions" for Universidad de São Paulo:

Figure 51 from HD Williams, NL Trevaskis, SA Charman, RM Shanker, WN Charman, CW Pouton, and CJH Porter (2013) Strategies to Address Low Drug Solubility in Discovery and Development, Pharmacol Rev, 65(1): 315-499; DOI: https://doi.org/10.1124/pr.112.005660

Permission to reproduce the figure is granted for one-time use in any format or medium including print and electronic. The authors and the source of the materials must be cited in full, including the article title, journal title, volume, year, and page numbers.

Sincerely yours,

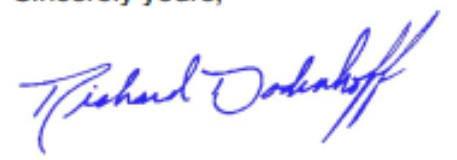

Richard Dodenhoff

Journals Director

Michael W. Wood

Chair, Program Committee

Neupharm LLC

Judith A. Siuciak

Executive Officer

Transforming Discoveries into Therapies

ASPET · 1801 Rockville Pike, Suite 210 - Rockville, MD 20852 - Office: 301-634-7060 · aspet.org $f y$ in 